GILDA APARECIDA ASSIS

NEUROR - SISTEMA DE APOIO À REABILITAÇÃO DOS MEMBROS SUPERIORES DE PACIENTES VÍTIMAS DE ACIDENTES

VASCULARES ENCEFÁLICOS 
GILDA APARECIDA ASSIS

\title{
NEUROR - SISTEMA DE APOIO À REABILITAÇÃO DOS MEMBROS SUPERIORES DE PACIENTES VÍTIMAS DE ACIDENTES VASCULARES ENCEFÁLICOS
}

\author{
Tese apresentada à Escola Politécnica \\ da Universidade de São Paulo \\ para obtenção do Título de \\ Doutor em Engenharia Elétrica. \\ Área de Concentração: \\ Sistemas Eletrônicos \\ Orientadora: \\ Profa. Dra. Roseli de Deus Lopes
}


Este exemplar foi revisado e alterado em relação à versão original, sob responsabilidade única do autor e com a anuência de seu orientador.

São Paulo, de março de 2010.

Assinatura do autor

Assinatura do orientador

FICHA CATALOGRÁFICA

Assis, Gilda Aparecida de

Neuror - sistema de apoio à reabilitação dos membros superiores de pacientes vítimas de acidentes vasculares encefá licos / G.A. de Assis. -- ed.rev. -- São Paulo, 2010.

$158 \mathrm{p}$.

Tese (Doutorado) - Escola Politécnica da Universidade de São Paulo. Departamento de Engenharia de Sistemas Eletrônicos.

1. Reabilitação 2. Acidente cerebrovascular 3. Membros superiores (Reabilitação) I. Universidade de São Paulo. Escola Politécnica. Departamento de Engenharia de Sistemas Eletrônicos II. t. 


\title{
DEDICATÓRIA
}

\begin{abstract}
À minha mãe Maria José e os meus irmãos Márcia e Gilson pelo amor, apoio e compreensão. Especialmente ao meu pai José Fagundes e ao meu irmão Márcio que estarão sempre no meu coração.
\end{abstract}




\section{AGRADECIMENTOS}

A Deus que me ilumina, protege e guia todos os dias de minha vida.

À Roseli de Deus Lopes, minha orientadora, pela orientação, pelo estímulo e por acreditar nas minhas idéias.

À minha família, minha mãe Maria José, meus irmãos Gilson e Márcia e meus sobrinhos Letícia, Luan e Eduarda, muito obrigada pelo carinho, apoio e compreensão durante o doutorado.

Ao meu pai José Fagundes e ao meu irmão caçula Marcinho, que não estão mais entre nós, mas onde estiverem, eu sei que estão felizes e olhando por mim.

À Irene Ficheman, Ana Grasielle Corrêa, Valkíria Venâncio e Alexandre Martinazzo, meus colegas durante o doutorado, pelo grande apoio e colaboração.

Agradeço a ajuda imprescindível do Dr. Cícero José Nunes Vaz, do Centro de Reabilitação do Hospital Israelita Albert Einstein.

A Ramona Straube, pela imensa ajuda na revisão.

Às fisioterapeutas e colegas Sílvia Lemos Fagundes e Maria Bernardete R. Martins pelo apoio e ajuda fundamentais na etapa de testes do sistema.

Agradeço ao Alexandre Klein, aluno do curso de Ciência da Computação da Feevale pela grande ajuda com a otimização do código e a interface cérebro-computador.

À aluna de fisioterapia Karin Tavares Lugtenburg pelo grande apoio nas intervenções e aplicação dos testes de desempenho motor.

Agradeço aos professores Jefferson Loss e Alexandre Balbinot da UFRGS pelas inspiradoras contribuições sobre músculos e EMG.

Agradeço à equipe da empresa Miotec de Porto Alegre, em especial ao Tiago e ao Vinicius, que disponibilizaram a dll para acesso direto ao equipamento Miograph.

Agradeço também a todos os amigos e familiares que direta ou indiretamente me incentivaram, me apoiaram e me ajudaram a dar este passo para frente. 


\section{RESUMO}

Acidentes vasculares encefálicos têm causado a incapacidade física em adultos e até mesmo em crianças, em todo o mundo. As deficiências motoras provocadas por essa patologia se caracterizam por paralisia ou fraqueza no lado do corpo oposto ao da lesão, gerando déficits no movimento do membro superior e na marcha. A reabilitação desempenha um papel importante no sentido de corrigir ou diminuir as deficiências motoras e aumentar a independência funcional dos pacientes. Nesta pesquisa, é proposto e implementado o NeuroR, um sistema de realidade aumentada que permite investigar se a percepção visual da movimentação de um braço virtual tridimensional, sobreposto à imagem do paciente e conectado ao ombro substituindo o braço real lesado, pode afetar positivamente a reabilitação motora deste membro comprometido. Relatos clínicos têm mostrado que a percepção visual de conectividade com o corpo pode reduzir a sensação de dor e de desconforto em amputações, o que norteou a adoção deste requisito para o sistema. Para avaliar a aplicabilidade do NeuroR foram realizados testes com pacientes, conduzidos por fisioterapeutas neurofuncionais. Nas intervenções, o fisioterapeuta estimula a prática mental de forma que o paciente realize a tarefa solicitada no ambiente de realidade aumentada, onde ele visualiza a si mesmo e o cenário real ao seu redor, como em um espelho. Também foi realizada a prática física, sendo esta disparada por sinais eletromiográficos captados de um músculo do braço parético do paciente. O sistema foi utilizado durante quatro sessões, por quatro pacientes de ambos os sexos, com lesões no hemisfério esquerdo ou direito, com hemiplegia há mais de um ano. $O$ comprometimento motor de cada paciente foi diagnosticado no início do tratamento através da escala Fugl-Meyer. Utilizando o NeuroR, observou-se que para três dos quatro pacientes, ao serem solicitados a imaginar o movimento visualizando sua imagem com o braço virtual, se esforçaram para executar o movimento fisicamente. No pós-teste, todos apresentaram um aumento na escala Fugl-Meyer, no mínimo de $17 \%$ e no máximo de $62 \%$.

PALAVRAS CHAVE: Realidade Aumentada. Reabilitação. Prática Mental. 


\section{ABSTRACT}

Stroke has caused the physical disability in adults and even children in the world. Stroke causes motor impairment characterized by paralysis or weakness on the side of the body opposite the site of injury. They produce deficits in movement of the upper limb and gait. The rehabilitation has an important role to correct or reduce motor impairment and in addition to providing functional independence. This research investigates how the perception of visual connectivity of a virtual arm, drawn from the side the patient's body, can affect the upper limb motor rehabilitation. Furthermore, clinical trials have shown that it can reduce the sensation of pain and discomfort for patients with amputations. Therefore, there is evidence that it leads us to investigate it and analyze it. This paper presents a proposal for a system that provides the visual stimulus of the movement of a virtual three-dimensional arm, which replaces the paralyzed arm in a real image of the patient. In the interventions the physiotherapist induces the mental practice of the patient such as he/she does the assigned task in the augmented reality environment, where he/she can visualize himself and surroundings, just like a mirror. The protocol included also physical practice. It was performed using electromyographic signals of a paretic arm muscle. The system was used by four chronic adults of both genders, who suffering lesions in different regions of the central nervous system. The sample included patients with lesions in the left or right hemisphere, which have upper-limb hemiplegia for over a year. This motor impairment was diagnosed before beginning the treatment through the Fugl-Meyer scale for the upper limb. In the trials, it was observed that for three of four patients, when asked to imagine their own movement by looking at their image with the virtual arm in the screen, they struggled to physically execute the movement. In the posttest, all showed an increase in the scale motor Fugl-Meyer, a minimum of $17 \%$ and a maximum of $62 \%$, and also had improvements in the range of motion of the shoulder, as measured by photogrammetry.

KEYWORDS: Augmented Reality. Rehabilitation. Mental Practice. 


\section{LISTA DE FIGURAS}

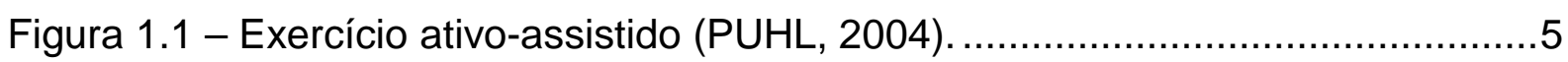

Figura 2.1 - Sistema nervoso humano (DIAS, 2009) ….......................................10

Figura 2.2 - Encéfalo humano (DOUGLAS, 2006) ..........................................11

Figura 2.3 - Áreas motoras no córtex (DOUGLAS, 2006). .....................................12

Figura 2.4 - Graus de liberdade do ombro (KAPANDJI, 2000)............................14

Figura 2.5 - Extensão e flexão de ombro (KAPANDJI, 2000)...............................15

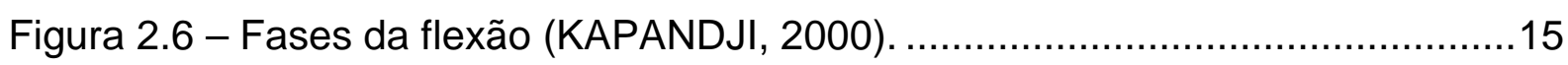

Figura 2.7 - Abdução de ombro (KAPANDJI, 2000). ...........................................16

Figura 2.8 - Fases da abdução (KAPANDJ, 2000) ..........................................17

Figura 2.9 - Músculo Deltóide (KAPANDJI, 2000) …........................................17

Figura 2.10 - Posição anatômica (KAPANDJI, 2000) .........................................18

Figura 2.11 - (a) Extensão e (b) flexão horizontal (KAPANDJI, 2000)....................18

Figura 2.12 - Padrão patológico pós-AVE (SULZBACHER, 2004) ………..............19

Figura 2.13 - Sistema nervoso normal X AVE (LUNDY-EKMAN, 2000) ..................20

Figura 2.14 - Sistema de RA (FISCHER; BARTZ; STRABER, 2005)......................30

Figura 2.15 - Projetores atrelados à cabeça (HUA et al., 2001)............................32

Figura 2.16 - Exemplo, Cubos virtuais na tela (CORREA et al., 2007)....................33

Figura 2.17 - Dispositivos espaciais óticos (OGl et al., 2001)...............................33

Figura 2.18 - Dispositivos espaciais com projetores (LOW et al., 2001).................34

Figura 2.19 - Capacete atrelado à cabeça de visão fechada. ..................................35

Figura 2.20 - Aplicação de remoção de fundo (TONIETTO, 2000)..........................36

Figura 2.21 - Erro de registro (Sanches, 2007) ................................................38

Figura 2.22 - Registro incorreto X correto (Sanches, 2007) .................................38

Figura 2.23 - Continuum de Milgram (MILGRAM; KISHINO, 1994).........................39

Figura 2.24 - Arquitetura de um sistema BCI (SCHALK et al., 2004) .....................41

Figura 2.25 - Sistema robótico para reabilitação motora (KREBS et al., 1998) ........42

Figura 2.26 - Sistema de RV para a reabilitação motora (GAGGIOLI et al., 2007) ..44

Figura 2.27 - Sistema de RA para pacientes com AVE (LUO et al., 2005). ..............46

Figura 2.28 - Sistema de Realidade Virtual para reabilitação da mão (ADAMOVICH et al., 2004) 
Figura 3.1 - Diagrama de casos de uso do sistema proposto.................................53

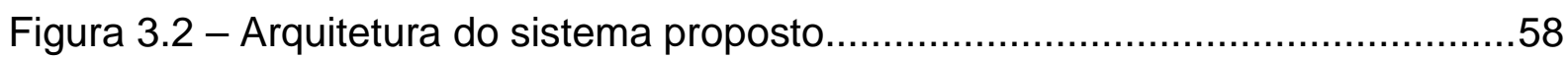

Figura 3.3 - Exercícios propostos (Marques, 1997) ……...................................61

Figura 3.4 - Grafo proposto para os exercícios do NeuroR. ..................................63

Figura 3.5 - Chromakey pelo método predominância de cor..................................66

Figura 3.6 - Chromakey pela predominância de cor com limiar................................67

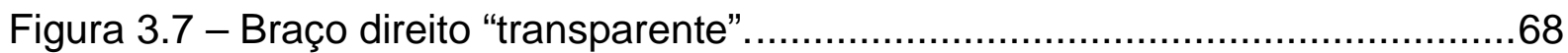

Figura 3.8-Modelo simplificado do braço em código C.........................................69

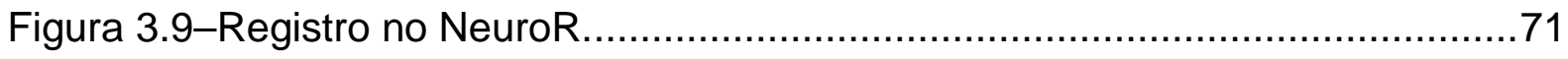

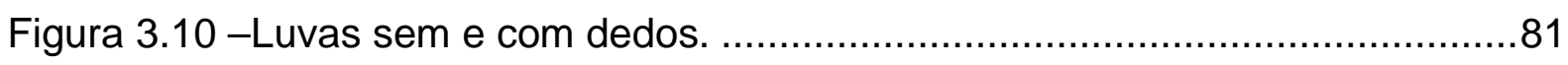

Figura 4.1 - Funcionamento do ARToolkit. …………..................................... 86

Figura 4.2 - Sistemas de referência Cal3D e OpenGL. .........................................8

Figura 4.3 - Cabeçalho do arquivo da malha poligonal. ........................................ 89

Figura 4.4 - Vértice do arquivo da malha poligonal. ...............................................89

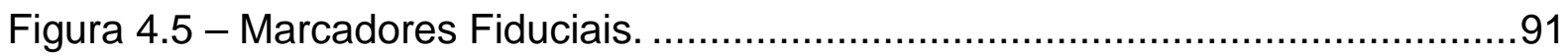

Figura 4.6 - Resultado do fitro de Sobel sem edge-linking...................................92

Figura 4.7 - Chromakey remove braço na imagem espelho ....................................93

Figura 4.8 - Interface de cálculo do RMS por janela móvel ....................................94

Figura 4.9 - Interface de cálculo do RMS com janela fixa. ......................................95

Figura 4.10 - Tela de cadastro de um protocolo com o NeuroR .............................95

Figura 4.11 - Tela de cadastro de intervenções no NeuroR. .....................................96

Figura 4.12 - Tela de histórico do paciente no NeuroR. ......................................97

Figura 5.1 - Braço virtual na cena sobreposto ao ombro......................................98

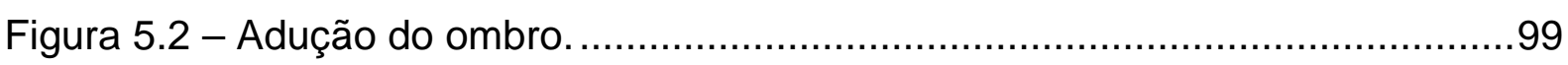

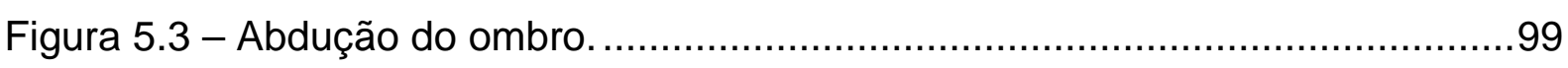

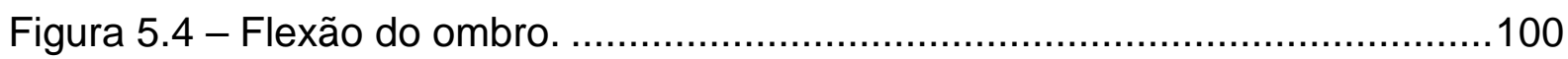

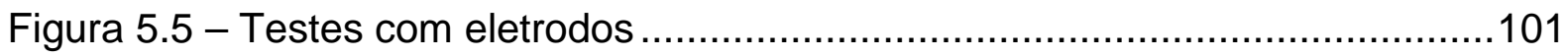

Figura 5.6 - Testes com eletrodo no deltóide ……….......................................101

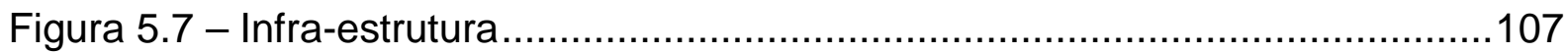

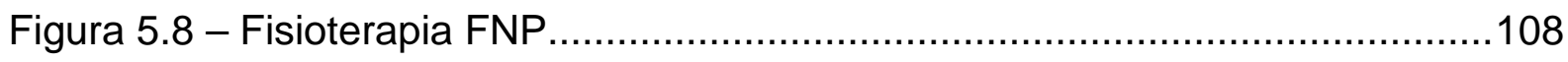

Figura 5.9 - Eletrodos no braço não lesado (esquerdo). .....................................108

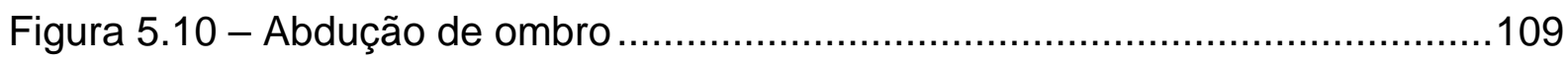

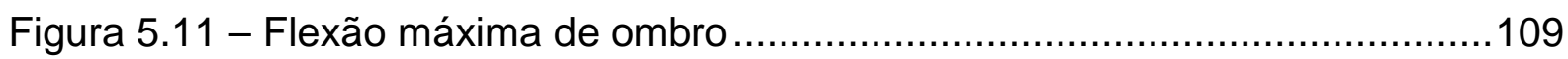

Figura 5.12 - (a) Adução máxima de ombro ..................................................110 
Figura 5.13 - Luva no braço comprometido (direito) 111

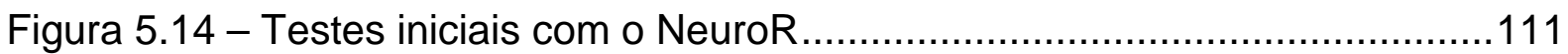

Figura 5.15 - EMG do deltóide no membro afetado (repouso) ….........................113

Figura 5.16 - Paciente AN utilizando o NeuroR ...................................................114

Figura 5.17 - Paciente AN utilizando o NeuroR …….......................................114

Figura 5.18 - Paciente AN utilizando o NeuroR …….........................................115

Figura 5.19 - (a) Marcador na posição correta. (b) Marcador posicionado inadequadamente.

Figura 5.20 - Captura do EMG do deltóide e do grande dorsal no membro direito comprometido.

Figura 5.21 - Abdução com o NeuroR.

Figura 5.22 - Abdução com o NeuroR. 118

Figura 5.23 - Inicialização do NeuroR 119

Figura 5.24 - Paciente CA utiliza abdução no NeuroR 120

Figura 5.25 - Flexão de ombro com Neuror. 121

Figura 5.26 - Paciente CA utiliza adução no NeuroR 122

Figura 5.27 - Falha de sincronismo na abdução com o NeuroR. 123

Figura 5.28 - EMG do deltóide no membro esquerdo comprometido 125

Figura 5.29 - Paciente utiliza o NeuroR 126

Figura 5.30 - Gráficos pré e pós-teste 129

Figura 5.31 - Paciente $C A$ faz abdução de ombro de 0 a 90 graus. 131

Figura 5.32 - Paciente AN faz abdução de ombro de 0 a 90 graus. 132

Figura 5.33 - Paciente MA faz abdução de 0 a 90 graus 133

Figura 5.34 - Paciente MA faz flexão de ombro de 90 a 180 graus. 134 


\section{LISTA DE TABELAS}

TABELA 3.1 - CENÁRIOS DE REABILITAÇÃO PROPOSTOS. ............................60

TABELA 3.2 - CRITÉRIOS DE INCLUSÃO .............................................................

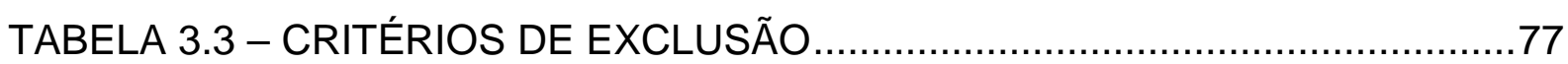

TABELA 3.4 - ESCALA DE ASHWORTH MODIFICADA ……..........................77

TABELA 3.5 - ESCALA DA FUNÇÃO SENSÓRIO-MOTORA DE MEMBROS

SUPERIORES DE FUGL-MEYER (FONTE: FUGL-MEYER ET. AL, 1975) .............79

TABELA 5.1 - CARACTERÍSTICAS DO GRUPO EXPERIMENTAL (GE) .............104

TABELA 5.2 - PRINCIPAIS QUEIXAS DOS PACIENTES DO GRUPO

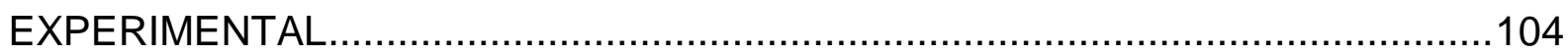

TABELA 5.3 - EXAME FÍSICO DO GE ANTES DO ESTUDO..............................105

TABELA 5.4 - DESEMPENHO MOTOR DO GE ANTES DO ESTUDO …..............106

TABELA 5.6 - PROTOCOLO DE INTERVENÇÃO APLICADO NO GE …..............112

TABELA 5.7 - TESTES DE DESEMPENHO MOTOR DO GE DEPOIS DO USO DO

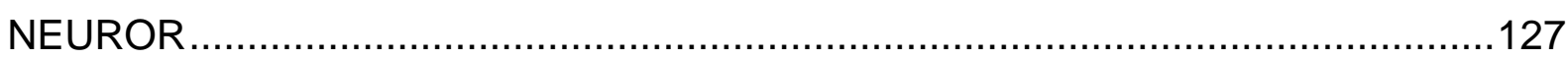

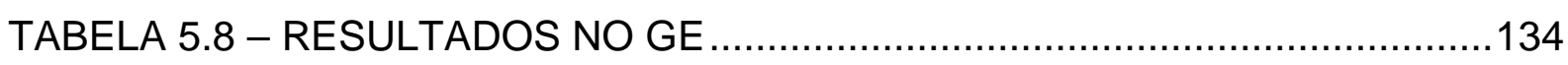

TABELA 5.9 - COMPARAÇÃO DOS TRABALHOS CORRELATOS E NEUROR ..140 


\section{LISTA DE ABREVIATURAS}

ADM Amplitude do Movimento Articular

AVE Acidente Vascular Encefálico

$\mathrm{BCl}$ Interface Cérebro-Computador (Brain-Computer Interface)

EMG Eletromiografia

FNP Facilitação neuromuscular proprioceptiva

GE Grupo Experimental ou Teste

HMD Head Mounted Display

LCD Display de Cristal Líquido

PDA Personal Digital Assistant

RA Realidade Aumentada

RMS Raiz Quadrada Média (Root Mean Square)

RV Realidade Virtual

TCLE Termo de Consentimento Livre e Esclarecido

TCUD Termo de Consentimento de Utilização dos Dados

3D Tridimensional

UE-FMA Upper Extremity itens of Fugl-Meyer Assessment (Itens Motores da Escala de Fugl-Meyer para os Membros Superiores) 


\section{SUMÁRIO}

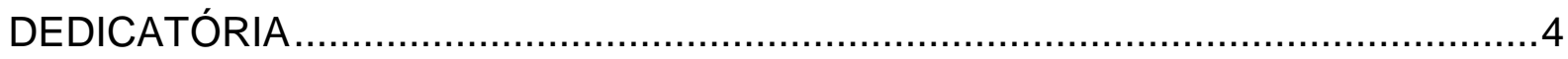

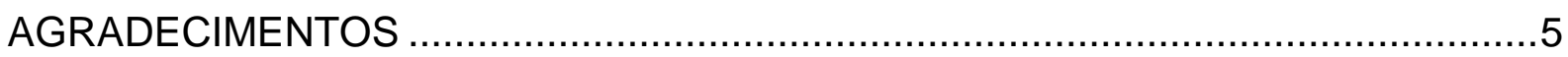

RESUMO

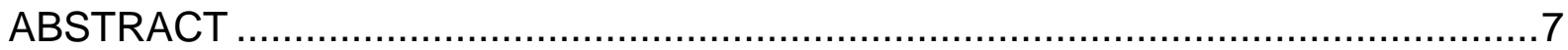

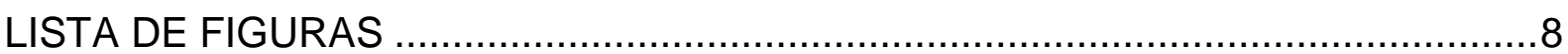

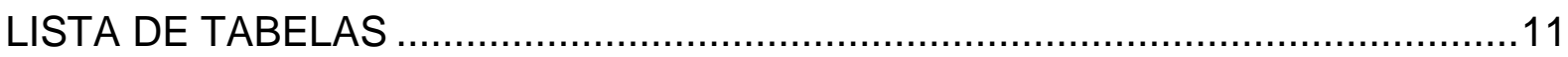

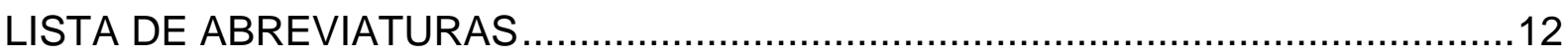

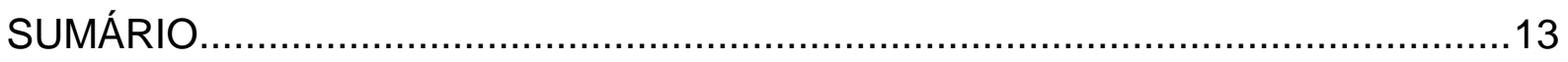

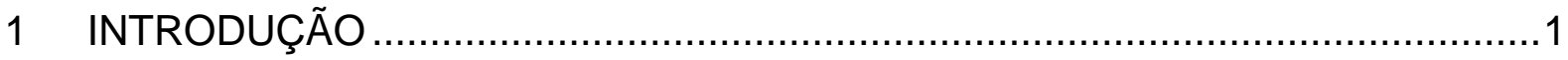

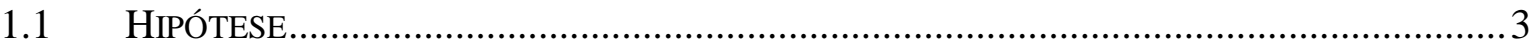

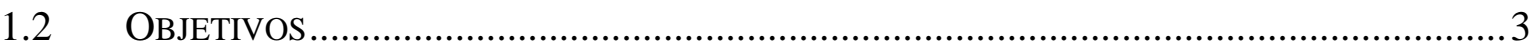

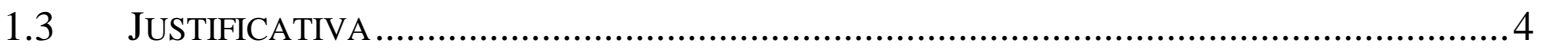

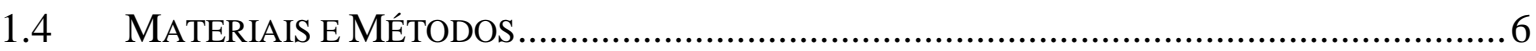

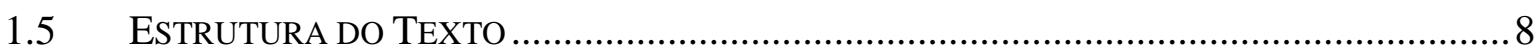

2 FUNDAMENTOS E TRABALHOS CORRELATOS ............................................

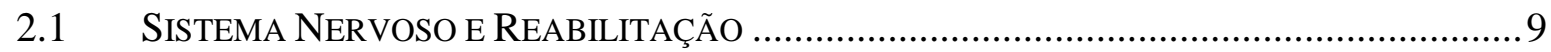

2.1.1 Sistema Nervoso Central .....................................................................

2.1.2 Sistema Motor …………………………….................................. 12

2.1.2.1 Fisiologia Muscular do Ombro ...................................................................... 14

2.1.3 Distúrbios Clínicos no Acidente Vascular Encefálico .....................................19

2.1.4 Eletromiografia .............................................................................2

2.1.4.1 Eletrodos de superfície .............................................................................2

2.1.4.2 Processamento do Sinal EMG no Domínio Temporal ..........................................25

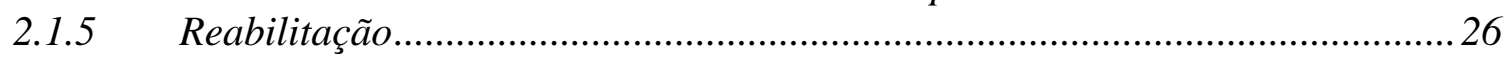

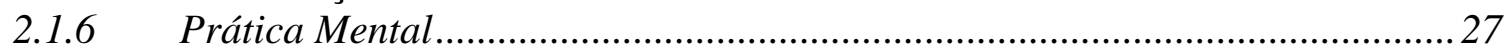

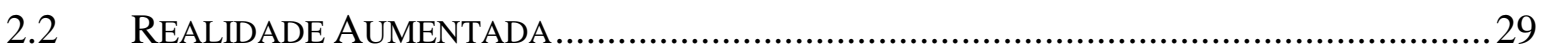

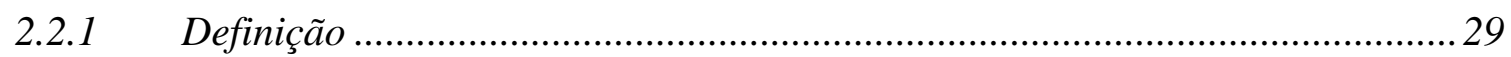

2.2.2 Tipos de Sistemas de Realidade Aumentada ………………………………...... 31

2.2.3 Aquisição de Imagens do Mundo Real ..............................................................35

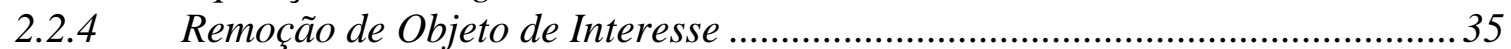

2.2.5 Registro em Realidade Aumentada.................................................................

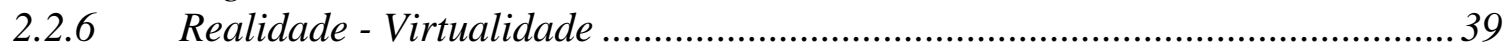

2.3 INTERFACE CÉREBRO-COMPUTADOR ………............................................................ 40

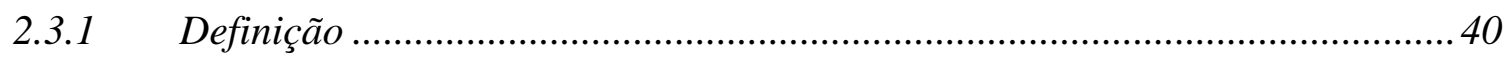

2.3.2 Arquitetura Básica de um Sistema BCI .........................................................4 40

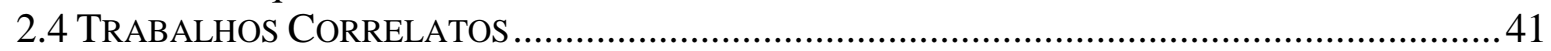

2.4.1 REABILITAÇÃO COM O BRAÇO MECÂNICO MANUS ……………………………..... 42 


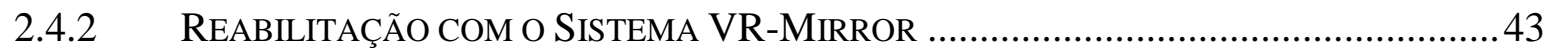

2.4.3 REABILITAÇÃO COM UM SISTEMA DE REALIDADE AUMENTADA ...........................45

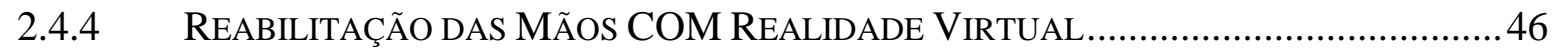

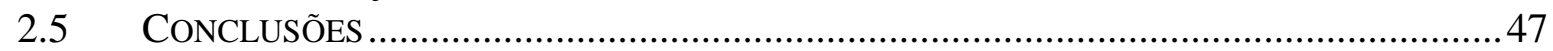

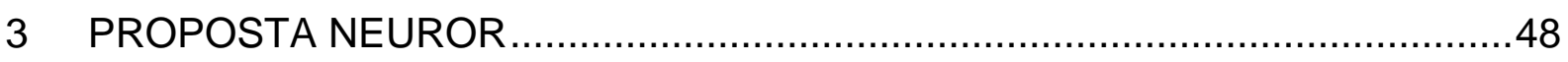

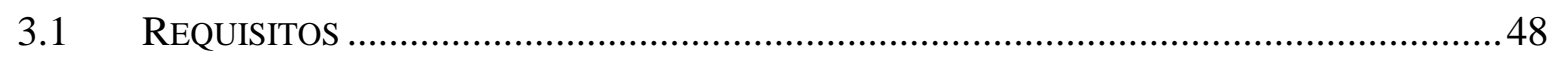

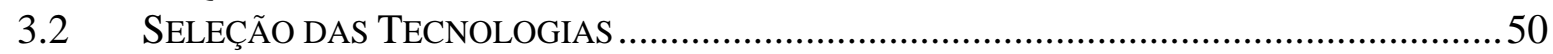

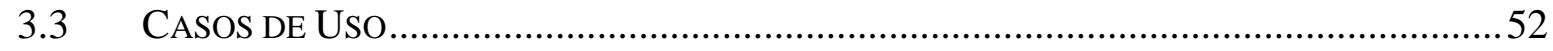

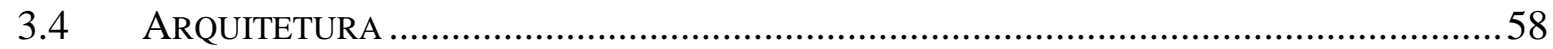

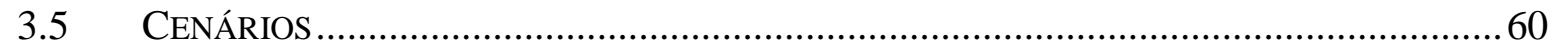

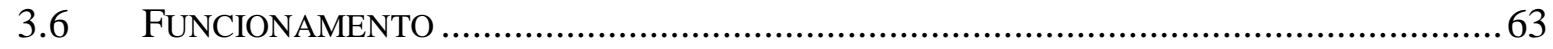

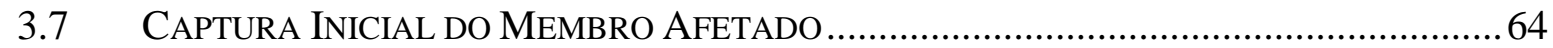

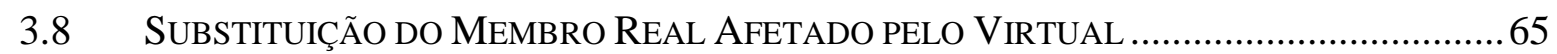

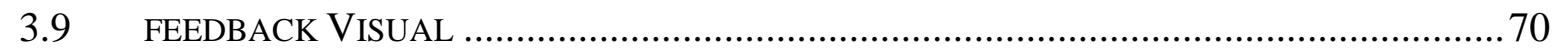

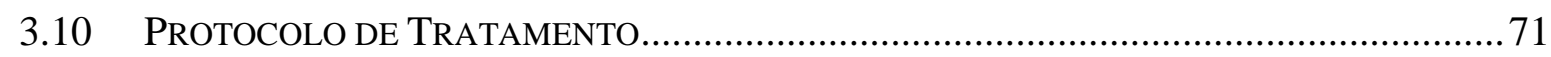

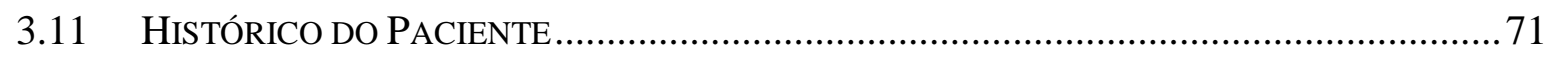

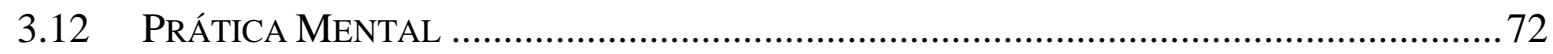

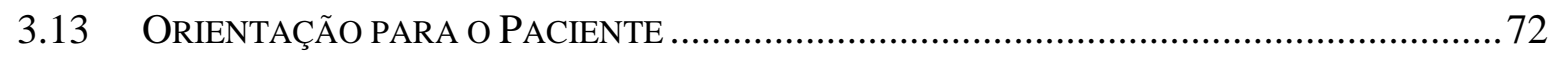

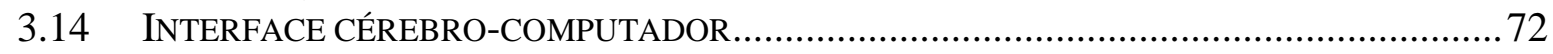

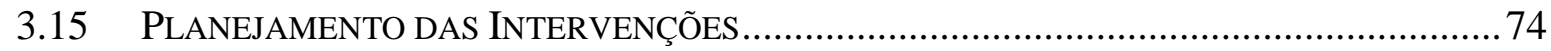

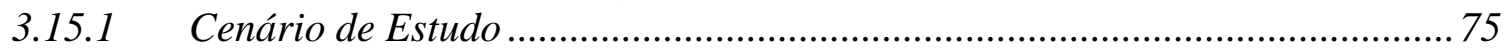

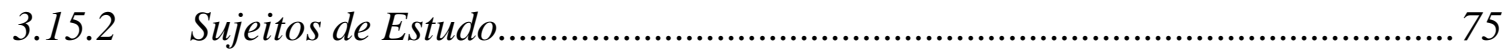

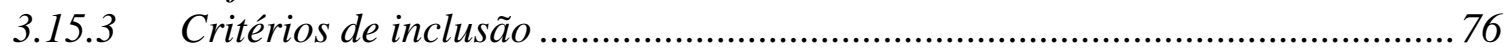

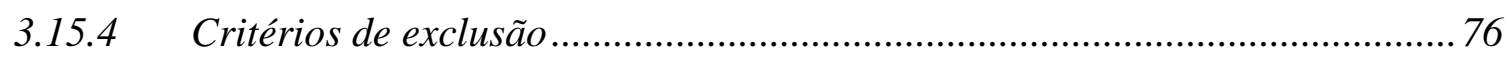

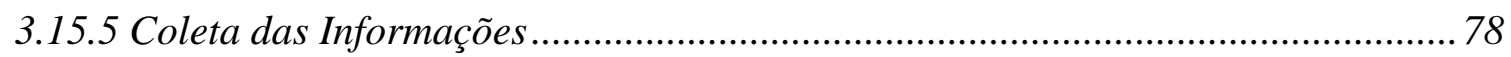

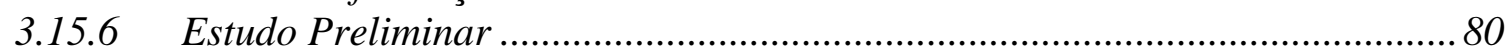

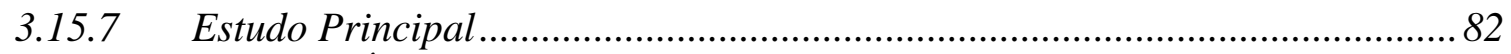

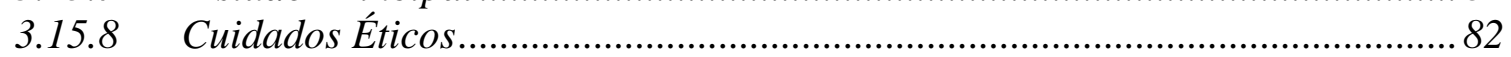

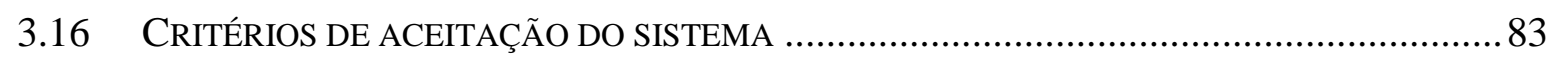

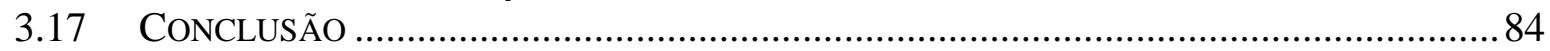

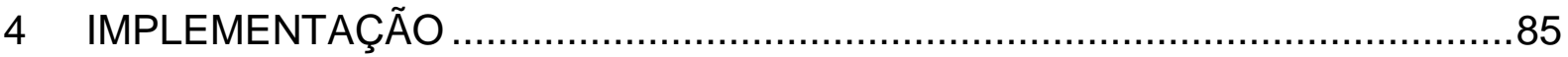

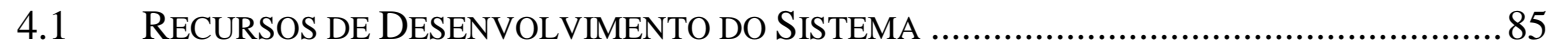

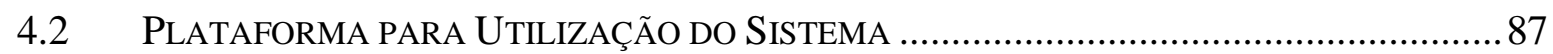

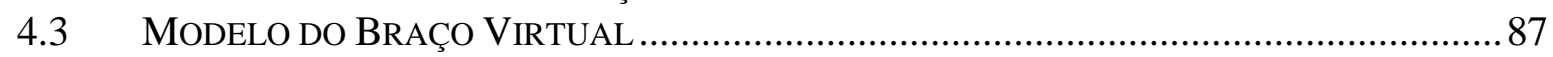

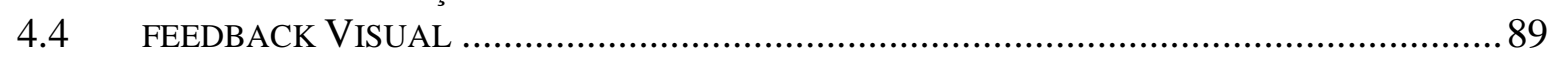

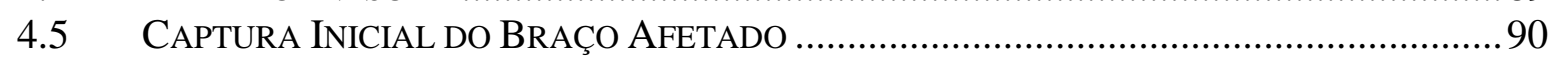

4.6 SUBSTITUIÇÃO DO MEMBRo REAl AFETAdo PELO VIRTUAL .....................................91

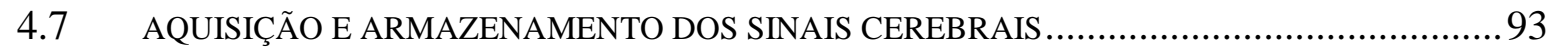

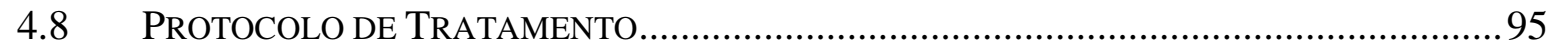

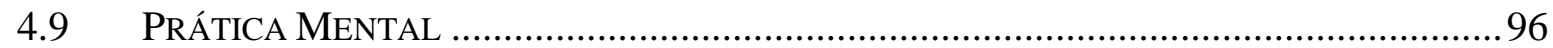

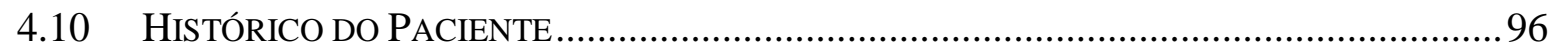

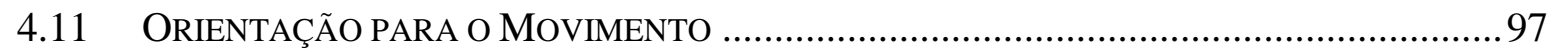

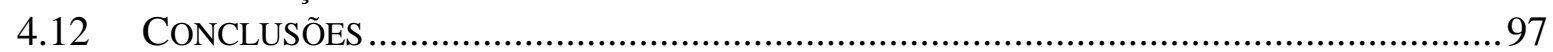

5 RESULTADOS E DISCUSSÃO DOS RESULTADOS ................................98

5.1 TESTES E AJUSTES DO APARATO TECNOLÓGICO …...................................98

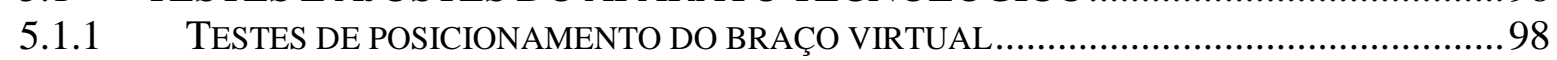

5.1.2 TESTES DE REMOÇÃO DO BRAÇO REAL ............................................................... 99

5.1.3 TESTES DAS ANIMAÇÕES DO BRAÇO VIRTUAL ...............................................99

5.1.4 TESTES DA INTERFACE CÉREBRO-COMPUTADOR ........................................... 100 
5.2 AVALIAÇÃO POR ESPECIALISTA EM MEDICINA FÍSICA........................................ 102

5.3 AVALIAÇÃO COM PACIENTES E FISIOTERAPEUTAS ............................................. 103

5.3.1 Caracterização dos Grupos Experimental ....................................................... 104

5.3.3 Estudo Preliminar com paciente do Grupo Experimental .............................. 107

5.3.4 Testes com o Grupo Experimental............................................................... 111

5.3.2 Teste com pacientes fora dos Grupos Experimental ..................................... 123

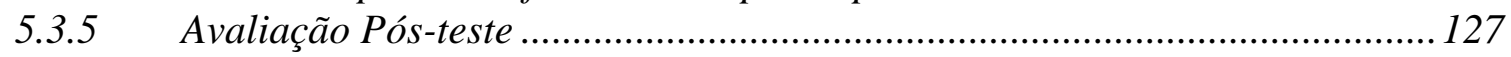

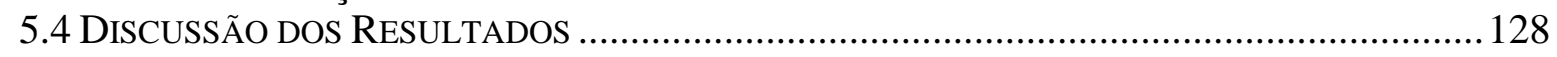

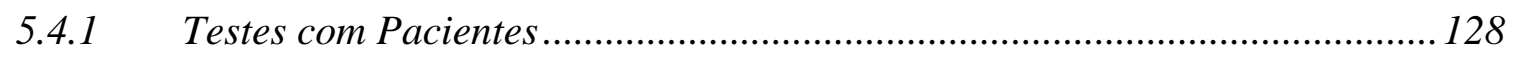

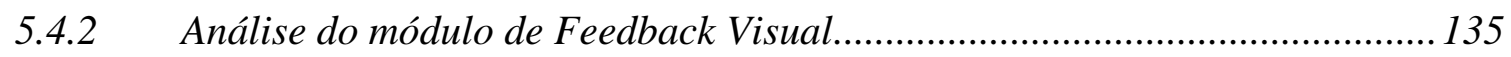

5.4.3 Análise do módulo de Aquisição e Armazenamento dos Sinais Cerebrais .... 136

5.4.3 Análise da Simulação ..................................................................................... 137

5.4.3 Procedimento e Instrumentos de Coleta e Análise dos Dados........................ 137

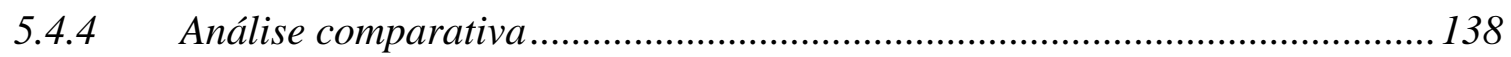

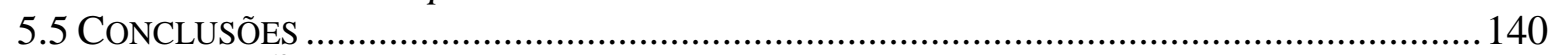

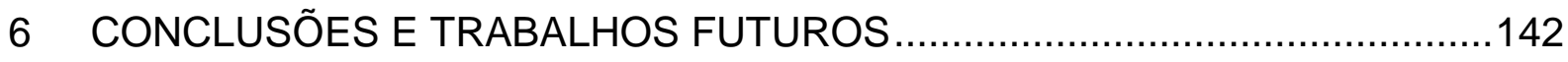

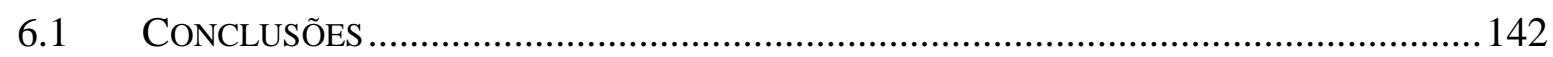

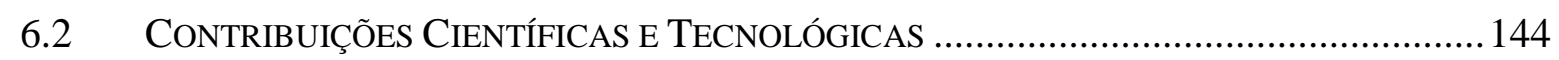

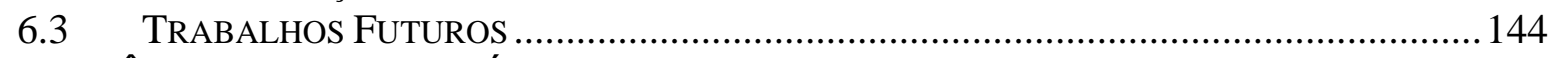

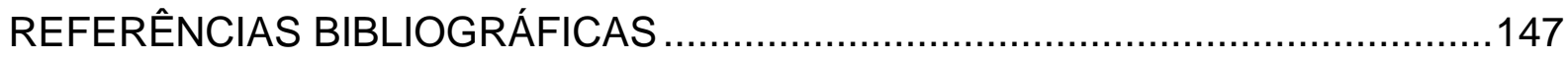

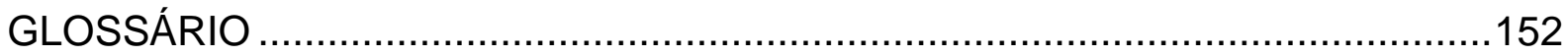

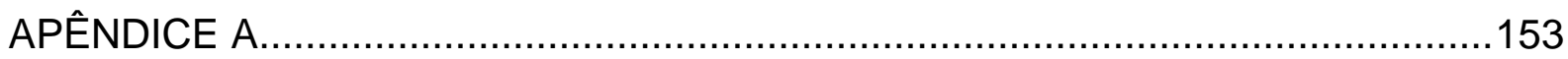

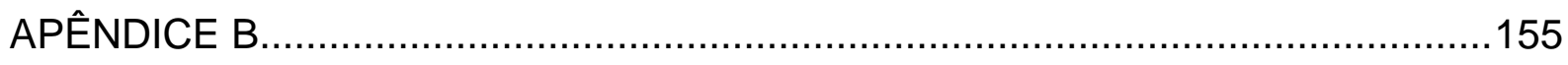

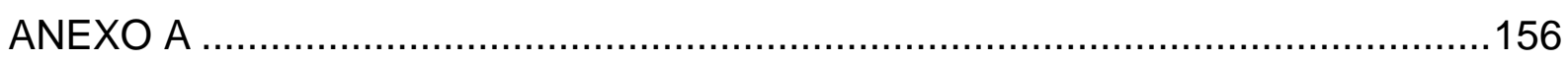




\section{INTRODUÇÃO}

O Acidente Vascular Encefálico (AVE) é a terceira causa de morte em todo mundo, atrás apenas das doenças do coração e câncer. Ele atinge homens, mulheres e até crianças, tendo maior incidência em idosos (AMERICAN HEART ASSOCIATION, 2009 - b). O AVE tem como conseqüências danos residuais motores, sensitivos e cognitivos, além de uma diminuição na capacidade de suportar esforços, sendo considerado o principal motivo de incapacidade física em adultos, em todo o mundo (OVANDO, 2009).

A reabilitação é o principal meio utilizado para promover a recuperação funcional do paciente após um AVE, e tem como objetivos restabelecer o controle dos movimentos e melhorar a autonomia funcional do paciente (OVANDO, 2009). A hemiparesia, ou seja, a fraqueza em um dos lados do corpo, é a sequela neurológica mais frequente após o AVE; o comprometimento do membro superior ocorre em $85 \%$ dos casos e, se mantém em 55 a $75 \%$ dos pacientes (CONFORTO, A. B. ; FERREIRA, J. R., 2009). Recuperar a habilidade de mover o braço e abrir a mão parece ser um das maiores preocupações dos sujeitos hemiparéticos após o AVE, uma vez que as habilidades manuais permitem independência e tem um impacto direto nas atividades da vida diária, como comer, se vestir e fazer a higiene pessoal. É a neuroplasticidade, ou plasticidade cerebral, que provê flexibilidade ao cérebro de forma que o sistema nervoso possa se modificar e responder a estímulos. A neuroplasticidade lançou luzes sobre a reabilitação, pois levou à compreensão de que pacientes que sofreram lesões encefálicas podem ser reabilitados dentro de certos limites porque são dotados da flexibilidade ou plasticidade cerebral e existem técnicas mais eficientes do que outras para realizar esse trabalho (GUIMARÃES, 2009).No caso de recuperação de uma lesão encefálica, a neuroplasticidade pode provocar três diferentes modificações no sistema nervoso central: alterações nas sinapses, reorganização funcional do sistema nervoso central e alterações na liberação de neurotransmissores (LUNDY-EKMAN, 2000). Há diversas técnicas para estimular a neuroplasticidade após uma lesão encefálica, as quais constituem as 
terapias de reabilitação e que podem promover a reabilitação física, cognitiva e psico-social do indivíduo (NUDO; PLAUTZ ; FROST, 2001).

As terapias de reabilitação física são técnicas que têm como objetivo corrigir ou diminuir as deficiências perceptuais e motoras do paciente. Várias terapias de reabilitação física têm sido utilizadas no tratamento de pacientes que sofreram um acidente vascular encefálico (AVE), como prática física, terapia ocupacional, terapia robótica, hidroterapia, musicoterapia, estimulação elétrica funcional e prática mental.

A prática mental é uma terapia de reabilitação que visa estimular a imagem motora do paciente. A imagem motora pode ser definida como um estado dinâmico no qual as representações de uma determinada ação motora são ensaiadas na memória de trabalho sem que haja necessariamente qualquer saída motora (DECETY, 1996).

No tratamento de pacientes no estágio crônico, ou seja, que sofreram um AVE há mais de um ano, os resultados de reabilitação motora de: redução no tônus muscular, recuperação da capacidade de fracionar os movimentos e uso do membro afetado nas atividades do dia-a-dia, são considerados difíceis de obter. Por esse motivo, muitos pacientes recebem alta do tratamento com as terapias de reabilitação convencionais quando completam um ano pós-AVE e também muitas empresas de planos de saúde cessam o financiamento do tratamento após o período de um ano.

Existe uma grande demanda para melhora no desempenho físico e recuperação das habilidades motoras nos pacientes com seqüelas pós-AVE. Este fato constitui-se no mais incapacitante efeito do AVE, sendo uma das condições tratadas na fisioterapia e na terapia ocupacional (PAGE et al, 2001). 


\subsection{HIPÓTESE}

A hipótese desta tese é que é possível desenvolver um aparato tecnológico que permite investigar se a percepção visual da movimentação de um braço virtual tridimensional, sobreposto à imagem do paciente neurológico e conectado ao ombro substituindo o braço real lesado, pode afetar positivamente a reabilitação motora deste membro comprometido.

\subsection{OBJETIVOS}

O objetivo geral deste trabalho é pesquisar, projetar e desenvolver um sistema de realidade aumentada que permita verificar a viabilidade de sua aplicação na investigação da reabilitação motora dos membros superiores de pacientes hemiplégicos com lesão encefálica, utilizando a técnica prática mental.

Para isso, os objetivos específicos do presente trabalho são:

- concepção geral do sistema;

- modelagem dos membros superiores de um ser humano sem amputações e com as suas principais articulações anatômicas e respectiva visualização num ambiente de Realidade Aumentada (RA);

- posicionamento adequado do braço virtual sobre o braço real lesado e remoção do braço real da imagem para evitar a exibição de um membro fantasma;

- levantamento e implementação das animações correspondentes às unidades de movimento necessárias para os exercícios previstos durante as intervenções terapêuticas;

- seleção e implementação de mecanismos de aquisição de sinais bioelétricos como forma de monitoramento e acompanhamento das atividades cerebrais 
do paciente durante a utilização do sistema e também como interface cérebro-computador;

- testes e valiação do sistema com uma amostra de pacientes;

- avaliação do sistema por especialistas da área.

\subsection{JUSTIFICATIVA}

Nos Estados Unidos, cerca de 795.000 pessoas sofrem um AVE por ano, o que significa que, em média, a cada 40 segundos uma pessoa sofre um AVE (AMERICAN HEART ASSOCIATION, 2009 - a). Uma pesquisa realizada com um grupo de idosos mostrou que $44 \%$ dos participantes que sofreram um AVE apresentavam limitações em no mínimo 5 atividades do dia-a-dia (CHAN et al., 2002).

No Brasil, segundo dados da Secretaria de Atenção à Saúde do Ministério da Saúde, o número de internações por AVE na faixa etária de 40 anos ou mais foi de 167.199 pessoas no ano de 2005 e de 161.184 pessoas em 2006 (MINISTÉRIO DA SAÚDE, 2006).

As terapias de reabilitação desempenham um papel importante na recuperação do paciente, pois as deficiências motoras que surgem após um AVE podem ser corrigidas ou reduzidas dependendo da quantidade, tipo e intensidade do tratamento de reabilitação (TAUB; USWATTE; MORRIS, 2003). O objetivo da reabilitação motora em pacientes com lesões no córtex cerebral é promover a neuroplasticidade através da reorganização funcional do encéfalo, de forma que outra região do cérebro possa assumir as funções da região danificada. A modulação sináptica busca modificar ou reestruturar as conexões entre os neurônios (sinapses).

As principais terapias convencionais utilizadas em pacientes com seqüelas pós-AVE são a cinesioterapia passiva e ativa, exercícios ativos-assistidos, crioterapia (terapia do frio), calor e hidroterapia (SULZBACHER, 2005), (PUHL, 2004). Na cinesioterapia passiva o fisioterapeuta (ativo) desenvolve técnicas de tratamento através do movimento enquanto o paciente fica relaxado (psíquico e físico), e não tem nenhuma 
participação motora voluntária. Esta técnica inclui massagens, mobilizações articulares, trações e posições articulares, entre outras. O exercício ativo-assistido compreende um tipo de amplitude de movimento ativa, na qual a assistência é realizada por uma força externa, manual ou mecânica, porque os músculos que iniciaram o movimento precisam de assistência para completá-lo. A Figura 1.1 mostra um exercício ativo-assistido em um paciente pós-AVE. Na cinesioterapia ativa há a participação ativa e consciente do paciente, que executa voluntariamente os movimentos. Estes exercícios podem sert feitos com ou sem resistência.

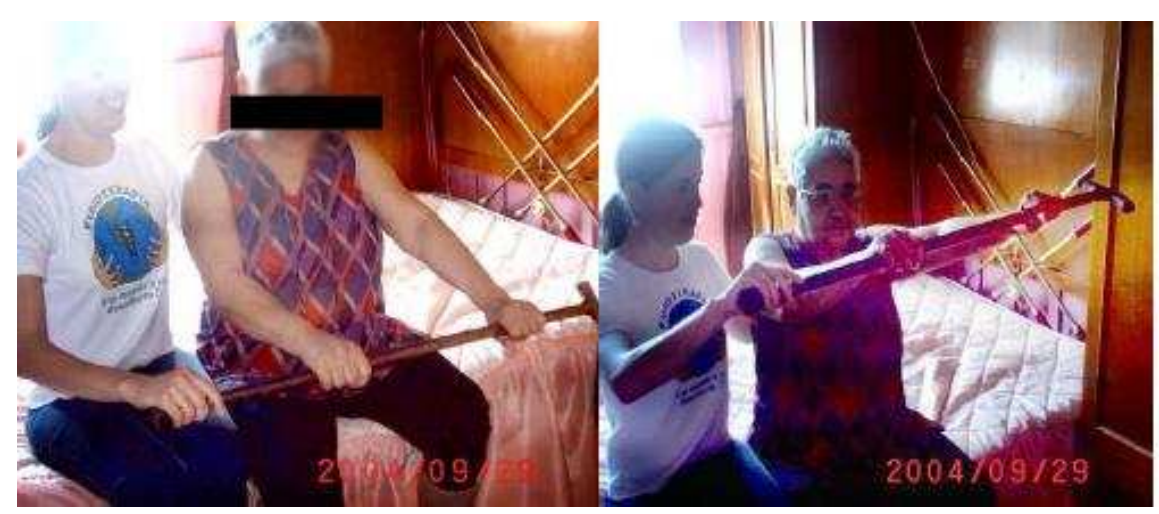

Figura 1.1 - Exercício ativo-assistido (PUHL, 2004).

A tecnologia de realidade virtual tem sido explorada por seus benefícios na intervenção terapêutica para a recuperação de padrões de movimentos coordenados (BURDEA; COIFFET, 1994). Esta tecnologia fornece a capacidade de criar um ambiente onde a intensidade da realimentação (feedback) e do treinamento podem ser sistematicamente manipuladas e melhoradas para criar um modelo de aprendizagem motor individualizado, mais apropriado ao paciente. Riva; Mantovani e Gaggioli (2004) afirmam que a realidade virtual oferece um conjunto de atributos atrativos para a reabilitação e o mais explorado deve ser a habilidade de criar simulações tridimensionais da realidade que podem ser exploradas por pacientes sob a supervisão de um terapeuta. Outra vantagem dos sistemas de reabilitação baseados em realidade virtual é que, de forma similar aos jogos computacionais, os exercícios de reabilitação em realidade virtual podem ser desafiadores para 0 paciente, o que é importante para promover a motivação do paciente (POPESCU, 2000). Sensores de rastreamento também podem ser usados para quantificar qualquer progresso feito pelo paciente em um sistema de realidade virtual, especialmente em termos de melhoria do controle motor. Embora a maioria dos 
casos de recuperação neurológica seja obtida de três a seis meses após o acidente vascular encefálico, alguns estudos têm investigado o resultado do tratamento um ano após a lesão e têm mostrado ganhos significativos em destreza, força e função (WERNER; KESSLER, 1996). Treinamentos em realidade virtual podem trazer novas opções para o tratamento após o período de hospitalização e reabilitação financiado pelos planos de saúde, que é de aproximadamente doze meses.

A realidade aumentada utiliza técnicas computacionais que geram, posicionam e mostram objetos virtuais integrados ao cenário real, em tempo real. Ela envolve quatro aspectos importantes que são: síntese em alta qualidade do mundo combinado; calibração precisa; registro no mundo real, ou seja, alinhamento dos objetos virtuais em posição e orientação dentro do mundo real; e interação em tempo real entre objetos reais e virtuais (TORI; KIRNER, 2006). Ela enriquece o ambiente real com objetos virtuais utilizando algum dispositivo tecnológico, em tempo real. Todos os benefícios citados acima da realidade virtual em reabilitação também se aplicam à realidade aumentada. Diferentemente da realidade virtual, que transporta o usuário para o ambiente virtual, a realidade aumentada mantém o usuário no seu ambiente físico e transporta o ambiente virtual para o espaço do usuário, permitindo a interação com o mundo virtual, de maneira mais natural e sem necessidade de treinamento ou adaptação (TORI; KIRNER, 2006).

O presente trabalho se torna relevante ao desenvolver soluções tecnológicas de baixo custo para melhorar a qualidade de vida dos pacientes que sofreram um AVE.

\subsection{MATERIAIS E MÉTODOS}

Esta seção descreve a metodologia adotada para a realização deste trabalho.

Inicialmente, foram realizadas reuniões com especialistas em medicina física e fisioterapeutas para a caracterização do problema e levantamento dos principais requisitos do sistema.

Em seguida, foram selecionados livros e artigos de fisiologia médica para estudo. Esta literatura especializada auxiliou na identificação dos distúrbios clínicos do 
sistema nervoso e principais técnicas de reabilitação física para pacientes vítimas de $\mathrm{AVE}$, de forma a prover uma fundamentação teórica quanto à viabilidade neurológica para o desenvolvimento do sistema de reabilitação proposto.

Também foram estudados alguns aspectos das interfaces cérebro-computador de forma a fornnecer subsídios para a seleção de métodos de aquisição e processamento de sinais cerebrais mais adequados ao problema de obter os sinais cerebrais para análise do efeito do experimento sob a neuroplasticidade do paciente.

Paralelamente à análise da viabilidade neurológica e estudo dos métodos de aquisição de sinais cerebrais foi feito o estudo de alternativas e a seleção da tecnologia para o desenvolvimento do sistema. Foi feito um estudo de diversos aspectos e tecnologias relacionadas a interfaces de realidade aumentada, como displays, calibração da(s) câmera(s) e métodos para combinação de imagens reais e virtuais. Também foi feita uma análise das tecnologias de hardware e software disponíveis, priorizando nas escolhas aquelas de baixo custo que pudessem satisfazer aos requisitos levantados nas reuniões com especialistas.

$\mathrm{Na}$ seqüência, teve início uma etapa de experimentação em que foram desenvolvidas algumas aplicações de RA simples com o objetivo de proporcionar a familiarização e domínio da tecnologia. Esta primeira versão rudimentar foi apresentada ao especialista que participou da definição inicial dos requisitos para uma avaliação preliminar.

Neste momento, foi encaminhado ao comitê de ética de uma instituição que atende pacientes vítimas de AVE um projeto de testes do sistema. O comitê autorizou a realização de testes de usabilidade do sistema com um grupo de pacientes voluntários. Este projeto de testes incluiu planejamento das intervenções, bem como avaliação da usabilidade do sistema, com critérios de recrutamento, duração e freqüência das intervenções, procedimentos de segurança antes, durante e depois de cada intervenção, bem como métodos de avaliação da eficácia do protocolo. As intervenções e avaliação do ponto de vista terapêutico foram conduzidas por dois fisioterapeutas, aqui nomeados como Fisioterapeuta 1 e Fisioterapeuta 2, com 0 consentimento dos pacientes e/ou responsáveis e foram registradas em vídeo. As intervenções compreendiam duas etapas: prática mental e prática física. Para a primeira etapa, prática mental, utilizou-se uma webcam, um tripé para fixar a 
câmera, um projetor multimídia, uma luva de tecido confeccionada para a pesquisa, um marcador fiducial em papel ou tecido e um computador. Para a execução da prática física, utilizou-se um aparelho disponível comercialmente que faz a aquisição em tempo real do sinal eletromiográfico (EMG) de um músculo do paciente, eletrodos de superfície para monitoração cardíaca e álcool e gase para limpeza da pele.

\subsection{ESTRUTURA DO TEXTO}

O presente trabalho está estrutura da seguinte forma.

O capítulo 2 apresenta uma fundamentação teórica sobre sistema nervoso e reabilitação, aspectos da tecnologia de realidade aumentada relevantes para o projeto, e algumas características de interfaces cérebro-computador. Ele também descreve quatro trabalhos correlatos, onde todos os sistemas utilizam algum aparato tecnológico como apoio à reabilitação dos membros superiores de pacientes que sofreram um AVE.

O Capítulo 3 apresenta a proposta deste trabalho. São descritos os requisitos, a arquitetura e o funcionamento do sistema proposto.

O Capítulo 4 descreve a implementação do sistema. São apresentadas as plataformas de desenvolvimento e de execução do sistema, bem como uma descrição dos módulos implementados.

O Capítulo 5 mostra os resultados e uma breve discussão deste trabalho. Ele contém os testes realizados com a aplicação em laboratório bem como os testes de usabilidade com o grupo de pacientes, denominado grupo experimental ou de teste. Também é descrita uma avaliação da interface do sistema realizada por um especialista em medicina física.

O Capítulo 6 sumariza as conclusões e perspectivas para trabalhos futuros, desencadeadas a partir deste trabalho. 


\section{FUNDAMENTOS E TRABALHOS CORRELATOS}

Este capítulo apresenta uma revisão sobre conceitos importantes para a compreensão do escopo e do funcionamento da proposta deste trabalho. Também são descritos quatro trabalhos relacionados à problemática da investigação que está sendo realizada.

\subsection{SISTEMA NERVOSO E REABILITAÇÃO}

O objetivo desta seção é descrever os mecanismos de ativação dos movimentos voluntários no sistema nervoso central humano e as principais conseqüências motoras de um acidente vascular encefálico (AVE), bem como um dos tratamentos de reabilitação existentes.

\subsubsection{Sistema Nervoso Central}

O sistema nervoso, composto principalmente por células denominadas neurônios, se divide em sistema nervoso central e sistema nervoso periférico.

O sistema nervoso central (SNC) se divide em duas partes: encéfalo e medula espinhal (Figura 2.1). O encéfalo fica situado no crânio enquanto a medula localizase no canal vertebral. Os órgãos que compõem o encéfalo são: cérebro ou córtex cerebral, cerebelo, tálamo e tronco encefálico (formação reticular, núcleos ou gânglios de base, ponte e bulbo) (DOUGLAS, 2006). A Figura 2.2 mostra um corte mediano do encéfalo. O SNC é um conjunto de neurônios centrais, que, sob o ponto de vista funcional podem ser sensitivos ou aferentes, motores ou eferentes ou internunciais (responsáveis pelas intercomunicações). Os neurônios motores são 
aqueles que produzem sinais cerebrais que são enviados do SNC para a periferia não-neural, como músculos e glândulas. Os neurônios sensitivos, por sua vez, recebem os sinais ou estímulos provenientes da periferia para o SNC.

No SNC existem dois hemisférios: direito e esquerdo, os quais se comunicam por meio de axônios, que são os canais de saída do neurônio, os quais cruzam de um lado para outro do encéfalo.

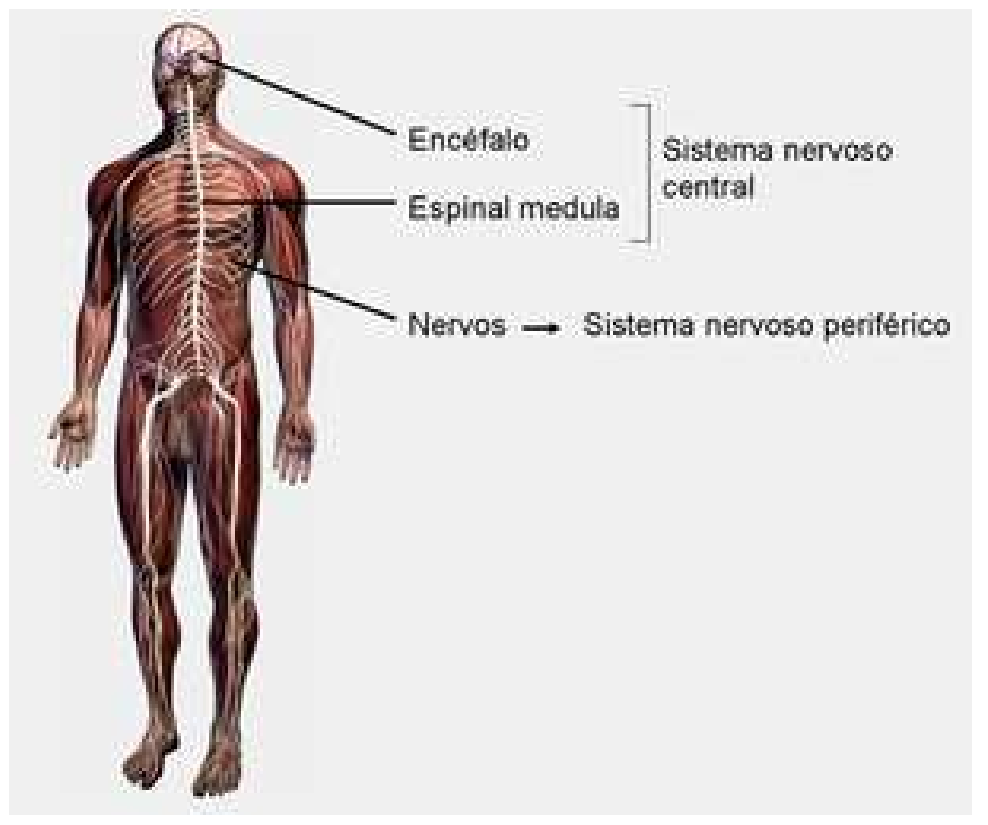

Figura 2.1 - Sistema nervoso humano (DIAS, 2009)

O SNC determina os fenômenos de controle da função motora e a célula nervosa que controla esta atividade é o neurônio motor ou motoneurônio (DOUGLAS, 2006).

Os motoneurônios se dividem em motoneurônios superiores e inferiores. Os motoneurônios inferiores têm seus corpos celulares na medula espinhal e no tronco encefálico. Já os motoneurônios superiores ocorrem no córtex cerebral e no tronco encefálico. Os motoneurônios inferiores transmitem sinais diretamente para os músculos esqueléticos, produzindo a contração das fibras musculares apropriadas para mover o ombro, braço, cotovelo, pulso e os dedos. Já os motoneurônios superiores se dividem em dois grupos: (a) grupo que controla a atividade automática dos músculos esqueléticos e (b) grupo que controla os movimentos aprendidos e voluntários (LUNDY-EKMAN, 2000). Os motoneurônios inferiores podem ser excitados ou inibidos por aferências musculares ou por neurônios superiores. 


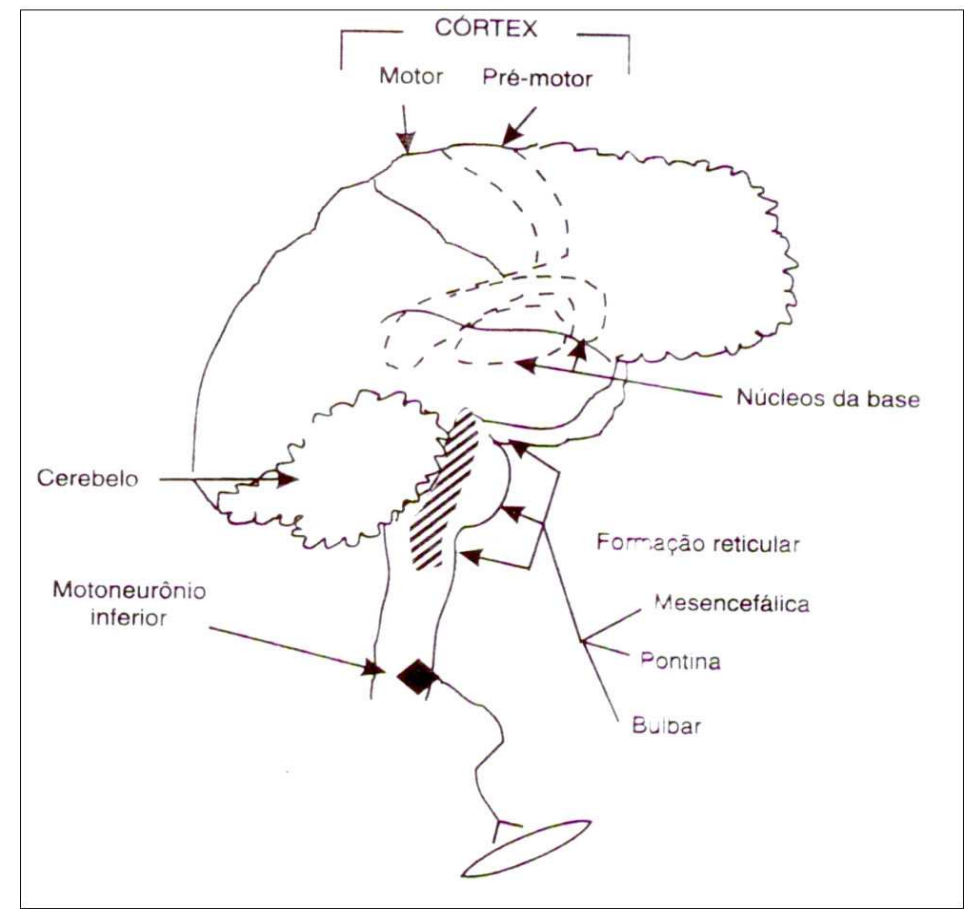

Figura 2.2 - Encéfalo humano (DOUGLAS, 2006).

A formação reticular descendente facilitadora é quem atua estimulando um tipo específico de motoneurônio inferior, denominado gama-motoneurônio. A formação reticular facilitadora é estimulada por aferências sensitivas, principalmente pelas visuais. Isto é, quando a retina é excitada e o córtex cerebral recebe impulsos visuais, a formação reticular facilitadora também é excitada, aumentando o tônus muscular (DOUGLAS, 2006). É a partir disso, que presume-se que o estímulo visual pode auxiliar na reabilitação do paciente, uma vez que estímulos visuais podem excitar a formação reticular e esta, por sua vez, estimula os gama-motoneurônios.

A formação reticular descendente supressora é estimulada pela área 4-S do córtex cerebral e pelo cerebelo. A área 4-S localiza-se entre o córtex motor e pré-motor na Figura 2.2. Um movimento tem início quando o córtex cerebral estimula a formação reticular (DOUGLAS, 2006). A função do córtex cerebral motor e do córtex pré-motor é iniciar os movimentos voluntários. Na Figura 2.3, o córtex motor é representado pela área 4 e o córtex pré-motor pela área 6 . Na área 4 , é representada a somatotopia, em que esquematicamente se dá a seqüência: 1 - boca, 2 - face, 3 dedos (mãos), 4 - extremidades (tronco), 5 - pé (artelho) (DOUGLAS, 2006). 


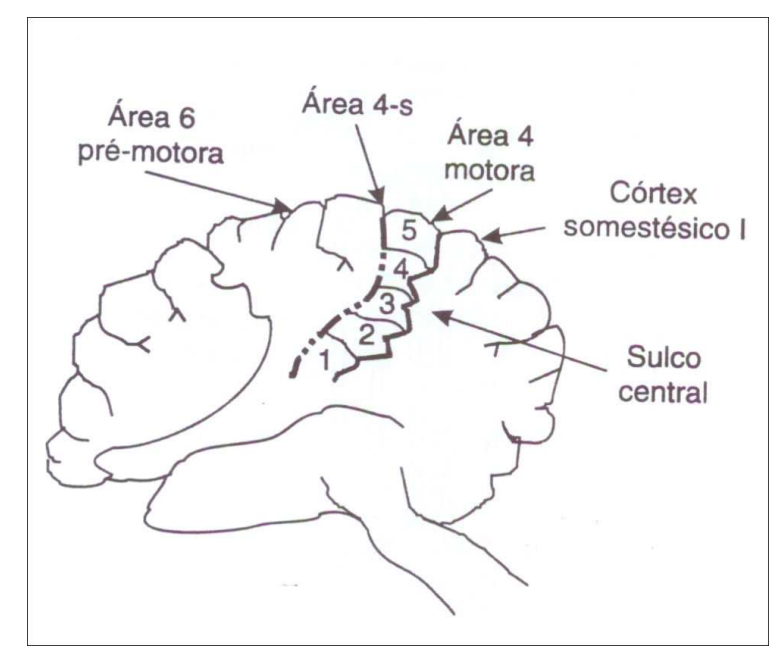

Figura 2.3 - Áreas motoras no córtex (DOUGLAS, 2006).

Os circuitos de controle são formados pelos gânglios ou núcleos da base e o cerebelo. Estes circuitos ajustam a atividade dos motoneurônios superiores no córtex pré-motor por meio do tálamo. Eles não mantêm conexão direta com os motoneurônios inferiores, mas controlam certos aspectos do movimento. Por exemplo, os gânglios da base participam da comparação entre a informação proprioceptiva e os comandos para o sequenciamento dos movimentos e regulação do tônus e da força musculares (LUNDY-EKMAN, 2000).

\subsubsection{Sistema Motor}

Mas, como o sistema nervoso central controla um ato motor simples, como o de pegar uma caneta? A seqüência da atividade neural começa com a decisão, que ocorre na parte anterior do lobo frontal no córtex cerebral. A seqüência é a seguinte: (1) decisão, (2) áreas de planejamento motor, (3) circuitos de controle, (4) vias motoras descendentes, (5) interneurônios medulares, (6) motoneurônios inferiores, (7) músculos esqueléticos.

A área de planejamento motor é formada pelo córtex motor (área 4), enquanto os circuitos de controle são compostos pelo cerebelo e pelos gânglios ou núcleos da base. As vias motoras descendentes, por sua vez, correspondem aos motoneurônios superiores, e levam sinais para os interneurônios medulares ou diretamente para os motoneurônios inferiores. Os motoneurônios inferiores 
transmitem sinais diretamente para os músculos esqueléticos, produzindo a contração das fibras musculares apropriadas para mover o membro superior e os dedos para executar tarefas como a de pegar uma caneta.

Duas regiões anteriores ao córtex motor participam da preparação para o movimento: área pré-motora e área motora suplementar. A estimulação da área prémotora provoca atividade muscular que atinge diversas articulações. Já o córtex motor suplementar tem atividade antes de movimentos bimanuais e seqüenciais.

Os circuitos de controle também controlam aspectos do movimento. O cerebelo tem duas funções principais: comparação do movimento em curso com o movimento pretendido e correção do movimento, quando necessária, através de ajustes nos motoneurônios superiores. Já os gânglios da base atuam na comparação entre a informação proprioceptiva e os comandos para o sequenciamento dos movimentos e regulação do tônus e da força musculares (LUNDY-EKMAN, 2000).

A visão e a sensibilidade somática são essenciais para o movimento de alcance/agarrar. A visão fornece informação da localização, forma e tamanho do objeto. O fluxo da informação visual para o movimento vai do córtex visual para o córtex parietal posterior no cérebro. Os neurônios do córtex parietal que recebem a informação visual se projetam para as áreas corticais pré-motoras, as quais controlam os movimentos de alcance, de agarrar e oculares. A propriocepção é responsável pelo sentido somato-sensorial, fornecendo informação sobre as cargas (pesos) e as posições relativas das partes do corpo. Ela é usada de modo semelhante à visão na preparação do movimento e para fornecer informações sobre erros do movimento. A informação proprioceptiva também provoca alterações no movimento, por exemplo, quando o contato com o objeto faz com que os dedos se fechem. O "agarrar visual" (fixação do objeto na visão central) e a informação proprioceptiva sobre a posição do membro superior são necessários antes de iniciar o movimento de alcance e agarrar (LUNDY-EKMAN, 2000). 


\subsubsection{Fisiologia Muscular do Ombro}

O ombro é considerado uma articulação proximal do membro superior e é a mais móvel de todas as articulações do corpo humano. Possui três graus de liberdade, possibilitando a orientação do membro superior em relação aos três planos do espaço: sagital, frontal e horizontal (KAPANDJI, 2000). A Figura 2.4-(a) mostra os três graus de liberdade de movimento do ombro, onde a direção 1 possibilita os movimentos de abdução, o membro superior se afasta do plano de simetria do corpo, e adução, o membro superior se aproxima do plano de simetria no plano frontal (B), a direção 2 permite movimentos de extensão e flexão no plano sagital $(A)$ e a direção 3 permite movimentos de flexão e extensão no plano horizontal (C).

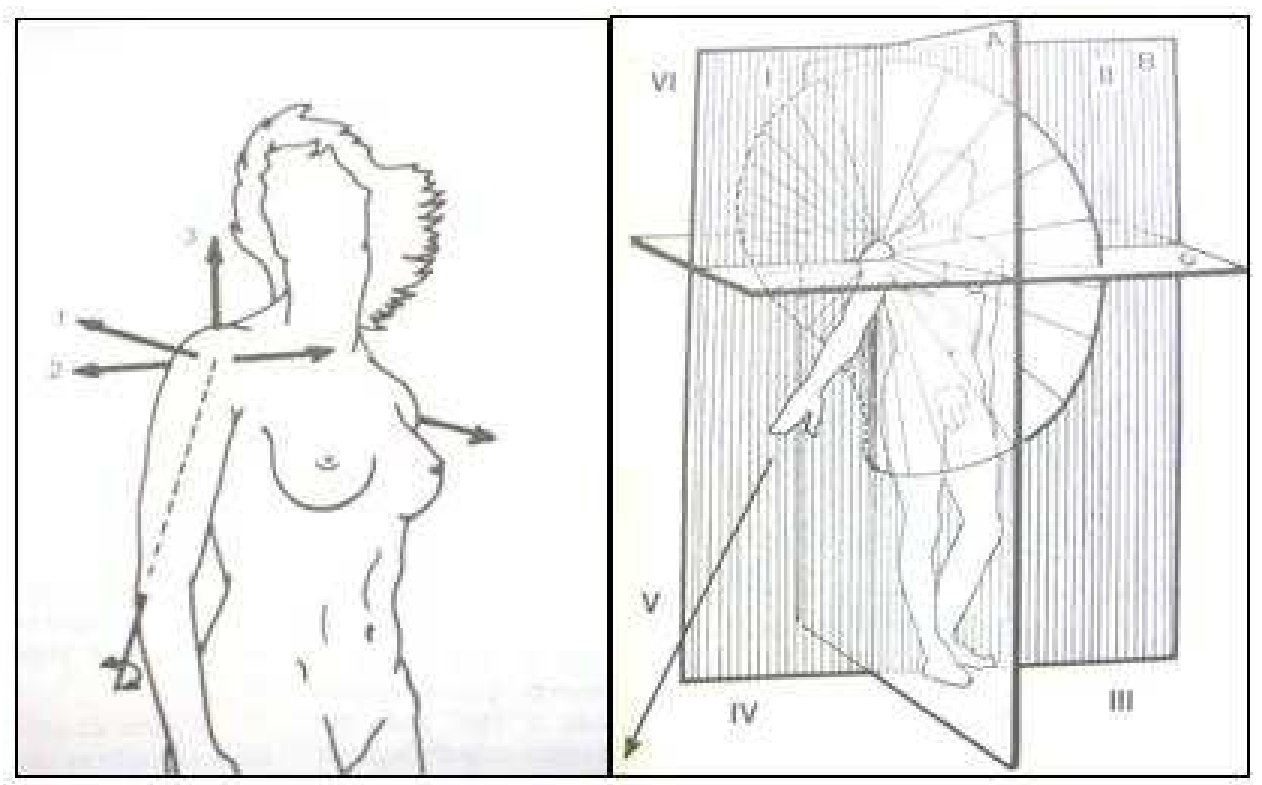

(a)

(b)

Figura 2.4 - Graus de liberdade do ombro (KAPANDJI, 2000).

O movimento de extensão de ombro é um movimento de pouca amplitude, 45 a 50 graus como mostra a Figura 2.5-(a), enquanto o movimento de flexão de ombro, na Figura 2.5-(b), é um movimento de grande amplitude, cerca de 180 graus. 


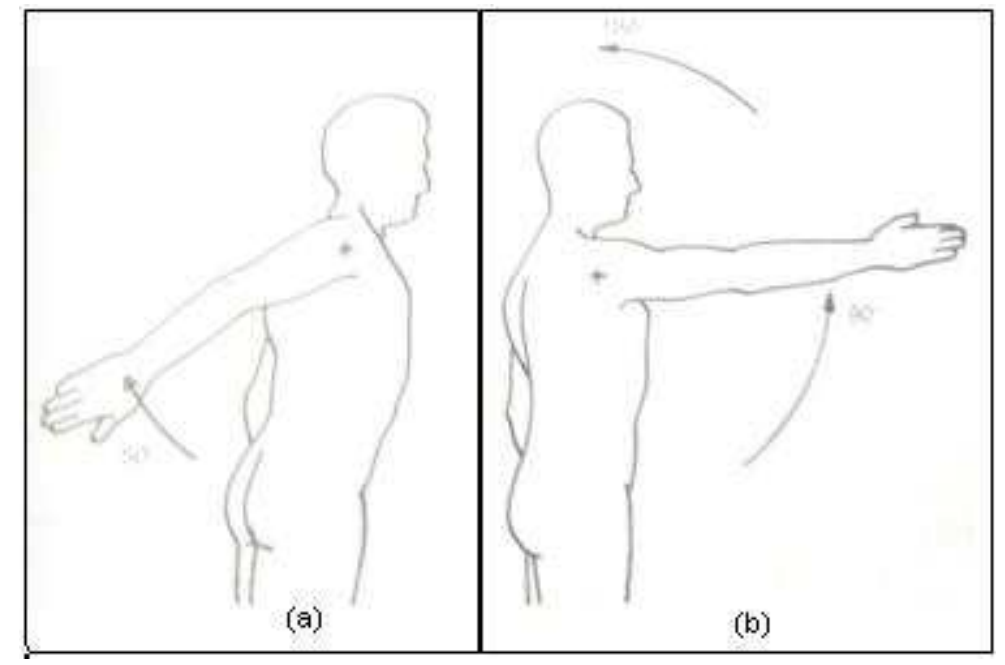

Figura 2.5 - Extensão e flexão de ombro (KAPANDJl, 2000).

A flexão de ombro é composta de três fases (Figura 2.6). Na primeira fase que vai de 0 a 50-60 graus, os músculos motores agonistas, isto é, a favor do movimento, são: fascículo anterior do deltóide, coráquio-braquial e fascículo superior do peitoral maior. Nesta fase, os músculos antagonistas, que fazem oposição ao movimento, são: redondo menor, redondo maior e infra-espinhal. A segunda fase da flexão vai de 60 a 120 graus e tem como músculos agonistas os mesmos da abdução: trapézio e serrátil anterior. Os músculos antagonistas nesta fase são: grande dorsal e a porção inferior do peitoral maior. A terceira fase vai de 120 a 180 graus. Esta fase também inclui como músculos agonistas o trapézio e o serrátil anterior.

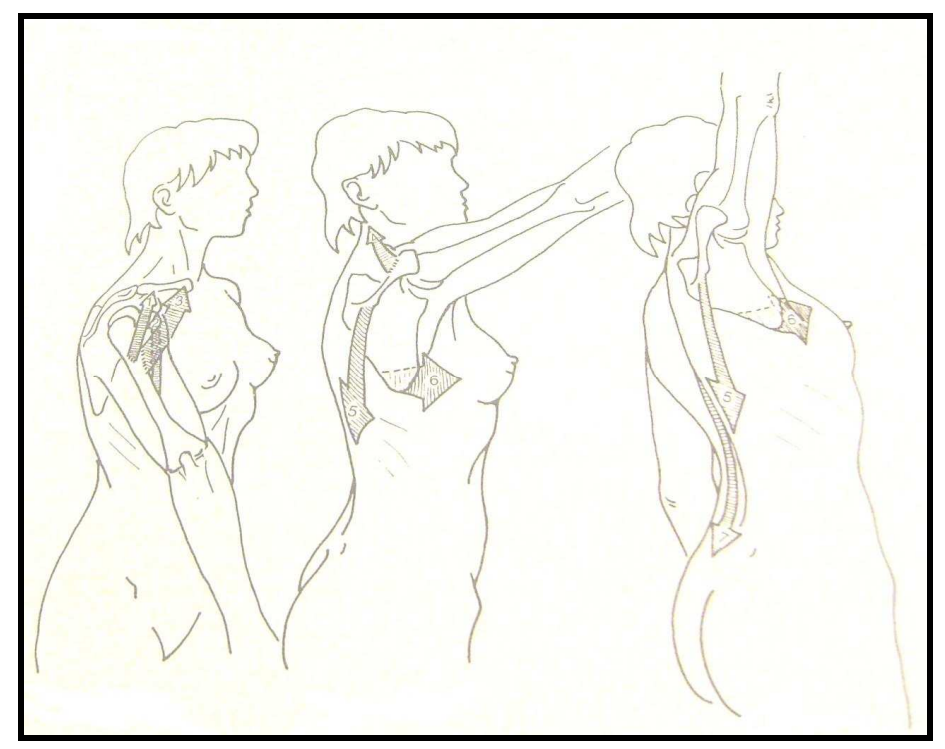

Figura 2.6 - Fases da flexão (KAPANDJl, 2000).

A abdução de ombro é um movimento que afasta o membro superior do tronco e alcança uma amplitude de 180 graus (Figura 2.7). A abdução pura é um movimento 
pouco comum no dia a dia, entretanto, a abdução associada com uma flexão formando um ângulo de 30 graus com o plano frontal é o movimento mais utilizado, principalmente para levar a mão à nuca ou à boca.

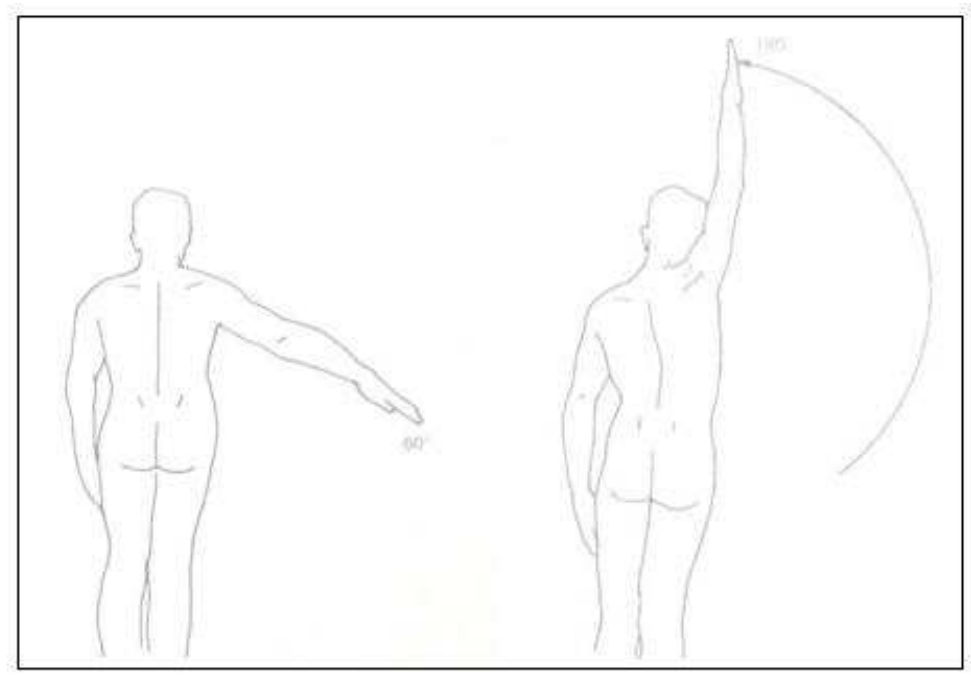

Figura 2.7 - Abdução de ombro (KAPANDJI, 2000).

A fisiologia da abdução é constituída de três fases (Figura 2.8). A primeira fase da abdução de 0 a 90 graus é resultado da ação dos seguintes músculos: o deltóide e 0 supra-espinhal. A segunda fase é de 90 a 150 graus e tem como músculos motores o trapézio e o serrátil anterior, sendo que os músculos grande dorsal e peitoral maior atuam como antagonistas, fazendo resistência à abdução. A terceira fase da abdução é de 150 a 180 graus e conta com a participação dos músculos espinhais também. Ao final da abdução todos os músculos motores da abdução devem estar contraídos. O deltóide é um músculo ativo desde o início da abdução e sua atividade máxima se estabelece ao redor dos 90 graus de abdução. $O$ fascículo médio do deltóide é um músculo de abdução pura durante todo o movimento (Figura 2.9). O músculo supra-espinhal se opõe ao deltóide sendo muito útil e eficiente principalmente no início da abdução. 


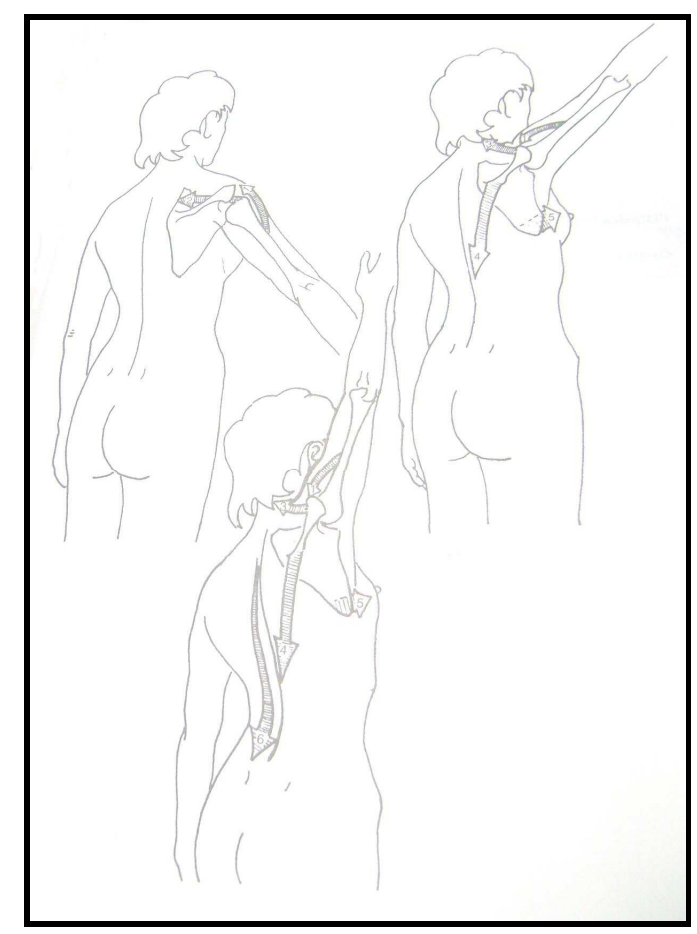

Figura 2.8 - Fases da abdução (KAPANDJl, 2000).

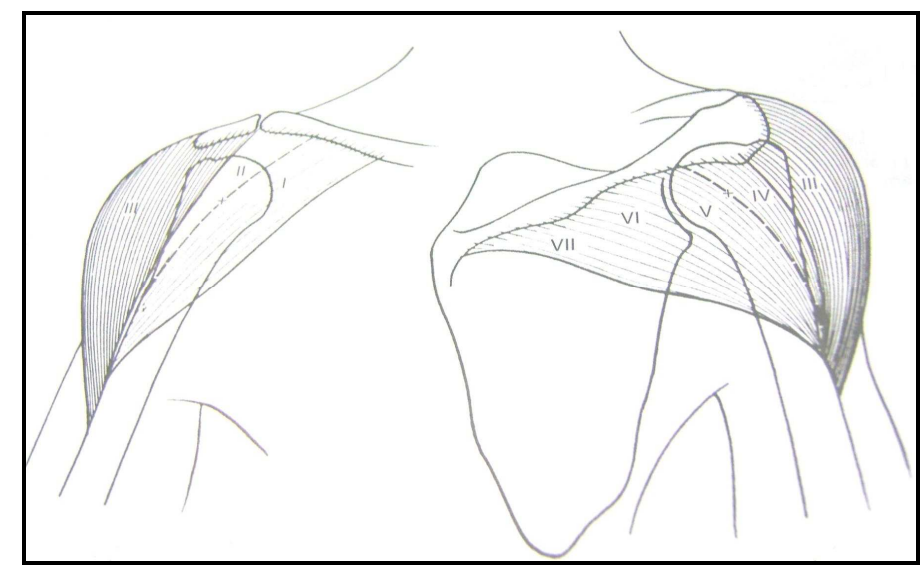

Figura 2.9 - Músculo Deltóide (KAPANDJI, 2000).

A posição anatômica para os movimentos de abdução e flexão de ombro é o membro superior vertical, a palma da mão girada para dentro, o polegar apontando para frente (Figura 2.10). 


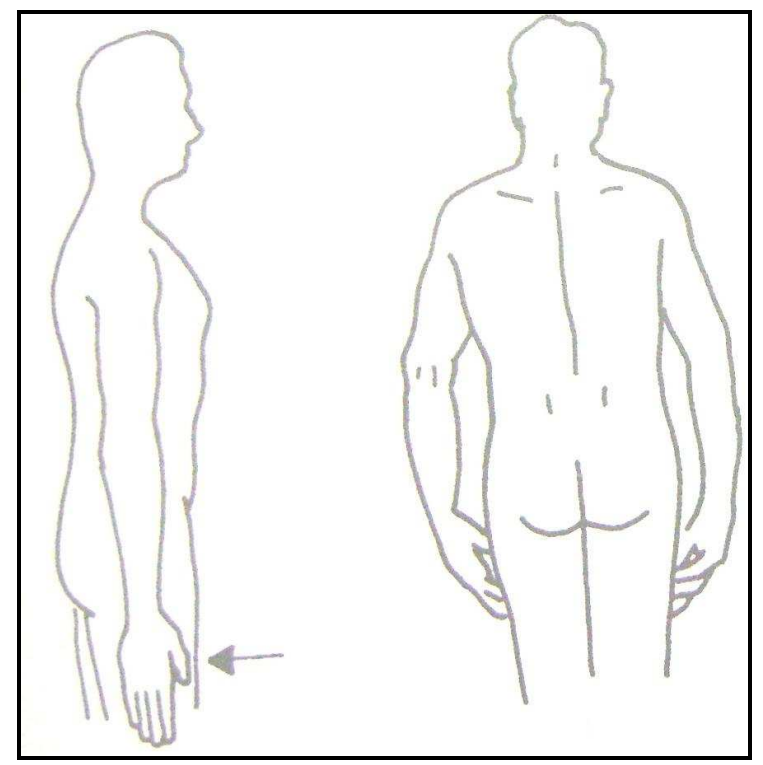

Figura 2.10 - Posição anatômica (KAPANDJI, 2000).

A flexão-extensão horizontal é o movimento do membro superior no plano horizontal (Figura 2.11). A posição anatômica para este movimento é o membro superior em abdução de 90 graus no plano frontal, o que provoca a contração dos músculos deltóide, supra-espinhal, trapézio superior e inferior e serrátil anterior. $\mathrm{Na}$ flexão horizontal a amplitude máxima é de 140 graus e ela ativa os seguintes músculos: deltóide, subescapular, peitoral maior e menor, serrátil anterior. Já a extensão horizontal tem uma amplitude menor de 30-40 graus e ativa o deltóide, supraespinhal, infra-espinhal, redondo maior e menor, rombóides, trapézio e grande dorsal em antagonismo com o deltóide. O principal músculo destes movimentos é novamente o deltóide.

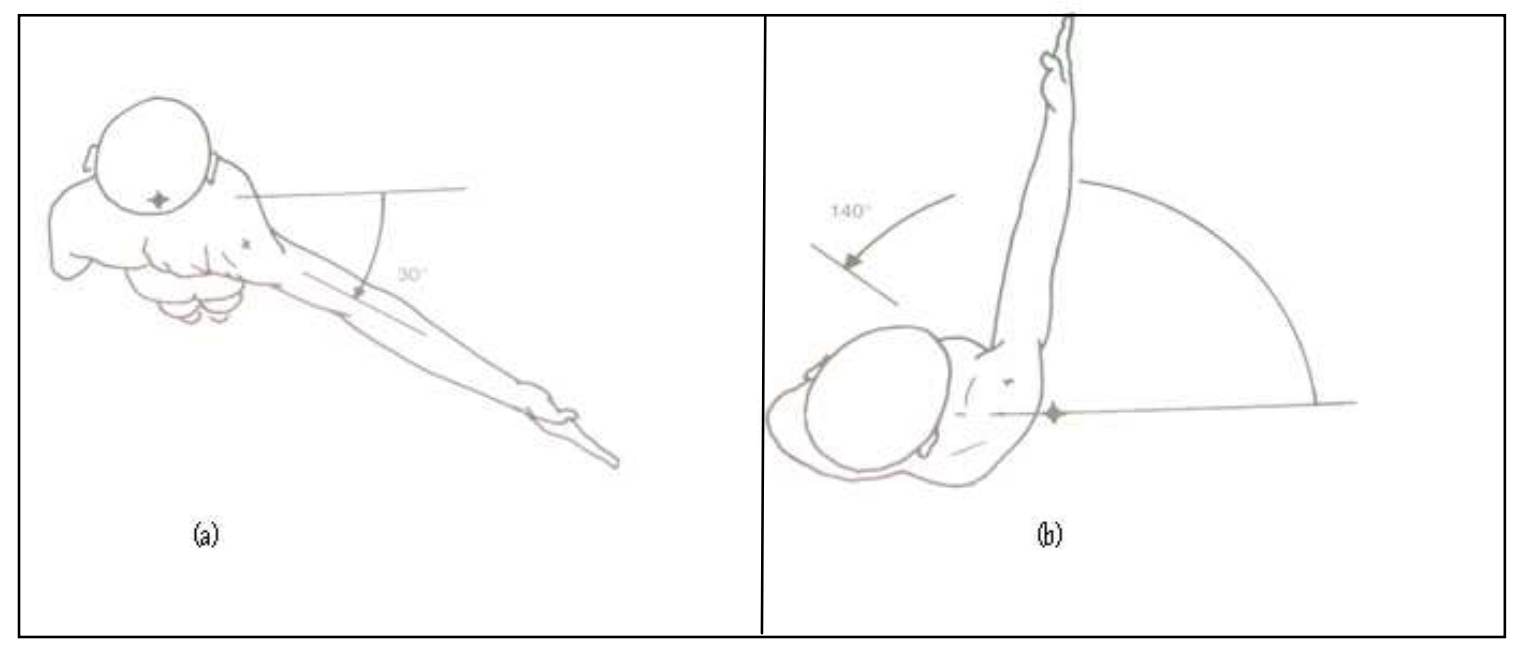

Figura 2.11 - (a) Extensão e (b) flexão horizontal (KAPANDJI, 2000). 


\subsubsection{Distúrbios Clínicos no Acidente Vascular Encefálico}

O acidente vascular encefálico (AVE) é o início súbito de deficiências neurológicas decorrentes de interferência do suprimento sanguíneo para o encéfalo (LUNDYEKMAN, 2000).

A paresia, a espasticidade e a perda da capacidade de fracionar os movimentos são os principais determinantes do comprometimento motor em pessoas vítimas de AVE. Paresia é perda parcial da contração voluntária, enquanto espasticidade é a hipertonia muscular dependente da velocidade, ou seja, se o músculo for estirado com rapidez haverá mais resistência do que se ele for estirado lentamente (LUNDYEKMAN, 2000). Mas também podem ocorrer seqüelas não relacionadas diretamente ao sistema motor, como afasias, por lesão das áreas de Broca ou Wernicke, relacionadas à linguagem, amusia ou perda das capacidades musicais e agnosia, que é a perda da capacidade de interpretar os sentidos. A Figura 2.12 mostra o padrão patológico comum em pacientes que sofreram um AVE. A seta na figura representa a circundução do quadril na fase de oscilação do membro hemiplégico, uma vez que, os pacientes, ao invés de flexionar quadril e joelho para dar um passo à frente como seria na marcha normal, realizam uma circundução do quadril mantendo o joelho em extensão.

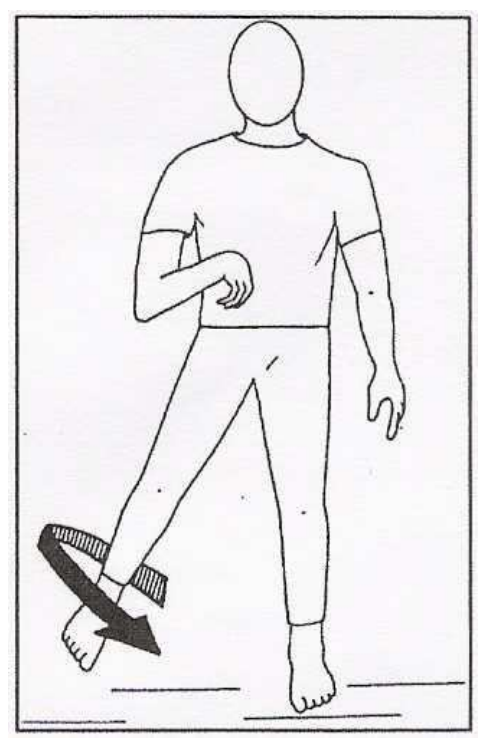

Figura 2.12 - Padrão patológico pós-AVE (SULZBACHER, 2004) 
Num AVE é freqüente que as lesões ocorram na via piramidal, que faz parte do córtex motor e controla os motoneurônios inferiores. Cerca de $90 \%$ dos axônios desta via cruzam para o lado oposto, fazendo com que o lado oposto seja o lado afetado, o que é denominado paralisia contralateral (DOUGLAS, 2006).

Uma lesão no cerebelo prejudica a coordenação dos movimentos e o controle postural, além disso, o tônus muscular fica diminuído. Por tônus muscular entendese a resistência do músculo ao estiramento passivo (LUNDY-EKMAN, 2000).

A Figura 2.13-B mostra uma lesão no córtex cerebral em uma pessoa vítima de AVE. A lesão ocorreu no lado direito do encéfalo, que controla os flexores e extensores do lado esquerdo. Na Figura 2.13-A, tem-se o sistema nervoso de uma pessoa normal, onde é possível ver que o trato córtico-espinhal lateral não foi afetado, o qual se origina nas áreas de planejamento motor (área 4) e seus axônios cruzam para o lado contralateral fazendo sinapses com os motoneurônios inferiores que controlam os movimentos finos distais.

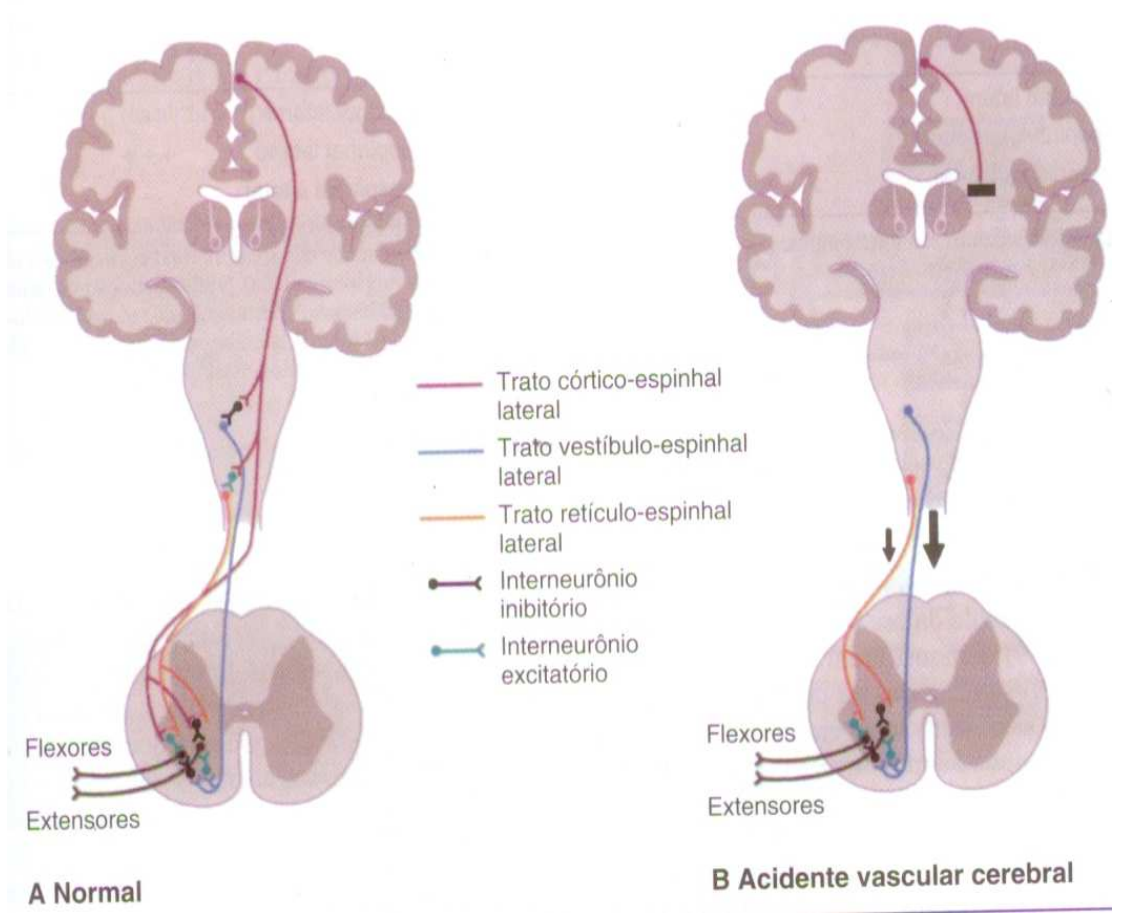

Figura 2.13 - Sistema nervoso normal X AVE (LUNDY-EKMAN, 2000). 


\subsubsection{Eletromiografia}

A eletromiografia (EMG) se refere à representação gráfica da atividade elétrica do músculo. É um método de estudo da atividade neuromuscular (CORREIA; MILHOMENS, 2004).

A entrada de uma fibra muscular em ação é sempre antecedida de uma corrente eletroquímica que percorre a sua membrana e que pode ser detectada e registrada através de eletrodos. Dada a reduzida amplitude dos sinais detectados, é necessário amplificar o fenômeno antes de registrá-lo.

Existem duas formas de fazer a aquisição dos sinais EMG: EMG de superfície e EMG de profundidade.

Na EMG de superfície, o eletrodo utilizado é um sensor que, através de uma superfície de detecção, capta a atividade elétrica produzida pelo músculo e propagada até a pele. Os eletrodos de superfície são colocados sobre a pele e permitem o registro da soma de atividade elétrica de todas as fibras musculares ativas. A EMG de superfície é normalmente escolhida para os estudos cinesiológicos.

Já na EMG de profundidade, os eletrodos são colocados no interior do músculo. Os eletrodos de profundidade podem ser eletrodos de agulha ou eletrodos de fio de arame. Este é um método intrusivo e pode ocasionar sensações dolorosas e derrame intramuscular.

No âmbito da investigação cinesiológica, a EMG pode ser útil para diversos problemas, como:

- estudos da função muscular normal em diferentes movimentos e posturas;

- estudos da atividade muscular nos gestos desportivos, profissionais e na reabilitação;

- estudos de coordenação muscular;

- estudos sobre a relação entre o trabalho mecânico e o EMG;

- avaliação de métodos de treino; 
- estudos sobre fadiga;

- estudos ergonômicos sobre a influência de material e equipamentos na atividade muscular.

A derivação bipolar corresponde ao registro da diferença de potencial entre dois eletrodos, localizados na mesma região muscular com atividade elétrica, tendo como referência um terceiro, localizado sobre uma região sem atividade neural proveniente, geralmente uma região óssea, como o queixo, por exemplo.

Em função da baixa amplitude do sinal de EMG de superfície, de microvolts até no máximo milivolts, faz-se necessário amplificar o sinal para posterior processamento. $O$ ideal para EMG é utilizar um amplificador diferencial. As freqüências características de um sinal de EMG situam-se entre 1 a $3.000 \mathrm{~Hz}$. No entanto, a energia mais significativa vai apenas até os $1.000 \mathrm{~Hz}$ e estudos mostraram que freqüências de EMG de superfície variam até no máximo $500 \mathrm{~Hz}$.

O ganho de um amplificador EMG é a razão entre a voltagem que entra no amplificador e aquela que sai. A EMG de superfície apresenta na contração voluntária máxima uma amplitude de até no máximo 5 milivolts. Assim, o ganho utilizado para amplificar o EMG de superfície deve ser ajustado entre 100 e 1.000.

Na prática, a saída do registro de EMG contém ruído e interferências, além da atividade elétrica do músculo monitorado. Estes sinais são chamados de artefatos e podem ser fisiológicos (EMG de músculos vizinhos, potenciais de eletrocardiograma) ou não fisiológicos (rede elétrica que gera acoplamento de campo elétrico e/ou campo magnético nos cabos dos eletrodos).

Para minimizar os artefatos não fisiológicos de acoplamento de campo elétrico nos cabos dos eletrodos são usados cabos blindados e filtros. Também se utiliza circuitos que objetivam eliminar a corrente de fuga para reduzir os efeitos das interferências nos cabos.

Para minimizar os artefatos não fisiológicos de acoplamento de campo magnético nos cabos dos eletrodos utiliza-se blindagem magnética e cabos trançados entre 0 paciente e o aparelho. Além disso, evita-se utilizar outros aparelhos elétricos no mesmo ambiente. Também se deve evitar realizar a aquisição do EMG próximo de emissoras de rádio, televisão ou radar. 
Os filtros são seletores de freqüência. Define-se para cada filtro a banda de interesse, a banda de rejeição e a freqüência de corte. Existem quatro tipos de filtro: passa-baixa, passa-alta, passa-faixa e rejeita-faixa.

A transição entre a banda de passagem ou interesse e a banda de rejeição não é instantânea, ela define uma região de transição. Existe oscilação tanto na banda de passagem quanto na banda de rejeição.

No sentido de se conseguir a tradução da curva EMG num sinal mensurável, que permita tirar dele o máximo de informação, devem ser aplicadas sucessivas transformações na curva EMG. Dois tipos de processamento são normalmente utilizados na investigação cinesiológica: processamento no domínio temporal e processamento no domínio da freqüência. O processamento no domínio temporal é utilizado nos estudos de coordenação motora e estudos sobre a relação entre EMG e força. Neste processamento é feita a análise da intensidade do EMG durante o tempo de contração. Já o processamento no domínio da freqüência é utilizado para determinar a freqüência, tipo e sincronização do disparo das diferentes unidades motoras ou em estudos sobre fadiga muscular.

\subsubsection{Eletrodos de superfície}

A superfície de detecção mais utilizada nos eletrodos é a prata por apresentar uma polarização bastante estável. Para estudos cinesiológicos, os autores aconselham que os eletrodos tenham uma superfície de detecção com diâmetro de 4 a $10 \mathrm{~mm}$ (CORREIA; MIL-HOMENS, 2004).

Existem duas técnicas para adquirir o EMG de superfície: monopolar e bipolar. $\mathrm{Na}$ configuração monopolar, apenas um eletrodo é colocado na pele em cima do músculo a investigar. Este eletrodo detecta o potencial elétrico relativamente a um eletrodo de referência, colocado num local onde não é afetado pela atividade elétrica gerada pelo músculo a ser estudado. Esta configuração é usada em ambientes clínicos. Na configuração bipolar, diferenças de potencial na pele são detectadas por duas superfícies em relação a um eletrodo de referência, colocado num ponto neutro 
em relação ao músculo estudado. Os dois sinais captados nas superfícies de detecção são enviados para um amplificador diferencial onde a diferença entre eles é amplificada, sendo eliminado o sinal comum antes da amplificação.

Os eletrodos podem ser passivos ou ativos. Os eletrodos passivos limitam-se a detectar a atividade mioelétrica e enviá-la por cabo para um amplificador. Já os eletrodos ativos contêm no seu interior um pré-amplificador diferencial que subtrai e amplifica o sinal logo após a saída da pele. Isso reduz as interferências produzidas pelos deslocamentos nos cabos.

Para minimizar a influência da resistência da pele no sinal é necessário preparar a pele, limpando-a com álcool e deixando um intervalo de tempo de no mínimo 5 minutos entre a colocação dos eletrodos e a captura do sinal.

O local do músculo onde os eletrodos são colocados pode interferir na qualidade do sinal. Os eletrodos não devem ser colocados no ponto motor.

Quando há necessidade de comparar sinais do mesmo indivíduo e da mesma tarefa em dias diferentes, é importante colocar os eletrodos no mesmo local do músculo. Para isso, duas precauções podem ser tomadas. Em primeiro lugar, pode-se marcar na pele os pontos exatos onde os eletrodos são colocados. Em segundo lugar, a colocação dos eletrodos deve ser feita com a articulação na mesma posição, de forma a garantir o mesmo comprimento do músculo no momento da colocação.

A orientação dos eletrodos em relação às fibras musculares deve ser longitudinal, ou seja, a linha que une duas superfícies de eletrodos deve ser paralela à orientação das fibras musculares.

Quando se capturam sinais EMG com eletrodos de superfície para fins cinesiológicos podem ocorrer interferências como artefatos mecânicos gerados pelo movimento dos eletrodos e de seus cabos de ligação ou interferências sinusoides que são originadas em campos eletromagnéticos provenientes de aparelhos elétricos vizinhos, como aparelhos de ondas curtas, lâmpadas de luz fluorescente. Os artefatos de movimento não excedem os 10-20 Hz e podem ser eliminados com um filtro passa-baixa, que corte as freqüências abaixo desses valores. No caso das interferências de sinusoides, devem-se eliminar as fontes de interferência.

A banda passante de um amplificador EMG corresponde aos valores de freqüência situados entre o filtro de corte de baixas freqüências e o filtro de corte de freqüências 
altas. A freqüência de corte inferior deve estar entre 10 e $20 \mathrm{~Hz}$, de forma a eliminar os artefatos de baixa freqüência. Assim, uma banda passante para o EMG de superfície situa-se entre os 10 e $1.000 \mathrm{~Hz}$.

\subsubsection{Processamento do Sinal EMG no Domínio Temporal}

A técnica de filtragem da curva EMG consiste em suprimir os sinais de freqüência acima e abaixo de determinados valores. Normalmente, para EMG de superfície, utiliza-se um filtro de baixas freqüências entre 10 e $20 \mathrm{~Hz}$ e de altas freqüências entre 300 e $500 \mathrm{~Hz}$ (CORREIA; MIL-HOMENS, 2004).

Uma forma de reduzir a variabilidade do sinal EMG consiste em eliminar as variações muito bruscas dos valores de amplitude do sinal bruto, através da suavização da curva. Uma técnica de suavização é a média local (averaging), onde são calculados valores médios de pequenos intervalos de tempo e as oscilações bruscas em relação à média são removidas.

Mesmo quando um movimento é reproduzido com precisão nas mesmas condições, existe uma variação no sinal EMG, de execução para execução. $O$ valor absoluto do sinal EMG fornece pouca informação, principalmente, quando é resultante de sinais de indivíduos diferentes ou do mesmo indivíduo em dias diferentes. Para contornar esta situação, utiliza-se a normalização em amplitude dos sinais EMG. Esta técnica transforma os valores absolutos que se pretende comparar em valores relativos a um EMG de referência. Diferentes valores de referência podem ser utilizados: EMG de contração isométrica voluntária máxima, pico de atividade verificada nas repetições que se pretende comparar, valor médio do EMG, valor do sinal em repouso.

A quantificação do sinal EMG pode ser feita por uma das três alternativas a seguir:

- valor integral do sinal EMG,

- valor absoluto do sinal EMG (VAM),

$$
V A M=\frac{1}{S} \sum_{1}^{S} f(s)
$$


- raiz quadrada média (RMS) do sinal EMG,

$$
R M S=\sqrt{\frac{1}{S} \sum_{1}^{S} f^{2}(s)}
$$

onde $\mathrm{S}$ é a dimensão da janela (número de amostras) e f(s) é o valor dos dados dentro da janela.

\subsubsection{Reabilitação}

A reabilitação pode ser física, cognitiva ou psico-social. Neste trabalho, é considerada apenas a reabilitação física.

As terapias de reabilitação física têm como objetivo corrigir ou diminuir as deficiências perceptuais e motoras do paciente, promovendo a neuroplasticidade (NUDO; PLAUTZ; FROST, 2001). No encéfalo adulto, as áreas corticais ajustam o modo como se processa a informação, conservando a capacidade de desenvolver novas funções. Muitos estudos mostram a realocação de funções neurais no córtex cerebral. Por exemplo, em (LUNDY-EKMAN, 2000) foi descrito um estudo de caso onde um indivíduo que amputou um membro superior teve a área cortical destinada à representação da mão ausente reorganizada para a representação da face.

As terapias de reabilitação também objetivam melhorar as habilidades funcionais do paciente, como, segurar os talheres, amarrar os cadarços, fechar os botões da camisa, realizar a higiene pessoal, de forma que este possa viver o mais independentemente possível.

A reabilitação física requer uma reeducação motora repetitiva de forma a modificar a organização neural (NUDO; PLAUTZ; FROST, 2001). Terapias de reabilitação físicas convencionais se concentram no fortalecimento dos músculos, aumento da faixa de movimento e melhoria no equilíbrio. Estas intervenções tendem a ser monótonas e fornecem poucas oportunidades para uma graduação sistemática do nível de dificuldade. Um dos principais desafios na reabilitação é identificar métodos de intervenção que sejam efetivos, motivadores e que transfiram a habilidade para uma função no mundo real (RIZZO et al., 2004). 
Estudos comprovam que a falta de movimentação ativa após uma lesão do córtex motor pode levar à perda subseqüente da função em regiões adjacentes, não lesadas, do encéfalo. Entretanto, o retreinamento pode prevenir esta perda subseqüente (LUNDY-EKMAN, 2000).

A terapia ocupacional é definida como um tipo de terapia de reabilitação que usa atividades da vida real para ajudar os pacientes a eliminar, diminuir ou superar as suas deficiências físicas, cognitivas e psico-sociais. Esta terapia é indicada para uma variedade de problemas incluindo as disfunções neurológicas. O terapeuta ocupacional deve não somente assistir o estado físico do paciente como também seu estado emocional (STANSFIELD et al., 2005).

O termo proximal (que significa mais próximo, em Latim) é usado para descrever o ponto mais próximo onde um apêndice ou parte se junta ao corpo. A palavra distal (que significa mais distante, em Latim), por sua vez, se refere ao ponto mais distante de conexão da parte ao corpo. No caso dos membros superiores, o ombro é proximal e os dedos são distais. A maioria das atividades da terapia ocupacional envolve movimentos das partes distais do braço, por serem mais funcionais e, assim, permitirem a realização de um maior número de atividades da vida diária, como, por exemplo, segurar e soltar um copo ou um garfo.

\subsubsection{Prática Mental}

A prática mental na reabilitação física tem como objetivo estimular a imagem motora no paciente. A imagem motora, conforme a definição apresentada na Introdução, é um estado no qual as representações de uma determinada ação motora são ensaiadas na memória de trabalho sem que haja necessariamente saída motora.

Em (PAGE; LEVINE; LEONARD, 2005) é descrita uma intervenção utilizando um protocolo de prática mental. As orientações para a intervenção foram gravadas em fitas de áudio por um psicólogo. Ele iniciava a fala orientando o paciente a realizar um relaxamento progressivo de 5 minutos. Isso era feito pedindo ao paciente que se imaginasse em um lugar relaxante (por exemplo, uma praia) e contraísse e 
relaxasse seus músculos. Após o relaxamento, ele sugeria ao paciente que criasse imagens relacionadas ao uso do membro afetado em tarefas funcionais. Os últimos 5 minutos eram utilizados para recolocar o paciente no mundo real.

Para determinar a eficácia do protocolo de prática mental no aumento do uso e função do membro mais afetado em pacientes vítimas de um AVE, os autores realizaram um experimento com onze pacientes crônicos (que sofreram um AVE há mais de um ano) que exibiam hemiparesia e não uso do braço afetado. Os pacientes foram divididos em dois grupos: experimental e controle. Os pacientes do grupo experimental receberam um tratamento que combinava a prática física com a prática mental nas atividades do dia-a-dia, enquanto os pacientes do grupo controle receberam apenas a prática física idêntica ao grupo experimental. Todos os pacientes receberam sessões de terapia de 30 minutos, dois dias por semana, durante seis semanas. As tarefas do dia-a-dia utilizadas nas sessões gravadas na fita de áudio foram:

1) alcançar e agarrar um copo,

2) virar a página de um livro,

3) usar de forma apropriada uma caneta ou lápis.

As tarefas foram aplicadas na ordem acima (1-2-3). A prática mental das tarefas era feita em casa e na clínica.

Antes da intervenção, os pacientes não usavam seus membros superiores afetados para atividades do dia-a-dia. Isso foi verificado pelas notas da quantidade de uso, obtidas na auto-avaliação dos pacientes nos pré-testes que foram de 1,1 para o grupo experimental e 0,9 para o grupo controle. Após a intervenção, as notas atribuídas pelos pacientes do grupo experimental aumentaram para 2,6 (aumento de 1,5). Em contraste, a quantidade de uso do membro afetado no grupo controle após a intervenção foi de 1,4 na auto-avaliação dos pacientes, com um aumento de apenas 0,5 .

O tratamento também teve efeito na qualidade do movimento. Antes da intervenção, a qualidade do movimento no pré-teste do grupo experimental foi de 0,59 e a do grupo controle foi 0,50 . Após a intervenção, a qualidade no grupo experimental subiu para 2,8 (aumento de 2,21) enquanto no grupo controle subiu para 0,67 (aumento de 0,17). 
Outros estudos também têm apontado a efetividade da prática mental aliada à prática física para melhorar o aprendizado motor e o desempenho em cenários de reabilitação. No trabalho apresentado em (FANSLER; POFF; SHEPHARD, 1985) ocorreram melhorias maiores nas tarefas de equilíbrio (por exemplo, ficar em pé numa perna só) entre as mulheres idosas que foram submetidas ao tratamento com prática mental e prática física do que nas mulheres que participaram do tratamento apenas com prática física.

Outros estudos relataram que, durante a prática mental, ativações correlacionadas ocorrem no nível cortical e na musculatura imaginada como sendo usada. $O$ trabalho descrito em (BREITLING; GUENTHER; RONDOT, 1986) relatou que ocorreram atividades similares nas áreas corticais quando as pessoas imaginavam 0 movimento dos dedos em um estado relaxado e quando elas estavam efetivamente executando os movimentos.

\subsection{REALIDADE AUMENTADA}

Esta seção apresenta os principais fundamentos relacionados às tecnologias de realidade aumentada.

\subsubsection{Definição}

A realidade aumentada $(R A)$ usa técnicas computacionais que geram, posicionam e mostram objetos virtuais integrados a um dado cenário real em tempo real. Objetos virtuais são combinados às imagens do mundo físico, enriquecendo o ambiente real com elementos virtuais. Diferentemente da realidade virtual (RV), que transporta o usuário para um ambiente virtual, a RA mantém o usuário no seu ambiente físico e transporta elementos do ambiente virtual para o espaço do usuário, permitindo a interação com o mundo real e virtual, de maneira natural e sem necessidade de adaptações (TORI; KIRNER, 2006). 
Um sistema completo de RA é constituído por uma ou mais câmeras, algum software para construção de objetos virtuais, sistema gráfico, dispositivo de interação e dispositivo de visualização, que pode ser tela de exibição (monitor ou tela de LCD ou plasma) ou projeção, HMD (head mounted display) ou alguma superfície de projeção espacial.

O funcionamento de um sistema de RA compreende:

- aquisição de imagens da cena real,

- criação de imagens virtuais,

- rastreamento para posicionamento e orientação espacial dos objetos virtuais,

- sobreposição/composição dos objetos virtuais no cenário real e

- interação em tempo real.

A Figura 2.14 mostra um sistema de RA, onde foi adicionado um objeto virtual (bule) à cena. $\mathrm{O}$ objeto foi posicionado em cima de um marcador de papel colocado sobre a mesa real.

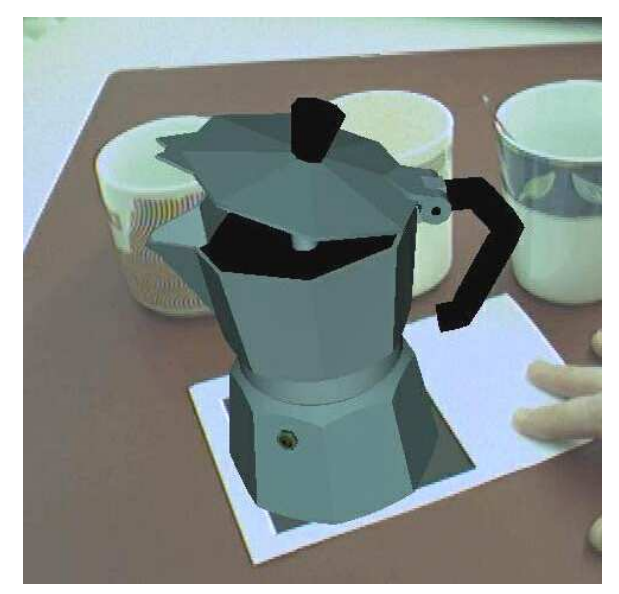

Figura 2.14 - Sistema de RA (FISCHER; BARTZ; STRABER, 2005).

O rastreamento utilizado na Figura 2.14 é baseado em visão computacional. Este rastreamento permite rastrear simultaneamente vários objetos na cena e fornece um rastreamento centrado em cada objeto. Os objetos físicos (reais) podem ser marcados com marcadores de rastreamento. 


\subsubsection{Tipos de Sistemas de Realidade Aumentada}

A RA pode ser classificada em RA direta e RA indireta, dependendo da forma que o usuário observa o mundo misturado. Quando o usuário vê o mundo misturado apontando os olhos diretamente para as posições reais, como na RA espacial, a RA é de visão direta ou imersiva. Quando o usuário vê o mundo misturado em algum dispositivo, como uma tela de exibição ou projeção, não alinhado com as posições reais, a RA é de visão indireta ou não imersiva (TORI; KIRNER, 2006).

Quanto aos dispositivos de visualização utilizados os tipos de sistema RA possíveis são (MILGRAM; KISHINO, 1994):

- visualização direta óptica,

- visualização direta baseada em vídeo,

- visualização indireta baseada em monitor,

- visualização indireta baseada em projetor,

- visualização direta baseada em projetor (RA espacial).

Os dispositivos de visualização das imagens misturadas podem ser atrelados à cabeça, como é o caso dos dispositivos de exibição na retina, capacetes ou HMD e mini-projetores colocados acima dos olhos. Por outro lado, existem dispositivos de exibição que são mantidos na mão (hand-held) e outros que são espacialmente alinhados no ambiente real e que ficam completamente desatrelados do usuário (BIMBER; RASKAR, 2005).

Dispositivos de exibição retinais produzem imagens mais brilhantes e com um campo de visão potencialmente mais largo do que os dispositivos de exibição baseados em tela. Também não existem relatos de versões estereoscópicas desta tecnologia até o momento (BIMBER; RASKAR, 2005).

Dispositivos estereoscópicos proporcionam a visão binocular. O princípio de funcionamento da maioria dos dispositivos estereoscópicos é baseado o oferecimento de imagens distintas ao olho esquerdo e ao direito do observador, proporcionando a sensação de profundidade (MACHADO; CARDOSO, 2006). 
Mini-projetores colocados na cabeça podem redirecionar o frustum de projeção com um espelho tal que as imagens possam ser irradiadas em superfícies retro-reflexivas localizadas na frente do observador. Estas superfícies podem ser cobertas por micro-cubos com a propriedade de refletir a luz de volta na direção incidente. Estes dispositivos fornecem um campo de visão maior sem a aplicação de lentes adicionais e previnem distorções incorretas da paralaxe causadas pelo casamento incorreto da distância entre pupilas, que são comuns nos capacetes atrelados à cabeça. Estes dispositivos também introduzem alguns problemas, pois são incômodos, pesados e os projetores miniatura ainda oferecem resolução e brilho limitados, o brilho da imagem depende da iluminação ambiente (Figura 2.15).

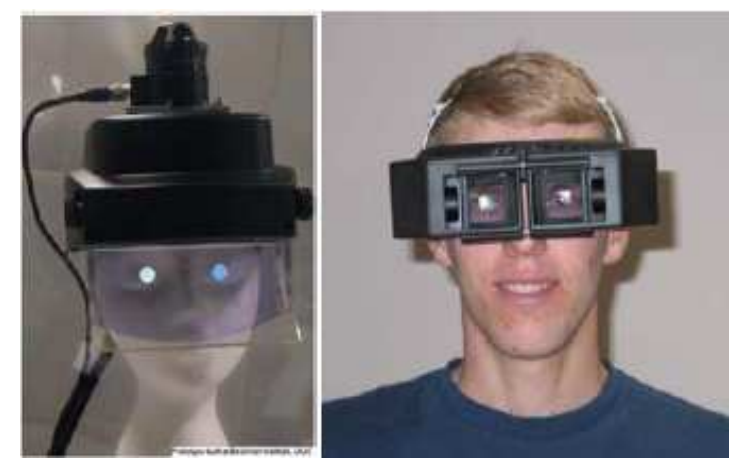

Figura 2.15 - Projetores atrelados à cabeça (HUA et al., 2001).

Exemplos de dispositivos de exibição mantidos na mão (hand-held) convencionais são os celulares, que combinam processador, memória, tela de exibição e interação em um único dispositivo e suportam manipulação móvel irrestrita e sem fio. As desvantagens destes dispositivos são o tamanho de tela limitado, que restringe o campo de visão coberto, e também o fato de não deixarem as mãos do usuário livres para o trabalho.

Os dispositivos espaciais desatrelam a tecnologia do usuário e a integram ao ambiente. Existem três alternativas para o uso destes dispositivos em RA: tela; dispositivos espaciais óticos; e dispositivos espaciais baseados em projetores (BIMBER; RASKAR, 2005).

A RA baseada em tela utiliza mistura de vídeo e objetos virtuais e mostra as imagens misturadas em um monitor (Figura 2.16). 


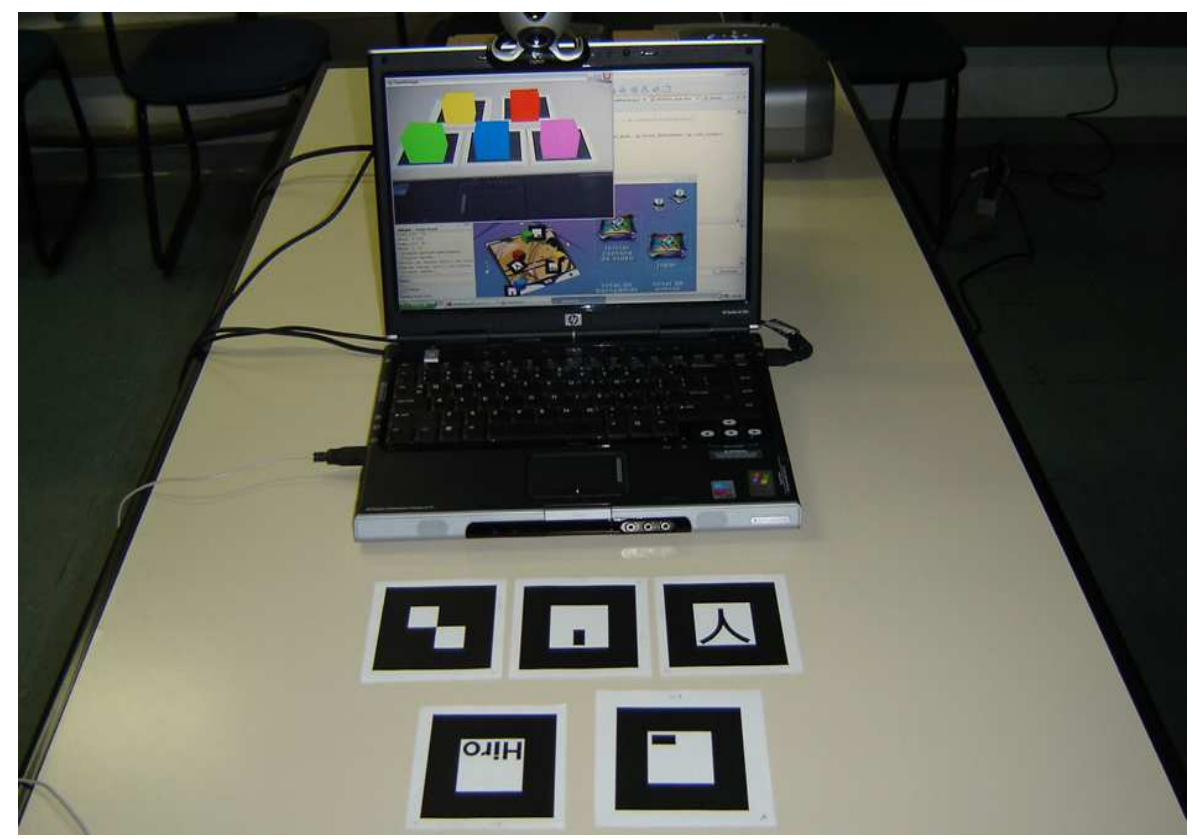

Figura 2.16 - Exemplo, Cubos virtuais na tela (CORREA et al., 2007).

Os dispositivos espaciais ópticos geram imagens que são alinhadas dentro do ambiente físico. Estes dispositivos usam componentes como espelhos planares ou curvos, telas transparentes ou hologramas ópticos. Um problema com esta tecnologia é que ela não suporta oclusão mútua entre objetos reais e virtuais (Figura 2.17).

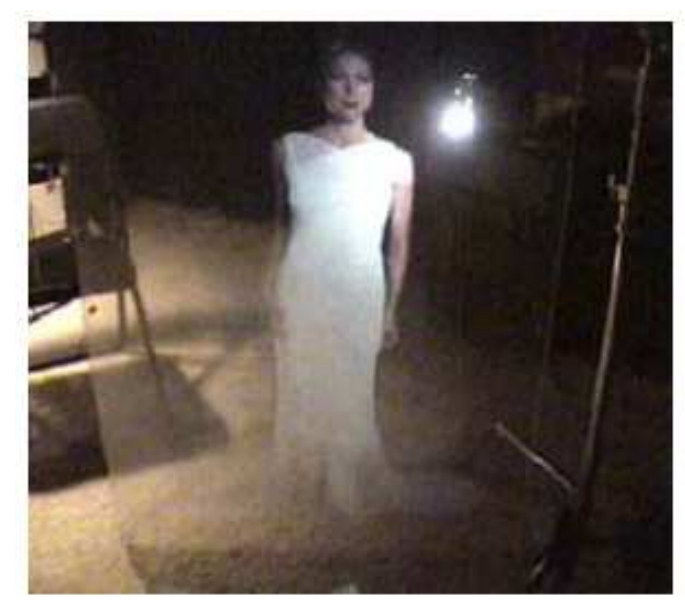

Figura 2.17 - Dispositivos espaciais óticos (OGI et al., 2001).

Os dispositivos de exibição espaciais baseados em projetores aplicam projeção na frente da superfície dos objetos físicos, ao invés de mostrá-los em um plano imagem no campo de visão do observador (Figura 2.18). 


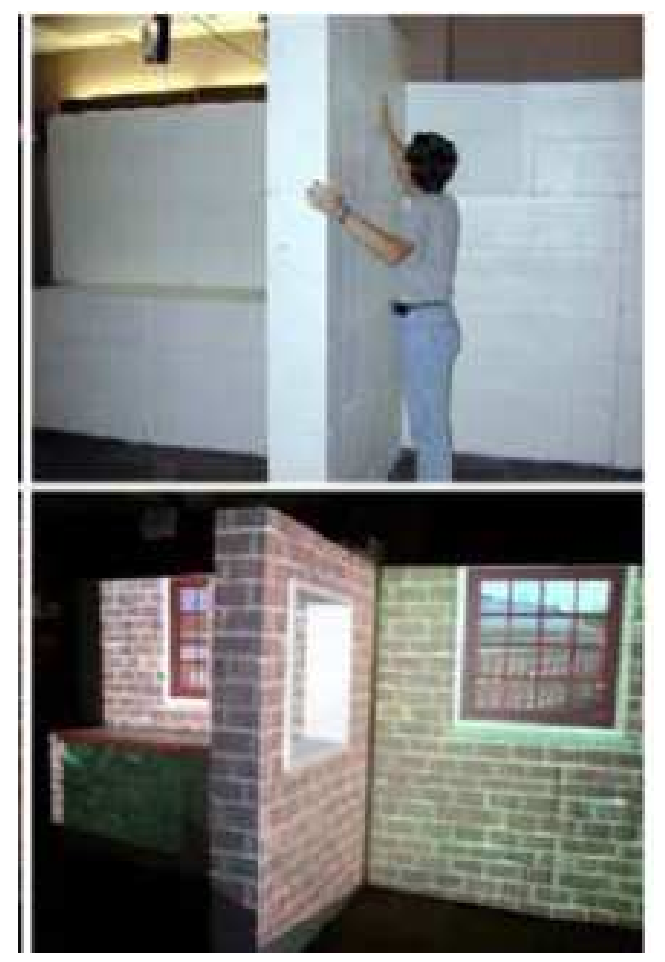

Figura 2.18 - Dispositivos espaciais com projetores (LOW et al., 2001).

Os capacetes atrelados à cabeça (HMD) são largamente usados em aplicações de RA. Existem duas tecnologias de HMD para RA, são elas:

- HMD com vídeo, que faz uso de mistura com vídeo e mostra as imagens dentro de um HMD com visão fechada, onde tanto o mundo real quanto as imagens sobrepostas são percebidos na resolução do vídeo ou do dispositivo de exibição (Figura 2.19).

- HMD ótico, que usa combinações óticas, espelho ou display de cristal líquido (LCD) transparente. Neste, as imagens virtuais (sobrepostas) são percebidas em uma resolução relativamente baixa, enquanto o mundo real pode ser percebido na resolução do sistema visual humano. Não permite fornecer efeitos de oclusão consistentes. 


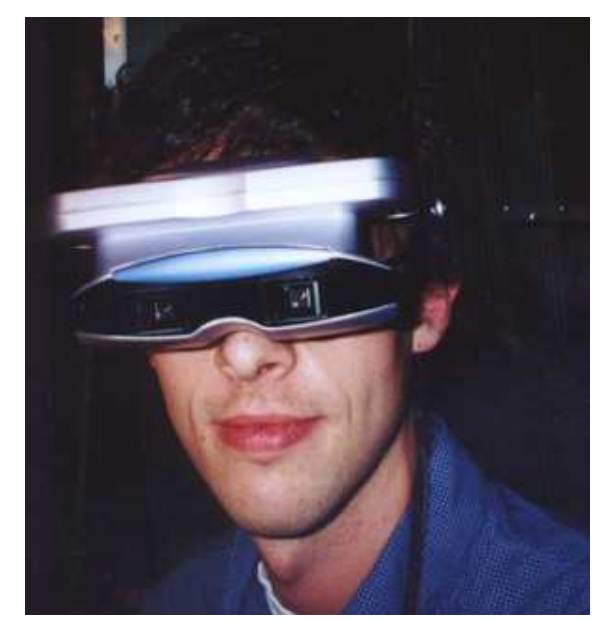

Figura 2.19 - Capacete atrelado à cabeça de visão fechada.

\subsubsection{Aquisição de Imagens do Mundo Real}

A aquisição de imagens do mundo real para a criação da imagem misturada pode ser feita através de uma ou mais câmeras. No caso de se utilizar mais de uma câmera, estas precisam ser calibradas e sincronizadas. Este processo compreende: calibração geométrica, correção de distorções das lentes e calibração de cores.

Para encontrar os pixels correspondentes em imagens provenientes de duas câmeras, por exemplo, é necessário realizar comparação entre janelas de pixels. Uma das técnicas utilizadas para realizar esta combinação é a de Visual Hull, que faz a segmentação da silhueta do objeto de interesse nas diferentes vistas, aproxima cada silhueta por um polígono, gera formas 3D (tridimensionais) por extrusão das silhuetas e calcula a interseção destas formas por geometria sólida construtiva (MATUSIK et al. 2000).

\subsubsection{Remoção de Objeto de Interesse}

As aplicações tradicionais de remoção de objetos de interesse são composições de imagens. Um exemplo é mostrado na Figura 2.20, onde é feita a extração de uma 
área de primeiro plano da imagem de origem de modo que possa ser inserida em um novo plano de fundo (TONIETTO, 2000).
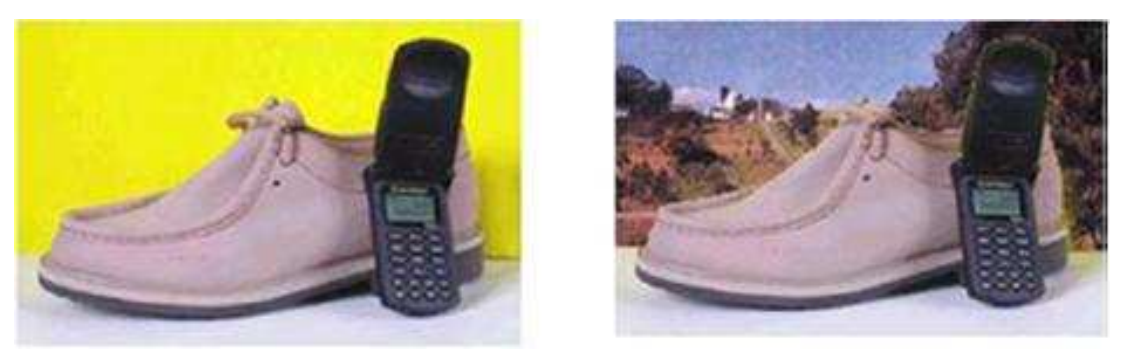

Figura 2.20 - Aplicação de remoção de fundo (TONIETTO, 2000).

Canal alfa é um mapa que indica se um pixel na imagem de origem pertence ao primeiro plano ou ao fundo. Na maioria das técnicas, esta informação é percentual, ou seja, cada pixel possui valores de zero a um (0\% a $100 \%$ de fundo). Uma das principais técnicas utilizadas para classificar os pixels em primeiro plano ou segundo plano é a técnica de chromakey.

A técnica de chromakey se baseia na identificação de partes da imagem onde se encontra uma determinada cor, denominada "cor chave" (Sanches, 2007). A máscara gerada (canal alfa) é utilizada para selecionar quais pixels devem permanecer e quais devem ser substituídos por pixels de outra imagem. Conceitualmente, a operação chromakey é muito simples, mas apenas a comparação de pixels da imagem com a cor chave, selecionada automaticamente ou por meio de um operador, pode conduzir a composições grosseiras e pouco naturais. Podem-se observar imperfeições nas bordas ao redor dos objetos de primeiro plano extraídos, sombras sobre o plano de fundo podem ser entendidas como elementos de primeiro plano, e a câmera de vídeo deve permanecer imóvel durante o processo, para que se mantenha a coerência entre as camadas de primeiro e segundo planos. $O$ fato de o ator possuir, em seu vestuário, alguma peça da mesma cor do plano de fundo, ou o objeto a ser extraído possuir partes dessa mesma cor constitui uma limitação implícita desta abordagem. Por esses motivos, muitos sistemas modernos que utilizam a técnica aplicam também algoritmos para preservar detalhes do objeto a ser isolado.

Geralmente, o chromakey é feito com a cor azul, pois as tonalidades de azul não são encontradas na pele humana. Uma alternativa é utilizar a cor verde, uma vez que as 
câmeras digitais atuais conseguem identificar mais facilmente os canais de verde (Sanches, 2007).

Outro recurso utilizado em aplicações de remoção de fundo ou de objeto de interesse é o trimap, que é um mapa auxiliar utilizado pelas técnicas que identificam o primeiro plano por refinamento de uma solução. Um pixel é classificado entre três valores no trimap: primeiro plano, segundo plano e desconhecido, utilizando chromakey, por exemplo. O processamento fica limitado à área desconhecida (MCGUIRE et al., 2005).

\subsubsection{Registro em Realidade Aumentada}

A representação correta da profundidade da cena é essencial para a obtenção de realismo em RA. Um alinhamento correto dos objetos virtuais em relação ao ambiente real é fundamental para obter a ilusão da coexistência entre eles (AZUMA, 1997).

Existem situações em que os marcadores estão visíveis à câmera e estão posicionados mais distantes do observador que um elemento real. E no momento da geração do objeto virtual, a cena é montada de forma incoerente, com a imagem real como fundo e o objeto virtual na frente.

O registro em realidade aumentada vai além da estimativa do posicionamento e da orientação do objeto virtual em relação ao ambiente real. É necessário que a cena seja visualizada de forma coerente, respeitando-se a profundidade dos elementos reais e virtuais.

A Figura 2.21 apresenta um exemplo de erro de registro. O cubo virtual azul deveria estar atrás da caixa real branca e não ao seu lado. 


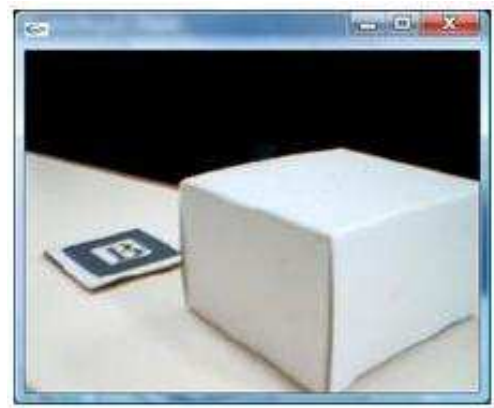

(a) Marcador real posicionado ao findo

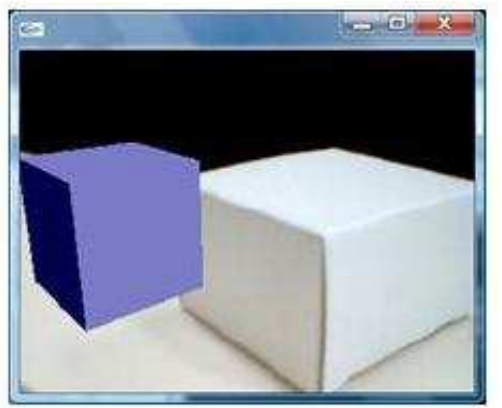

(b) Objeto virtual gerado em primeiro plano

Figura 2.21 - Erro de registro (Sanches, 2007).

Em Sanches (2007), o problema do registro foi resolvido com a colocação de um marcador no objeto de primeiro plano de interesse (no caso, o usuário). Assim também havia informação de profundidade sobre o objeto real de interesse. Na sua proposta, Sanches sobrepõe algumas partes da imagem combinada (virtual + real) que foi armazenada no frame buffer para posterior exibição. As partes do objeto de interesse que estão mais próximas do observador do que o objeto virtual são preenchidas com os pixels correspondentes, extraídos do objeto real de interesse ou primeiro plano. A Figura 2.22 ilustra este processo. Na Figura 2.22(a), tem-se o marcador fixo no fundo. A Figura 2.22(b) mostra um mapeamento de fundo com erro de registro. Já na Figura 2.22(c) tem-se o mapeamento de fundo e registro correto.

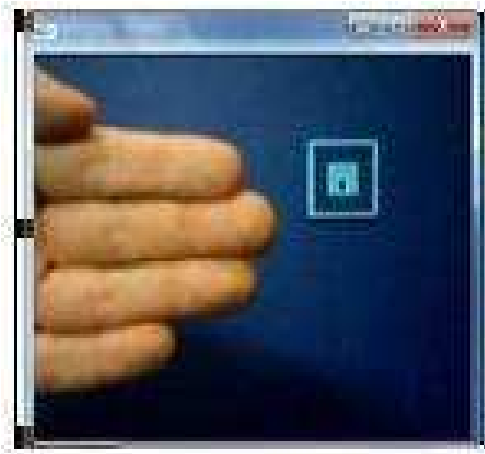

(a)

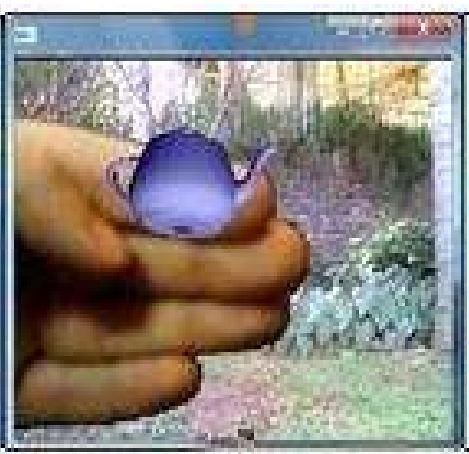

(b)

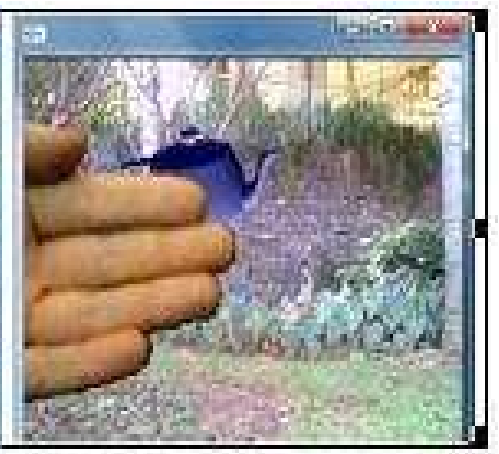

(c)

Figura 2.22 - Registro incorreto X correto (Sanches, 2007) 


\subsubsection{Realidade - Virtualidade}

De acordo com Milgram e Kishino (1994), as interfaces podem ser classificadas dependendo de quanto do ambiente é real e quanto é gerado por computador, tendo a realidade e a $\mathrm{RV}$ como extremos (Figura 2.23).

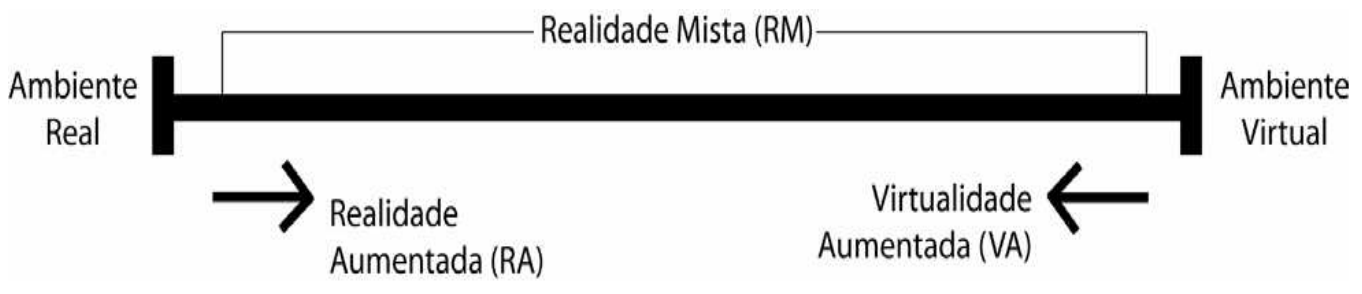

Figura 2.23 - Continuum de Milgram (MILGRAM; KISHINO, 1994)

Entre os extremos do continuum da realidade misturada estão as interfaces de RA e virtualidade aumentada. Interfaces de RA sobrepõem imagens virtuais no mundo real. A RA suplementa a realidade ao invés de substituí-la completamente. Azuma (2004) afirma que RA inclui a idéia de remover parte do mundo real, o que ele denomina como realidade mediada, "mediated or diminished reality".

$\mathrm{Na}$ equação (2.22) tem-se a classificação do continuum Realidade-Virtualidade de Milgram e Kishino (1994) nas cinco faixas da Figura 2.3 formulada em termos de três variáveis: $n$, número de objetos reais, $m$, número de objetos virtuais e $t$, o total de objetos na cena.

Equação 2.22 - Formulação da classificação do continuum de Milgram:

Ambiente $\operatorname{Re} a l \Leftrightarrow t=n$, onde $n \geq 1$

Realidade Aumentada $\Leftrightarrow t=n+m$, onde $n \geq 1, m \geq 1, n>m$

Realidade Mediada $\Leftrightarrow t=(n-m)+m$, onde $(n-m)$ são objetos reais e $n>m \geq 1$

Virtualidade Aumentada $\Leftrightarrow t=n+m$, onde $n \geq 1$ e $m \geq 1$ e $m>n$

Realidade Virtual $\Leftrightarrow t=m$, onde $m \geq 1$ 


\subsection{INTERFACE CÉREBRO-COMPUTADOR}

Esta seção descreve aspectos gerais das interfaces cérebro-computador, como conceituação e arquitetura básica.

\subsubsection{Definição}

Muitas pessoas com deficiências motoras severas precisam de tecnologias de comunicação aumentada, aqui entendidas como aquelas que proporcionam um tipo de comunicação não-muscular que possibilita a comunicação e controle de dispositivos por sinais cerebrais, que podem ser provenientes diretamente do encéfalo ou de outras partes do corpo, como os sinais bioelétricos dos músculos, por exemplo. As pessoas que são totalmente paralisadas não podem usar tecnologias convencionais, pois normalmente requerem alguma medida de controle muscular. Muitos estudos têm avaliado a possibilidade de que sinais cerebrais registrados do escalpo ou de dentro do cérebro ou de outras partes do corpo pudessem ser utilizados em tecnologias que não requeresse controle muscular, as chamadas interfaces cérebro-computador ou Brain-Computer Interface (BCl). Um sistema $\mathrm{BCl}$ é capaz de medir características específicas de atividade cerebral e transformar estas medidas em sinais de controle de dispositivos, como neuropróteses, cursores, mouses, controles de cadeira de rodas, entre outros (SCHALK et al., 2004).

\subsubsection{Arquitetura Básica de um Sistema BCI}

A Figura 2.24 apresenta um esquema básico do funcionamento de um sistema de interface cérebro-computador $(\mathrm{BCl})$. Os sinais cerebrais são adquiridos por eletrodos no escalpo e são processados para extração de medidas de características específicas como potenciais corticais lentos, potenciais evocados, ritmos sensório- 
motor registrados no escalpo, potenciais relacionados a eventos, etc. Estas medidas podem ser traduzidas em comandos para operar dispositivos como editor de textos, cadeira de rodas e neuroprótese.

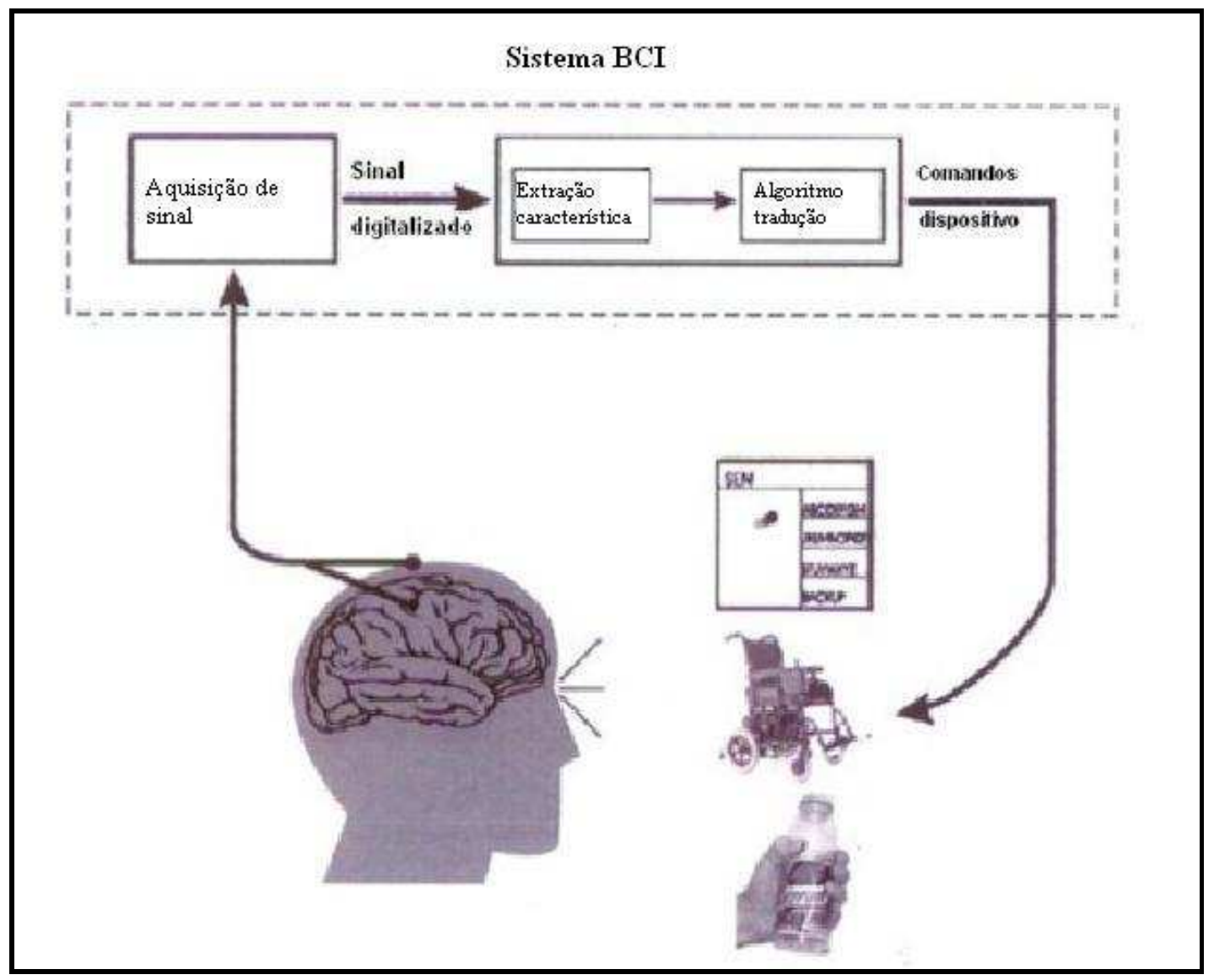

Figura 2.24 - Arquitetura de um sistema BCI (SCHALK et al., 2004).

Muitos fatores determinam o desempenho de um sistema $\mathrm{BCl}$. São eles: sinais cerebrais medidos, os métodos de processamento do sinal que extraem as características, os algoritmos que transformam estas características em comandos de dispositivo, os dispositivos de saída que executam estes comandos, o retorno fornecido ao usuário, e as características do usuário (SCHALK et al., 2004).

\subsection{TRABALHOS CORRELATOS}

Várias pesquisas estão sendo desenvolvidas na área de tecnologias para reabilitação motora. Esta seção apresenta alguns trabalhos de pesquisa que fazem 
uso de tecnologias como robótica, realidade virtual e realidade aumentada para reabilitação motora de membros superiores.

\subsubsection{REABILITAÇÃO COM O BRAÇO MECÂNICO MANUS}

Krebs et al (1998) descreve uma terapia de reabilitação motora assistida por um braço mecânico, com sensores de força, denominado MIT-MANUS.

Neste tratamento com robô, os pacientes são incumbidos de realizar uma tarefa, como, por exemplo, utilizar o braço mecânico para tentar mover um objeto na tela do computador. Outras atividades envolvem jogos digitais para estímulo visual do paciente, como mostra a Figura 2.25. Quando os sensores de força não registravam qualquer sinal do músculo do braço do paciente, o robô realizava o movimento para o paciente. Após algumas sessões, observou-se que os pacientes se tornaram capazes de realizar o movimento, ou seja, desenvolveram alguma modulação sináptica no cérebro para a execução da ação.

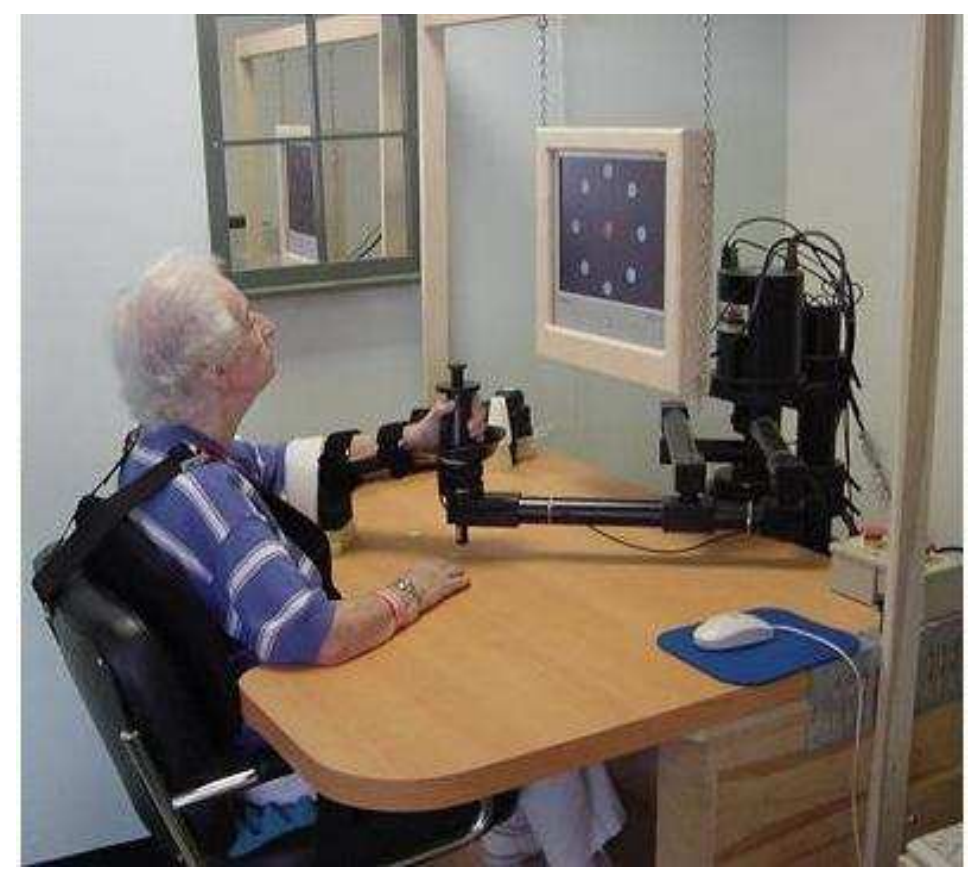

Figura 2.25 - Sistema robótico para reabilitação motora (KREBS et al., 1998)

Krebs et al. (1998) apresenta os resultados da aplicação desta terapia em 10 pacientes crônicos, ou seja, pacientes que sofreram um AVE há mais de um ano. 
Um grupo controle, com outros 10 pacientes crônicos, também participou do experimento, cujos pacientes receberam tratamento baseado em terapia ocupacional. Os pacientes da terapia com o robô superaram os pacientes do grupo controle em todas as avaliações clínicas das deficiências motoras do ombro e cotovelo do membro afetado. Estas avaliações utilizaram as seguintes medidas: Fugl-Meyer; potência motora e contagem do status motor e Motor Status Score, Os autores concluem que a terapia robótica influenciou a recuperação motora, entretanto não discorrem sobre as causas do desencadeamento deste processo.

\subsubsection{REABILITAÇÃO COM O SISTEMA VR-MIRROR}

Um protocolo clínico que utiliza um sistema denominado VR-MIRROR e as práticas física e mental, é proposto em (GAGGIOLI et al., 2004). Eles utilizam tecnologia interativa para fornecer aos pacientes dicas visuais e auditivas para direcionar sua atenção para a estrutura dinâmica de um movimento, contribuindo assim para a geração da imagem motora. GAGGIOLI et al (2007) descreve os equipamentos utilizados pelo VR-MIRROR: uma tela translúcida horizontal retro-projetada incorporada em uma mesa de madeira, sensores de rastreamento de movimento, um projetor LCD com correção de paralaxe colocado embaixo da mesa e um espelho que reflete os feixes provenientes do projetor na tela horizontal (Figura 2.26). 


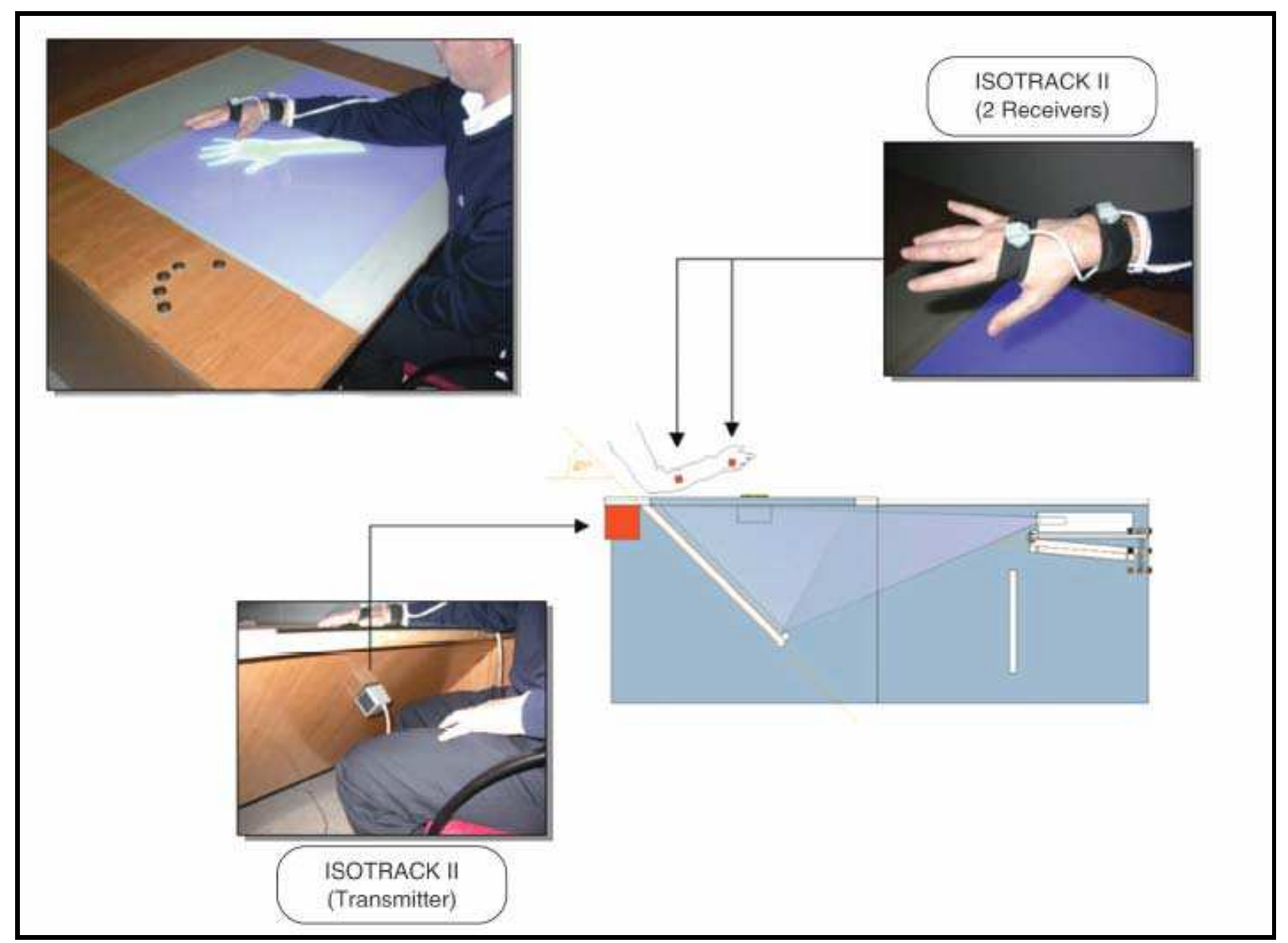

Figura 2.26 - Sistema de RV para a reabilitação motora (GAGGIOLI et al., 2007)

No VR-MIRROR, inicialmente o paciente realiza o movimento solicitado com o braço saudável. O sistema registra o movimento e gera uma simulação tridimensional espelhada deste movimento, que foi originalmente realizado pelo braço não lesado. Em seguida, os pacientes são orientados a realizar o exercício de ensaio mental, no qual eles são instruídos a imaginar o mesmo movimento sendo realizado com o braço lesado e simultaneamente assistir à animação no espelho de RV. Após assistir a animação na tela, os pacientes são orientados a executar fisicamente o exercício, movendo seu braço lesado juntamente com a imagem espelhada. Durante a execução da tarefa, o sistema rastreia o movimento do braço lesado.

Uma das vantagens deste protocolo é que o rastreamento do braço torna possível registrar as características dinâmicas do movimento, permitindo uma comparação em tempo real do movimento realizado pelo braço plégico e o movimento ideal (registrado com o braço saudável e que foi espelhado). 
Lozano et al. (2005) apresentam os resultados clínicos da aplicação do VR-MIRROR a um paciente de 46 anos de idade, vítima de um AVE há mais de um ano. As medidas da função do pulso mostraram aumento na faixa de movimentação durante a fase de intervenção com o VR-MIRROR.

Em (GAGGIOLI et al, 2007) são apresentados os resultados da aplicação de VRMIRROR a um grupo de 9 pacientes pós-AVE, três vezes por semana, durante oito semanas, Os instrumentos de avaliação utilizados foram os itens da extremidade superior da escala de desempenho físico Fugl-Meyer e o Teste da Ação da Extremidade Superior para Pesquisa, conhecido como teste ARA (Action Research Arm). Cinco dos nove pacientes mostraram redução na deficiência ao final das oito semanas, sem perda do ganho motor após alta, verificada aplicando os mesmos instrumentos de avaliação no início (pré-teste), quatro semanas depois (meio), oito semanas depois (pós-teste) e doze semanas após o término das intervenções com o sistema. Os autores concluíram no artigo que estes resultados incentivam ainda mais investigações adicionais sobre o papel que a prática mental guiada por computador pode representar na reabilitação dos membros superiores.

\subsubsection{REABILITAÇÃO COM UM SISTEMA DE REALIDADE AUMENTADA}

Luo et al. (2005) descreve o desenvolvimento de um sistema de RA para a reabilitação dos membros superiores de pessoas que sofreram um AVE e que em conseqüência perderam, parcialmente, os movimentos dos braços e adquiriram dificuldades em estender os dedos da mão (espasticidade). Neste sistema, o usuário permanece sentado utilizando um HMD atrelado à cabeça para visualização dos objetos 3D combinados com a imagem do mundo real. Um dispositivo assistivo (luva) foi projetado para controlar as extensões dos dedos. Este dispositivo contém um sistema pneumático de retorno de força, e pode ser calibrado de acordo com as necessidades do usuário. A Figura 2.27 mostra o usuário tentando agarrar uma lata de refrigerante projetada virtualmente com se fizesse parte do mundo real visualizada por meio do HMD. 


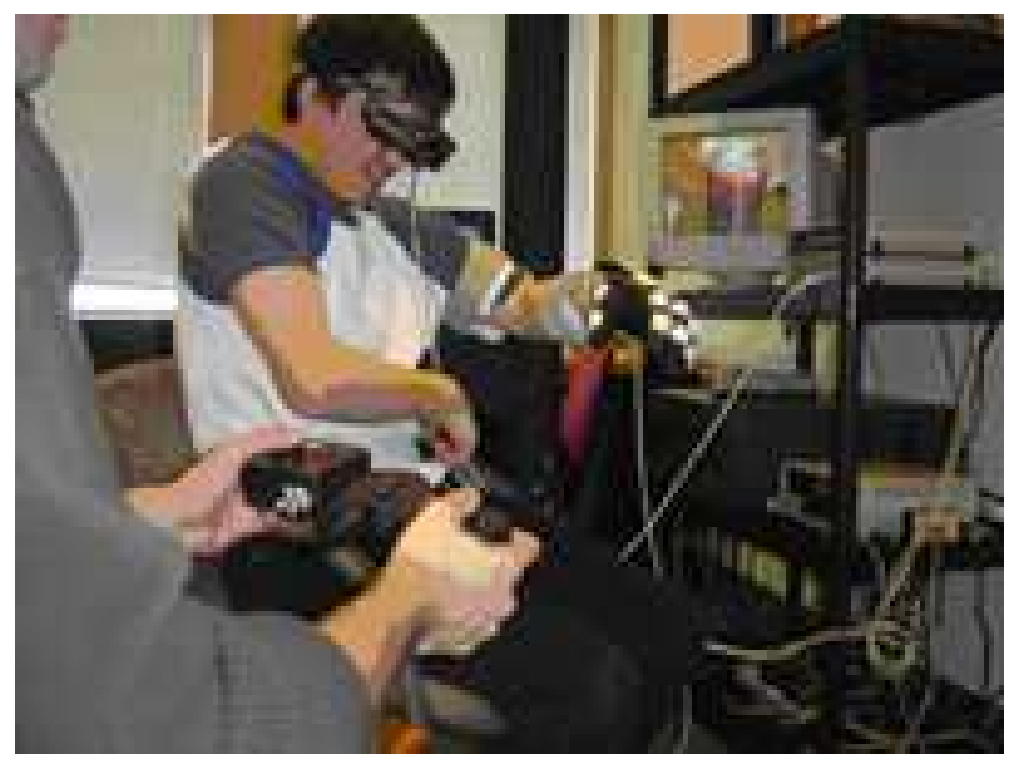

Figura 2.27 - Sistema de RA para pacientes com AVE (LUO et al., 2005).

O objetivo deste sistema é fazer com que o pacientes, que já realizam algum movimento com o membro comprometido, treinem os movimentos de "pegar e soltar" os objetos virtuais, sem o risco de queda de objetos reais. Este sistema permite que os desafios ao usuário sejam controlados através da intervenção do fisioterapeuta. Para isto, o terapeuta utiliza um joystick para mover o objeto virtual de lugar, podendo também rotacionar este objeto para que o paciente tente agarrá-lo de diferentes formas.

\subsubsection{REABILITAÇÃO DAS MÃOS COM REALIDADE VIRTUAL}

ADAMOVICH et al. (2004) apresenta resultados que indicam melhorias com o uso de um sistema de Realidade Virtual para reabilitação de mão, o qual utiliza luvas hápticas (com retorno de força) com sensores de movimento em cada dedo, palma e pulso. A Figura 2.28 mostra um exemplo de exercício para reabilitação de mão apresentado no artigo. Neste sistema, os pacientes precisam realizar algum movimento com a mão lesada antes de iniciar o uso do sistema. 


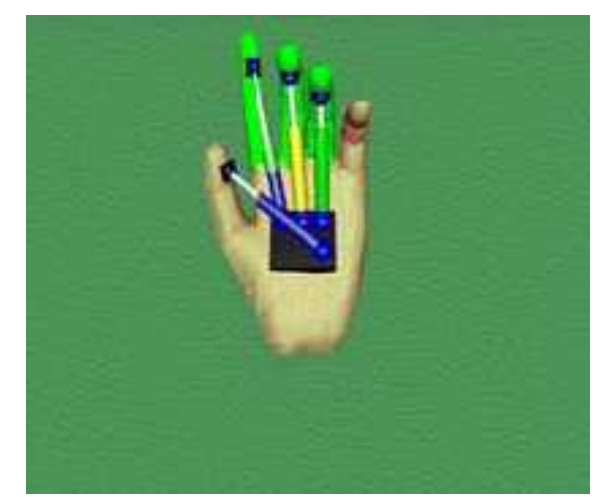

Figura 2.28 - Sistema de Realidade Virtual para reabilitação da mão (ADAMOVICH et al., 2004)

Os autores comentam que, nos testes clínicos, foram observadas melhorias no componente garra (habilidade de agarrar), mas não no componente de transporte do movimento. Também foi observado um aumento na faixa de movimento dos dedos em pacientes com severa espasticidade (quando certos músculos são continuamente contraídos) e reduções significativas nos tempos para completar as tarefas solicitadas.

\subsection{CONCLUSÕES}

Neste capítulo foram apresentados os principais fundamentos sobre o sistema nervoso e o sistema motor necessários para compreensão da formulação da viabilidade neurológica do sistema proposto, que será apresentado no capítulo seguinte. Foram apresentados os principais problemas motores em pessoas vítimas de AVE, a partir dos quais foi escolhido o problema foco desta pesquisa.

O estudo sobre realidade aumentada norteou a escolha da tecnologia de RA para a proposta. Neste capítulo também foram apresentados trabalhos correlatos encontrados na literatura, cabendo destacar que todos eles necessitam de algum hardware específico e utilizam a prática física como uma das terapias de reabilitação. 


\section{PROPOSTA NEUROR}

Este capítulo apresenta os requisitos, tecnologia adotada, cenários, arquitetura e funcionamento do sistema proposto.

\subsection{REQUISITOS}

Foram levantados alguns requisitos para o sistema e sua utilização junto a especialistas em medicina física e terapeutas ocupacionais de um hospital que prestam assistência a pacientes que sofreram um AVE. São eles:

- O principal desafio em reabilitação é a recuperação do movimento dos membros superiores. Assim, é importante elaborar experimentos no sistema para estimular a imagem motora nos ombro, braço, antebraço e mão.

- Abordagem envolvendo exercícios distais (dedos, mais funcional) e proximais (ombro, menos funcional). O robô MANUS desenvolvido inicialmente no Newman Laboratory for Biomechanics and Human Rehabilitation do MIT era um robô proximal. Atualmente está sendo desenvolvido um robô distal, denominado Robot Motion II, no laboratório do MIT. Entretanto, a proposta do NeuroR é utilizar tanto movimentos proximais como distais.

- Abordagem que incorpora exercícios distais de alcance e preensão de um alvo, que é funcional e fundamental para as atividades da vida diária, como se alimentar, se vestir, fazer a higiene pessoal, etc.

- A representação do paciente no cenário deve ser "contínua", sendo adequado representar todo o braço do paciente no mundo virtual, e não somente a mão. Por "representação contínua" entende-se a conectividade com o corpo do paciente. A justificativa para este requisito é baseada, em parte, na observação de um procedimento clínico adotado com amputados de membro inferior, onde se utiliza um recurso como um cabo de vassoura colocado embaixo do lençol de forma que o paciente, ao acordar, tenha uma reação 
mais conformada à amputação e possa se recuperar mais rapidamente do que se ele visualizar o desnível brusco de volume entre o coto e o local do membro amputado. Outra justificava está relacionada com o fenômeno dor fantasma, ou seja, dor no membro amputado. Um procedimento clínico adotado neste caso é a visualização da imagem espelhada do membro não amputado no lugar do membro amputado. Assim, o paciente movimenta o membro não amputado visualizado no lugar do membro amputado e, muitas vezes, a dor fantasma é reduzida ou eliminada.

- Alto grau de realismo. Como em muitos casos os pacientes também apresentam problemas cognitivos, é importante desenvolver cenários virtuais muito próximos da realidade, para evitar o agravamento das deficiências cognitivas.

- Exigência cognitiva baixa, pois muitos pacientes têm seqüelas neuropsicológicas de atenção e memória.

- Foco na tarefa. Um problema freqüente em pacientes que sofreram um acidente vascular encefálico é a atenção dividida. Portanto, o sistema deve direcionar a atenção do paciente para a tarefa ou exercício alvo da intervenção, evitando incluir elementos virtuais de desvio de atenção.

- Utilizar ordem verbal, ordem dirigida no sistema para estimular pacientes que apresentam déficit de iniciativa, que sofreram uma lesão frontal.

- Utilizar algum retorno de sensibilidade para o paciente. A sensibilidade tátil é perdida em $20 \%$ dos pacientes que sofreram um AVE, mas a sensibilidade vibratória não é perdida, podendo ser utilizada no sistema como estímulo nas tarefas de preensão da mão.

- Utilizar o sistema em intervenções com pacientes já estabilizados clinicamente, isto é, com no mínimo 6 meses após o AVE.

- Utilizar o sistema em pacientes que não têm déficit de compreensão.

Dos requisitos levantados acima, apenas o requisito de retorno vibratório não foi um requisito essencial e, portanto, não foi considerado na proposta NeuroR, pois se pretende avaliar primeiramente o impacto isolado do estímulo visual do braço virtual com conectividade na imagem motora em reabilitação, sem a interferência de outros estímulos como variáveis no estudo. 
Também foram levantados requisitos relacionados ao movimento junto a um grupo de fisioterapeutas que atuam em uma clínica-escola. São eles:

- Os exercícios escolhidos devem ser contrários ao padrão espástico do paciente, tentando inibir este comportamento patológico, que consiste no ombro em retração, depressão e rotação interna, antebraço em flexão e pronação e dedos em flexão e adução.

- Exercícios de preensão e flexão de cotovelo não devem ser utilizados por se tratar de exercícios que poderiam reforçar o padrão patológico do paciente.

- O sistema deve incluir exercícios para estender o membro superior comprometido.

$\mathrm{Na}$ análise dos requisitos levantados pelo grupo multidisciplinar acima,verificou-se que não existe um consenso quanto aos exercícios a serem incluídos no sistema. Dessa forma, optou-se por incorporar nesta proposta alguns exercícios de ombro (proximais) com todo o membro superior estendido e também exercícios de preensão de mão (distais), permitindo que os profissionais possam atuar nas intervenções com o sistema NeuroR de acordo com as suas próprias estratégias de reabilitação.

\subsection{SELEÇÃO DAS TECNOLOGIAS}

Nas reuniões para levantamento de requisitos com a equipe multidisciplnar, levantou-se que um desafio em reabilitação é a recuperação do movimento dos membros superiores. Assim, optou-se por elaborar experimentos para estimular a imagem motora nos ombro, braço, antebraço e mão.

Dois requisitos levantados para o NeuroR nortearam a escolha da tecnologia de realidade aumentada. São eles:

(1) A representação do paciente no cenário deve ser "contínua", deve-se manter a conectividade do braço virtual com o corpo do paciente. 
(2) Exigência cognitiva baixa, para evitar o agravamento das deficiências cognitivas.

O primeiro requisito é satisfeito em um sistema de $\mathrm{RA}$, pois a imagem do braço virtual é combinada com a imagem do paciente capturada pela câmera de forma que o braço virtual fique "conectado" ao corpo do paciente. O segundo requisito é satisfeito, pois durante o processo de reabilitação com o NeuroR o paciente se mantém no seu ambiente físico, sem a necessidade de se adaptar a um novo ambiente e novos mecanismos de interação.

A proposta do NeuroR é um sistema de RA para apoiar a reabilitação de pacientes hemiplégicos, por meio de um braço virtual que será acoplado ao corpo do paciente, no lugar do braço lesado. Um dos objetivos do NeuroR é que o paciente visualize o braço virtual no lugar do braço real e tenha a sensação visual de conectividade do membro.

A seguir, tem-se uma análise dos dispositivos de RA para o sistema proposto.

Os dispositivos de exibição retinais não são adequados para o NeuroR pois o paciente precisa ter a visão estereoscópica, ou seja, a visão de profundidade, no movimento do braço virtual.

Os projetores atrelados à cabeça do usuário também não são adequados ao sistema NeuroR, pois um dos requisitos levantados para o sistema foi o de alto grau de realismo e como este tipo de dispositivo oferece pouca resolução e brilho, ele não satisfaz este requisito. Além disso, como se trata de um dispositivo que é muito dependente do ambiente, ele tornaria inviável o uso do NeuroR em outros locais além da clínica, por exemplo, na casa do paciente.

Os dispositivos de exibição mantidos na mão (hand-held) não são adequados para o NeuroR, pois exigem que o paciente, que já apresenta uma hemiplegia, utilize a mão não afetada para segurar o dispositivo e assim visualizar a simulação. Isso é desconfortável e sujeito a erros. Além disso, o campo de visão de um dispositivo desses não seria capaz de cobrir todo o braço do paciente.

Os dispositivos espaciais óticos não são adequados para o NeuroR, pois o paciente veria o seu braço real e o braço virtual na cena, o braço virtual seria como um fantasma e o paciente poderia não percebe-lo como sendo seu. 
Os dispositivos de exibição espaciais baseados em projetores não se aplicam ao NeuroR, pois o paciente precisa ver o braço se mover e, portanto não seria conveniente projetar o braço virtual em cima do real, que está imóvel.

O HMD ótico não se aplica ao NeuroR, pois não é de visão fechada, de forma que o paciente veria o braço virtual e o braço real em resoluções diferentes, sem a oclusão correta do braço real pelo virtual.

Um tipo de realidade aumentada adequado ao NeuroR é a realidade aumentada baseada em tela, que representa uma solução de baixo custo e pode ser utilizada nas intervenções tanto na clínica quanto em outros cenários de reabilitação.

Outra alternativa é a RA de visão indireta baseada em capacete atrelado à cabeça (HMD), onde a visão é fechada, ou seja, o paciente não tem a visão periférica, vendo somente o braço virtual e não o braço real. O paciente deve estar limitado ao espaço da tarefa para que ocorra a reabilitação e sua atenção deve estar focada na tarefa proposta pelo terapeuta. O paciente deve permanecer sentado na cadeira e ser orientado a não se mover durante os experimentos, de forma a evitar algum risco à sua integridade física enquanto estiver utilizando o HMD.

O sistema NeuroR proposto mistura o real e o virtual em ambientes reais e substitui objetos reais por objetos virtuais. Assim, o sistema NeuroR pode ser considerado com um sistema de realidade mediada.

\subsection{CASOS DE USO}

Uma descrição dos casos de uso, seu fluxo normal de eventos, bem como pré e pós-condições foi elaborada para todos os casos de uso identificados. A Figura 3.1 apresenta o diagrama de casos de uso para o sistema proposto. 


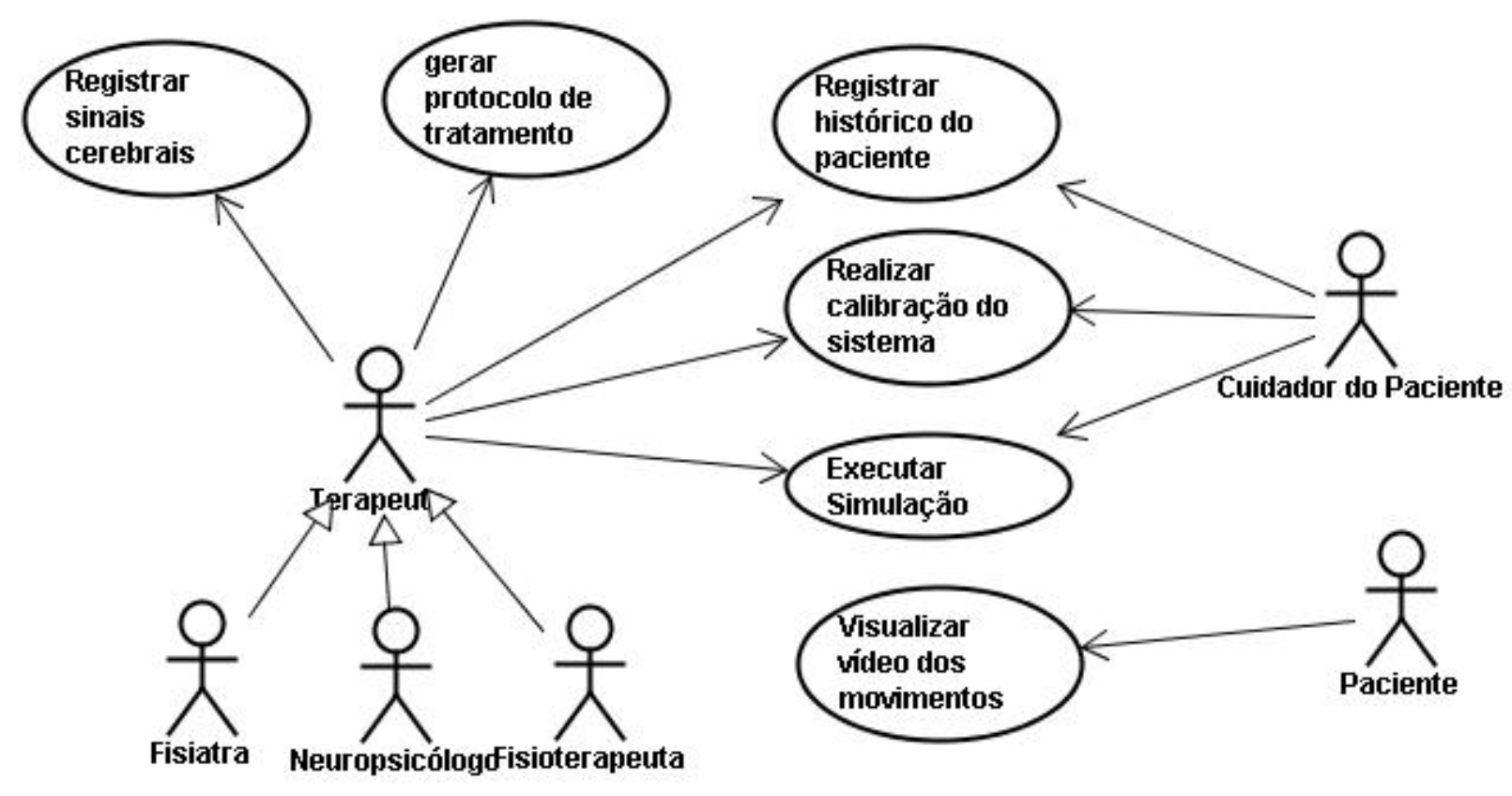

Figura 3.1 - Diagrama de casos de uso do sistema proposto.

Nome: Registrar histórico do paciente.

Atores: Terapeuta, Cuidador do Paciente.

Descrição: Registrar histórico do paciente é disparado pelo Terapeuta, no caso de uma intervenção na clínica, hospital ou centro de reabilitação, ou pelo Cuidador do Paciente no caso de uma intervenção em casa, após a realização de uma intervenção com o Paciente. Este caso de uso permite que o Terapeuta ou o Cuidador do Paciente faça anotações sobre o estado de saúde do paciente antes, durante e após a intervenção bem como anotações e observações sobre a intervenção realizada (conduta fisioterapêutica).

Casos de Uso Relacionados: Gerar Protocolo de Tratamento.

Pré-condição: Existe um protocolo de tratamento definido para o Paciente.

Curso Normal dos Eventos: O Terapeuta ou o Cuidador do Paciente seleciona a opção de registrar histórico do paciente. Ele seleciona o paciente bem como a intervenção associada no protocolo de tratamento do paciente. A intervenção selecionada pode conter um registro de histórico a ser alterado ou não. O Terapeuta ou o Cuidador do Paciente utiliza o caso de uso Gerar Protocolo de Tratamento para obter as intervenções já realizadas e previstas. É possível registrar informações do paciente como as medições de temperatura, pressão sanguínea e freqüência 
cardíaca bem como os resultados dos testes de desempenho motor utilizando os instrumentos escala Fugl-Meyer e também informações descritivas sobre a alimentação, sono, estado psicológico, fadiga, que podem gerar artefatos (ruído) e assim afetar os sinais de EMG. Também podem ser registradas informações sobre as intervenções realizadas como dificuldades técnicas, fatores externos, duração e reações do paciente.

Pós-Condição: Registro de histórico do paciente efetuado.

Nome: Gerar Protocolo de Tratamento.

Atores: Terapeuta.

Descrição: Gerar protocolo de tratamento é disparado pelo Terapeuta no início do tratamento. Este caso de uso permite que o Terapeuta elabore o protocolo de tratamento a ser adotado para o paciente em um cenário de reabilitação (casa, clínica, hospital, centro de reabilitação).

Pré-condição: Não tem.

Curso Normal dos Eventos: O Terapeuta seleciona a opção e fornece os dados de identificação do paciente como nome, idade, sexo e também os dados da deficiência do paciente como lado da lesão no cérebro (esquerdo, direito) e região afetada (lobo parietal, lobo frontal, tálamo, etc), espasticidade na escala Ashworth, equilíbrio, nível de comprometimento da fala, entre outros. Também podem ser fornecidos dados de tratamentos de reabilitação anteriores. Após, o Terapeuta fornece os dados do protocolo de tratamento a ser adotado que incluem o número de intervenções, o sequenciamento dos exercícios e o número de repetições para cada intervenção.

Pós-Condição: Registro de novo protocolo de tratamento efetuado.

Nome: Visualizar vídeo dos movimentos.

Atores: Paciente.

Descrição: Visualizar vídeo dos movimentos é disparado pelo Paciente e fornece uma orientação para a realização dos exercícios de reabilitação.

Pré-condição: Não tem. 
Curso Normal dos Eventos: O Paciente seleciona a opção para visualizar o vídeo dos movimentos que podem ser utilizados no exercício de prática mental. Após, ele seleciona uma das seguintes unidades de movimento de membro superior: flexão horizontal de ombro, abdução de ombro, flexão de ombro, extensão de punho, extensão dos dedos, preensão. É exibido um vídeo que mostra a realização do movimento selecionado.

Pós-Condição: Não tem.

Nome: Realizar calibração do sistema.

Atores: Terapeuta, Cuidador do Paciente.

Descrição: Realizar calibração do sistema é disparado pelo Terapeuta ou pelo Cuidador e obtém a imagem de fundo do sistema antes do início da simulação.

Também faz a calibração dos ângulos máximos dos movimentos com o braço não afetado para o espelhamento por meio de fotogrametria.

Pré-condição: Não tem.

Curso Normal dos Eventos: O Terapeuta ou o Cuidador deve selecionar as duas opções: capturar Imagem de fundo sem o paciente e capturar imagem de fundo com o paciente. Estas imagens são armazenadas e utilizadas pelo caso de uso Executar Simulação. Também é feita a calibração da cor da pele do paciente. O paciente deve posicionar sua mão sobre uma superfície com uma cor constante de fundo.

O paciente é orientado a executar o movimento com o braço não plégico para obter os ângulos do espelhamento do movimento com o braço plégico. Para isso, são colocadas faixas da cor utilizada no chromakey no ombro e no pulso do braço saudável do paciente. O quadro do início do movimento é capturado e o quadro final do movimento também é capturado. Em cada um dos quadros (inicial e final) é aplicado o chromakey. Se o lado do encéfalo em que ocorreu a lesão for Direito então é feita uma busca a partir da borda esquerda nos quadros capturados. Esta busca é de cima para baixo para identificar o primeiro pixel classificado pelo chromakey no ombro e de baixo para cima para identificar o primeiro pixel classificado pelo chromakey no pulso. A busca é feita na metade horizontal da janela, ou seja, o primeiro pixel no ombro é obtido na metade superior e o primeiro 
pixel no pulso é obtido na metade inferior. Após o processamento dos dois quadros de início e fim do movimento, os vetores obtidos podem ser visualizados por meio do algoritmo de Bresenham para desenho de linhas.

O ângulo entre os vetores ou linhas inicial (V1) e final (V2) do movimento é calculado como:

$$
\theta=\cos \quad-1\left(\frac{V_{1} \bullet V_{2}}{\left|V_{1}\right| V_{2} \mid}\right) \quad \text { Equação 3.1 - Cálculo do Ângulo }
$$

Onde V1 $=(x 1-x 2, y 1-y 2)$ e V2 $=(x 3-x 2, y 3-y 2)$, sendo que $(x 1, y 1)$ são as coordenadas do pixel do pulso determinadas no quadro do início do movimento, (x3, y3) são as coordenadas do pixel do pulso determinadas no quadro final do movimento e (x2, y2) são as coordenadas do ponto base, que neste caso representa o pixel do ombro determinado no quadro inicial do movimento. Estes ângulos são armazenados para posterior utilização no caso de uso Executar simulação.

Nome: Executar simulação.

Atores: Terapeuta, Cuidador do Paciente.

Descrição: Executar Simulação é disparado pelo Terapeuta, no caso de uma intervenção na clínica, hospital ou centro de reabilitação ou pelo Cuidador, no caso de uma intervenção em casa. Ele permite a execução da prática mental associada ao estímulo visual do braço virtual se movendo na tela, sobreposto à imagem do paciente capturada pela câmera.

Casos de Uso Relacionados: Realizar calibração do sistema, Gerar Protocolo de Tratamento.

Pré-condição: Existe um protocolo de tratamento definido para o Paciente.

Curso Normal dos Eventos: Primeiramente, o Terapeuta ou o Cuidador seleciona a intervenção que será executada a partir do protocolo de tratamento do paciente. Após, ele seleciona a opção para iniciar a simulação. O sistema reproduz o arquivo de áudio de início (relaxamento progressivo) seguido pelo arquivo de áudio que orienta o paciente a criar imagens relacionadas ao uso do membro afetado em tarefas funcionais correspondentes ao exercício no protocolo de tratamento. Outra 
alternativa é que o relaxamento progressivo e a orientação para o movimento sejam conduzidos pelo fisioterapeuta, sem a necessidade do áudio. Após, tem-se início a animação do braço virtual na tela. $O$ braço virtual é desenhado sobreposto à imagem do paciente, na posição do braço onde foi fixado um marcador fiducial. O paciente visualiza sua imagem e o braço virtual na tela, como em um espelho. Após o término da intervenção, o sistema pode ou não reproduz o arquivo de áudio para recolocar o paciente no mundo real. O Terapeuta ou o Cuidador deve então proceder à execução da próxima repetição do exercício ou execução de outro movimento conforme a intervenção corrente ou encerrar o procedimento antes da sua finalização.

Pós-Condição: Não tem.

Nome: Registrar sinais cerebrais.

Atores: Terapeuta.

Descrição: Registrar sinais cerebrais é disparado pelo Terapeuta no caso de uma intervenção na clínica, hospital ou centro de reabilitação, antes do início da intervenção. Este caso de uso permite que o Terapeuta faça o registro dos sinais de eletromiografia do paciente para posterior análise.

Ele também pode disparar a execução da simulação do braço virtual quando a quantificação do sinal EMG atinge um valor que considera o músculo agonista do movimento como ativo.

Pré-condição: Existe um protocolo de tratamento definido para o Paciente.

Curso Normal dos Eventos: Primeiramente, o Terapeuta deve colocar os eletrodos no paciente em um dos músculos agonistas do movimento solicitado. Também devese utilizar um eletrodo de referência, colocado em uma região sem atividade muscular, como na estrutura infra-clavicular. Ele deve então orientar o paciente e permanecer em repouso e iniciar a captura dos sinais cerebrais EMG e armazenálos. Esta captura inicial poderá auxiliar na identificação no futuro de possíveis artefatos (ruídos) nos sinais bioelétricos que são capturados durante a intervenção.

Pós-Condição: Novo arquivo de EMG foi criado. 


\subsection{ARQUITETURA}

A arquitetura do sistema é composta de oito módulos, como mostra a Figura 3.2.

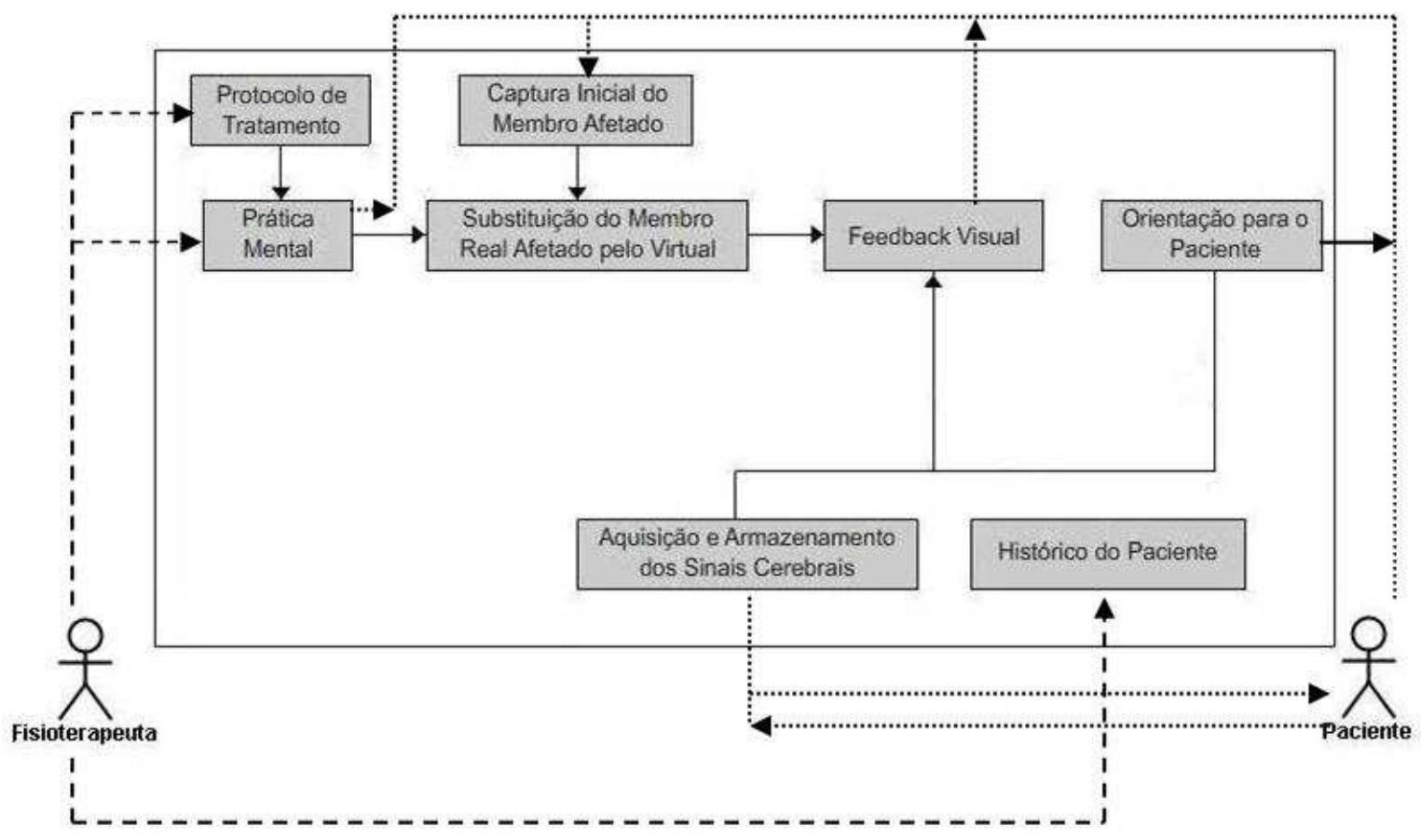

Figura 3.2 - Arquitetura do sistema proposto.

Inicialmente o fisioterapeuta define a configuração do sistema, selecionando um programa de reabilitação adequado ao paciente. Durante a intervenção, o módulo de "Protocolo de Tratamento" segue o programa de reabilitação selecionando o exercício correto para a intervenção atual.

O módulo de "Prática Mental" é sincronizado com o exercício selecionado do programa de reabilitação. As orientações para a prática mental podem ser gravadas em arquivos de áudio e fornecidas pelo fisioterapeuta ao sistema. $O$ arquivo de áudio da prática mental inicia com um relaxamento. Nos minutos finais da intervenção a prática mental reconduz o paciente ao espaço presente. As orientações para a prática mental também podem ser feitas pelo fisioterapeuta durante a intervenção, sem o uso dos arquivos de áudio.

O módulo de "Aquisição e Armazenamento dos Sinais Cerebrais" está continuamente obtendo amostras de sinais EMG (eletromiografia) do músculo selecionado e armazenando-as juntamente com a informação do tempo em um 
arquivo padrão de dados. Ele também pode se comunicar com o módulo de Feedback Visual para disparar a animação do braço virtual durante a prática física.

Uma câmera de vídeo captura a imagem frontal do paciente. Um marcador fiducial, impresso, é fixado no ombro do membro lesado. O módulo "Captura Inicial do Membro Afetado" utiliza um software baseado em visão computacional para o rastreamento do marcador.

O módulo de "Substituição do Membro Real Afetado pelo Virtual" remove o braço paralisado da imagem e mistura a imagem com o braço virtual.

Cada quadro da câmera é processado por um computador que sobrepõe o gráfico 3D na imagem. O módulo "Feedback visual" mostra a imagem em RA na tela do computador. Durante a intervenção, quando a prática mental induz um exercício, o módulo "Feedback Visual" inicia a animação, que é disparada pelo operador do sistema.

O módulo "Histórico do Paciente" registra as informações coletadas pelos médicos e outros profissionais de saúde que cuidaram do paciente e também o acompanhamento do bem-estar do indivíduo: assistência, fatores de risco, exercícios e perfil psicológico. Este módulo poderá fornecer informações para o prontuário eletrônico do paciente (PEP). Um PEP é um registro eletrônico de saúde, é qualquer informação relacionada com o passado, presente ou futuro da saúde física e mental, ou condição de um indivíduo, que reside num sistema eletrônico usado para capturar, transmitir, receber, armazenar, disponibilizar, ligar e manipular dados multimídia para um serviço de saúde (MURPHY; HANKEN; WATERS, 1999).

O módulo "Orientação para o Movimento" apresenta vídeos que ilustram os movimentos a serem realizados pelo paciente durante a prática mental. Estas orientações podem ser fornecidas pelo próprio fisioterapeuta, sem o uso dos vídeos do módulo. 


\subsection{CENÁRIOS}

Também foram definidos alguns cenários virtuais para o tratamento de reabilitação. A Tabela 3.1 mostra os cenários de reabilitação propostos.

Tabela 3.1 - Cenários de reabilitação propostos.

\begin{tabular}{|c|c|}
\hline Com ou Sem déficit Cognitivo & Sem déficit cognitivo \\
\hline $\begin{array}{l}\text { Cenário de alcance e meta de } \\
\text { complexidade: agarrar bola (só a mão a } \\
\text { objeto). }\end{array}$ & $\begin{array}{l}\text { Cenário de memória de sons e cores de baixa } \\
\text { complexidade: Genius (só a mão aperta o } \\
\text { objeto). }\end{array}$ \\
\hline $\begin{array}{l}\text { Cenário de alcance e meta d } \\
\text { complexidade: agarrar bola (mover o } \\
\text { agarrar o objeto e voltar). }\end{array}$ & $\begin{array}{l}\text { Cenário de memória de sons e cores de alta } \\
\text { complexidade: Genius (mover o braço, apertar } \\
\text { o objeto e voltar). }\end{array}$ \\
\hline
\end{tabular}

Dentre os cenários levantados junto aos especialistas, foram selecionados os cenários de alcance e meta para serem incorporados ao NeuroR. Estes cenários foram escolhidos por apresentarem exercícios focados nas atividades motoras e que envolvem os principais submovimentos do membro superior: flexão, abdução, adução, extensão e preensão (MARQUES, 1997).

O movimento de flexão do ombro é realizado levando o braço para frente do corpo com a palma da mão voltada paralela ao plano sagital. A Figura 3.3-(d) mostra a flexão de ombro, com o goniometro para medir o ângulo. 


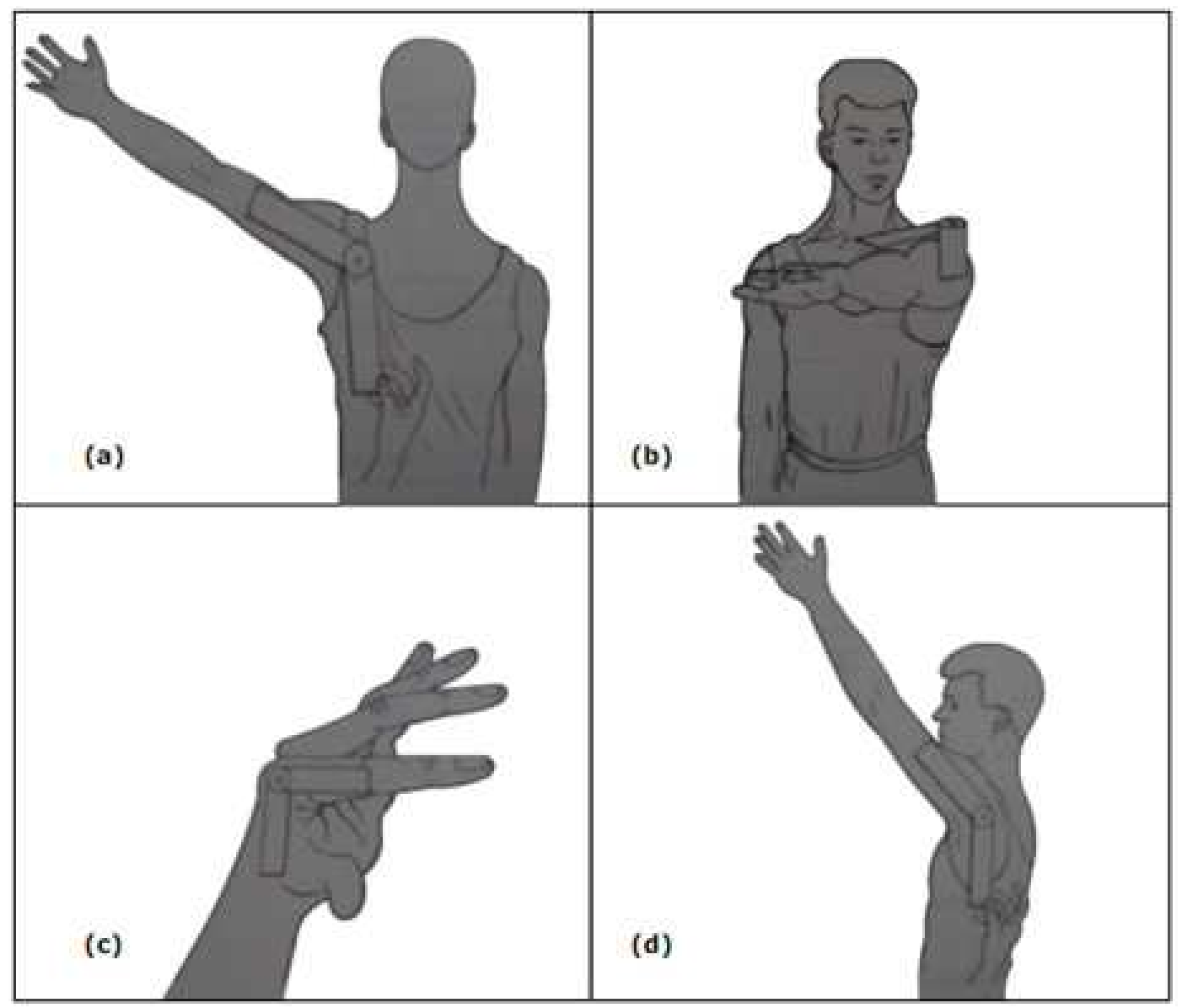

Figura 3.3 - Exercícios propostos (Marques, 1997)

O movimento de abdução do ombro é realizado elevando o braço lateralmente em relação ao tronco (Figura 3.3a).

Segundo (Marques, 1997), o movimento de adução ou flexão horizontal é realizado na frente do corpo com o cotovelo, punho e dedos inicialmente estendidos e palma da mão voltada para baixo. O movimento consiste na flexão do úmero (Figura 3.3b).

O movimento de extensão do punho ocorre com o antebraço em pronação e o cotovelo flexionado a 90 graus. O movimento consiste na flexão em torno de um eixo na superfície medial do punho.

O movimento de flexão das articulações metacarpofalangianas (Figura 3.3c) é necessário para a realização do movimento de preensão. O movimento de preensão (agarrar) consiste na flexão de todos os dedos ao mesmo tempo.

O autômato finito determinístico mostrado na Figura 3.4 foi desenvolvido para mostrar como os movimentos básicos podem ser combinados nos exercícios propostos. Um autômato finito determinístico é uma 5-tupla M dada por: 


\section{$\mathbf{M}=\left(\Sigma, \mathbf{Q}, \delta, q_{0}, \mathrm{~F}\right) \quad$ Equação 3.2 - Autômato Finito (MENEZES, 2002)}

Onde:

$\sum$ é o alfabeto de símbolos de entrada.

Q é o conjunto finito de estados possíveis do autômato.

$\delta$ é a função de transição, que a partir do símbolo e do estado corrente mapeia o próximo estado.

$\mathrm{q}_{0}$ é o estado inicial, tal que $\mathrm{q}_{0}$ é elemento de $\mathrm{Q}$.

F é o conjunto de estados finais, tal que F está contido em Q.

O estado inicial do autômato é o estado parado, com o braço na posição anatômica para os movimentos de abdução e flexão de ombro. Todos os movimentos são estados finais. O alfabeto de entrada é composto de exercício selecionado para a intervenção: Alcance e meta de baixa complexidade (objeto alvo é colocado próximo da mão para preensão); alcance e meta de alta complexidade(objeto alvo é colocado afastado da mão para tarefa de preensão); exercício de flexão do ombro; flexão horizontal também chamado de adução de ombro, extensão do punho, etc.

Se o alvo está localizado na frente do paciente, o movimento de alcance inicia com uma flexão do ombro. Porém, se o alvo está colocado na lateral, o movimento de alcance inicia pela abdução do ombro. Posteriormente, o movimento passa para a preensão, que consiste na flexão simultânea das articulações metacarpofalangianas para agarrar o alvo. Na seqüência, ocorre o movimento de encolhe braço, quando o braço volta para perto do corpo. Todos os movimentos também podem ser feitos isoladamente. 


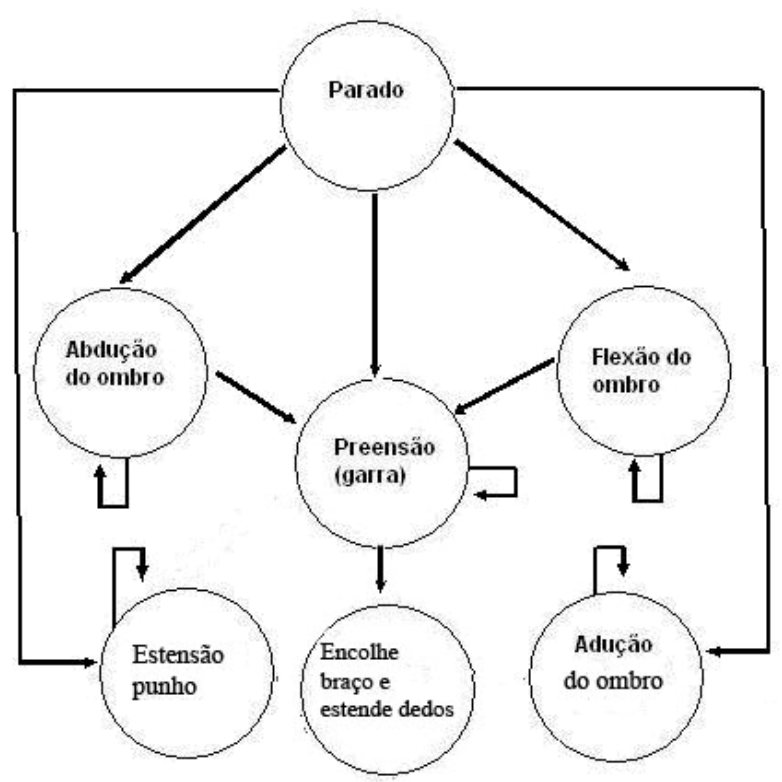

Figura 3.4 - Grafo proposto para os exercícios do NeuroR.

\subsection{FUNCIONAMENTO}

Como foi dito anteriormente na seção sobre Seleção de Tecnologias, existem duas alternativas de funcionamento do sistema NeuroR. São elas:

(1) Visualização do braço virtual em uma perspectiva de primeira pessoa com tela. Neste caso, utiliza-se a RA baseada em tela, com a câmera posicionada na frente e os eletrodos para captura do EMG no braço do paciente.

(2) Visualização do braço virtual em uma perspectiva de primeira pessoa com HMD. Neste caso, utiliza-se a RA de visão indireta baseada em capacete atrelado à cabeça, com a câmera acoplada ao capacete.

A definição dos critérios para seleção dos pacientes aptos à terapia utilizando o NeuroR bem como o seqüenciamento dos exercícios e o número de repetições são apresentados no planejamento das intervenções. Para a etapa de seleção do exercício no NeuroR é necessário armazenar o número de repetições de um determinado exercício já realizadas pelo paciente, de forma a realizar a troca do exercício quando o número de repetições é atingido. As medidas de função motora adotadas e que são efetuadas em pontos de controle são monitoradas pelo 
terapeuta e o auxiliam na tomada de decisão de quando o tratamento não é mais efetivo e, portanto pode ser encerrado.

Primeiramente é colocado um marcador no ombro do braço lesado do paciente e é executada a inicialização do sistema NeuroR, isto é, a calibração da(s) câmera(s). Após esta etapa, é selecionado o exercício para a intervenção e tem início a prática mental. Se o paciente estiver realizando a terapia sem o auxílio do terapeuta , o próprio paciente ou pessoa que o auxilia deve executar a inicialização do sistema e reproduzir o arquivo de áudio para estimular a prática mental. Caso contrário, não é necessário reproduzir o arquivo de áudio pois o próprio terapeuta fornece as orientações para a atividade.

\subsection{CAPTURA INICIAL DO MEMBRO AFETADO}

Este algoritmo é composto de duas partes. A primeira parte consiste em capturar e armazenar duas imagens de fundo, uma sem o paciente e outra com o paciente sentado na cadeira, já vestido com a luva, mas ainda sem o marcador. Estas imagens serão serem utilizadas durante a animação. A segunda parte compreende a calbração de cores da pele.

Este procedimento foi feito com o auxílio de uma luva de cor amarela colocada no braço afetado, para facilitar o chromakey. Ainda que na literatura a cor azul seja a mais recomendada para isso, optou-se por não utilizar uma luva azul por causa do pouco contraste entre o marcador colocado no ombro e a luva, pois o marcador apresenta um padrão na cor branca em cima de um retângulo em uma cor escura, no caso a cor preta, e com a luva na cor azul o contraste entre a base e a luva não seria adequado para o reconhecimento do marcador.

Considera-se que o modelo de cores adotado é o sistema aditivo RGB (Red, Green, Blue), que possui como cores primárias o vermelho, o verde e o azul. Este modelo utiliza um sistema de coordenadas cartesianas $R, G, B$, cujo espaço de representação é um cubo. Neste modelo de cores, a cor amarela não apresenta componente de cor azul. 
Na calibração de cores da mão, os passos são:

(a) Definir faixa de intensidade de pele para o paciente. O paciente mostra a mão sobre um fundo branco ou azul, que pode inclusive ser a mão do membro sem hemiplegia.

(b) Classificar os pixels em fundo ou pele, utilizando chromakey.

(c) Obter o histograma dos pixels da pele e armazenar as médias das componentes de cor R, G e B bem como o desvio padrão, de forma a aplicar posteriormente essas cores no modelo do braço virtual.

\subsection{SUBSTITUIÇÃO DO MEMBRO REAL AFETADO PELO VIRTUAL}

O módulo de "Substituição do Membro Real Afetado pelo Virtual" remove o braço paralisado da imagem e mistura a imagem com o braço virtual.

Ele compreende os seguintes passos:

1) Captura um quadro do vídeo.

2) Pesquisa por regiões com o marcador e o reconhece na imagem capturada.

3) Aplica um filtro de mediana em cada canal de cor do quadro atual, para obter um melhor resultado no chromakey da luva.

4) Define a região de corte na imagem.

Isso é feito através de uma varredura na imagem a partir do limite vertical do marcador até a borda da janela. Esta varredura é feita de $x$ mínimo até a borda direita da janela no caso de uma hemiplegia direita e do x máximo do marcador até a borda esquerda no caso de uma hemiplegia esquerda. Aplica-se um algoritmo de chromakey de cor com limiar na região selecionada de forma que os pixels são classificados em luva ou não luva.

Após, os pixels cujas coordenadas estão dentro do retângulo definido pelos x mínimo e x máximo e y mínimo e y máximo do marcador também são classificados como luva. $O$ resultado deste processamento é um mapa do tamanho da imagem, com pixels com valores 0 ou 1 , onde 1 indica que o pixel pertence ao braço a ser removido da imagem.

Três abordagens para o chromakey foram analisadas. São elas.

(a) Algoritmo de predominância de cor: 
Se (componente_cor_vermelho > componente_cor_azul) e (componente_cor_verde > componente_cor_azul) então o pixel atual é classificado como pertencente à luva (amarelo).

Entretanto, esta abordagem apresenta alguns problemas de classificação incorreta, eliminando alguns tons de cinza da imagem, que são erroneamente classificados como "amarelo", como mostra a Figura 3.5, onde os pixels classificados como luva foram preenchidos com a cor preta.

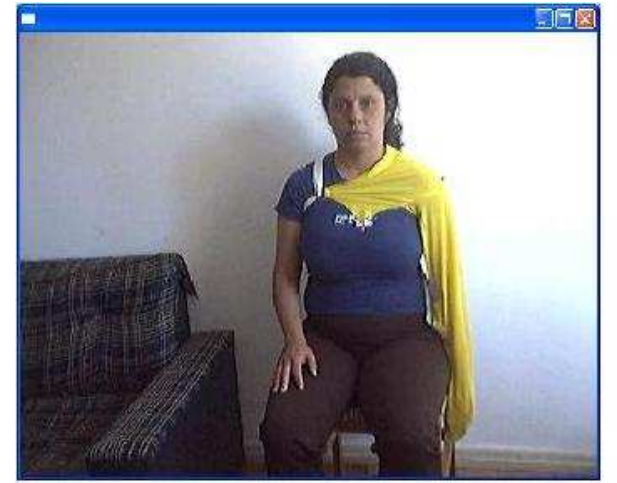

(a)

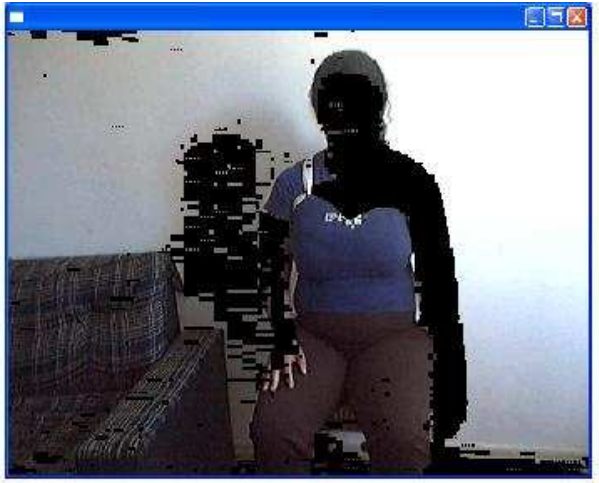

(b)

Figura 3.5 - Chromakey pelo método predominância de cor.

(b) Algoritmo de faixa de cor:

Primeiramente é feita uma calibração da luva, onde uma janela de seleção de cor é usada para definir um retângulo da luva. Após, é calculado o histograma desta amostra da imagem. O resultado do histograma é usado para estabelecer os limites máximo e mínimo de cada canal de cor. Esta abordagem apresenta problemas com sombra dos elementos reais sobre o fundo e mudanças na iluminação, que podem provocar ruídos na imagem.

(c) Algoritmo de predominância de cor com limiar:

Se (componente_cor_vermelho > componente_cor_azul + limiar) e (componente_cor_verde > componente_cor_azul + limiar) então o pixel atual é classificado como pertencente à luva.

Neste método o limiar pode ser ajustado dependendo do histograma da luva. A Figura 3.6 mostra a aplicação deste método com limiares de 50 (Figura 3.6-b) e 80 (Figura 3.6-c), onde os pixels classificados como luva, foram preenchidos com a cor preta. Na Figura 3.6-(b) alguns pixels que não pertenciam à luva foram classificados como luva enquanto na Figura 3.6-(c) alguns pixels que pertenciam à luva não foram classificados como luva. 


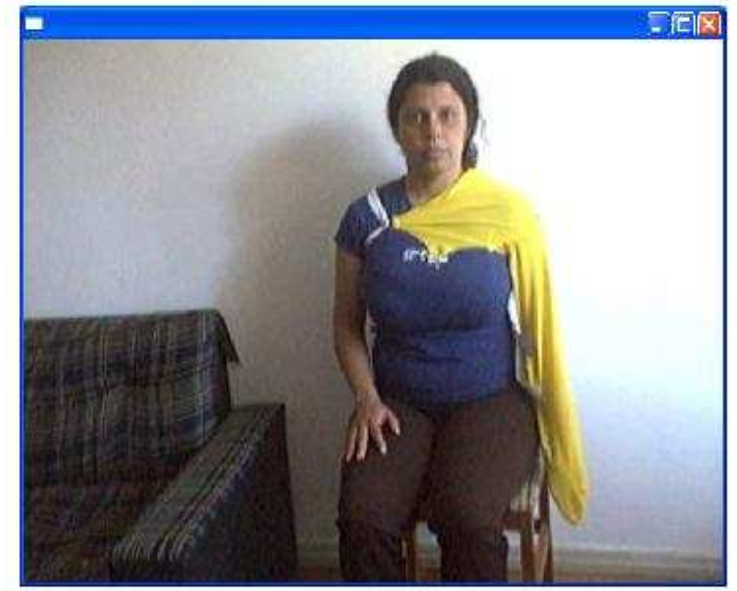

(a)

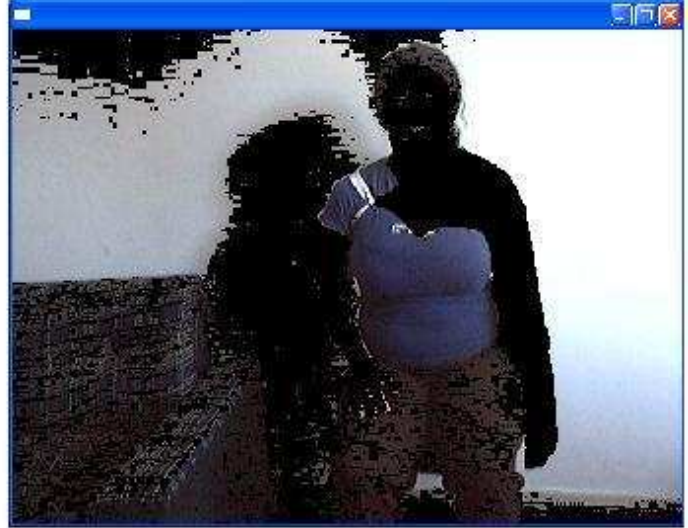

(b)

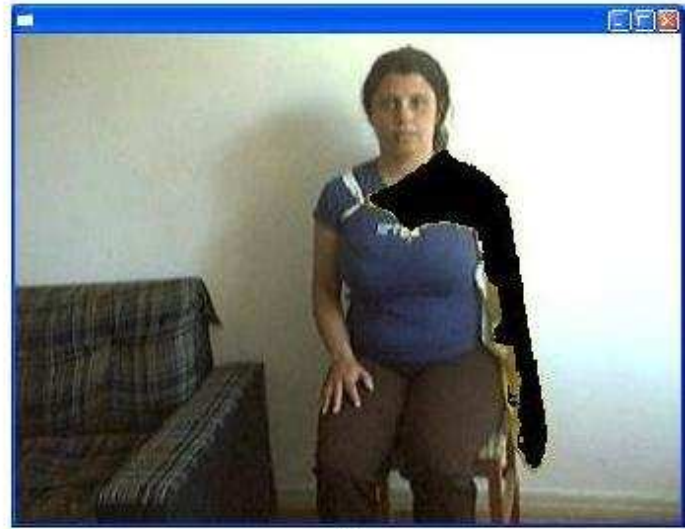

(c)

Figura 3.6 - Chromakey pela predominância de cor com limiar.

Em todo processo de segmentação por cores através de chromakey, o usuário não pode vestir roupas nem o ambiente pode ter elementos da cor que está sendo rastreada. Entretanto, no NeuroR, é feito um crescimento de região tendo como semente um pixel segmentado e que está na faixa da imagem delimitada pelo marcador, ou seja, um pixel que pertence à luva. Assim, os outros pixels segmentados na imagem com a cor da luva que não pertencem à mesma região que a região da luva são ignorados. Dessa forma, outros elementos da cena podem ter a cor que está sendo rastreada, desde que não estejam na região de corte da imagem.

5) No mapa correspondente à região de corte gerado no passo anterior, todos os pixels cujo valor é 1 são substituídos pelo pixel da imagem de fundo sem o paciente, indicando que o pixel é interno ao braço lesado. Considerou-se como condição de contorno que o paciente deve iniciar a simulação com o braço na posição supinado e com a mão aberta (posição anatômica da abdução e flexão). De acordo com esta restrição, todos os pixels classificados como luva devem ser substituidos pelos pixels correspondentes na imagem de fundo. 
Na Figura 3.7-(c) tem-se o resultado da "remoção" dos pixels classificados como luva com um limiar de 50 localizados à direita da borda esquerda do marcador, que foram substituídos pelos pixels correspondentes na imagem de fundo da Figura 3.7(a).

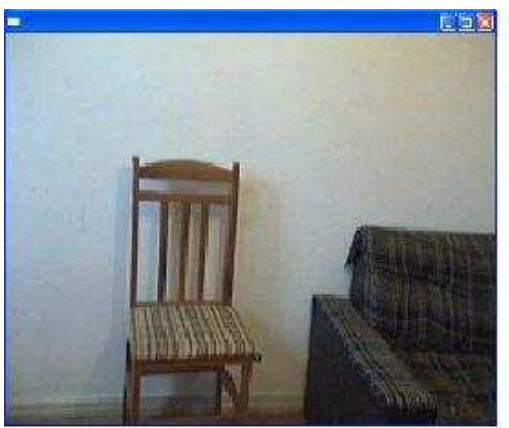

(a)

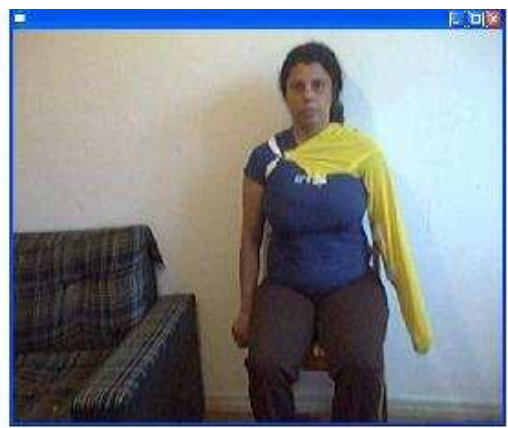

(b)

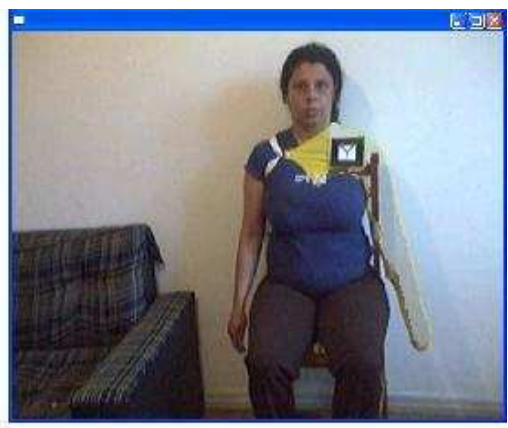

(c)

Figura 3.7 - Braço direito "transparente".

6) Define modelo simplificado do braço real.

Este modelo simplificado armazena a largura máxima e a altura máxima da luva. Considera-se aqui que o modelo simplificado do braço é obtido a partir da posição anatômica, com o braço supinado, ao longo do corpo. Estes valores são utilizados na matriz de transformação de escala do braço 3D.

Para determinar as larguras do braço real, o algoritmo percorre todas as linhas horizontais e procura o primeiro pixel da esquerda e da direita de cada linha onde o valor correspondente no mapa é 1. Calcula-se a distância entre os pixels na mesma linha horizontal. Se esta distância for maior que um limiar, que é a largura mínima do braço, ela é considerada para análise, juntamente com as coordenadas dos pixels que a originaram. As larguras máxima e mínima são obtidas e é feita uma comparação das coordenadas de seus pixels com as coordenadas do marcador para decidir se é largura de pulso, braço, mão ou cotovelo.

Já a altura do braço real é obtida percorrendo-se todas as colunas verticais de cima para baixo até o encontrar o primeiro pixel superior e de baixo para cima até encontrar o primeiro pixel inferior onde o valor correspondente no mapa é 1. A altura do braço é dada pela distância na vertical entre os pixels encontrados.

Se houver mais uma câmera capturando uma visão lateral do paciente também será possível obter a espessura do braço real. A Figura 3.8 mostra uma definição da estrutura do modelo simplificado do braço. 


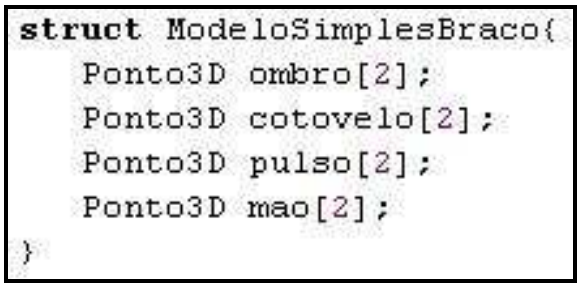

Figura 3.8-Modelo simplificado do braço em código C.

6) Cria as seguintes matrizes de transformação: Escala do braço, gerada a partir das medidas de largura e altura do modelo simplificado do braço e Translação, que posiciona o braço 3D na origem, ou seja, nas coordenadas do osso úmero do esqueleto do braço virtual.

7) Se o braço virtual está sendo animado, deve-se calcular as matrizes correspondentes ao movimento (flexão, adução, abdução) no instante de tempo e estas matrizes são acumuladas para serem aplicadas ao braço virtual.

8) Aplica as matrizes de transformação ao modelo geométrico (malha poligonal) do braço virtual.

9) Combina as imagens: real (capturada pela câmera) e imagem do braço virtual no local onde está o marcador ombro fiducial.

10) Se o braço real (luva) está na frente do corpo, ou seja, xmin_marcador_pulso > xmax_marcador_ombro para braço esquerdo ou xmin_marcador_pulso $<$ xmax_marcador_ombro para braço direito então braçoFrenteCorpo é definido como verdadeiro e é feito o preenchimento do braço real (luva) com a imagem de fundo, como descrito abaixo. Os valores xmin_marcador_pulso e xmax_marcador_pulso são obtidos percorrendo o mapa de baixo para cima (xmin_marcador_pulso) e de cima para baixo (xmax_marcador_ombro) e selecionando os pixels com menor distância da borda de partida.

(a) Se braçoFrenteCorpo é verdadeiro então substituir os pixels selecionados pelos pixels correspondentes na imagem de fundo com o paciente, gerando uma nova imagem resultante.

(b) Senão substituir os pixels selecionados pelos pixels correspondentes na imagem de fundo capturada sem o paciente, gerando uma nova imagem.

(c) Combinar esta nova imagem com o braço virtual (RA).

Um problema que ocorre com essa abordagem é que se o paciente se mover muito durante a simulação, as silhuetas da imagem capturada no inicio e da nova imagem podem não coincidir, gerando falhas na sobreposição dos pixels.

A técnica adotada para a animação do braço virtual é movimentar a malha através da movimentação dos ossos, pois é mais simples movimentar os ossos que são eixos locais facilmente transformáveis, ao invés de movimentar diretamente o conjunto de vértices da malha poligonal. Além disso, não é simples representar a 
hierarquia do modelo diretamente na estrutura de dados da malha poligonal, sendo a mesma facilmente representada no esqueleto.

\subsection{FEEDBACK VISUAL}

Este módulo desenha o braço virtual parado ou em movimento na cena na aplicação de RA, na posição determinada pela intervenção.

Para desenhar o braço virtual em movimento, este módulo aplica a matriz da animação correspondente. Esta matriz é calculada no módulo Substituição do braço real afetado pelo virtual.

Se o lado afetado pelo AVE é o lado direito, o braço é desenhado a partir da malha poligonal original. Se o lado afetado é o lado esquerdo, primeiramente o braço é invertido na horizontal através de uma escala de -1 em torno do eixo X, e o modelo resultante é desenhado. As animações de abdução, adução e flexão de ombro são executadas da mesma forma, independente do lado.

A solução adotada para o problema do registro do braço virtual em RA foi baseada na solução apresentada em (SANCHES, 2007). Foi feita a sobreposição da parte do objeto virtual desenhada em cima do marcador por algo real da cena, dando a ilusão de uma "manga" desenhada sob o braço virtual na imagem composta. A Figura 3.9 mostra o objeto virtual parado com o problema do registro e depois com a "manga" desenhada em cima do marcador. Quando o braço virtual está sendo animado na abdução de ombro (movimento de abertura na lateral), é mantida a sobreposição, o mesmo acontece com o movimento de flexão e de adução até 90 graus. Depois, a sobreposição não é mais realizada, sendo retomada no retorno do braço à sua posição de 90 graus até 0 . 


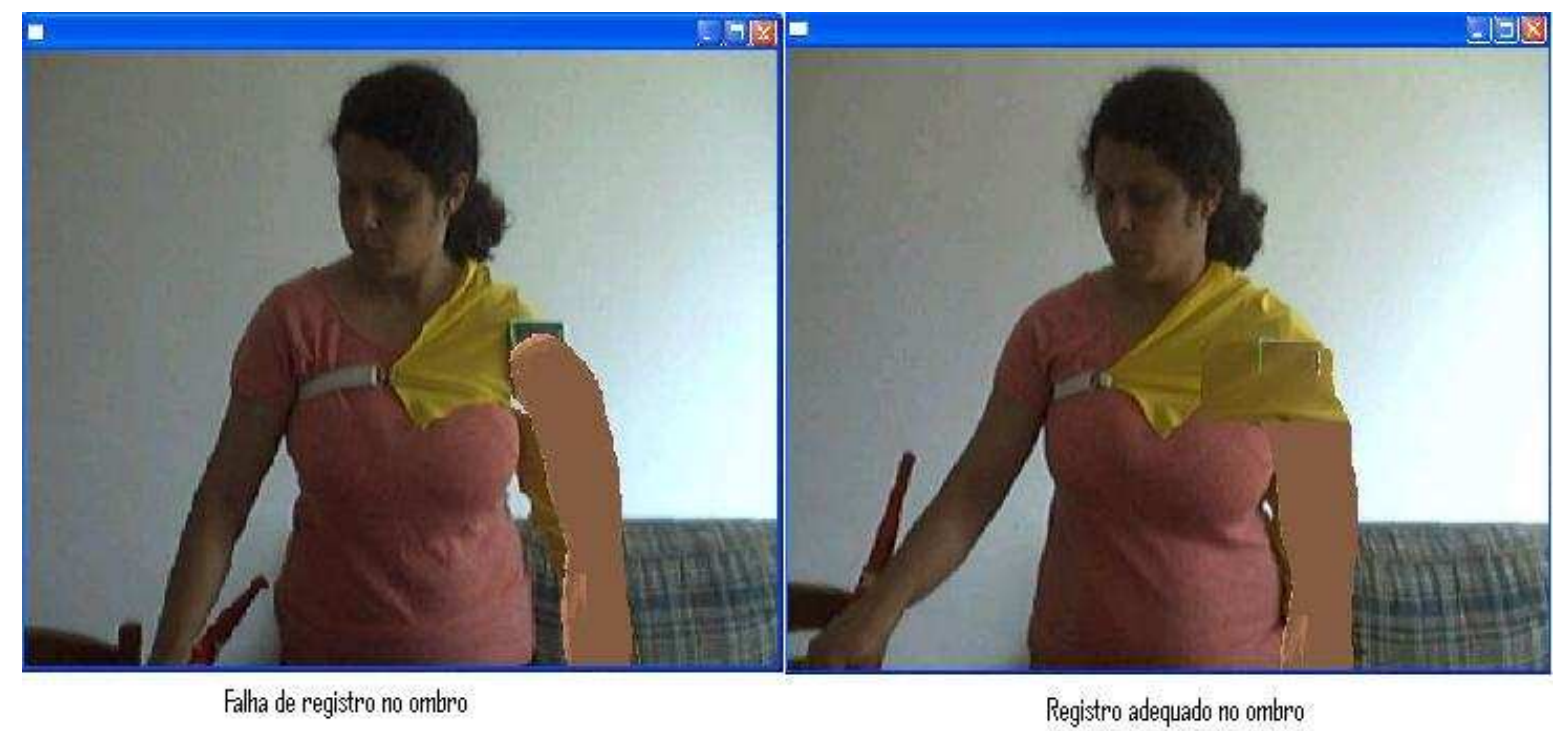

Figura 3.9-Registro no NeuroR.

\subsection{PROTOCOLO DE TRATAMENTO}

Registra o terapeuta responsável pelo tratamento, dados pessoais do paciente como nome, sexo, idade, dados da lesão do paciente (lado do cérebro, espasticidade, descrição das deficiências), tratamentos anteriores, data de início do tratamento, quantidade de intervenções e para cada intervenção os exercícios a serem realizados e o número de repetições de cada um.

\subsection{HISTÓRICO DO PACIENTE}

Para o formulário do histórico, foram utilizados alguns dos campos do PEP para registro de fisioterapia em UTI. São eles: sinais vitais, anamenese e conduta fisioterapêutica. Também foi utilizada a medida de resistência galvânica, sugerida pela equipe médica e os testes de desempenho motor utilizando a escala FuglMeyer, previstos no planejamento das intervenções. 


\subsection{PRÁTICA MENTAL}

Pode ser realizada com as orientações do fisioterapeuta durante a intervenção ou através de arquivos de áudio fornecidos pelo fisioterapeuta para a mesma. Neste último caso, tem-se arquivos de áudio para o relaxamento (reproduzido uma única vez no início da intervenção), para cada movimento (flexão, adução, abdução, ...) reproduzido o número de repetições previsto pelo terapeuta no protocolo de tratamento e para o retorno (reproduzido uma única vez no fim da intervenção)

\subsection{ORIENTAÇÃO PARA O PACIENTE}

Pode ser realizada pelo fisioterapeuta durante a intervenção ou através de vídeos gravados previamente e que mostram como realizar os movimentos .

\subsection{INTERFACE CÉREBRO-COMPUTADOR}

Os sinais elétricos capturados pelo EMG em tempo real são utilizados para disparar o movimento do braço virtual durante a prática física. No capítulo 2, na seção de Fisiologia Muscular do Ombro, foram apresentados os músculos motores (agonistas) e resistentes (antagonistas) para os principais movimentos de ombro: abdução, flexão, extensão horizontal e flexão horizontal. Vários músculos estão envolvidos em cada um destes movimentos. Cada indivíduo tem o seu próprio engrama motor para realizar um movimento, portanto, cada individuo pode recrutar seus músculos em diferentes proporções, sozinhos ou em conjunto, e também num sequenciamento muscular próprio, individualizado. Assim, uma decisão importante numa interface cérebro-computador baseada em EMG está relacionada a quais músculos serão monitorados para a tomada de decisão. Se os músculos escolhidos para 0 monitoramento não estiverem sendo recrutados pelo indivíduo para o movimento, a 
interface cérebro-computador não irá refletir o nível de ativação muscular e portanto o resultado não será o esperado. O músculo escolhido para o monitoramento do EMG no NeuroR é o deltóide médio ou acromial. Esta escolha foi norteada pelos estudos sobre fisiologia muscular do ombro, onde identificou-se que o deltóide médio está ativo e atua como agonista em todas as fases da abdução e também está presente nos movimentos de flexão e flexão horizontal do ombro.

Caso o músculo monitorado não seja suficiente para a tomada de decisão, pode-se utilizar a redundância muscular, ou seja, monitorar outros músculos.

Foram elaborados dois algoritmos para a análise do sinal EMG e tomada de decisão. O primeiro algoritmo compreende os seguintes passos:

1) Efetua a aquisição do sinal EMG do braço plégico do paciente em repouso durante um período de tempo fixo, em torno de tempo de 5 segundos. Este período de tempo foi sugerido por um especialista em EMG.

2) Os sinais EMG são enviados em pacotes de tamanho variável e estes sinais são analisados com auxílio de filtros no domínio da freqüência como Transformada Rápida de Fourier para identificação de possíveis ruídos e posterior remoção destes ruídos do sinal.

3) Extrai os sinais centrais da aquisição do paciente em repouso e armazena como sinal de referência. $O$ especialista sugeriu descartar os primeiro e último segundos da amostra.

4) Calcula o RMS do sinal de referência por janelamento móvel.

5) Calcula a média e o desvio padrão do RMS do sinal de referência (repouso) coletado anteriormente.

6) Inicia a aquisição do sinal de EMG para a prática física.

7) Calcula RMS do sinal adquirido por janelamento móvel, com o mesmo tamanho da janela utilizado no cálculo do sinal de referência anterior (repouso).

8) Se RMS atual > média $+3 x$ desvio padrão da referência então

8.1) Se total de segundos decorridos desde a última mensagem enviada > intervalo de tempo definido para análise, por exemplo, 10 segundos, então

8.1.1) Envia mensagem de aviso para o sistema NeuroR iniciar a animação.

8.1.2) Inicia a animação do último movimento executado na prática mental ou seleciona o movimento desejado na própria interface $\mathrm{BCl}$.

O segundo algoritmo consiste em:

1) Efetua a aquisição do sinal EMG do braço plégico do paciente em repouso durante um período de tempo fixo. 
2) Calcula RMS do sinal adquirido no passo anterior por janelamento fixo.

3) Define um limiar para o desvio padrão padrão da amostra, de forma que variações acima deste valor detectem um pico no sinal.

4) Define variação acumulada entre os RMS dos pacotes como sendo zero, ou seja, variação_rms = 0 .

5) Para cada pacote de dados faça:

5.1) Calcula o RMS do pacote de dados atual (rms_atual) utilizando janelamento fixo de tamanho variável, onde o tamanho é o número de amostras do pacote.

5.2) variação_rms = variação_rms + (rms_atual $\left.-r m s \_a n t e r i o r\right)$.

5.3) $r$ rms_anterior $=$ rms_atual.

5.4) Desvio padrão é calculado com o valor absoluto da variação acumulada |variação_rms| .

5.5) Se desvio padrão > limiar definido no passo 3, então

5.5.1) Se total de segundos decorridos desde a última mensagem enviada > intervalo de tempo definido para análise, por exemplo, 10 segundos, então

5.5.1.1) Envia mensagem de aviso para o NeuroR iniciar a animação.

5.5.1.2) Inicia animação do último movimento executado na prática mental ou seleciona-se o movimento desejado na própria interface.

\subsection{PLANEJAMENTO DAS INTERVENÇÕES}

Um planejamento para o recrutamento e as intervenções em pacientes em estágio subagudo ou crônico de AVE utilizando o NeuroR foi elaborado e discutido com um especialista em medicina física e duas fisioterapeutas. O planejamento prevê a realização das intervenções com o NeuroR em dois estágios. No primeiro estágio serão realizados testes com pacientes proporcionando apenas estímulo visual. Em um segundo estágio, será incorporado um dispositivo háptico ao braço da hemiplegia do paciente de forma a proporcionar um retorno de sensibilidade vibratória para os exercícios de preensão, que foi um dos requisitos levantados mas não contemplado na primeira proposta NeuroR. Optou-se pela sensibilidade vibratória ao invés da tátil, pois a sensibilidade tátil é perdida em parte dos pacientes que sofreram um $A V E$, mas a vibratória não é perdida. 
Os pacientes recrutados para o GE devem satisfazer os critérios de inclusão e exclusão.

O projeto de pesquisa, juntamente com o termo de consentimento livre esclarecido (TCLE) e o termo de compromisso de utilização de dados(TCUD) foram encaminhados ao Comitê de Ética em Pesquisa (CEP) de uma instituição para obter a autorização para realizar os testes que avaliam a funcionalidade do sistema NeuroR na reabilitação dos membros superiores de pacientes vítimas de AVE. Após a aprovação do CEP foi feito o estudo preliminar (projeto piloto) com um paciente para adequação da pesquisa. O TCLE e o TCUD são apresentados nos Apêndices A e B.

Após os ajustes do projeto piloto, foi iniciado o estudo principal com uma amostra de cinco pacientes.

Os estudos preliminar e principal foram conduzidos pela pesquisadora com o auxílio de dois fisioterapeutas e com o consentimento dos pacientes e responsável.

\subsubsection{Cenário de Estudo}

Este estudo foi desenvolvido dentro de um projeto de extensão de uma instituição de ensino superior em datas e horários acordados com os participantes e nas dependências da instituição.

\subsubsection{Sujeitos de Estudo}

Participaram do estudo 5 (cinco) pacientes de ambos os gêneros que sofreram um acidente vascular encefálico e apresentam seqüelas motoras em um dos membros superiores, que tinham satisfeito os critérios de inclusão e exclusão abaixo e 
concordaram em participar voluntariamente da pesquisa. A faixa etária estabelecida para a pesquisa foram pacientes de 35 a 74 anos.

\subsubsection{Critérios de inclusão}

Serão incluídos na pesquisa os pacientes que aceitarem a participação, após terem recebido e lido o TCLE (Apêndice $A$ ), contendo a identificação da pesquisadora responsável, bem como, das Instituições às quais pertence com informações sobre os objetivos da pesquisa e desde que satisfaçam todos os critérios de inclusão apresentados na tabela 3.2.

\section{Tabela 3.2 - Critérios de inclusão}

Pacientes com idade igual ou superior a 18 anos.

Pacientes já estabilizados clinicamente, isto é, pacientes com no mínimo 6 meses após o AVE.

Pacientes com hemiplegia de membro superior, preferencialmente hemiplegia esquerda, pois de acordo com o especialista o lado direito do cérebro é mais visoespacial que o lado esquerdo do cérebro.

Pacientes que já participaram do tratamento de reabilitação convencional e receberam alta do tratamento.

\subsubsection{Critérios de exclusão}

Serão excluídos deste estudo os participantes que não assinarem o TCLE ou não aceitarem realizar as tarefas propostas no instrumento Fugl-Meyer tanto no início quanto no final da pesquisa. Também são excluídos os participantes que satisfaçam pelo menos um dos critérios de exclusão da amostra (Tabela 3.3). 
Tabela 3.3 - Critérios de exclusão

Pacientes pós-AVE com contraturas e deformidades estabelecidas, isto é, grau de espasticidade maior que 2 na escala modificada de espasticidade de Ashworth (MINUTOLI et al, 2007). A escala é apresentada na Tabela 3.4.

Pacientes que têm déficit de compreensão.

Pacientes que apresentaram anteriormente crise compulsiva ou de labirintite.

Pacientes que têm agnosia visual, isto é, perda da capacidade de interpretar os sentidos.

Pacientes que apresentam afasias graves (seqüelas relacionadas à linguagem) isto é, apresentam um nível de afasia que compromete a comunicação.

Presença de co-morbidades ou doenças prévias ao AVE que interfiram com o funcionamento físico ou mental, como doenças psiquiátricas ou do sistema nervoso.

Histórico de incapacidade prévia ao AVE ou de doenças músculo-esqueléticas do membro superior relatadas pelo paciente ou pelos acompanhantes.

Existência de medicações que alteram o tônus muscular ou o estado de vigília.

A graduação da espasticidade ou contratura do paciente pode ser avaliada na prática clínica por meio da escala de tônus de Ashworth modificada (Tabela 3.4), sendo feita enquanto se move passivamente a articulação na direção contrária a ação do músculo ou grupo muscular a ser avaliado.

Tabela 3.4 - Escala de Ashworth Modificada

\begin{tabular}{l|l}
\hline Grau & Observações clínicas \\
\hline 0 & Tônus muscular normal. \\
\hline 1 & $\begin{array}{l}\text { Leve aumento do tônus muscular, manifestado por tensão momentânea ou por } \\
\text { mínima resistência no final da amplitude de movimento, quando a região afetada é } \\
\text { movida em flexão ou extensão. }\end{array}$ \\
\hline $1+$ & $\begin{array}{l}\text { Leve aumento do tônus muscular, manifestado por tensão abrupta, seguida de } \\
\text { resistência mínima em menos da metade da amplitude de movimento restante. }\end{array}$ \\
\hline 2 & $\begin{array}{l}\text { Aumento mais acentuado no tônus muscular durante a maioria da amplitude de } \\
\text { movimento, mas as partes afetadas são facilmente movidas. }\end{array}$ \\
\hline 3 & Aumento considerável do tônus muscular, movimento passivo difícil. \\
\hline 4 & Partes afetadas rígidas, na flexão ou na extensão. \\
\hline
\end{tabular}

Fonte: MINUTOLI et. al, 2007 


\subsubsection{Coleta das Informações}

No início da pesquisa, no estudo preliminar, foi aplicado um instrumento para avaliar a capacidade de imaginação dos pacientes.

O questionário que foi utilizado é o MIQ-R (Revised Movement Imagery Questionnaire) em português, validado em (STECKLOW, 2006) (Anexo A).

A coleta de dados também foi feita através de testes de desempenho motor onde os pacientes realizaram tarefas utilizando os itens motores da escala de desempenho físico de Fugl-Meyer para membros superiores. Este instrumento é uma medida cumulativa das deficiências motoras do paciente. Em termos gerais avalia a motricidade voluntária, a coordenação, dois aspectos da sensibilidade (tato e propriocepção), mobilidade passiva, dor a movimentação passiva e testes de equilíbrio (FUGL-MEYER et al, 1975). A escala Fugl-Meyer para extremidade superior é composta de 33 tarefas com 3 escalas ordinais de pontuação (0-2) com uma pontuação máxima de 66. Nesta escala a graduação de cada item segue a seguinte ordenação:

- $\quad$ zero (0) de pontuação em qualquer item significa nenhuma função.

- pontuação 1 significa função incompleta.

- $\quad$ pontuação 2 indica que o item foi realizado perfeitamente (PLATZ et al, 2005).

Cada movimento deve ser executado primeiro com o membro não comprometido e posteriormente com o membro parético, possibilitando comparação.

Na tabela 3.5 é apresentada a escala da função sensória-motora de Membros Superiores de Fugl-Meyer (UE-FMA). 
Tabela 3.5 - Escala da Função Sensório-motora de Membros Superiores de Fugl-Meyer (Fonte: FUGL-MEYER et. al, 1975)

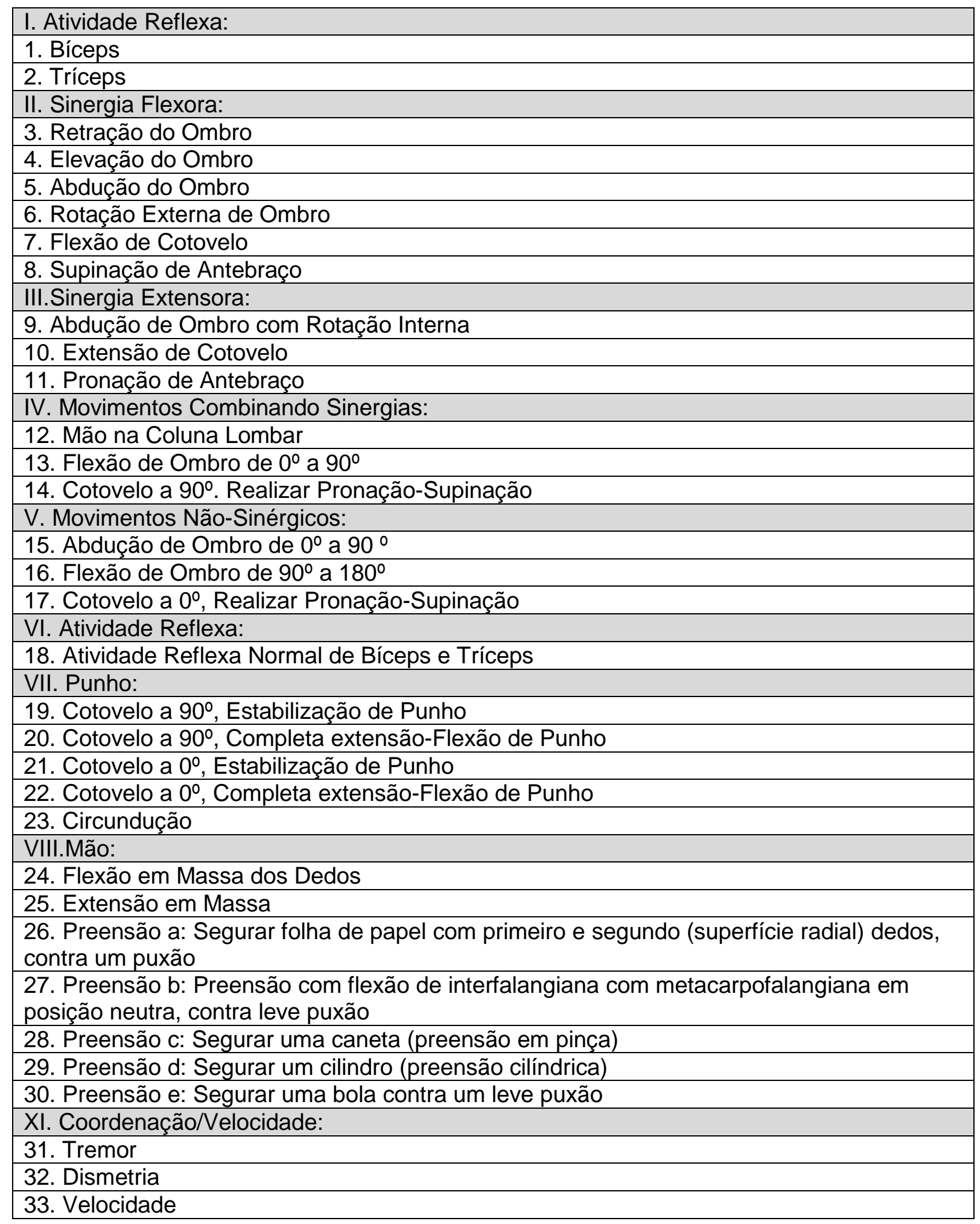


Os testes de desempenho motor foram registrados em vídeo. Os vídeos foram feitos com o auxílio de uma câmera digital e um tripé, posicionados na frente do paciente a uma distância fixa, suficiente para capturar a imagem de todo o corpo do paciente, esteja ele em pé ou sentado.

Os vídeos foram gravados em dois momentos. Primeiro, no pré-teste, ou seja, antes do início das intervenções com o sistema. Segundo, no pós-teste, isto é, após a última intervenção com o sistema.

Os vídeos gravados durante os testes de desempenho motor foram convertidos para uma seqüência de imagens e as imagens foram processadas para a extração de informações relevantes para o projeto.

Os vídeos serão guardados pelo pesquisador proponente durante 5 (cinco) anos, sendo descartados após este período. Também tem-se o cuidado com a preservação do anonimato dos pacientes.

\subsubsection{Estudo Preliminar}

Inicialmente foi feito um projeto piloto com um paciente para adequação dos instrumentos e procedimentos da pesquisa.

Para a realização deste projeto piloto, o paciente compareceu ao local do estudo uma vez por semana durante duas semanas. A duração dos testes foi de 45 a 60 minutos.

A pesquisa foi dividida em três etapas: (1) pré-teste de desempenho motor e capacidade de imaginação, (2) testes com o sistema NeuroR, (3) pós-teste de desempenho motor.

Antes de o projeto iniciar, o paciente assinou o TCLE.

Durante os testes com o sistema foram utilizados os seguintes materiais: um computador, webcam, tela de projeção, projetor multimídia, luva de tecido, marcador de papel, cadeira com pés fixos e sem braços, um tripé, um aparelho de 
eletromiografia, eletrodos, álcool e gase para higienização do braço antes da fixação dos eletrodos, esparadrapo para fixar os cabos do EMG.

Foi solicitado ao participante que, com o auxílio da equipe do projeto, vestisse uma luva de tecido para cobrir todo o braço afetado e utilizasse uma camiseta sem mangas. A luva é fornecida pelo projeto (Figura 3.17).

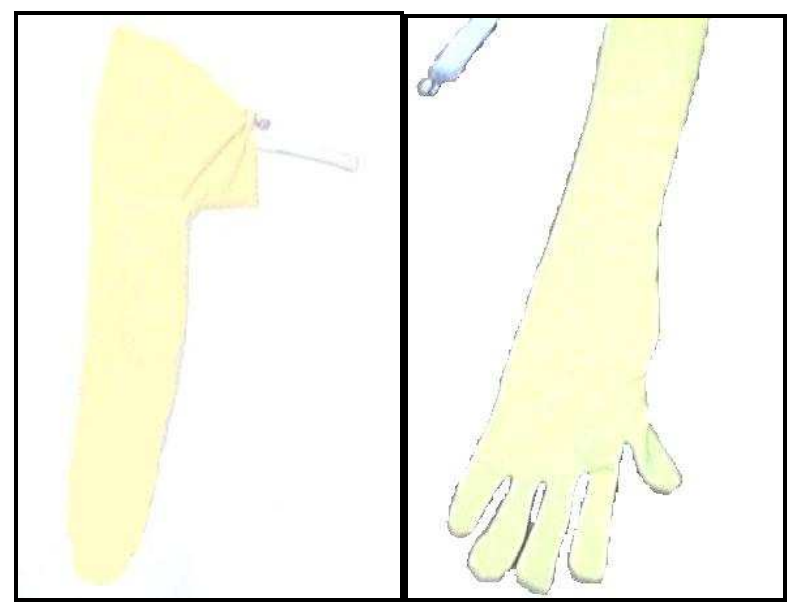

Figura 3.10 -Luvas sem e com dedos.

Antes do início de cada teste é adotado o procedimento de segurança de questionar o paciente quanto à ausência ou presença de dor no membro lesado e também com relação ao seu bem-estar. Se o paciente não relatar dor no membro plégico nem algum problema de saúde, são iniciados os testes.

Cada paciente permanece sentado, a uma distância de aproximadamente $130 \mathrm{~cm}$ da webcam, de forma que a câmera possa capturar uma visão frontal do mesmo com todo o braço plégico no campo de visão. Ele visualiza a sua imagem capturada em tempo real sendo projetada em uma tela de projeção à sua frente. A equipe do projeto orienta o paciente a realizar os movimentos solicitados primeiramente com o braço não lesado e a seguir com o braço plégico, sempre olhando fixamente para a sua imagem refletida na tela de projeção. Ele não visualiza a luva na tela de projeção e sim um braço tridimensional posicionado no lugar da luva.

No final do projeto o paciente é submetido a um pós-teste com o instrumento UEFMA. 


\subsubsection{Estudo Principal}

O estudo principal só teve início após os ajustes definidos no estudo preliminar. Neste estudo ocorreram todas as etapas já citadas anteriormente, porém com um número maior de colaboradores. Participaram deste estudo cinco pacientes, que satisfaziam aos critérios de inclusão e exclusão da amostra e que concordaram em participar da pesquisa, como voluntários. Antes de o estudo iniciar, cada um dos pacientes ou seu responsável assinou o TCLE.

As intervenções utilizadas no protocolo de tratamento com o sistema VR-MIRROR em (LOZANO et al., 2005) consistiram de duas vezes por semana, por oito semanas consecutivas. Em (GAGGIOLI et al, 2006) foi apresentado um estudo feito com um participante de 46 anos de idade que tinha sofrido um AVE isquêmico cerca de treze meses antes e que recebeu uma sessão diária com duração de 60 minutos, sendo meia hora de fisioterapia padrão e meia hora de utilização do VR-Mirror, três vezes por semana, durante quatro semanas. No estudo de prática mental descrito em (PAGE; LEVINE; LEONARD, 2005), todos os pacientes receberam sessões de terapia de 30 minutos, dois dias por semana, durante seis semanas.

Para a realização deste estudo principal, planejou-se duas sessões por semana durante oito semanas, como em (LOZANO et al., 2005). Entretanto, pelas dificuldades de deslocamento, os pacientes do GE compareceram ao local do estudo uma vez por semana durante quatro semanas. A duração dos testes foi de 30 a 60 minutos por dia.

\subsubsection{Cuidados Éticos}

Os direitos dos voluntários participantes foram mantidos e respeitados durante todo o processo de pesquisa, atendendo a resolução 196/96 do Conselho Nacional de Saúde que regulamenta pesquisas envolvendo seres humanos (HARDY; BENTO; OSIS, 2002). 
A utilização de vídeos e fotografias como instrumento de coleta de dados da pesquisa, ocorreu somente para a análise dos mesmos atendendo às diretrizes e normas de pesquisa com seres humanos contidas na Resolução 196/96 do Conselho Nacional de Saúde.

Foi desconsiderado, por questões éticas, o nome dos colaboradores participantes do estudo, sendo eleitos codinomes para sua identificação.

\subsection{CRITÉRIOS DE ACEITAÇÃO DO SISTEMA}

Como os sistemas de realidade aumentada são considerados sistemas de tempo real, eles possuem restrições rígidas quanto ao tempo de resposta. Portanto um primeiro critério é o de desempenho do módulo de Feedback Visual, que pode ser avaliado através da taxa de quadros por segundo.

Um segundo critério de aceitação importante para o sistema NeuroR é que o braço 3D não pode desaparecer durante a simulação, mesmo que o marcador não seja mais detectado. Isso ocorre quando, por exemplo, o marcador foi parcialmente obstruído ou por causa de efeitos da iluminação na cena. Se o braço 3D desaparecer durante a simulação o paciente pode perder o seu referencial e prejudicar a imagem motora em formação.

Um terceiro critério de aceitação para a aplicação é que a imagem apresentada na tela deve ser coerente com uma imagem espelho, de forma que se o paciente mover a cabeça para a direita, a sua cabeça na imagem espelhada também deve ser movida para a direita.

O quarto critério de aceitação é que o braço virtual deve realizar os movimentos com a mesma amplitude e velocidade que o braço não comprometido. Por exemplo, se o paciente realizou um movimento de flexão de ombro com ângulo de 130 graus, o braço virtual deve realizar o movimento espelhado, com o mesmo ângulo de 130 graus.

Um quinto critério de aceitação é a coerência temporal e visual nos movimentos do braço virtual, com o braço virtual iniciando na posição supinado, executando o 
movimento nos quadros intermediários sem "saltos", ou seja, sem mudanças bruscas de direção e posição e ao final da animação retornando à posição inicial de supinado.

Por fim, o sexto critério de aceitação para análise é que o braço virtual e as animações do mesmo devem ser coerentes com o braço comprometido (direito ou esquerdo).

\subsection{CONCLUSÃO}

O sistema proposto tem potencial para verificar a hipótese apresentada anteriormente de que é possível desenvolver um aparato tecnológico para auxiliar na investigação se o estímulo visual do movimento de um braço virtual conectado ao corpo do paciente, o qual substitui o braço real lesado numa imagem do paciente, pode apoiar a reabilitação deste membro.

A proposta apresentada evidencia que o sistema poderá ser utilizado em diferentes cenários de reabilitação, como na clínica, hospital ou em casa, com diferença nos acessórios.

Os módulos de "Protocolo de Tratamento", "Histórico do Paciente" e "Aquisição e Armazenamento dos Sinais Cerebrais" também reforçam a característica da proposta NeuroR como um "sistema de apoio à reabilitação", pois eles poderão disponibilizar uma ferramenta integrada para que profissionais multidisciplinares possam discutir e acompanhar o tratamento. 


\section{IMPLEMENTAÇÃO}

Foram implementados os módulos Protocolo de Tratamento, Captura Inicial do Membro Afetado, Substituição do Membro Real Afetado pelo Virtual, Feedback Visual, Aquisição e Armazenamento dos Sinais Cerebrais e Histórico do Paciente.

\subsection{RECURSOS DE DESENVOLVIMENTO DO SISTEMA}

Foram utilizados os seguintes recursos de hardware e software na implementação do NeuroR.

- uma webcam Logitech, Inc. QuickCam Pro 4000;

- compilador de linguagem de programação C;

- software livre de modelagem 3D Blender;

- Exporter Cal3D: script escrita em Python, que permite exportar modelos de personagens 3D desenvolvidos no Blender para o formato Cal3D (DESMECHT; DACHARY; HEIDELBERGER, 2007);

- ARToolKit: biblioteca, escrita em C, que permite aos programadores desenvolver, de forma rápida, aplicações de RA. O pacote inclui bibliotecas de rastreamento e disponibiliza o código fonte completo (GEIGER; SCHMIDT; STOCKLEIN, 2004);

- biblioteca GTK para construção da interface gráfica do sistema;

- banco de dados Mysql;

- aparelho para aquisição de EMG e eletrodos. Foram utilizados um aparelho comercial desenvolvido por uma empresa brasileira chamado Miograph e eletrodos comerciais $3 \mathrm{M}$;

- biblioteca para acesso ao aparelho de EMG, escrita em C-sharp, desenvolvida pela empresa desenvolvedora do Miograph e disponibilizada exclusivamente para a pesquisa, a partir de contato feito pela pesquisadora. 
O ARToolKit utiliza técnicas de visão computacional para calcular a posição e orientação de marcadores, identificados no cenário real, a partir das seqüências de vídeo capturados por uma webcam, possibilitando a sobreposição de objetos virtuais nos marcadores. A Figura 4.1 mostra o ciclo básico da execução da biblioteca ARToolKit. Inicialmente a imagem do mundo real é capturada por um dispositivo de entrada de vídeo para dar início à identificação dos marcadores. A imagem real capturada é transformada em imagem binária. Esta imagem é analisada em busca de regiões quadradas. Ao encontrar uma região quadrada, a ferramenta calcula a posição e orientação da câmera em relação a esta região buscando identificar figuras específicas, denominadas marcadores. Os marcadores são símbolos distintos e previamente cadastrados através de um treinamento da rede neural do ARToolKit para seu reconhecimento efetivo. Uma vez reconhecido o marcador, a ferramenta calcula o ponto em que o objeto virtual deve ocupar no mundo real e realiza a sobreposição das imagens retornando ao usuário a combinação visual do mundo real e do objeto virtual.

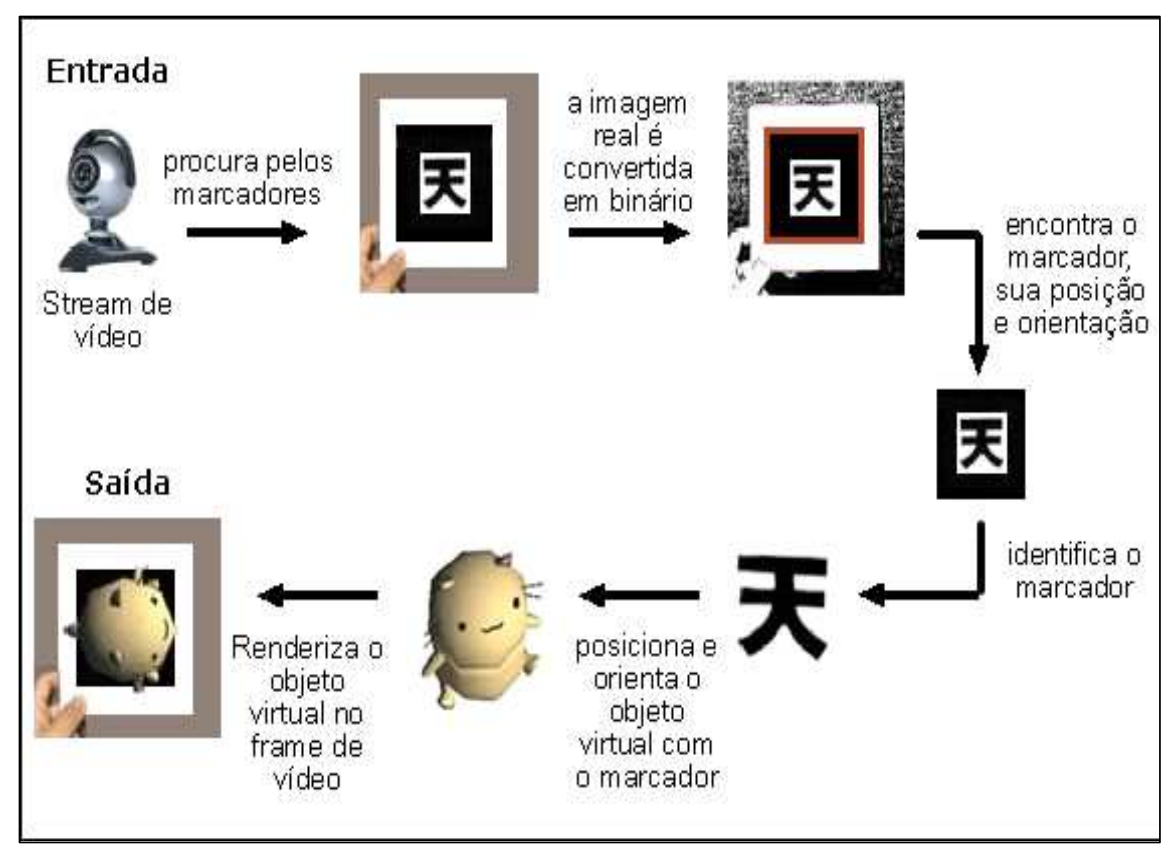

Figura 4.1 - Funcionamento do ARToolkit.

Em implementações futuras do NeuroR poderão ser incorporados outros equipamentos, como um HMD fechado e outra webcam, com duas câmeras para captura das imagens do paciente, numa vista frontal e outra lateral. 


\subsection{PLATAFORMA PARA UTILIZAÇÃO DO SISTEMA}

Para a execução do sistema são necessários um computador com suporte a Opengl, uma webcam e um marcador fiducial para o ombro, impresso em papel ou tecido e com fita adesiva ou outro recurso que o mantenha fixo no ombro do paciente.

Também é necessário uma luva de tecido para facilitar a remoção do braço real plégico da cena. Esta luva deve ser vestida no braço comprometido do paciente.

Na versão do sistema que inclui o módulo de Aquisição de Sinais Cerebrais, a qual registra os sinais de EMG, necessita-se de eletrodos de superfície e também de um instrumento que captura, amplifica e converte o sinal EMG analógico em digital.

Durante a obtenção dos traçados do EMG, o registro eletromiográfico é freqüentemente perturbado pela presença de artefatos, que podem dificultar a interpretação do gráfico. Os artefatos são devidos a: potenciais musculares provenientes de outros músculos, sudorese, fatores externos como ruídos em geral provocados por alguns aparelhos elétricos. Portanto, o ambiente de utilização do sistema NeuroR com o módulo de aquisição de sinais cerebrais deve conter o menor número possível de aparelhos elétricos.

O paciente deve estar sentado, a uma distância da câmera suficiente para que a câmera possa capturar uma visão frontal do paciente com todo o braço plégico no campo de visão, tanto com o braço na posição anatômica, ou seja, braço ao longo do corpo na lateral quanto em abdução de 90 graus (braço com abertura lateral máxima) ou em abdução ou flexão máximas.

\subsection{MODELO DO BRAÇO VIRTUAL}

A malha poligonal do braço 3D foi modelada no software Blender. Foi desenvolvido um esqueleto contendo 17 ossos, de acordo com a anatomia humana e que foi associado à malha poligonal do braço. $\mathrm{O}$ modelo $3 \mathrm{D}$ foi exportado para o formato livre Cal3D, um formato livre, baseado em notação XML. O esqueleto foi 
implementado para facilitar a implementação futura dos exercícios de cotovelo, punho e dedos.

Neste formato Cal3D um osso é definido como uma transformação relativa a um osso pai. Esta transformação é dividida em translação e rotação. Portanto, recursivamente devem-se percorrer todos os nós da árvore calculando a matriz global via cinemática direta. Desta forma, a transformação absoluta de um osso é calculada de forma recursiva a partir do primeiro osso pai.

A matriz de transformação global de um osso i, cujos ossos ancestrais (pai, avô, bisavô, etc) na hierarquia do esqueleto, são $\mathrm{k}$ ossos e estão em um vetor Pai $[0, \ldots, \mathrm{k}-$ 1], ou seja, onde o osso k-1 é o pai de i, é dada por:

\section{$M_{i}^{G_{i}}=M_{0} \times M_{1} \times M_{2} \times \ldots \times M_{k-1} \times M_{i}$ Equação 4.1-Matriz de transformação global do osso $\mathrm{i}$}

Por exemplo, para encontrar a matriz de transformação do osso "falange2", é necessário multiplicar a matriz de transformação de seu pai (carpo2) pela de seu avô (metacarpo2), pela de seu bisavô (rádio) e pela de seu tataravô (úmero).

A ordem para aplicar as matrizes de transformação é primeiramente rotação e depois translação, ou seja, primeiro se faz a rotação com o objeto na origem e depois se move o objeto para a posição final.

O sistema de coordenadas utilizado pelo Cal3D não é o mesmo utilizado por OpenGL (Figura 4.2). Para converter os sistemas de coordenadas foi necessário efetuar uma rotação de 90 graus anti-horário em torno do eixo $X$.

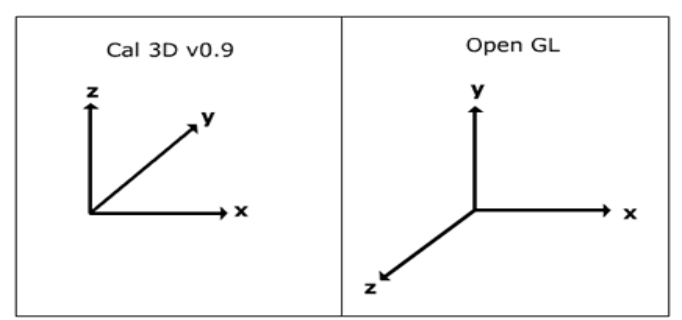

Figura 4.2 - Sistemas de referência Cal3D e OpenGL.

Os arquivos Cal3D contém um cabeçalho que informa a versão e o tipo de arquivo, se é malha poligonal ou material ou animação ou esqueleto. $O$ cabeçalho é seguido pelos dados do modelo. Na Figura 4.3 tem-se o cabeçalho do arquivo que contém a malha poligonal. 


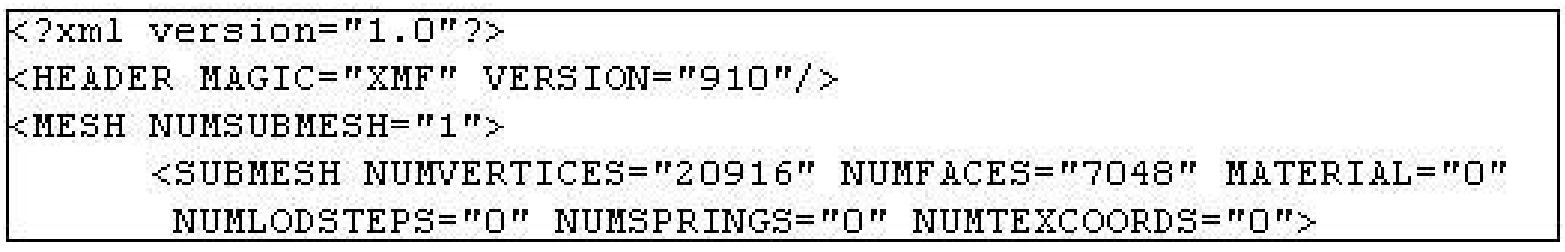

Figura 4.3 - Cabeçalho do arquivo da malha poligonal.

Na Figura 4.4 é apresentado um vértice da malha.

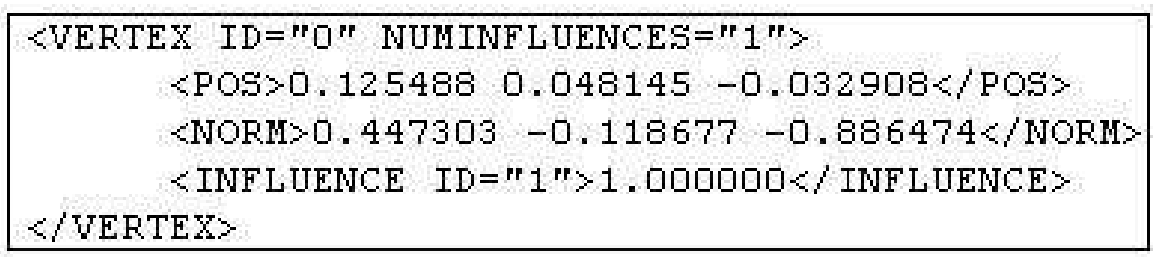

Figura 4.4 - Vértice do arquivo da malha poligonal.

O tempo de carregamento do modelo do braço 3D para a memória a partir dos arquivos XML no formato Cal3D ficou em torno de 3 a 5 minutos. Foi feita uma otimização no sistema através da implementação de um conversor do formato Cal3D para formato binário que precisa ser executado apenas uma vez para gerar o arquivo binário no formato de 32 bits ou 64 bits, dependendo do processador. Desse ponto em diante, o sistema NeuroR carrega os vértices e esqueleto dos arquivos binários diretamente para a memória. Esta otimização resultou em uma considerável redução no tempo de carga do modelo 3D, que passou a ser feito em segundos.

\subsection{FEEDBACK VISUAL}

Este módulo tem duas atribuições:

- exibição: apresentar as imagens geradas ao observador,

- rastreamento: rastrear a posição do observador.

Neste âmbito, o termo "rastrear" tem o significado de conhecer a posição de um objeto de interesse, no caso, o ombro do observador,) em cada ciclo de atualização do sistema (TRIAS, 2009).

Este módulo desenha o braço virtual na cena em cima do marcador. 
Inicialmente, é feita a conversão dos pontos da malha poligonal do sistema de referência do Cal3D para o sistema de referência do OpenGL.

A solução adotada para desenhar o braço virtual foi a criação de uma lista de triângulos com o comando gINewList, com a inserção de todas as faces da malha na lista e desenho da lista utilizando o comando glCallList.

Como o método de detecção de marcadores do ARToolKit é muito suscetível a variações na iluminação e pequenas mudanças na posição do marcador, é feita a primeira detecção do marcador ombro. Após, a cada quadro, é feita novamente a detecção do marcador. Caso ele não seja mais detectado na imagem, as coordenadas do último marcador detectado são usadas para o posicionamento do braço 3D na cena. Isso evita que o braço 3D "desapareça" durante a simulação.

Quanto às animações, foram implementadas apenas as animações para os exercícios proximais de ombro com pontos de parada, quando o braço virtual se mantém na posição durante um período de tempo ou um número de quadros definidos. São elas: abdução de ombro de máxima, flexão de ombro máxima, flexão de ombro de 0 a 90 graus seguida de rotação horizontal máxima, em torno de 40 graus,

Nesta primeira versão não foram implementados os exercícios distais de punho e dedos nem exercícios de cotovelo.

\subsection{CAPTURA INICIAL DO BRAÇO AFETADO}

Este módulo consiste na calibração da cor da pele e captura de duas imagens de fundo, sem e com o paciente e também na detecção do marcador colocado no ombro do paciente. A captura dos quadros do vídeo e a detecção do marcador colocado no ombro são realizadas com o auxílio da ARToolkit.

Neste módulo também são feitas as calibrações dos ângulos dos movimentos. Esta calibração é feita por fotogrametria, através da captura do quadro inicial e final do movimento realizado pelo braço não comprometido. 


\subsection{SUBSTITUIÇÃO DO MEMBRO REAL AFETADO PELO VIRTUAL}

A imagem é espelhada na horizontal. Para isso é feita uma cópia da imagem capturada pela câmera, com os pixels invertidos na horizontal, Figura 4.5-(b). O marcador é detectado na imagem já espelhada. Entretanto, com o espelhamento, o marcador pode não ser mais detectado. Para resolver este problema, foram escolhidos apenas marcadores simétricos, como o marcador da Figura 4.5-(c).

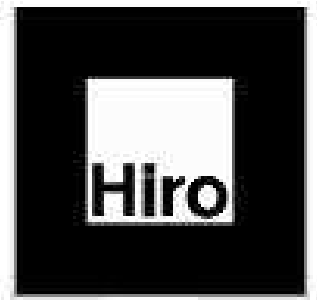

(a)

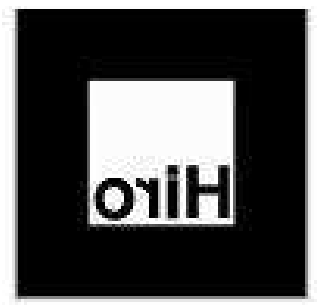

(b)

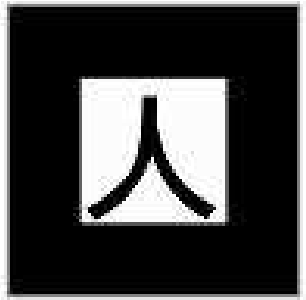

(c)

Figura 4.5 - Marcadores Fiduciais.

Para desenhar as bordas do marcador na imagem espelhada, não é possível utilizar a função argDrawSquare da ARToolkit pois esta função desenha no quadro original capturado pela câmera e não na imagem invertida. Para isso foi implementada a função que desenha linhas pelo algoritmo de Bresenham.

Foram implementados dois algoritmos para a "remoção" do braço comprometido da imagem, um que utiliza detecção de bordas e outro a técnica de chromakey. No primeiro algoritmo, após a detecção do marcador na imagem, utilizou-se o algoritmo de Sobel para a detecção de bordas, que faz a convolução da imagem com duas máscaras para encontrar os gradientes horizontal e vertical (GONZALEZ; WOODS, 2000). O resultado do filtro de Sobel é um mapa de bordas, com zero ou um para cada pixel da imagem, onde zero corresponde a fundo e um a borda. Utiliza-se um algoritmo de edge-linking para preencher os pixels do contorno que não foram classificados como borda no algoritmo de Sobel. Em seguida, o algoritmo define a região de corte na imagem original da seguinte forma: 
(a) Pesquisar uma região da imagem começando no limite do marcador ombro e avançando na horizontal $(x+1)$ até encontrar borda direita, ou seja, até que mapa de borda $(x, y)$ seja igual a 1.

(b) Pintar o pixel com a cor do pixel correspondente a uma das imagens de fundo (sem ou com o paciente), armazenadas anteriormente.

A Figura 4.6 ilustra uma das etapas do algoritmo implementado, a detecção de bordas por Sobel.

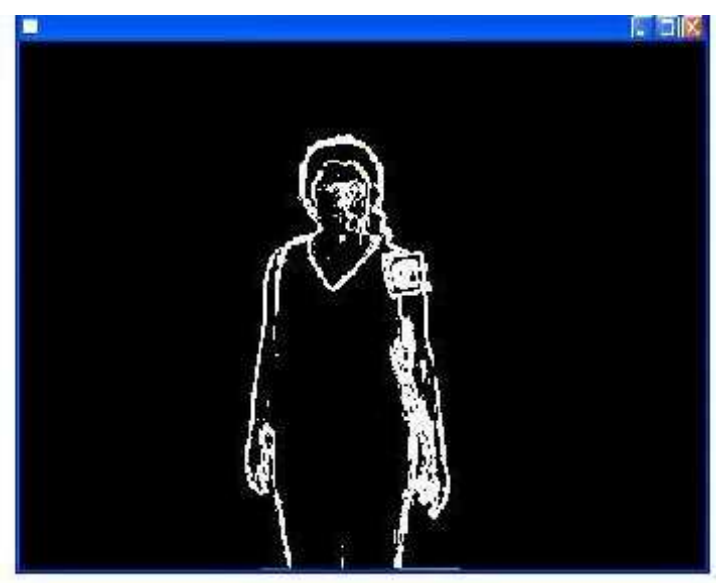

Figura 4.6 - Resultado do fitro de Sobel sem edge-linking.

O segundo algoritmo foi implementado utilizando a técnica de chromakey de predominância de cor com limiar, descrita na seção 3.8. A Figura 4.7 mostra o resultado deste segundo algoritmo aplicado na imagem com amarelo como corchave. Ele compreende os seguintes passos:

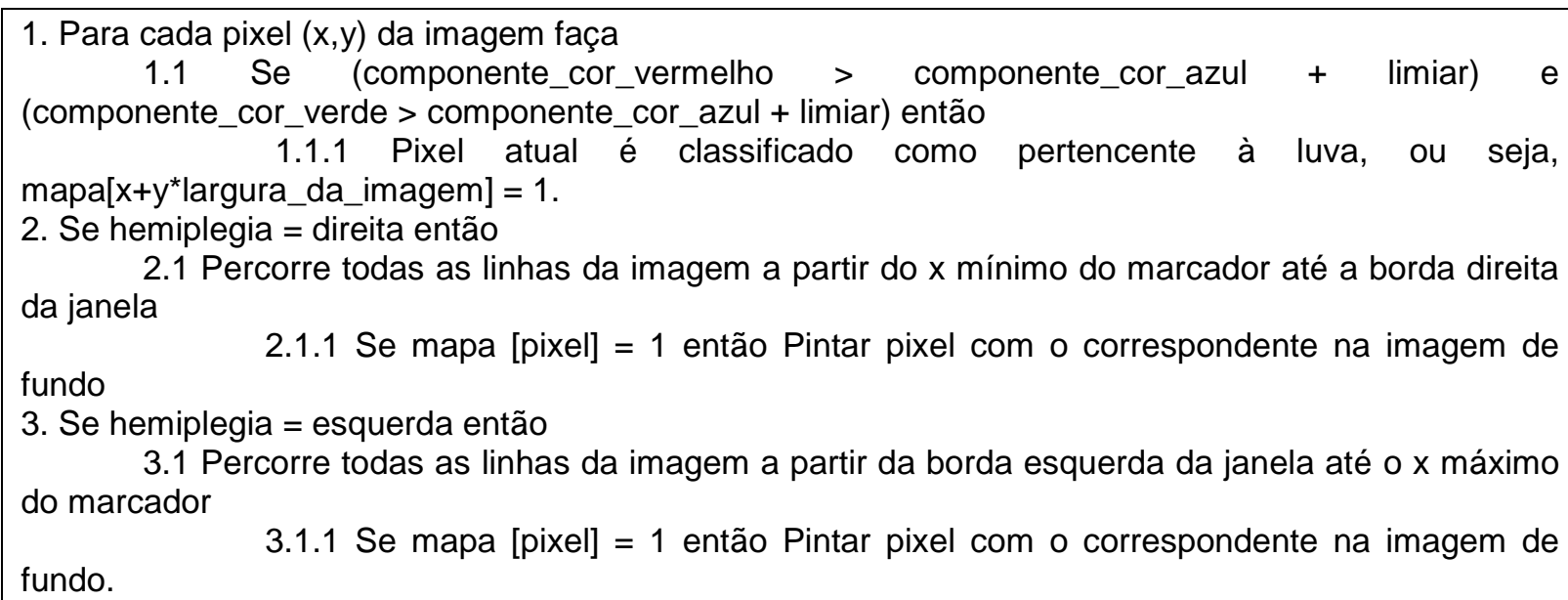



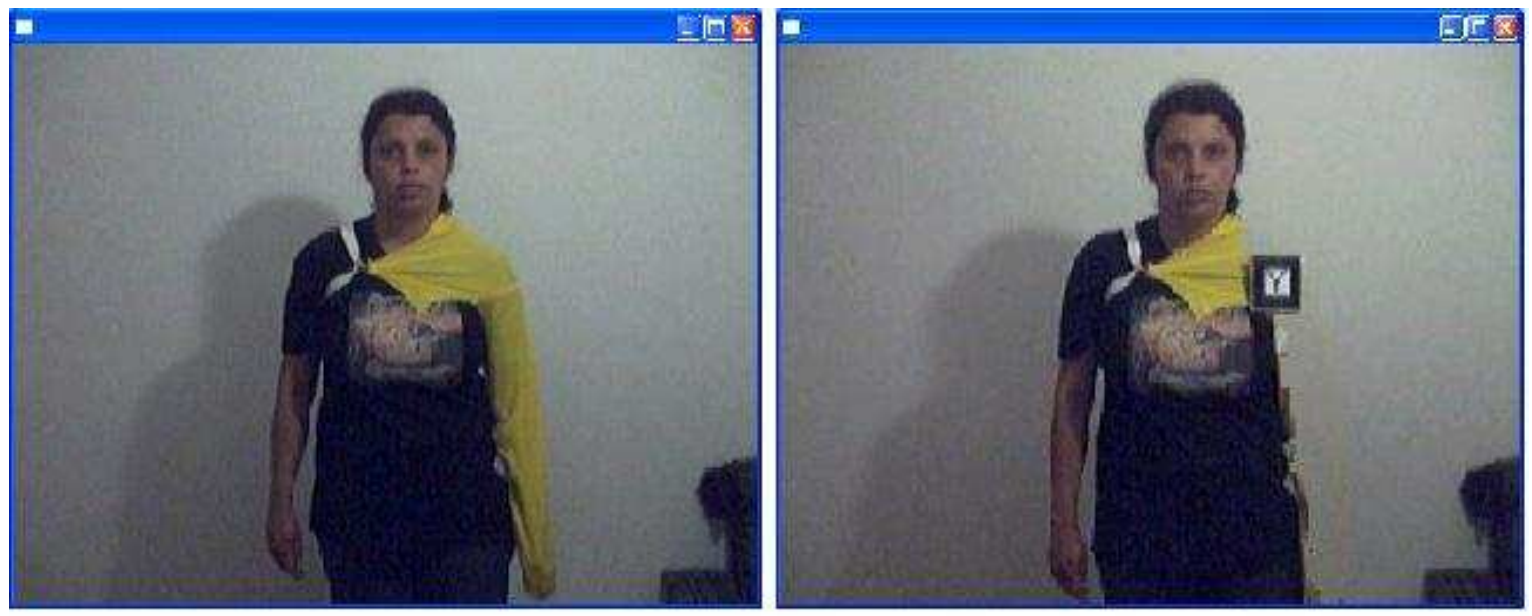

Figura 4.7 - Chromakey remove braço na imagem espelho

\subsection{AQUISIÇÃO E ARMAZENAMENTO DOS SINAIS CEREBRAIS}

O aparelho para aquisição do EMG utilizado na pesquisa é uma aparelho disponível comercialmente. Foi feito um contato com a empresa que desenvolveu o aparelho e a partir deste contato a empresa disponibilizou uma biblioteca e um módulo em Csharp para permitir o acesso ao aparelho de EMG e coleta do sinal bruto em tempo real, antes de ser processado. O módulo envia uma mensagem inicial para conectar ao aparelho e obter os sinais através de uma thread em C-sharp.

Optou-se por implementar as rotinas processamento do sinal em tempo real no módulo de interface com o dispositivo. A comunicação entre os módulos Aquisição e Armazenamento dos Sinais Cerebrais e Feedback Visual foi implementada através de troca de mensagens do sistema operacional, de forma a manter o baixo acoplamento entre os módulos. Foi feita a comunicação entre processos locais utilizando mensagens através do comando sendMessage de forma que o início da aquisição do sinal possa ser disparado pelo módulo Feedback Visual (linguagem C) e a animação do movimento do braço virtual durante a prática física possa ser iniciada pelo módulo de Aquisição e Armazenamento dos Sinais Cerebrais, a partir do disparo do processo de interfaceamento com o aparelho (linguagem C-sharp). Para que a simulação correta seja iniciada, foi feito um registro no NeuroR do último movimento executado na prática mental. Assim, quando o processo do módulo de 
Feedback Visual recebe uma mensagem do processo de interfaceamento do aparelho, ele executa a animação correspondente ao último movimento executado, ou seja, o movimento que deve ser repetido. Também pode-se selecionar o movimento a ser executado na interface cérebro-computador. As mensagens utilizadas para comunicação entre os processos foram eventos de teclado. Nos testes, muitas vezes a tecla não era recebida pelo processo do módulo de Feedback Visual, ou seja, o evento era perdido antes de ser processado. A solução implementada foi enviar duas mensagens de SendKey para cada tecla, utilizando redundância para evitar a perda do evento.

O primeiro algoritmo com janelamento móvel para cálculo do RMS foi implementado para o processamento do sinal EMG bruto, com tamanho da janela de 100 pontos. Foi utilizado um buffer de tamanho 1000 para armazenar os pacotes de dados enviados pelo aparelho. A janela móvel se deslocava dentro do buffer de dados. A Figura 4.8 mostra a tela deste algoritmo.

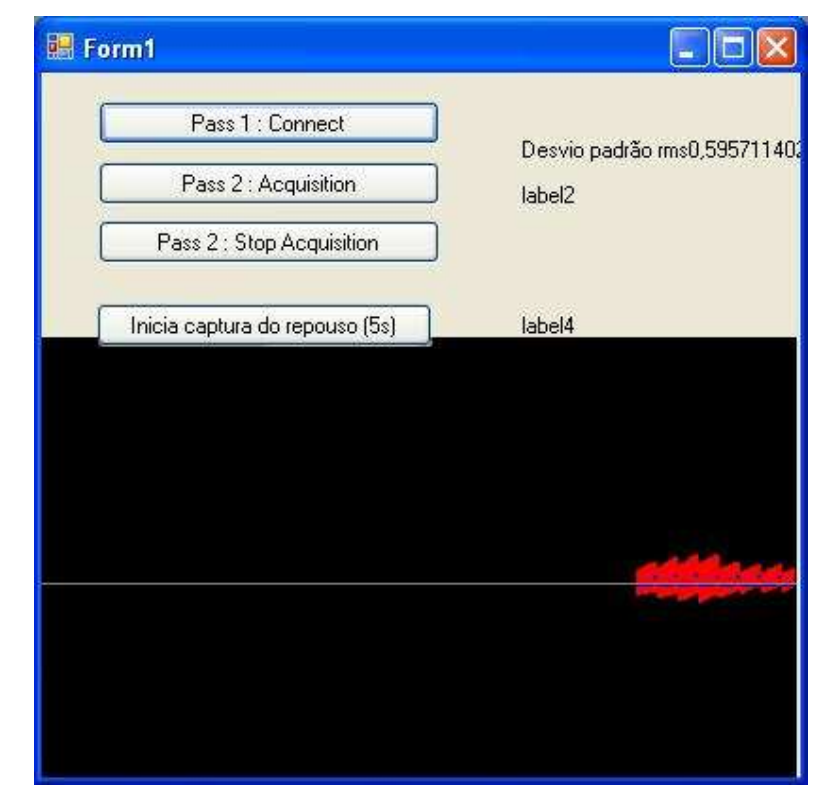

Figura 4.8 - Interface de cálculo do RMS por janela móvel

Também foi implementado o segundo algoritmo para cálculo do RMS para o processamento do sinal EMG bruto, que utiliza janelamento fixo e tamanho da janela igual ao tamanho do pacote de dados. A Figura 4.9 mostra a tela deste algoritmo. 


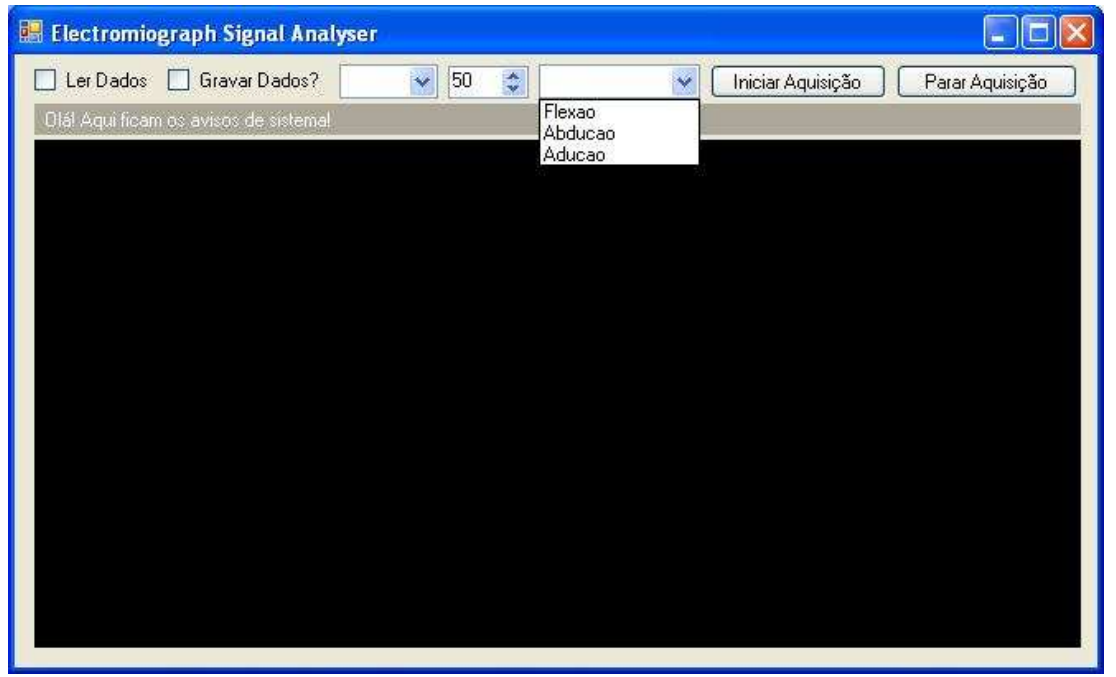

Figura 4.9 - Interface de cálculo do RMS com janela fixa.

Para facilitar os testes quando o equipamento não estava disponível, foi implementado um gerador de números aleatórios para simular os sinais EMG.

\subsection{PROTOCOLO DE TRATAMENTO}

Foram criadas as tabelas do banco de dados de protocolo e intervenção e também as telas e as rotinas para armazenamento (Figuras 4.10 e 4.11).

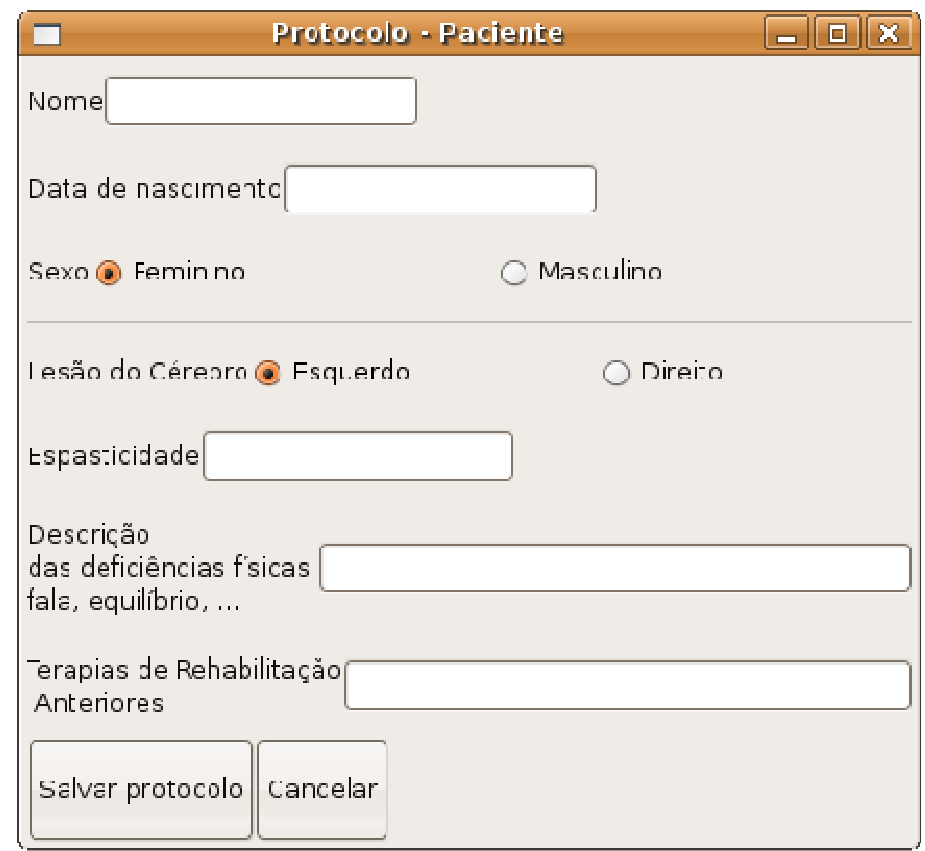

Figura 4.10 - Tela de cadastro de um protocolo com o NeuroR. 


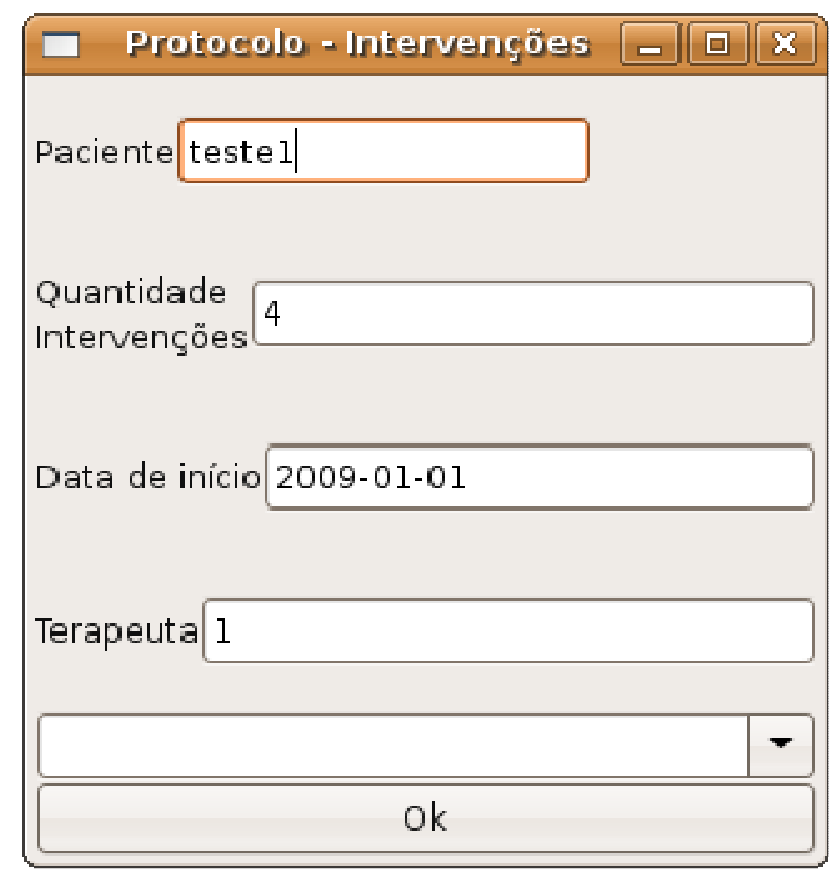

Figura 4.11 - Tela de cadastro de intervenções no NeuroR.

\subsection{PRÁTICA MENTAL}

A implementação deste módulo não foi realizada e os testes foram realizados com a presença de um fisioterapeuta, que conduziu a prática mental, conforme projeto aprovado no CEP.

\subsection{HISTÓRICO DO PACIENTE}

Foi criada a tabela do banco de dados de histórico e também foram criadas as telas (formulários) e as rotinas para armazenamento no banco de dados (Figura 4.12). 


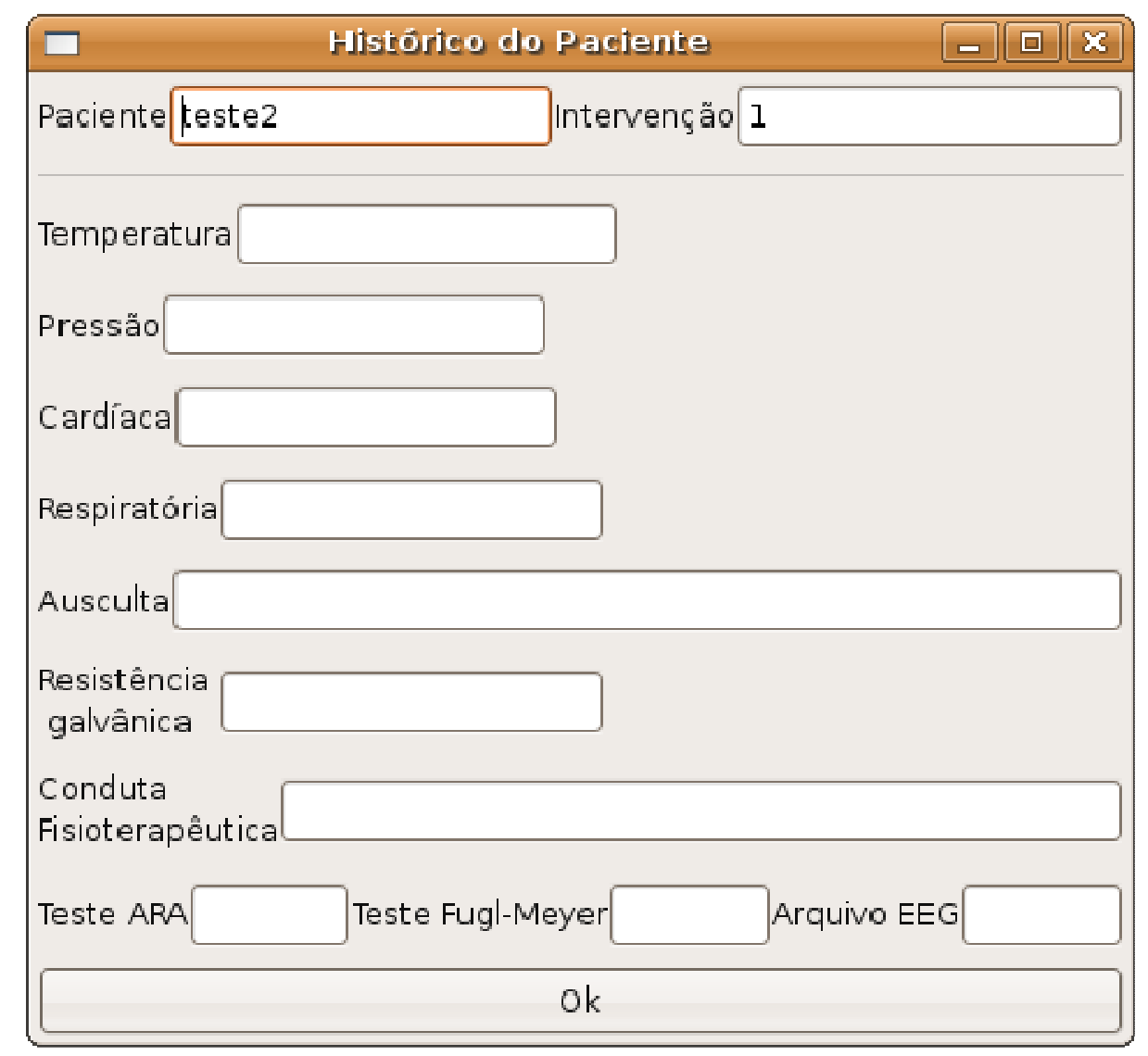

Figura 4.12 - Tela de histórico do paciente no NeuroR.

\subsection{ORIENTAÇÃO PARA O MOVIMENTO}

A implementação deste módulo não foi realizada e os testes foram realizados com a presença de um fisioterapeuta, conforme projeto aprovado no CEP.

\subsection{CONCLUSÕES}

Este capítulo apresentou os resultados da implementação do sistema proposto. 


\section{RESULTADOS E DISCUSSÃO DOS RESULTADOS}

\subsection{TESTES E AJUSTES DO APARATO TECNOLÓGICO}

Esta seção descreve os principais testes e ajustes realizados no sistema NeuroR, do ponto de vista computacional.

\subsubsection{TESTES DE POSICIONAMENTO DO BRAÇO VIRTUAL}

A Figura 5.1 mostra o braço virtual sobreposto ao marcador, após a malha poligonal ter sido carregada e o marcador, que representa o ombro, ter sido identificado.

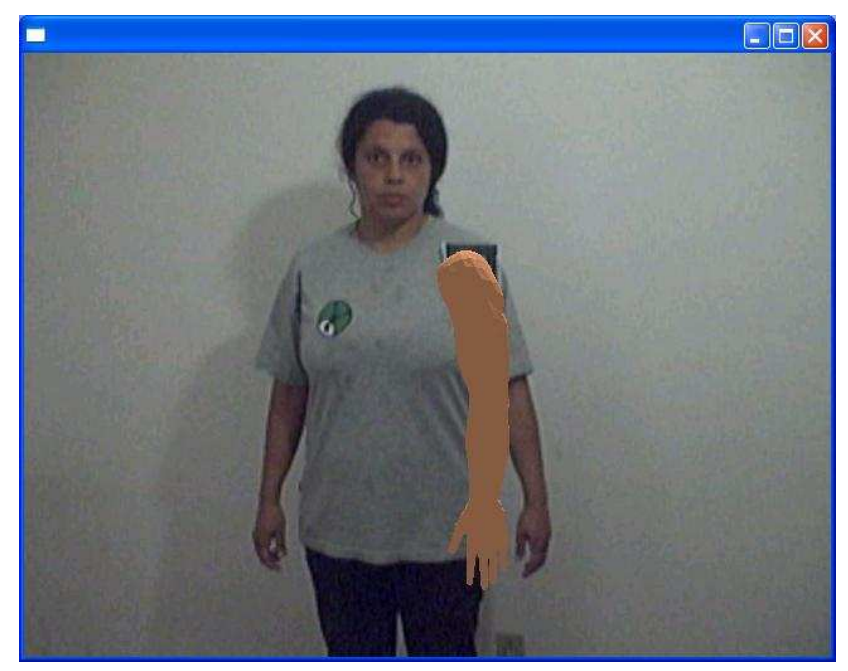

Figura 5.1 - Braço virtual na cena sobreposto ao ombro.

Nos testes iniciais foram identificados problemas de não detecção do marcador pela biblioteca ARToolkit quando havia uma mudança de ambiente ou iluminação. Para reduzir estes problemas, utilizou-se um software de calibração que acompanha a biblioteca ARToolkit para calibrar o marcador a cada mudança. 


\subsubsection{TESTES DE REMOÇÃO DO BRAÇO REAL}

Foram feitos testes para a "remoção" do braço comprometido da imagem com dois algoritmos, um que utiliza detecção de bordas e outro a técnica de chromakey.

Ocorreram problemas com o primeiro algoritmo quando o fundo não era constante. Assim, muitas vezes, as bordas do braço a ser removido eram conectadas a outras arestas do fundo da imagem, removendo partes do fundo erroneamente. Por outro lado, o segundo algoritmo, que utiliza chromakey, não apresentou este problema.

\subsubsection{TESTES DAS ANIMAÇÕES DO BRAÇO VIRTUAL}

Foram implementadas, testadas e ajustadas animações correspondentes aos movimentos de adução (Figura 5.2), abdução (Figura 5.3) e flexão do ombro (Figura 5.4). Nestes figuras são mostradas apenas a primeira parte da animação, a partir da posição anatômica inicial. A segunda parte consiste no retorno do braço ao início.
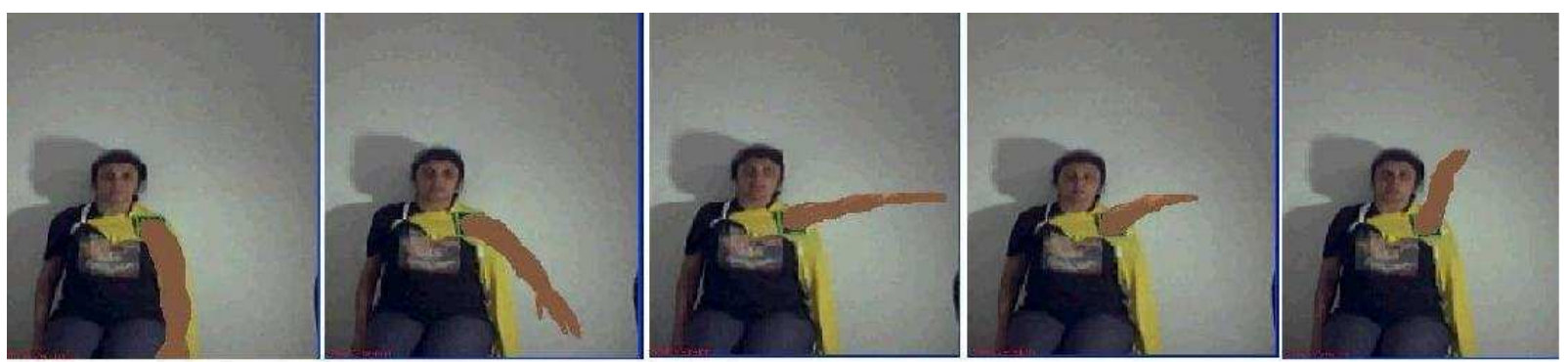

Figura 5.2 - Adução do ombro.
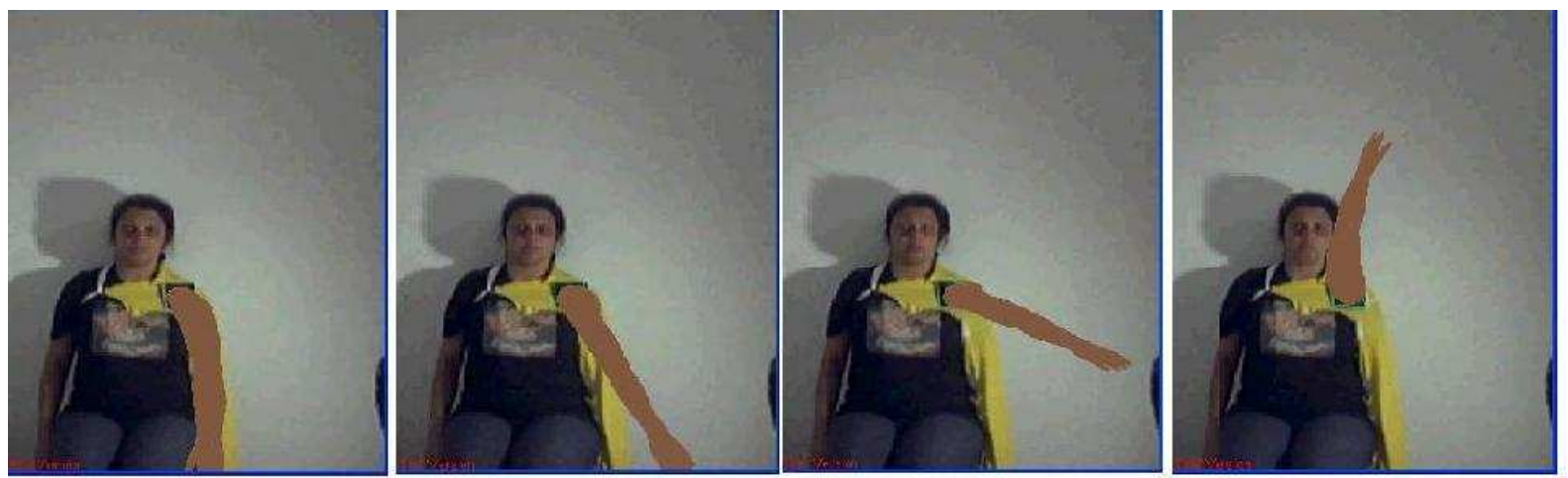

Figura 5.3 - Abdução do ombro. 


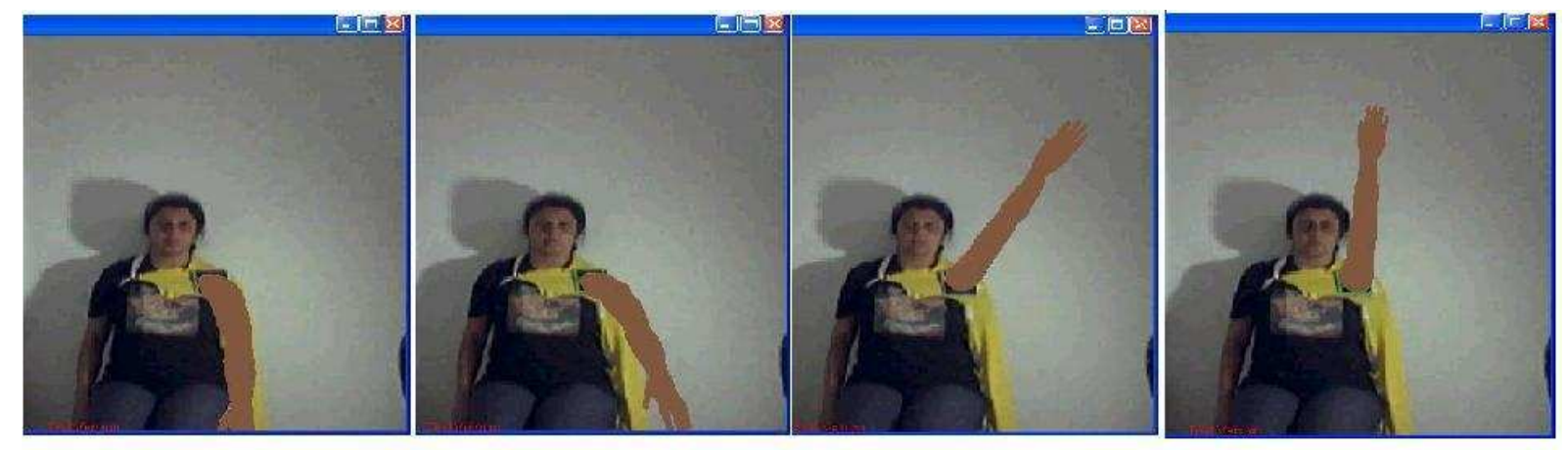

Figura 5.4 - Flexão do ombro.

\subsubsection{TESTES DA INTERFACE CÉREBRO-COMPUTADOR}

Foi desenvolvida uma interface cérebro-computador como parte do módulo de Aquisição e Armazenamento dos Sinais Cerebrais, para disparar o movimento do braço 3D durante a prática física. O sinal elétrico proveniente do músculo é capturado em tempo real e o RMS correspondente é calculado. Considerou-se que, quando a amplitude do sinal assume um valor superior à amplitude média do repouso mais três vezes o desvio padrão dos sinais capturados, tem-se um possível ponto de ativação muscular (informação verbal) ${ }^{1}$. Neste momento, o módulo de Aquisição e Armazenamento dos Sinais Cerebrais envia uma mensagem para o módulo de Feedback Visual do NeuroR, indicando que ele deve iniciar a animação selecionada no módulo de Aquisição e Armazenamento de Sinais Cerebrais (Flexão, Abdução ou Adução).

Foram feitos testes com três posicionamentos de eletrodos:

1. No plexo cervical $\mathrm{C} 4$, de onde partem os nervos nervos que têm trajeto descendente, cruzam a clavícula, superficialmente, e inervam a pele do ombro, como mostra a Figura 5.5-(a).

2. No músculo grande peitoral, que recobre todos os músculos do peito, estendendo-se do esterno e da clavícula ao úmero, e que tem a função de levar o braço para dentro, Figura 5.5-(b).

\footnotetext{
${ }^{1}$ Método descrito pelo professor Jeferson Fagundes Loss em reunião informal no LAPEX (Laboratório de Pesquisa do Exercício) na ESEF-UFRGS, em setembro de 2009.
} 
3. No músculo deltóide, que é o principal músculo da abdução de ombro, Figura 5.8-(a).

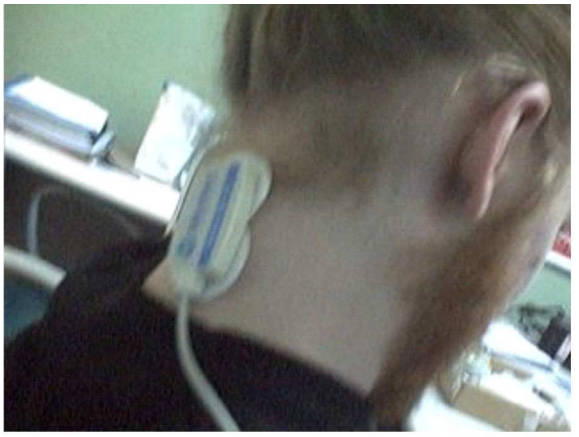

(a) Eletrodos no C4

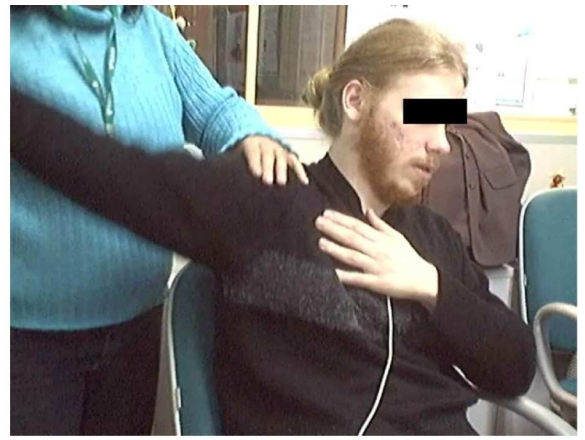

(b) Eletrodos no músculo peitoral

Figura 5.5 - Testes com eletrodos

O sinal registrado no C4 apresentou muitos artefatos, em razão dos sinais elétricos enviados para movimentar a cabeça, olhos, etc. No músculo peitoral também apareceram muitos artefatos, provavelmente por causa da musculatura do coração. $\mathrm{Na}$ Figura 5.6-(b), tem-se o sinal biolétrico da abdução de ombro com o eletrodo posicionado no músculo deltóide.

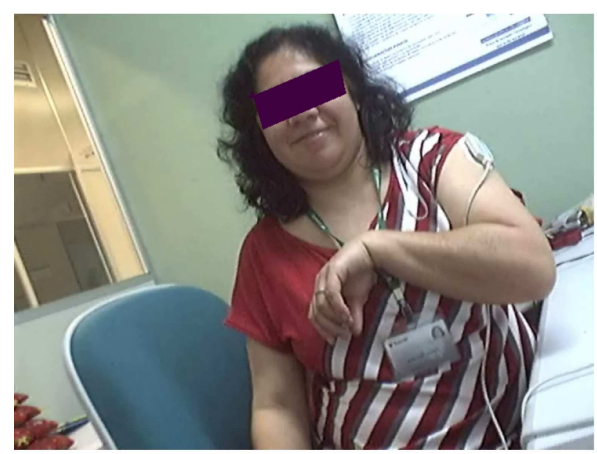

(a) Eletrodo no músculo deltóide

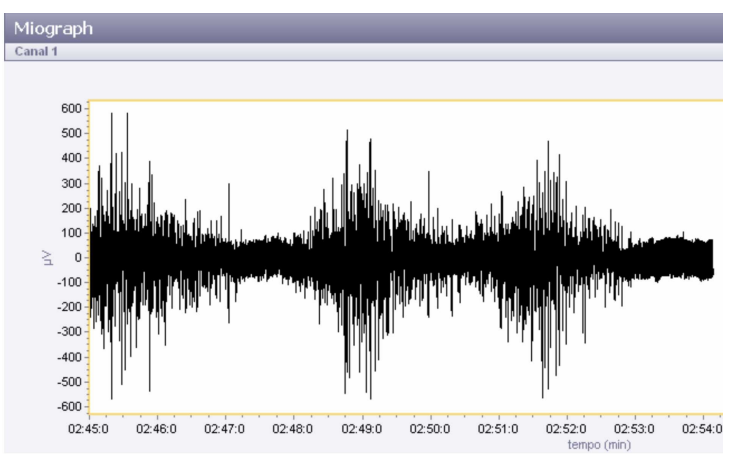

(b) Sinal bioelétrico durante abdução

Figura 5.6 - Testes com eletrodo no deltóide

Das três alternativas de posicionamento dos eletrodos, selecionou-se o músculo deltóide médio, que apesar de apresentar uma amplitude de sinal bioelétrico inferior ao do plexo cervical $\mathrm{C} 4$ e ao do músculo peitoral, registrou poucos artefatos em relação às outras duas alternativas, o que torna o processamento do sinal mais simples, sem a necessidade de muitas filtragens no sinal de origem.

Observou-se que os pacientes mantêm o braço com contração do padrão espástico, que é característico da patologia, durante todo o tempo, mesmo durante o repouso, o que pode ser causado pelo tônus aumentado, uma das principais consequências da patologia. O padrão espástico consiste no ombro em retração, depressão e 
rotação interna, antebraço em flexão e pronação e dedos em flexão e adução. Os músculos necessitam ter um tónus suficiente para permitir mover o corpo ou manter a sua posição contra a gravidade. Ao mesmo tempo, deve ser possível relaxar os músculos para o seu descanso e proporcionar movimentos controlados, com flexibilidade e fluidez. Quando os músculos dos pacientes que sofreram AVE ficam "presos" e os movimentos não são bem controlados, isso pode ocorrer devido à espasticidade. Assim, para cada um dos pacientes é necessário calibrar dois sinais, o sinal de repouso e o de contração voluntária máxima (amplitude máxima do movimento), pois cada um tem um tônus e sinais bioelétricos diferentes no repouso e durante a ativação muscular.

Observou-se nos testes que o movimento de abdução de ombro foi o que obteve maior amplitude de sinal bioelétrico no músculo deltóide.

Foram feitos testes com um algoritmo que utiliza janelamento móvel, tipo retangular, com tamanho fixo de amostras, para calcular o RMS e verificou-se um atraso no processamento. Este atraso ocorreu por causa do tempo necessário para processar cada buffer de dados, que levou à perda de pacotes quando o buffer ainda não havia sido totalmente processado e novos pacotes de dados estavam chegando. Para um buffer de 1.000 amostras, com janelamento de 100 pontos, é feito o cálculo do RMS para as amostras de 1 a 100, de 2 a 101, de 3 a 102, e assim por diante até 899 a 998. Este atraso foi da ordem de grandeza de segundos e comprometeu os primeiros resultados, pois muitos pacotes de dados não eram processados porque o buffer ainda estava cheio, sendo portanto desconsiderados no cálculo do RMS. Uma segunda solução, com um algoritmo que utiliza janelamento fixo, tipo retangular, com tamanho variável de acordo com o tamanho do pacote de dados, se mostrou mais eficiente, sem atraso significativo no processamento e na tomada de decisão da interface cérebro-computador.

\subsection{AVALIAÇÃO POR ESPECIALISTA EM MEDICINA FÍSICA}

Antes dos testes com pacientes, foi feita uma avaliação preliminar do sistema por um especialista em medicina física, que relatou, em uma conversa informal, que o 
rendering do braço virtual the parecia realístico o suficiente para ser utilizado em testes de cenários terapêuticos, uma vez que o braço tinha a cor da pele, as partes anatômicas do modelo eram proporcionais a um braço humano (braço, ante-braço, mão e dedos) e também pela característica tridimensional do mesmo, com espessura. Ele considerou que os exercícios propostos no NeuroR estavam adequados para os testes iniciais de aplicabilidade do sistema, uma vez foram projetados com baixa carga cognitiva, pois são movimentos simples, que envolvem apenas a articulação ombro e que são movimentos normalmente utilizados em intervenções fisioterapeuticas. Além disso, comentou que permitem utilizar metáforas simples para estimular o paciente a realizar os movimentos propostos, como "abrir o braço", "pegar algo que está na sua frente", "dar um abraço". Comentou que a capacidade cognitiva dos pacientes pode ter sido prejudicada, e que por isso é importante projetar cuidadosamente as tarefas e o retorno áudiovisual do sistema. Sugeriu a inclusão de realimentação e encorajamentos sonoros para estimular pacientes com déficit de iniciativa, com dano no córtex pré-frontal.

\subsection{AVALIAÇÃO COM PACIENTES E FISIOTERAPEUTAS}

Foram realizados testes com uma amostra não significativa de pacientes com 0 intuito de verificar se as decisões iniciais de projeto estavam adequadas ao públicoalvo. Os testes não foram realizados com o rigor científico necessário para possibilitar conclusões sobre melhoria ou não do membro comprometido, sendo, entretanto, úteis para evidenciar a aplicabilidade da proposta.

O projeto foi submetido e aprovado pelo Comitê de Ética em Pesquisa da Insttuição onde os testes foram realizados sob o número de protocolo 1.03.02.09.1330.

Inicialmente foi feito um estudo preliminar, projeto piloto, com um paciente, para ajustes no sistema.

O grupo experimental ou de teste (GE) foi selecionado de acordo com os critérios de inclusão, descritos na seção 3.15 - Planejamento das Intervenções, a partir de um 
convite feito a pacientes atendidos em um projeto de extensão numa Instituição, localizada em Novo Hamburgo, RS.

\subsubsection{Caracterização dos Grupos Experimental}

Cinco pacientes concordaram em participan do grupo experimental ou teste (GE). Todos assinaram o termo de consentimento livre e esclarecido (Apêndice A). A tabela 5.1 apresenta os dados da anamnese dos pacientes do GE, obtidos de seus prontuários de atendimento na clínica.

Tabela 5.1 - Características do Grupo Experimental (GE)

\begin{tabular}{|c|c|c|c|c|c|c|c|}
\hline & Paciente & Gênero & Idade & $\begin{array}{l}\text { Lado } \\
\text { Dominante }\end{array}$ & $\begin{array}{l}\text { Diagnóstico } \\
\text { clínico }\end{array}$ & $\begin{array}{c}\text { Tempo } \\
\text { decorrido } \\
\text { desde o } \\
\text { AVE }\end{array}$ & Hemiplegia \\
\hline \multirow{5}{*}{ 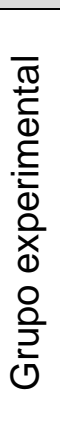 } & JO & Masculino & 63 & Direito & $\begin{array}{l}\text { AVE de tronco } \\
\text { cerebral }\end{array}$ & 42 meses & Direita \\
\hline & AN & Masculino & 39 & Esquerdo & AVE isquêmico & 69 meses & Direita \\
\hline & MA & Feminino & 43 & Direito & $\begin{array}{c}\text { AVE } \\
\text { hemorrágico } \\
\text { de tronco } \\
\text { cerebral } \\
\end{array}$ & $\begin{array}{c}102 \\
\text { meses }\end{array}$ & Direita \\
\hline & $\mathrm{SH}$ & Masculino & 46 & Direito & AVE isquêmico & 19 meses & Direito \\
\hline & $\mathrm{CA}$ & Masculino & 57 & Direito & AVE isquêmico & 47 meses & Esquerdo \\
\hline
\end{tabular}

O tempo decorrido desde o AVE, na tabela acima, é o tempo a partir da data do primeiro AVE no lado hemiplégico considerado.

A tabela 5.2 apresenta as principais queixas dos pacientes do grupo experimental, levantadas a partir dos prontuários de atendimento na clínica.

Tabela 5.2 - Principais Queixas dos Pacientes do Grupo Experimental

\begin{tabular}{|l|l|}
\hline Paciente & Queixa Principal \\
\hline JO & $\begin{array}{l}\text { "Dói minha perna e meu braço direito. Quando caminho minha perna tranca, } \\
\text { tenho medo de cair, mas com a muleta eu me equilibro". } \\
\text { "MN }\end{array}$ "Minha mão não obedece". \\
\hline MA & "Quero dobrar o joelho para caminhar melhor". \\
\hline SH & "Quero movimentar o braço como antes". \\
\hline CA & "Não consigo mexer o braço". \\
\hline
\end{tabular}


A tabela 5.3 apresenta as últimas avaliações dos pacientes do GE coletadas a partir dos prontuários de atendimento disponíveis na clínica de fisioterapia.

Tabela 5.3 - Exame físico do GE antes do estudo

\begin{tabular}{|c|c|c|}
\hline & Paciente & Diagnóstico fisioterapêutico e exame físico geral \\
\hline \multirow{5}{*}{ 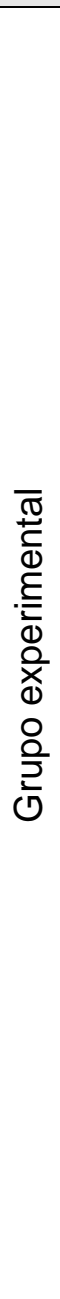 } & JO & $\begin{array}{l}\text { Diminuição de amplitude de movimento (ADM) e força nos membros } \\
\text { superiores e inferiores, comprometendo a coordenação motora. Apresenta leve } \\
\text { flexão de cotovelo e punho do membro superior direito. Compensa com o } \\
\text { tronco nos movimentos de flexão de quadril direito e extensão e abdução de } \\
\text { ombro direito. Hipertonia leve de hemicorpo direito. Sensibilidades tátil, térmica } \\
\text { e dolorosa preservadas. Alimenta-se e toma banho sozinho. }\end{array}$ \\
\hline & AN & $\begin{array}{l}\text { Hemiplegia com espasticidade em hemicorpo direito levando a alterações } \\
\text { posturais, dificuldade na marcha, fala. Marcha ceifante. Desvio de comissura } \\
\text { labial à esquerda e fala lenta. Sensibilidades tátil, térmica e dolorosa } \\
\text { levemente comprometidas em hemicorpo direito. Hipertonia nos membros } \\
\text { superior e inferior direito. O paciente apresenta independência total na } \\
\text { interação social e AVDs. }\end{array}$ \\
\hline & MA & $\begin{array}{l}\text { Seqüelas de AVE em hemicorpo direito com hemiparesia espástica, déficit de } \\
\text { coordenação e equilíbrio e hipotrofia leve. Dificuldades na marcha. Marcha } \\
\text { ceifante. Dificuldade na fala, desvio de comissura labial direita e dificuldade } \\
\text { para fixar foco no olho direito. Dor na linha articular do joelho direito. Hipertonia } \\
\text { leve e espasticidade em hemicorpo direito. Dedos em garra. ADM de flexão e } \\
\text { de abdução de ombro baixas. Todos os movimentos estão com velocidade } \\
\text { diminuída no lado direito. Sensibilidades tátil, térmica e dolorosa diminuídas. }\end{array}$ \\
\hline & $\mathrm{SH}$ & $\begin{array}{l}\text { Hemiplegia direita com diminuição da força muscular e da ADM nos membros } \\
\text { superior e inferior direito. Marcha ceifante e rotação. Possui controle de tronco } \\
\text { e cervical. Luxação da articulação glenoumeral. Comissura labial a direita. } \\
\text { Realiza as AVDs com auxílio do membro superior esquerdo. Hipotonia no } \\
\text { membro superior direito. Sensibilidades tátil, térmica e dolorosa } \\
\text { comprometidas. }\end{array}$ \\
\hline & $\mathrm{CA}$ & $\begin{array}{l}\text { Hemiplegia espástica esquerda. Alterações posturais e nos movimentos } \\
\text { voluntários. Paciente hipertônico em membro superior esquerdo levando ao } \\
\text { padrão flexor no braço, antebraço e punho. Força muscular diminuída em } \\
\text { membros esquerdos. Dor em deltóide e trapézio superior. Nas AVDs toma } \\
\text { banho sozinho e precisa de auxílio para se alimentar e vestir. }\end{array}$ \\
\hline
\end{tabular}

A tabela 5.4 apresenta os resultados dos testes de desempenho motor dos pacientes, utilizando o instrumento escala Fugl-Meyer para membro superior (UEFMA). Os testes foram conduzidos pelos Fisioterapeutas 1 e 2 que orientaram os pacientes quanto à execução de cada um dos itens motores avaliados, primeiro com o braço não comprometido e depois com lado hemiplégico. Todos obtiveram 66 pontos, que é a nota máxima, com o membro não comprometido nos testes de desempenho motor, o que indica que não há evidências de problemas motores ou deformidades no membro não comprometido. Para avaliar o item 32 - dismetria, ambos, Fisioterapeuta 1 e 2 orientaram cada paciente a levar o dedo indicador até a ponta do nariz. Os itens tremor e velocidade foram avaliados por observação. 
Tabela 5.4 - Desempenho motor do GE antes do estudo

\begin{tabular}{|c|c|c|c|c|c|}
\hline \multirow[t]{2}{*}{ Escala Fugl-Meyer para membro superior (UE-FMA) } & \multicolumn{5}{|c|}{ Grupo experimental } \\
\hline & $\mathrm{JO}$ & AN & MA & $\mathrm{SH}$ & $\mathrm{CA}$ \\
\hline \multicolumn{6}{|l|}{ I. Atividade Reflexa: } \\
\hline 1. Bíceps & 2 & 1 & 1 & 2 & 1 \\
\hline 2. Tríceps & 2 & 1 & 1 & 2 & 1 \\
\hline \multicolumn{6}{|l|}{ II. Sinergia Flexora: } \\
\hline 3. Retração do Ombro & 1 & 1 & 1 & 1 & 1 \\
\hline 4. Elevação do Ombro & 1 & 1 & 1 & 0 & 0 \\
\hline 5. Abdução do Ombro & 1 & 1 & 1 & 0 & 1 \\
\hline 6. Rotação Externa de Ombro & 0 & 0 & 0 & 0 & 0 \\
\hline 7. Flexão de Cotovelo & 2 & 1 & 2 & 0 & 1 \\
\hline 8. Supinação de Antebraço & 1 & 0 & 1 & 0 & 0 \\
\hline \multicolumn{6}{|l|}{ III.Sinergia Extensora: } \\
\hline 9. Abdução de Ombro com Rotação Interna & 1 & 0 & 0 & 0 & 0 \\
\hline 10. Extensão de Cotovelo & 1 & 1 & 1 & 0 & 0 \\
\hline 11. Pronação de Antebraço & 1 & 0 & 1 & 0 & 0 \\
\hline \multicolumn{6}{|l|}{ IV. Movimentos Combinando Sinergias: } \\
\hline 12. Mão na Coluna Lombar & 1 & 0 & 0 & 1 & 0 \\
\hline 13. Flexão de Ombro de $0^{\circ}$ a $90^{\circ}$ & 1 & 1 & 1 & 1 & 0 \\
\hline 14. Cotovelo a 90, Pronação-Supinação & 1 & 0 & 1 & 0 & 0 \\
\hline \multicolumn{6}{|l|}{ V. Movimentos Não-Sinérgicos: } \\
\hline 15. Abdução de Ombro de $0^{\circ}$ a $90^{\circ}$ & 1 & 1 & 0 & 1 & 0 \\
\hline 16. Flexão de Ombro de $90^{\circ}$ a $180^{\circ}$ & 0 & 0 & 1 & 0 & 0 \\
\hline 17. Cotovelo a $0^{\circ}$, Pronação-Supinação & 0 & 0 & 1 & 0 & 0 \\
\hline \multicolumn{6}{|l|}{ VI. Atividade Reflexa: } \\
\hline 18. Atividade Reflexa Normal de Bíceps e Tríceps & 2 & 1 & 1 & 2 & 1 \\
\hline \multicolumn{6}{|l|}{ VII. Punho: } \\
\hline 19. Cotovelo a $90^{\circ}$, Estabilização de Punho & 1 & 0 & 1 & 0 & 0 \\
\hline $\begin{array}{l}\text { 20. Cotovelo a } 90^{\circ} \text {, Completa extensão-Flexão de } \\
\text { Punho }\end{array}$ & 1 & 0 & 1 & 0 & 0 \\
\hline 21. Cotovelo a $0^{\circ}$, Estabilização de Punho & 2 & 1 & 1 & 2 & 0 \\
\hline $\begin{array}{l}\text { 22. Cotovelo a } 0^{\circ} \text {, Completa extensão-Flexão de } \\
\text { Punho }\end{array}$ & 1 & 0 & 1 & 0 & 0 \\
\hline 23. Circundução & 0 & 0 & 0 & 0 & 0 \\
\hline \multicolumn{6}{|l|}{ VIII.Mão: } \\
\hline 24. Flexão em Massa dos Dedos & 2 & 1 & 2 & 0 & 1 \\
\hline 25. Extensão em Massa & 2 & 0 & 1 & 0 & 0 \\
\hline $\begin{array}{l}\text { 26. Preensão a: Segurar folha de papel com } \\
\text { primeiro e segundo dedos, contra um leve puxão }\end{array}$ & 1 & 1 & 2 & 0 & 1 \\
\hline $\begin{array}{l}\text { 27. Preensão b: Preensão com flexão de } \\
\text { interfalangiana e metacarpofalangiana em posição } \\
\text { neutra, contra leve puxão }\end{array}$ & 0 & 1 & 2 & 0 & 0 \\
\hline 28. Preensão c: Segurar uma caneta (pinça) & 2 & 1 & 1 & 0 & 0 \\
\hline 29. Preensão d: Segurar um cilindro & 2 & 2 & 2 & 0 & 1 \\
\hline 30. Preensão e: Segurar uma bola contra puxão & 0 & 0 & 0 & 0 & 0 \\
\hline \multicolumn{6}{|l|}{ XI. Coordenação/Velocidade: } \\
\hline 31. Tremor & 1 & 1 & 0 & 2 & 0 \\
\hline 32. Dismetria & 1 & 1 & 0 & 0 & 0 \\
\hline 33. Velocidade & 0 & 1 & 0 & 0 & 0 \\
\hline Total & 35 & 16 & 31 & 14 & 9 \\
\hline
\end{tabular}


Os valores dos testes apresentados na tabela anterior serão úteis quando comparados com os resultados dos mesmos testes aplicados após as intervenções com o sistema, como forma de mensurar a evolução motora do membro superior.

\subsubsection{Estudo Preliminar com paciente do Grupo Experimental}

Foi feito um pré-teste com um paciente do sexo masculino de 46 anos, identificado no grupo experimental como SH. Este indivíduo sofreu um AVE isquêmico no lado esquerdo do encéfalo, apresentando hemiplegia direita. Ele participou dos testes com o NeuroR aproximadamente 1 ano e 7 meses após o AVE. O diagnóstico inicial foi obtido através dos prontuários de atendimento do paciente na clínica de fisioterapia, apresentado na Tabela 5.3.

A infraestrutura utilizada nos testes é apresentada na Figura 5.7 e é composta de tripé, webcam, projetor multimídia.

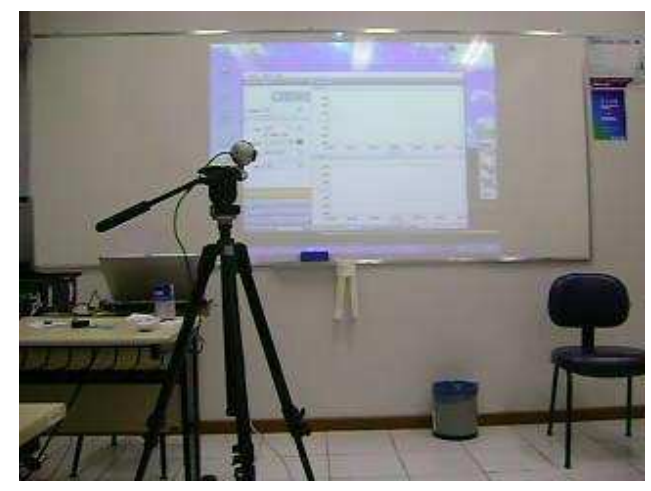

Figura 5.7 - Infra-estrutura

O paciente SH apresentava luxação no ombro no início da sessão. Ele sentia dor ao deixar o braço solto do lado do corpo, na posição supinado sem apoio. Porisso, durante os testes, ele deixou a mão apoiada sob a perna.

Primeiramente, a Fisioterapeuta 1 aplicou o padrão de FNP no paciente (Figura 5.8). 


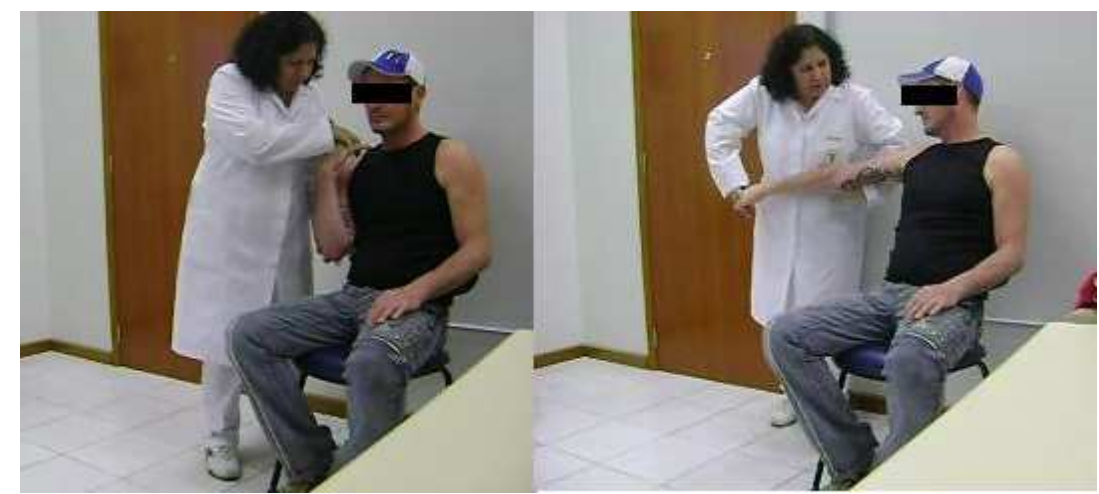

Figura 5.8 - Fisioterapia FNP

A seguir, foram colocados eletrodos no músculo deltóide médio e um eletrodo de referência no infra-clavicular do paciente (Figura 5.9).

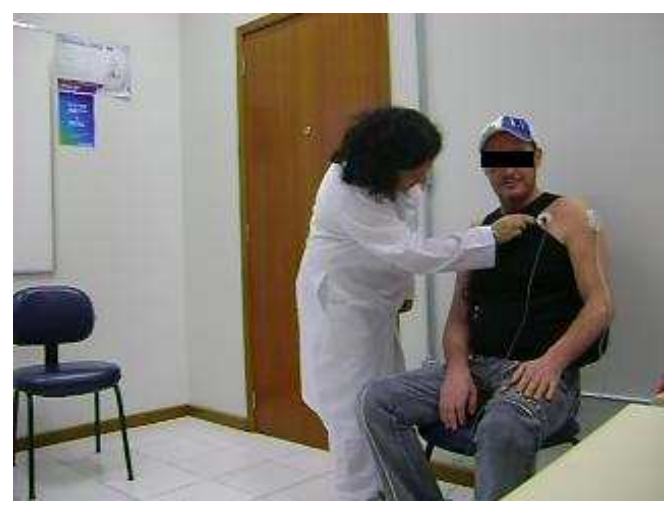

Figura 5.9 - Eletrodos no braço não lesado (esquerdo).

O paciente foi orientado a executar os três movimentos de ombro com o braço não comprometido e depois com o braço comprometido (Figura 5.10, 5.11 e 5.12). Os sinais bioelétricos foram registrados para posterior análise . 


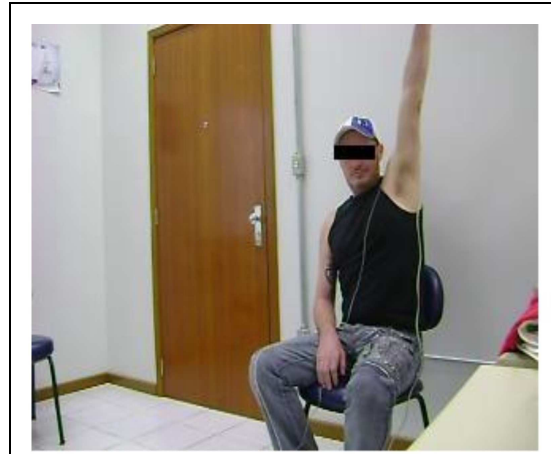

(a) Abdução de ombro com braço não comprometido

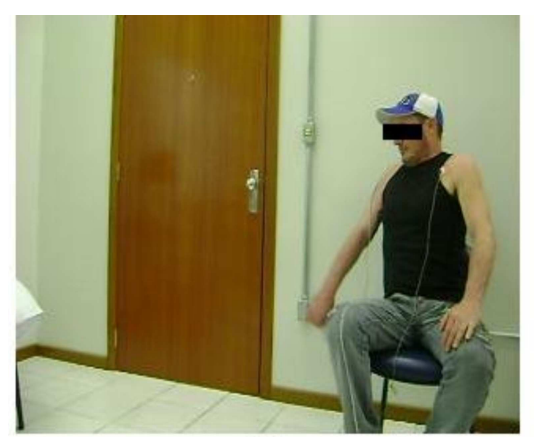

(b) Abdução de ombro com braço comprometido
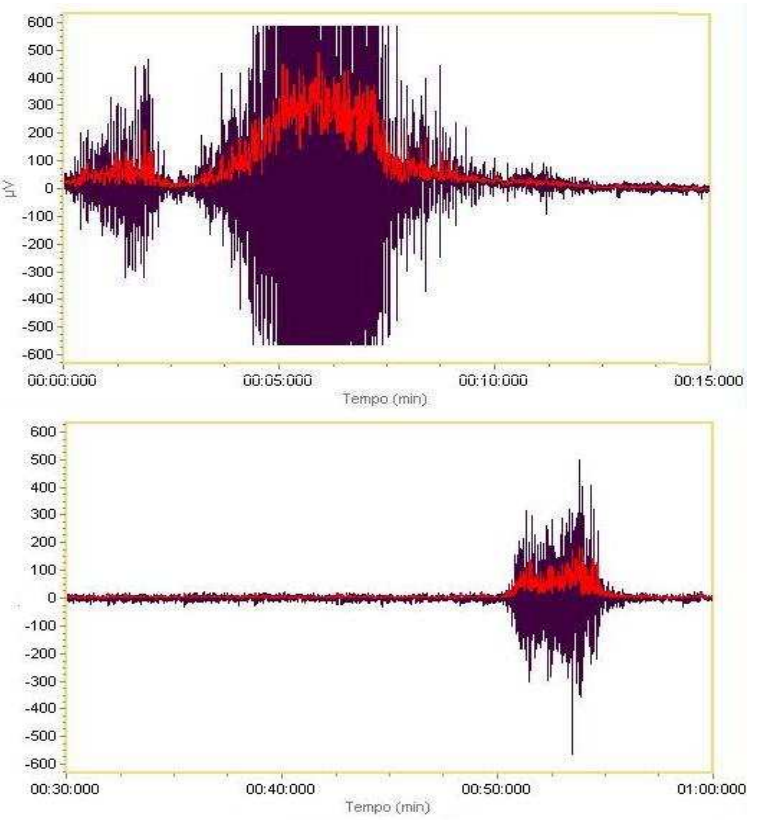

(c) EMG da abdução com o braço não comprometido e (d) comprometido

Figura 5.10 - Abdução de ombro

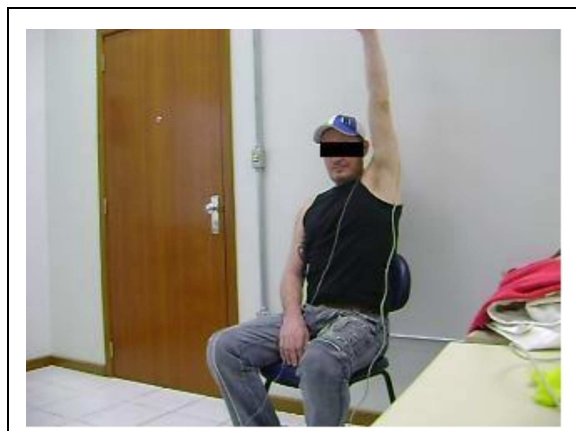

(a) Flexão máxima com’braço não comprometido

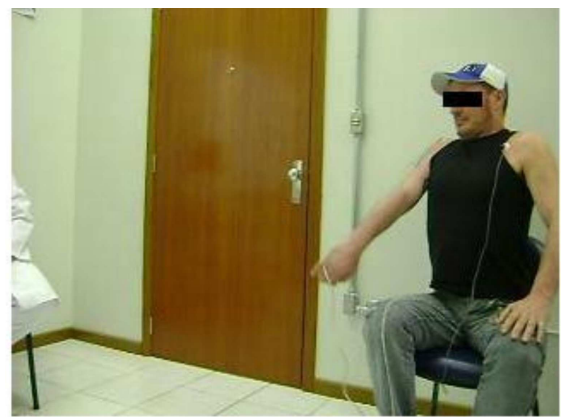

(b) Flexão máxima com braço comprometido
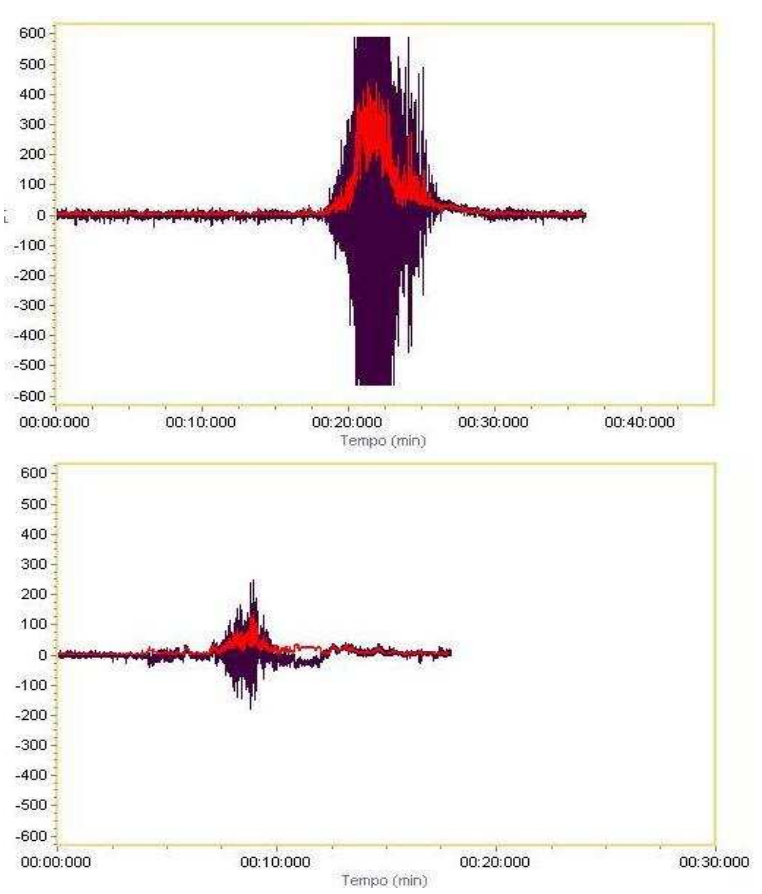

(c) EMG da flexão máxima com o braço não comprometido e (d) comprometido 


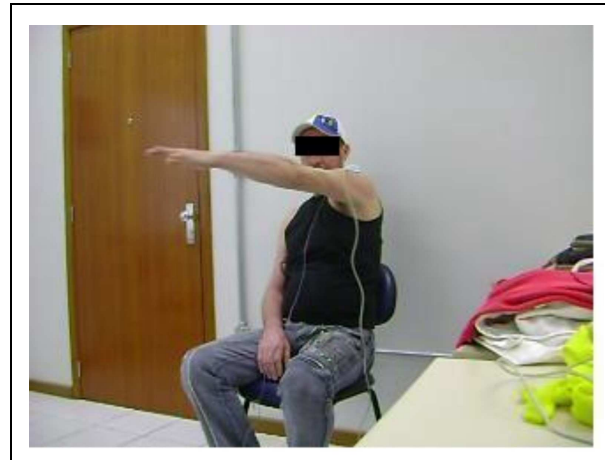

(a) Adução máxima com braço não comprometido

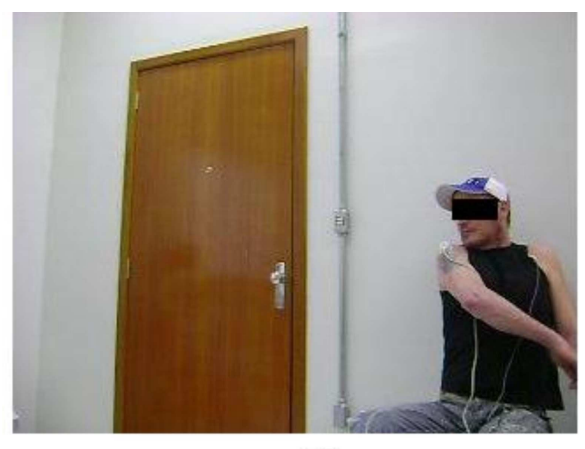

(b) Adução máxima com braço comprometido
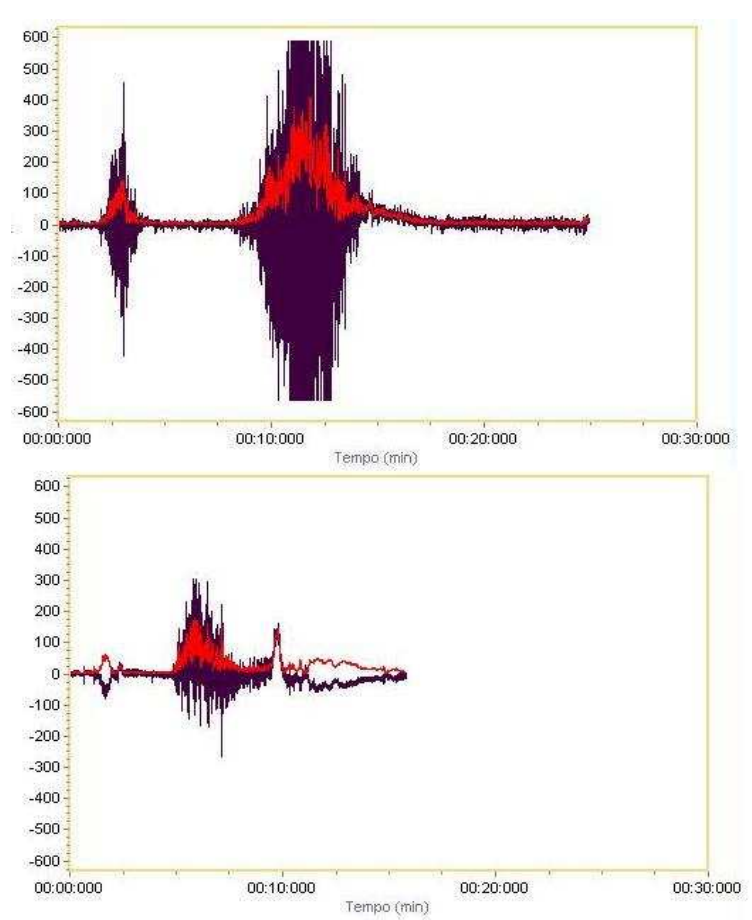

(c) EMG da flexão máxima com o braço não comprometido e (d) comprometido

Figura 5.12 - (a) Adução máxima de ombro

Observou-se que o sinal saturou durante 0 movimento com 0 braço não comprometido, tendo uma amplitude máxima superior ao limite definido pelo aparelho. Isso sugere que o ganho de amplificação do sinal, que foi ajustado em 2.000, não foi ajustado apropriadamente para este caso. Para os testes seguintes de membros não comprometidos, utilizou-se um ganho de 100, que, de acordo com o especialista em eletromiografia, é adequado para o membro não comprometido de não obesos. O ganho de 2.000, por sua vez, se mostrou adequado para o membro comprometido.

$\mathrm{Na}$ seqüência, a Fisioterapeuta 1 auxiliou 0 paciente a vestir uma luva especialmente desenvolvida para os testes (Figura 5.13). 


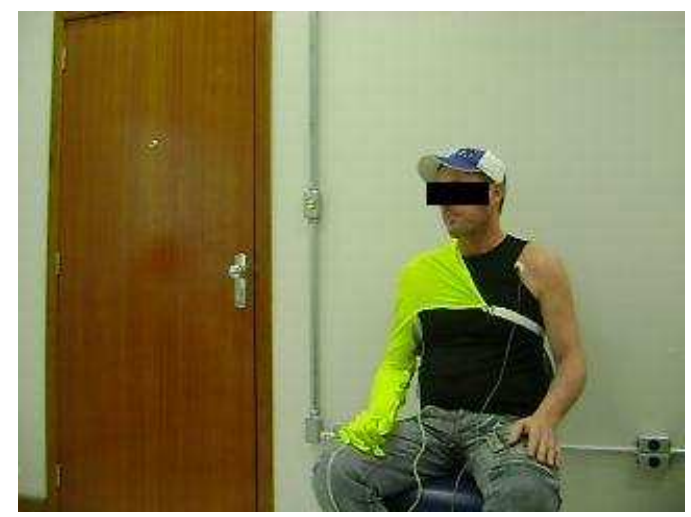

Figura 5.13 - Luva no braço comprometido (direito)

Como o paciente apresentava muita espasticidade na mão, foi difícil vestir a luva nele. Estas dificuldades enfrentadas para vestir a luva nortearam a confecção de uma nova luva sem dedos, mais fácil de vestir em pacientes espásticos.

Durante a prática mental (Figura 5.14), apesar de não ter sido solicitado a ele que fizesse movimentos físicos, o paciente tentou mover o próprio braço quando o braço $3 \mathrm{D}$ se movia na tela, o que sugere que ele associou o movimento do braço virtual ao seu. Neste pré-teste não foi feita a prática física com a interface cérebro-computador baseada no EMG coletado no músculo deltóide médio.

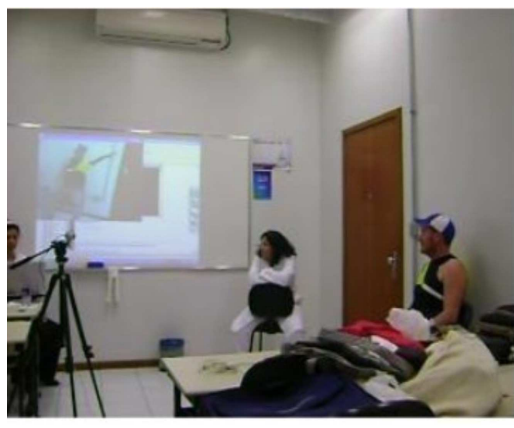

(a) Prática mental da abdução

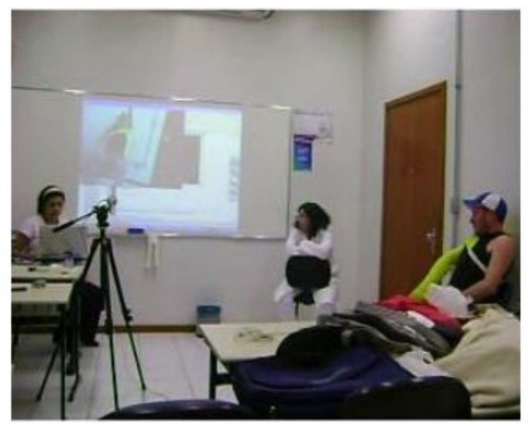

(b) Prática mental da flexão

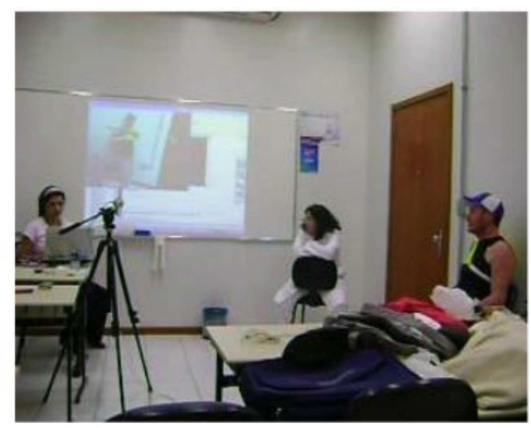

(c ) Prática mental da adução

Figura 5.14 - Testes iniciais com o NeuroR

\subsubsection{Testes com o Grupo Experimental}

Nesta seção é apresentado o protocolo de intervenção aplicado aos pacientes do GE (Tabela 5.6) e são relatadas especificidades das quatro sessões feitas com quatro dos cinco pacientes voluntários do grupo experimental. Um dos pacientes 
desistiu por motivos pessoais a partir da terceira seção e é considerado como perda da amostra.

\section{Tabela 5.6 - Protocolo de intervenção aplicado no GE}

(1) Prática mental:

(a) Fisioterapeuta executa fisicamente o movimento de abdução de ombro de 0 a no máximo 180 graus para orientar o paciente.

(b) Paciente visualiza a si mesmo e a abdução de ombro de 0 a 180 graus, executada pelo braço virtual na tela.

(2) Prática mental:

(a) Fisioterapeuta executa fisicamente o movimento de flexão de ombro de 0 a no máximo 180 graus para orientar o paciente.

(b) Paciente visualiza a si mesmo a flexão de ombro de 0 a 180 graus, realizada pelo braço virtual na tela.

(3) Prática mental:

(a) Fisioterapeuta executa fisicamente o movimento de flexão de ombro de 0 a 90 graus seguida de flexão horizontal de ombro de 0 a 40 graus para orientar 0 paciente.

(b) Paciente visualiza a si mesmo e a flexão de ombro de 0 a 90 graus seguida de flexão horizontal de 0 a 40 graus, executada pelo braço virtual na tela.

(4) Prática física de:

(a) Fisioterapeuta executa fisicamente o movimento de abdução de ombro de 0 a no máximo 180 graus para orientar o paciente.

(b) Paciente é orientado pelo fisioterapeuta a realizar a abdução fisicamente com o braço comprometido, olhando para o braço virtual na tela, inicialmente parado, enquanto o sinal EMG do braço é captado. Quando a $\mathrm{BCl}$ dispara o movimento de abdução do braço virtual, um aviso sonoro é emitido e o braço virtual executa a animação.

(5) Prática física de:

(a) Fisioterapeuta executa fisicamente o movimento de flexão de ombro de 0 a no máximo 180 graus para orientar o paciente.

(b) Paciente é orientado pelo fisioterapeuta a realizar a flexão fisicamente com o braço comprometido, olhando para o braço virtual na tela enquanto o sinal EMG do braço é adquirido. Quando a BCl dispara o movimento de abdução do braço virtual, um aviso sonoro é emitido e o braço virtual executa a animação.

(6) Prática física de:

(a) Fisioterapeuta executa fisicamente o movimento de de flexão de ombro de 0 a 90 graus seguida de flexão horizontal de ombro de 0 a 40 graus para orientar 0 paciente.

(b) Paciente é orientado pelo fisioterapeuta a realizar o movimento fisicamente com o braço comprometido, olhando para o braço virtual na tela enquanto o sinal EMG do braço é obtido. Quando a $\mathrm{BCl}$ dispara o movimento de abdução do braço virtual, um aviso sonoro é emitido e o braço virtual executa a animação.

(7) Cinco repetições do padrão FNP no braço comprometido com auxílio da fisioterapeuta.

\section{Primeira sessão}

Na primeira sessão com o paciente CA, hemiplegia esquerda, foram colocados os eletrodos no braço esquerdo e no infra-clavicular (Figura 5.15) Foi solicitado a ele que realizasse os movimentos com o braço plégico e o sinal foi armazenado. 


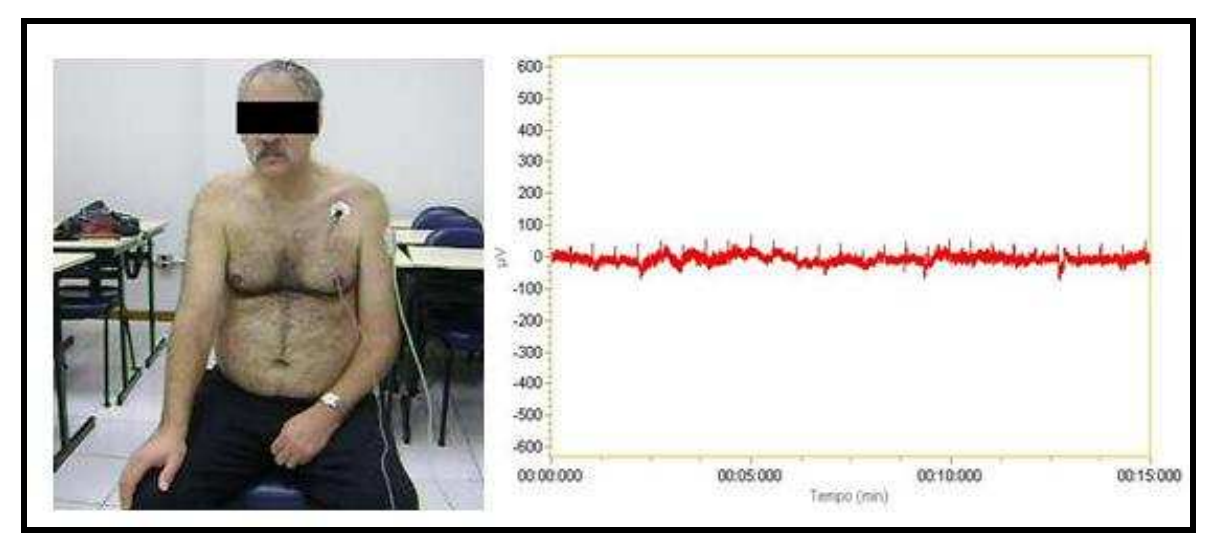

Figura 5.15 - EMG do deltóide no membro afetado (repouso)

A seguir, a Fisioterapeuta 1 vestiu a luva no paciente.

Os exercícios foram executados na seguinte ordem: abdução, flexão e adução. A cada exercício, a fisioterapeuta executou o movimento fisicamente para orientar 0 paciente e depois solicitou que ele realizasse o movimento olhando para a tela. Cada exercício foi executado apenas uma vez. Alguns comentários de CA durante a prática mental com o braço 3D. "Há quanto tempo meu braço não subia assim desse jeito", "Isso é que é o braço virtual?", "Olha só AN, há quanto tempo seu braço não ficava retinho deste jeito". "Esse trabalho é pra que?". A Fisioterapeuta 1 então respondeu ao paciente que ao ter um AVE ocorre uma mudança no cérebro e a memória do movimento fica fraca, apagada e cada vez que for observado o movimento o cérebro poderá registrar e reaprender o movimento perdido.

Durante o exercício de rotação horizontal de 0 a 40 graus com o braço flexionado em 90 graus, houve falha de sincronismo pois o paciente executou o movimento no sentido contrário ao realizado pelo braço 3D. Com isso ocorreu uma falha no registro e o braço 3D ficou na frente do paciente, sem a conectividade com o ombro físico.

Na primeira sessão com o paciente AN também foram colocados os eletrodos no braço direito e no infra-clavicular. Foi solicitado que ele realizasse os movimentos com o braço plégico e o sinal foi armazenado. Após, a Fisioterapeuta 1 o auxiliou a vestir a luva. Ele tem dificuldades de fala, fala muito devagar mas compreende bem. Da mesma que ocorreu com o paciente $\mathrm{CA}$, foi feito apenas uma repetição de cada um dos três movimentos com o braço 3D (Figuras 5.16, 5.17, 5.18). No movimento sinérgico de flexão 90 graus, seguido de adução 40 graus para dentro, e retorno à posição inicial de supinado, a Fisioterapeuta 1 utilizou metáforas para explicar o movimento para o paciente, como, por exemplo, "dar um tapa". 


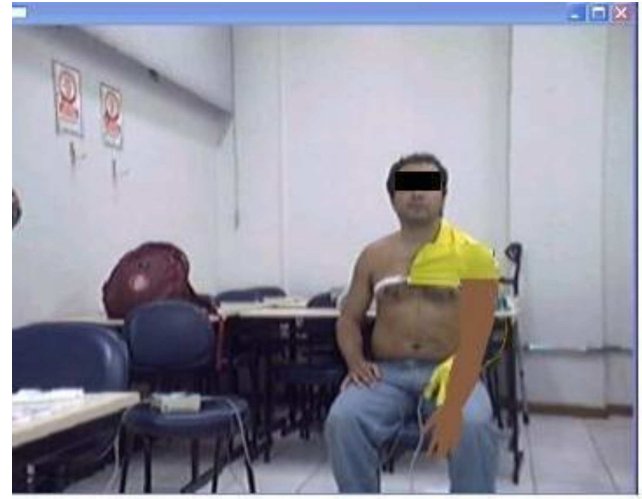

(a)Posição Inicial

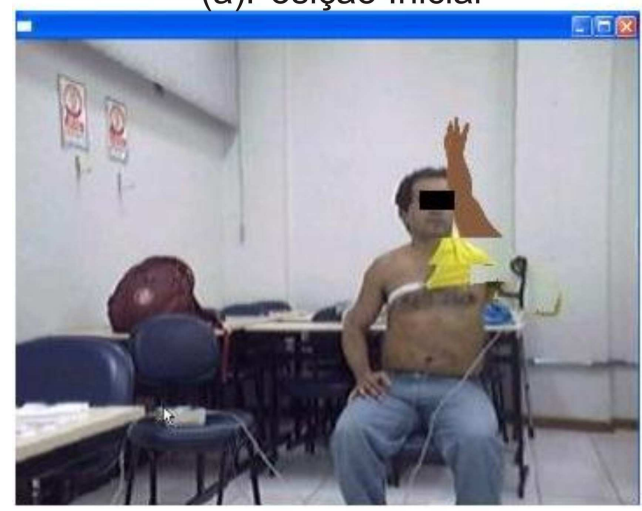

(c ) Fim da abução

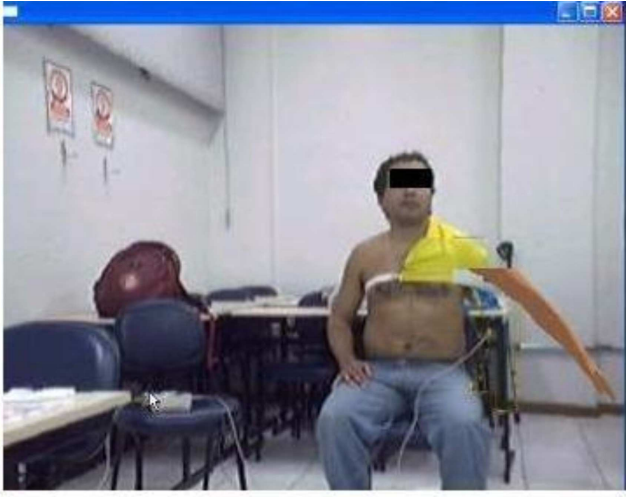

(b) Início da abdução

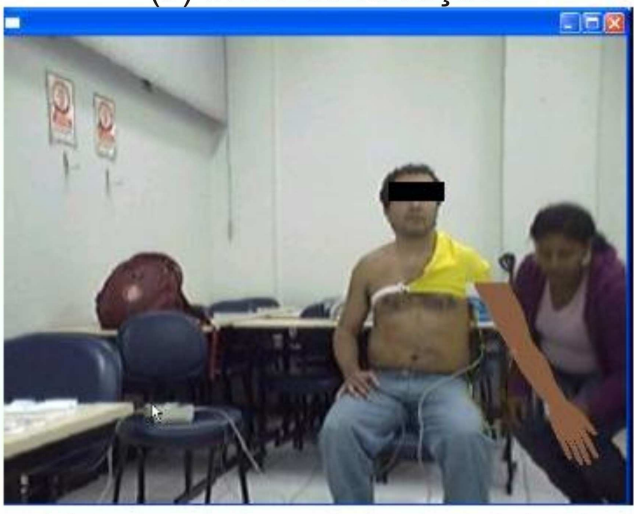

(d) Braço retorna à posição inicial

Figura 5.16 - Paciente AN utilizando o NeuroR

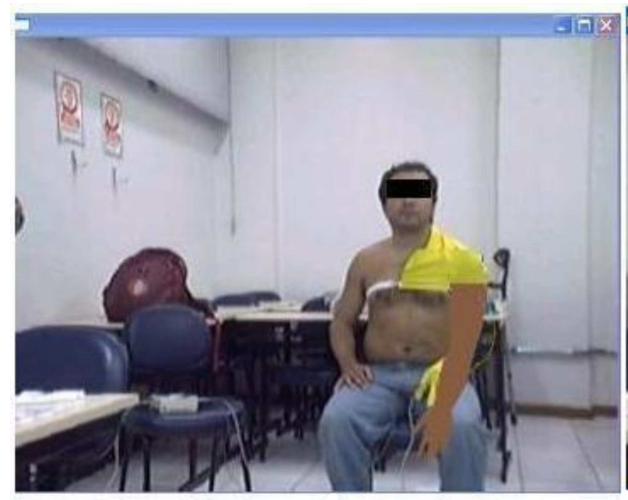

(a) Posição' inicial

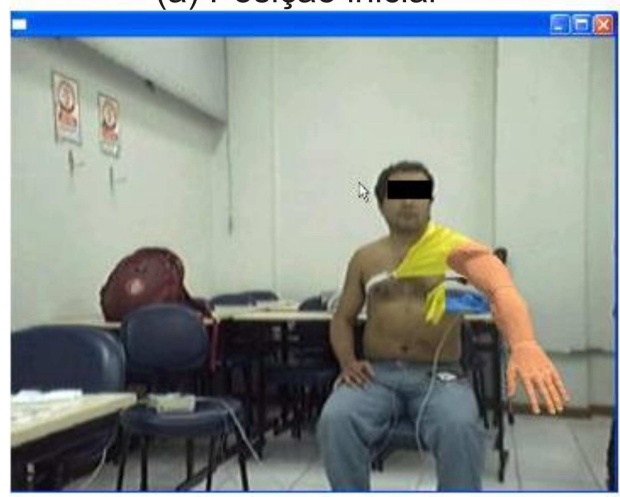

(c ) Flexão inferior a 90 graus

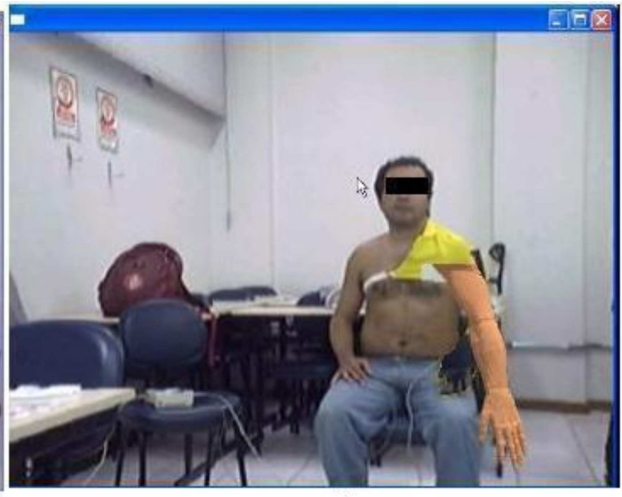

(b) Início da flexão

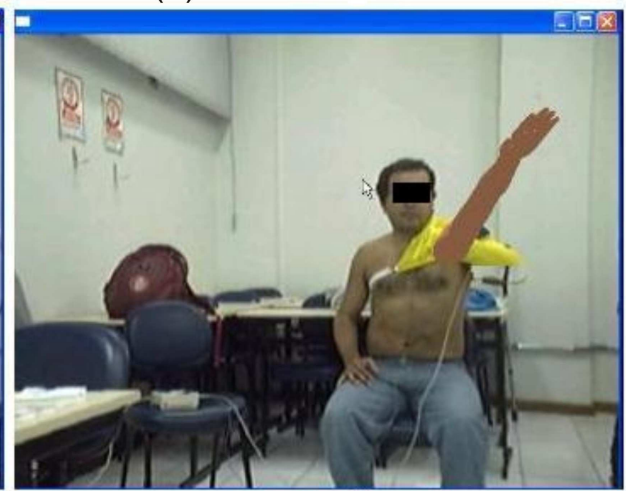

(d) Flexão entre 90 e 180 graus

Figura 5.17 - Paciente AN utilizando o NeuroR 


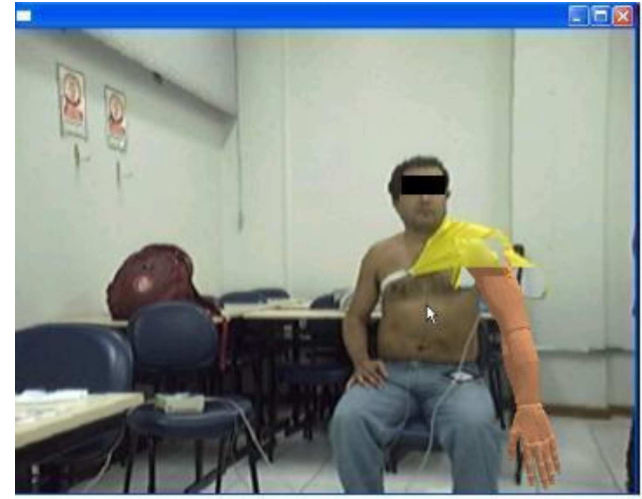

(a) Início da flexão a 90 graus

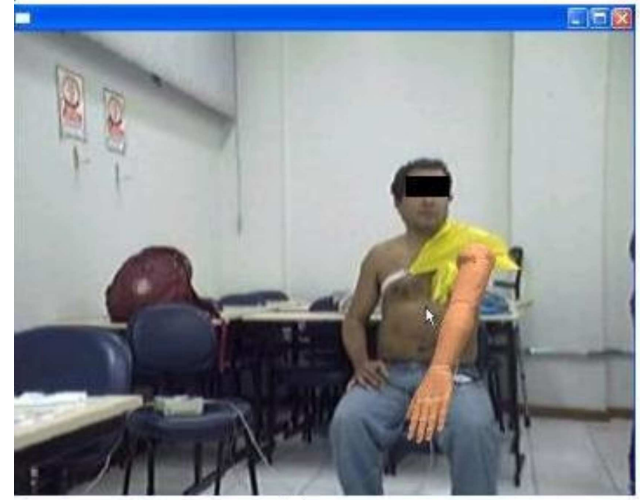

(c ) Início da flexão horizontal de 0 a 40 graus

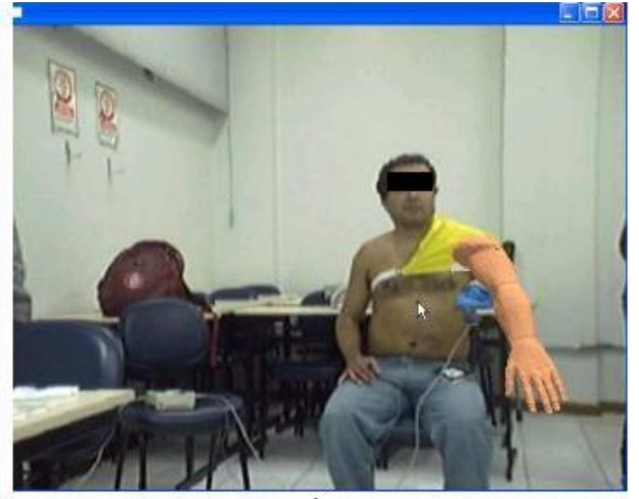

(b) Flexão a 90 graus

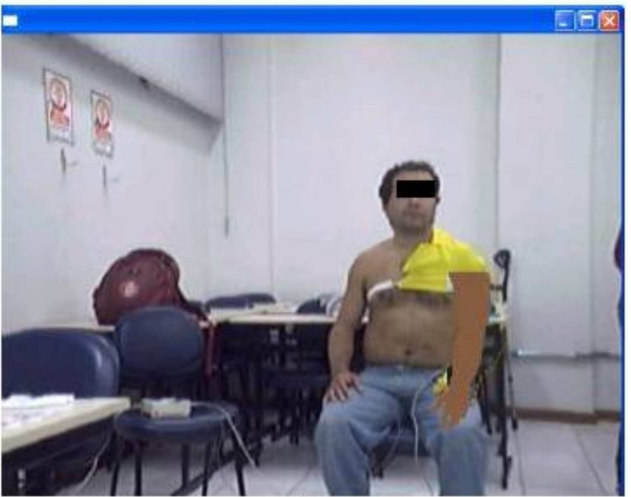

(d) Fim da flexão horizontal

Figura 5.18 - Paciente AN utilizando o NeuroR

O posicionamento correto do marcador no ombro é importante para o registro correto do braço 3D, como pode ser visto na Figura 5.19.

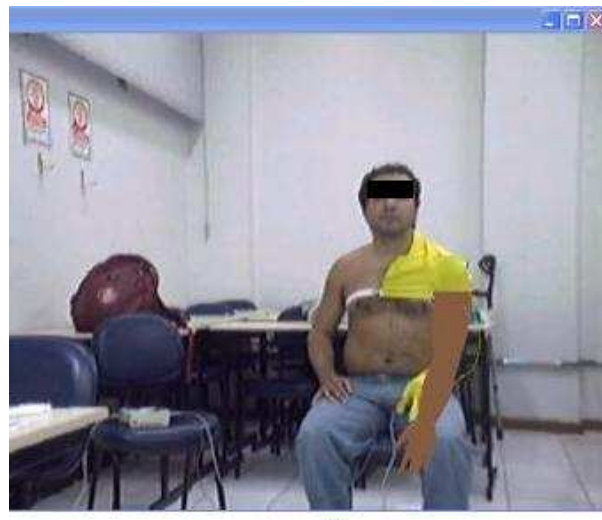

(a)

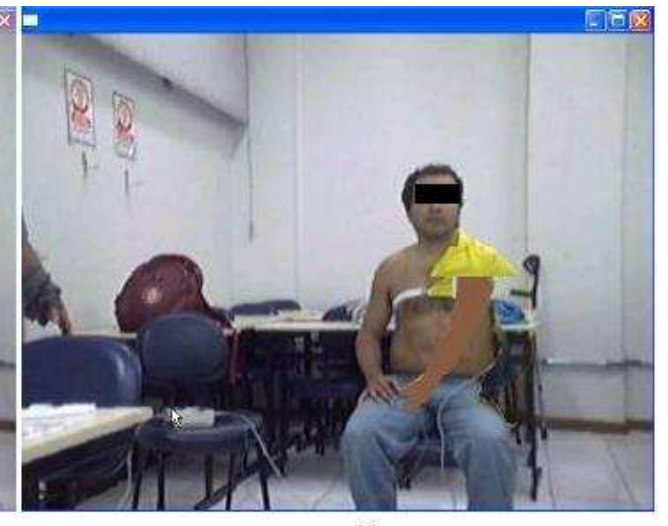

(b)

Figura 5.19 - (a) Marcador na posição correta. (b) Marcador posicionado inadequadamente.

Ao final da primeira sessão, a Fisioterapeuta 1 aplicou o protocolo FNP nos pacientes CA e AN. Ela comentou que o procedimento com pacientes neurológicos não é repetir o protocolo um número fixo de vezes, mas observar a reação do paciente e adaptar o número de repetições à resposta do mesmo. O paciente CA 
respondeu mais rapidamente ao protocolo FNP que o paciente AN. A fisioterapeuta insistiu com os pacientes que eles devem acompanhar com o olhar todo o exercício FNP para aumentar a amplitude do movimento. Observou-se que quando o paciente AN acompanhava com o olhar o movimento sendo executado, o seu braço "abria" mais.

Na primeira sessão com a paciente MA foi feito um monitoramento do sinal EMG no músculo agonista deltóide médio e no músculo antagonista grande dorsal. O ganho utilizado nos testes foi de 2000. A Figura 5.20 mostra os sinais EMG capturados nos dois músculos após a aplicação de um filtro passa-alta de $20 \mathrm{~Hz}$. O gráfico superior representa o músculo deltóide médio e o gráfico inferior o grande dorsal (antagonista). Primeiramente a paciente estava em repouso, depois ela executou a abdução, flexão e abdução de ombro seguida de flexão horizontal para dentro.

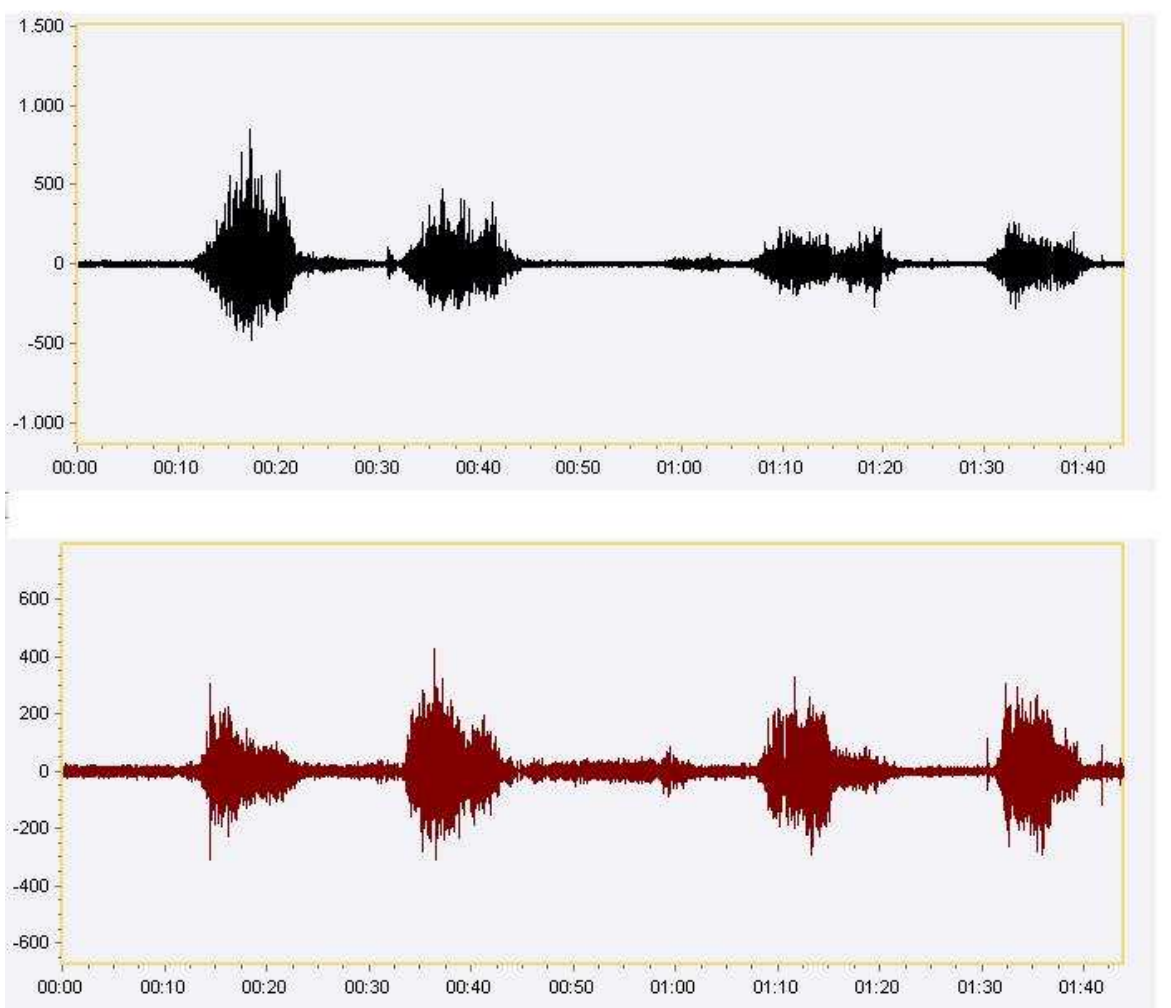

Figura 5.20 - Captura do EMG do deltóide e do grande dorsal no membro direito comprometido.

Após a aquisição dos sinais bioelétricos, a paciente MA utilizou o sistema NeuroR para realizar os movimentos de abdução, flexão e adução, nesta ordem. A Figura 5.21 mostra MA realizando a abdução de ombro. Na primeira execução da abdução com o NeuroR a paciente não acompanhou fisicamente o movimento do braço 
virtual, entretanto, nos demais exercícios, a paciente "acompanhou" o braço virtual com o braço plégico. Na repetição da abdução no final da intervenção, ela também tentou executar fisicamente o movimento.
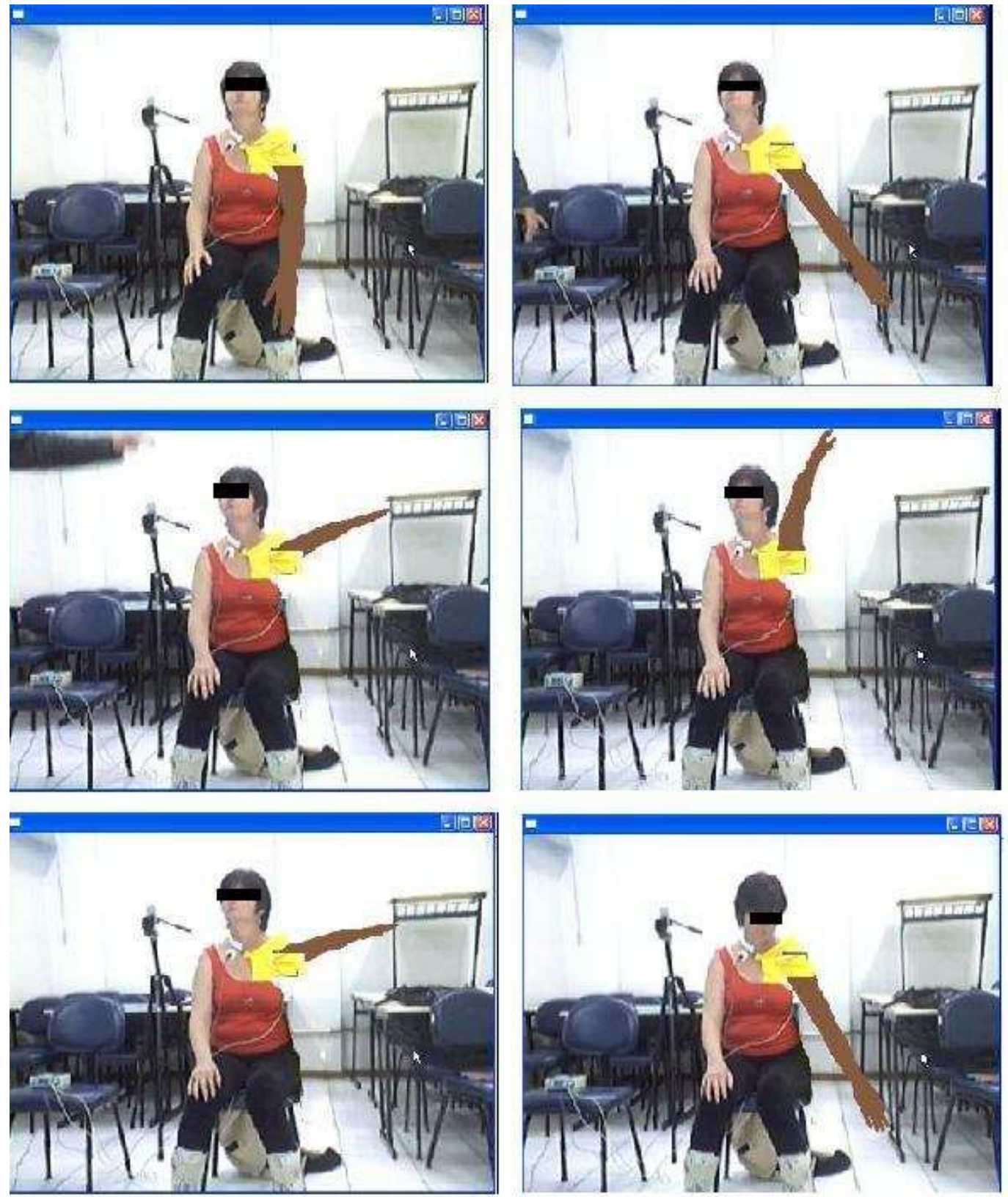

Figura 5.21 - Abdução com o NeuroR.

Na primeira sessão com o paciente JO observou-se que, durante a intervenção, o paciente não parecia ter identificado o braço 3D como sendo seu. Acredita-se que ele executou o movimento porque o Fisioterapeuta 2 solicitou que ele fizesse isso, mas sem relacionar o braço 3D como sendo o seu próprio braço físico. Trata-se de um paciente que sofreu um AVE há 42 meses, ocasionando hipodensidades no tálamo e nos núcleos de base, além de rarefação da substância branca 
periventricular causada por microangiopatia, como descrito no laudo da tomografia computadorizada de crânio. Verificou-se que, durante a intervenção o paciente não olhava fixamente para a tela, ele desviava o olhar para o próprio membro que estava realizando a ação motora. O paciente JO também tem dificuldades de visão. Ocorreram muitos problemas de registro com JO, como pode ser visto na abdução de ombro, na Figura 5.22.

Ao final da intervenção, o Fisioterapeuta 2 aplicou o protocolo FNP no paciente. Primeiramente, o fisioterapeuta executou a modulação do tônus do paciente. $O$ paciente reclamou de dor no cotovelo durante a estimulação FNP.
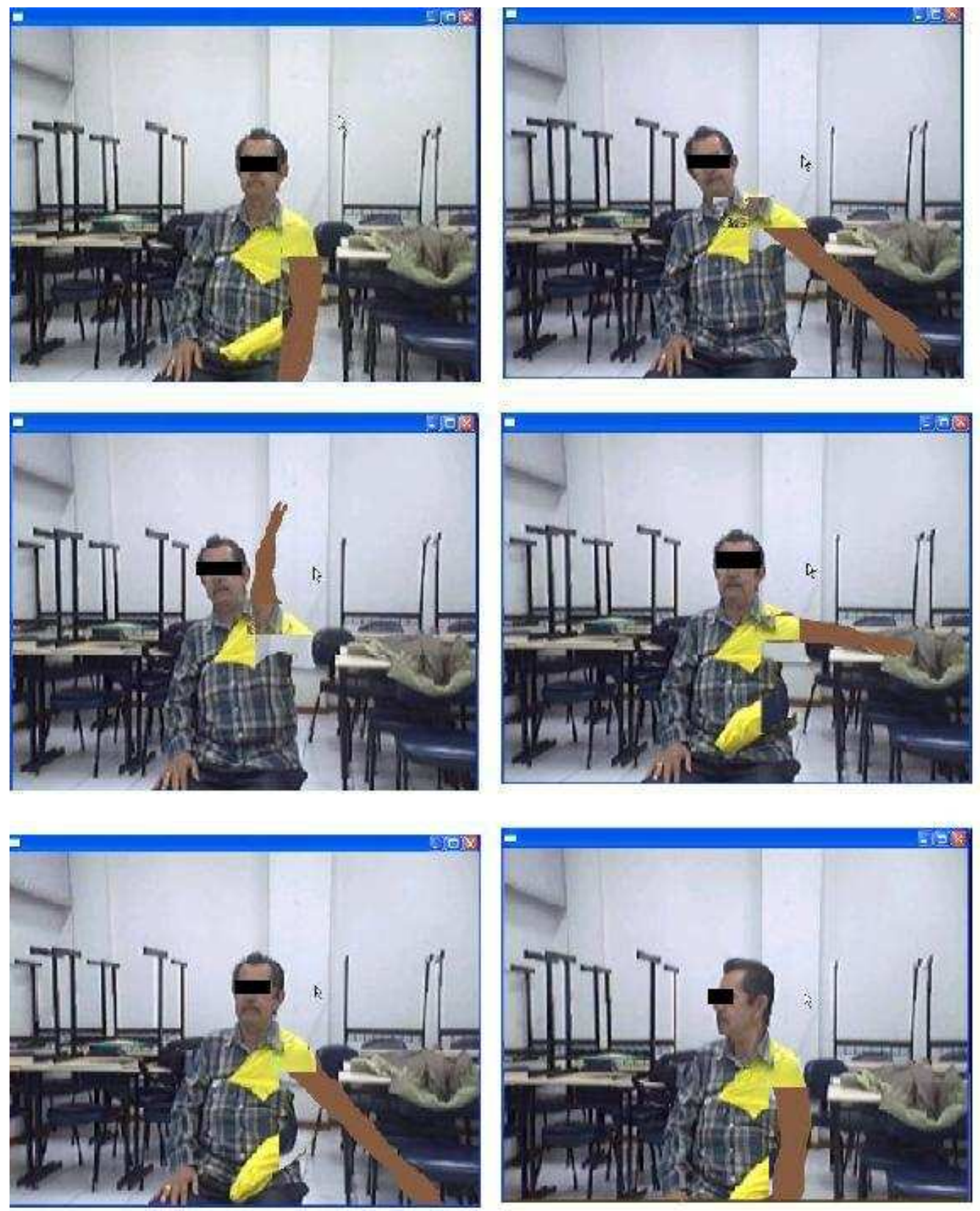

Figura 5.22 - Abdução com o NeuroR. 


\section{Segunda Sessão}

$\mathrm{Na}$ segunda sessão com os pacientes AN e CA observou-se que eles estavam bastante motivados para as atividades com o braço virtual.

Para esta sessão foram feitos ajustes no sistema NeuroR. Foi feito um chromakey para "tornar transparente" o braço real (luva) mesmo acima dos limites do marcador e não apenas abaixo do marcador, como implementado anteriormente. Assim, no caso do braço esquerdo, o chromakey que substitui os pixels classificados como luva pela imagem de fundo foi executado da margem esquerda da imagem até a borda direita do marcador, da base até o topo da janela. No caso de hemiplegia direita, o chromakey que substitui os pixels classificados como luva pela imagem de fundo capturada sem o paciente foi executado da borda direita do marcador até a margem direita da janela, percorrendo os pixels da base até o topo da janela. Outro ajuste feito no algoritmo foi a captura da imagem do paciente quadro a quadro, evitando assim falhas na costura da imagem atual e a imagem utilizada na substituição dos pixels da "manga" do braço 3D, utilizada para o correto registro na região do ombro. A Figura 5.23 mostra o início da execução para o paciente CA.

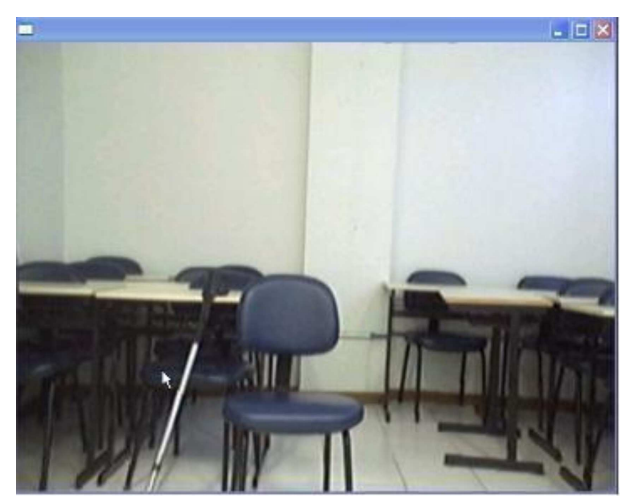

(a) Imagem de fundo

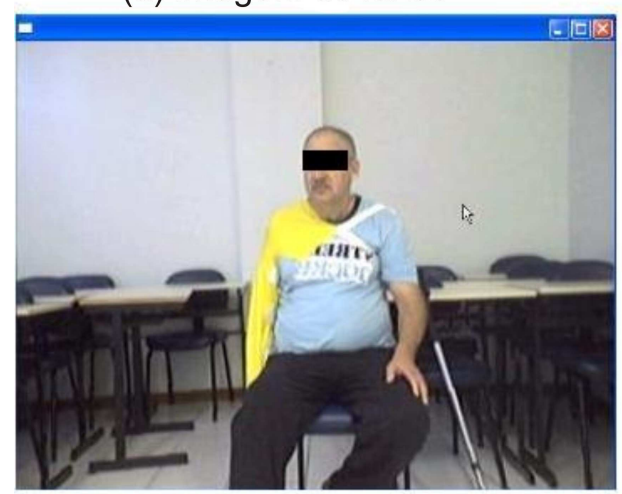

(c ) Imagem espelhada

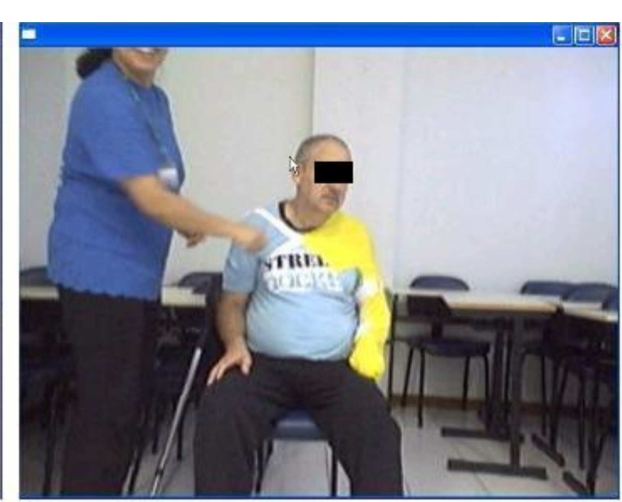

(b) Paciente CA vestindo a luva

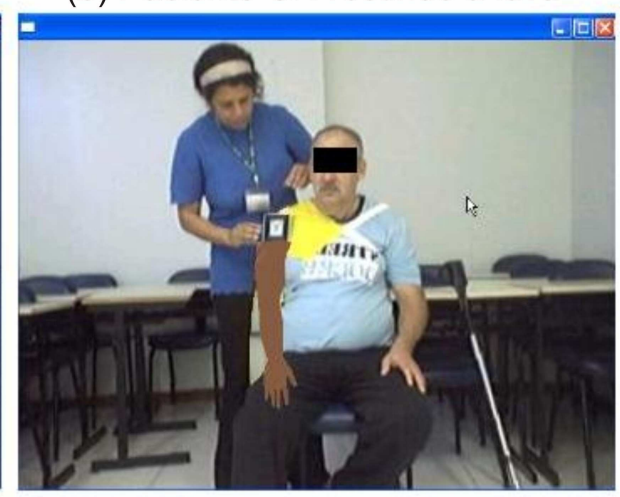

(d) Posicionamento do marcador e desenho do braço virtual

Figura 5.23 - Inicialização do NeuroR 
A Figura 5.24 mostra o paciente CA executando a abdução de ombro.

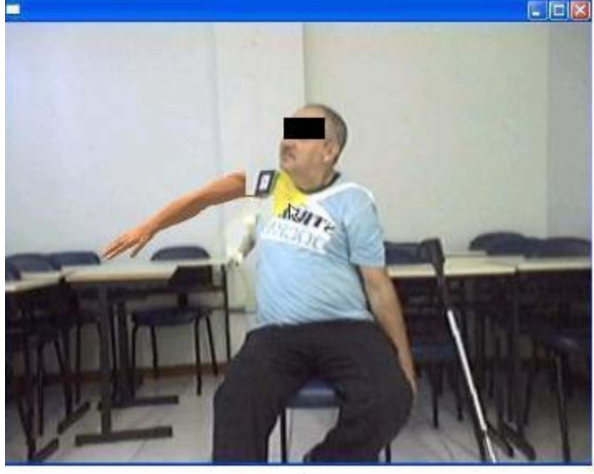

(a) Início dà abdução

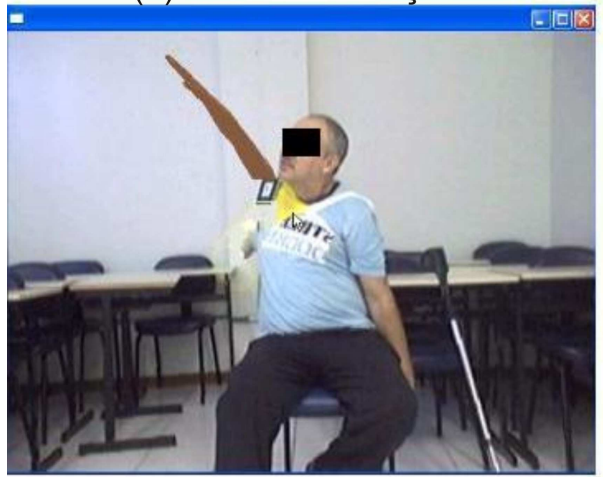

(c ) Abdução na subida

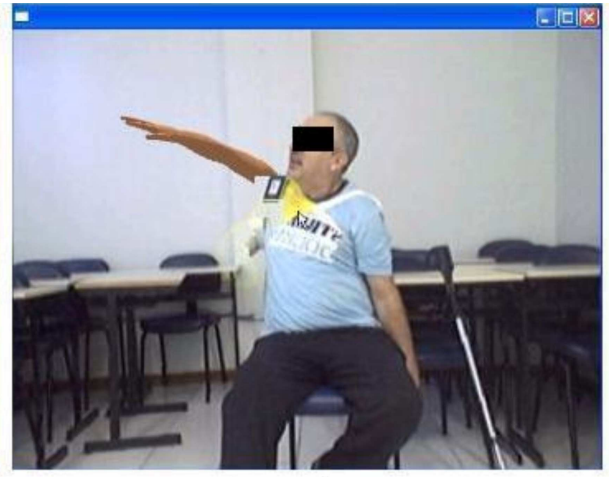

(b) Abdução nà subida

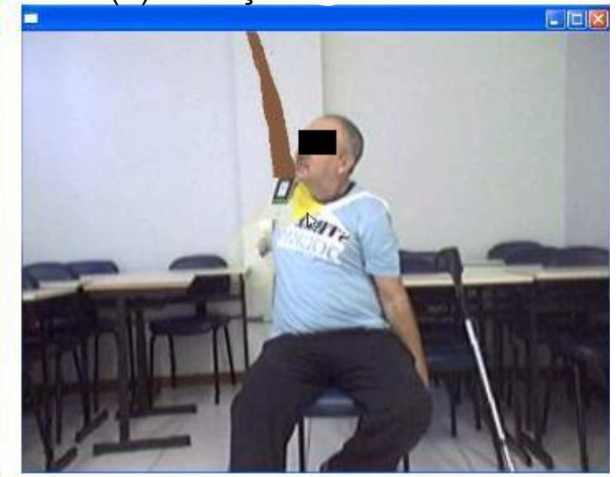

(d) Final da abdução na subida

Figura 5.24 - Paciente CA utiliza abdução no NeuroR

A Figura 5.25 mostra o paciente CA executando a flexão de ombro. 


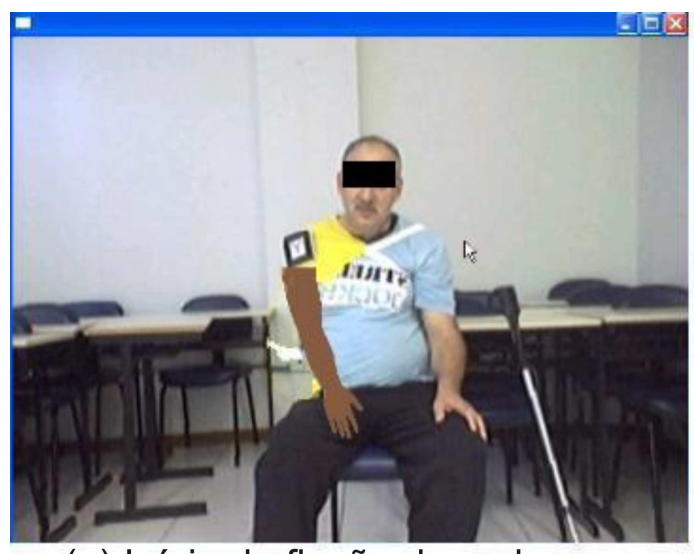

(a) Início da flexão de ombro

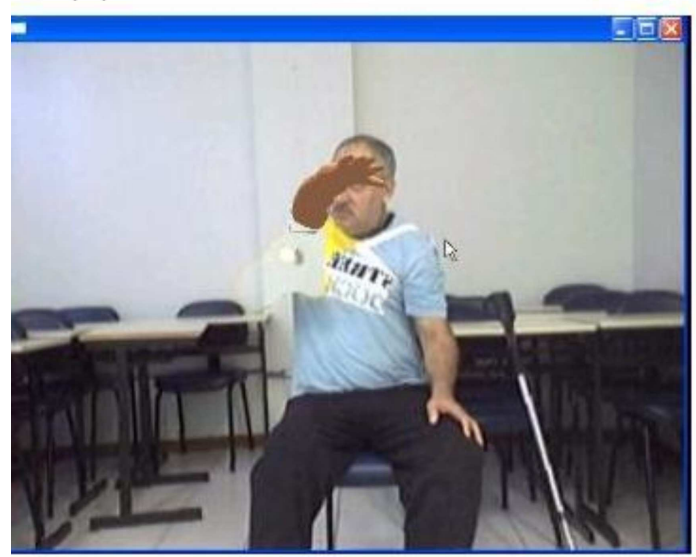

(c ) Flexão de ombro na subida

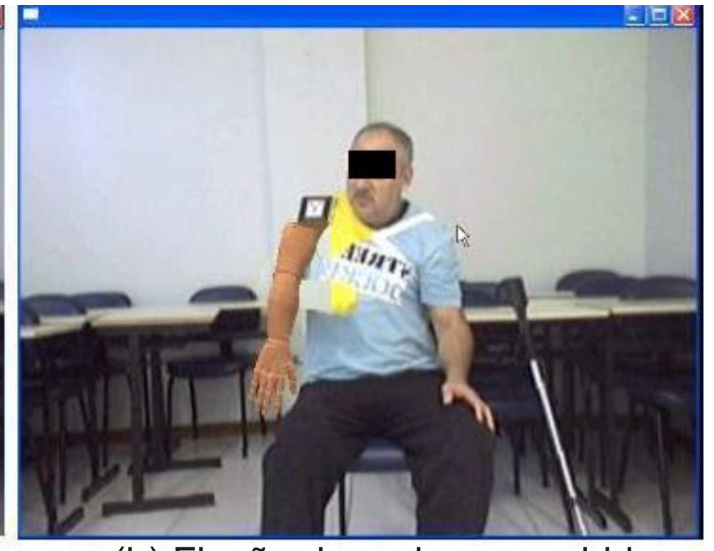

(b) Flexão de ombro na subida

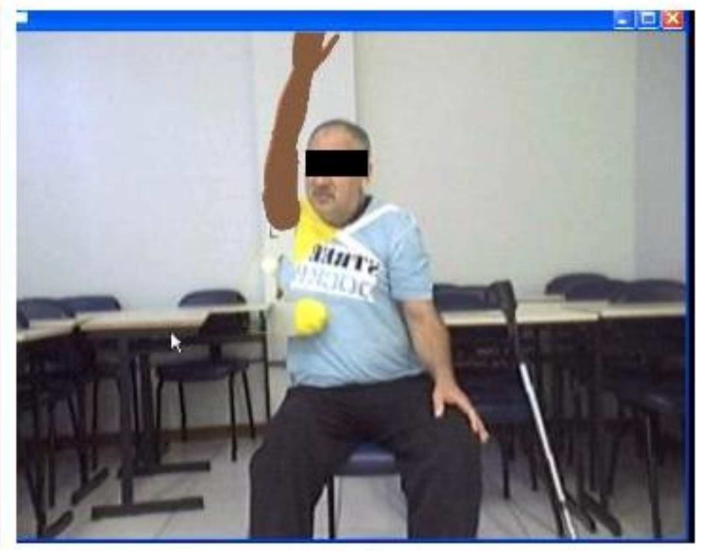

(d) Final da flexão de ombro na subida

Figura 5.25 - Flexão de ombro com Neuror

A Figura 5.26 mostra o paciente CA executando o movimento de adução, que corresponde a uma flexão horizontal de ombro com o ombro flexionado a 90 graus. 


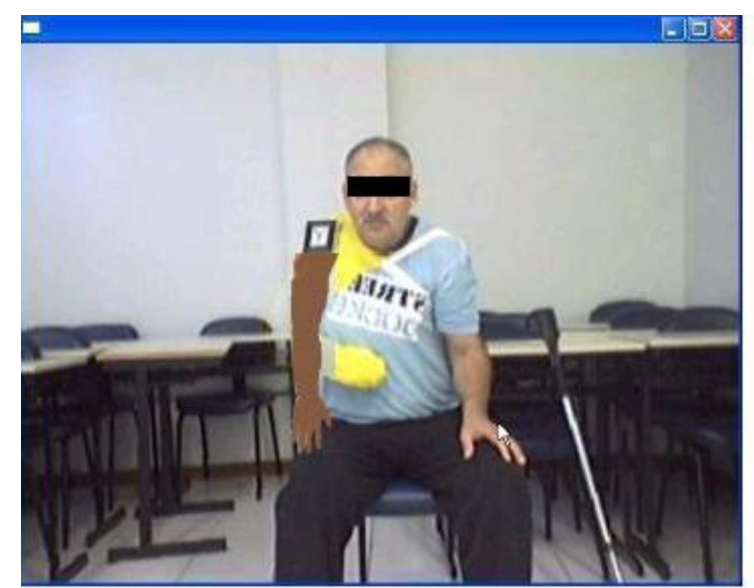

(a) Início do movimento

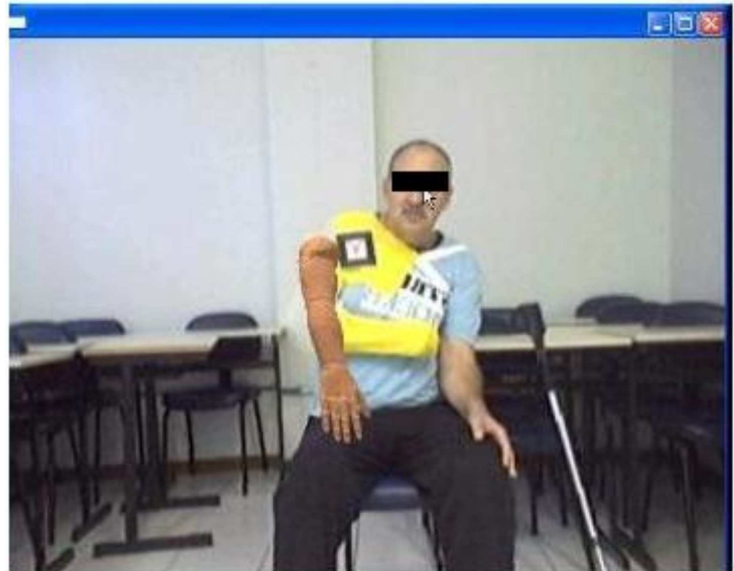

(c ) Falha de registro

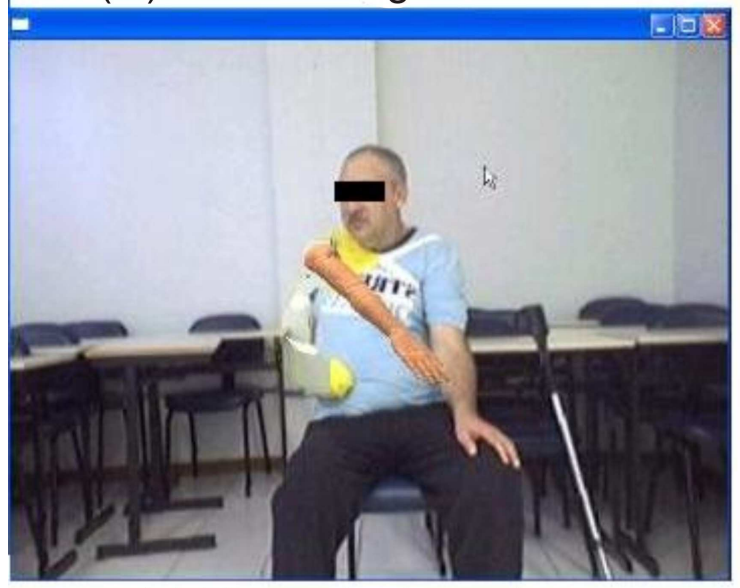

(e) Flexão horizontal

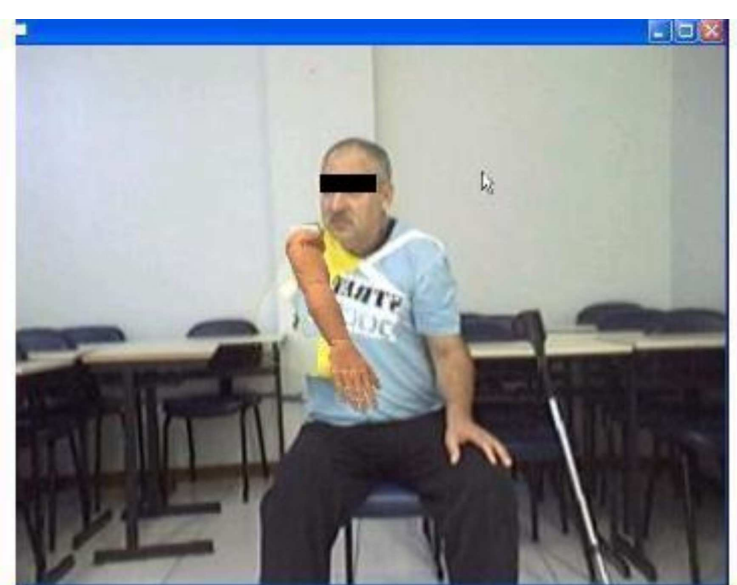

(b) Flexão na subida

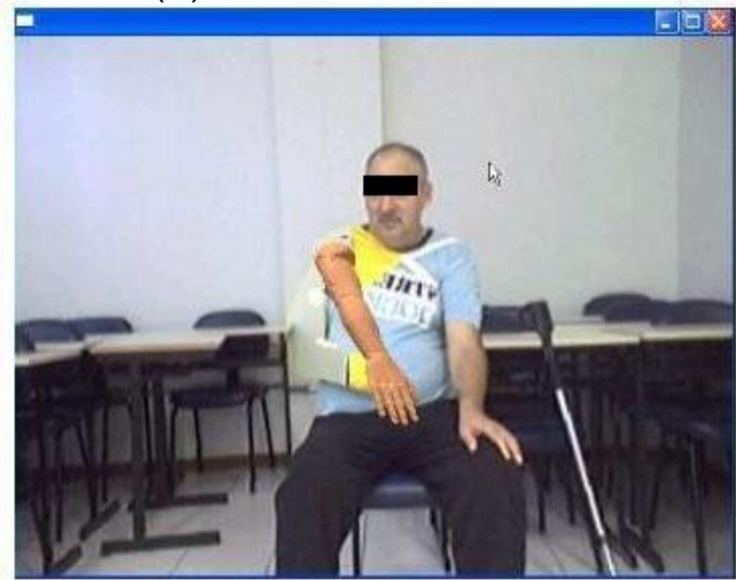

(d) Flexão horizontal

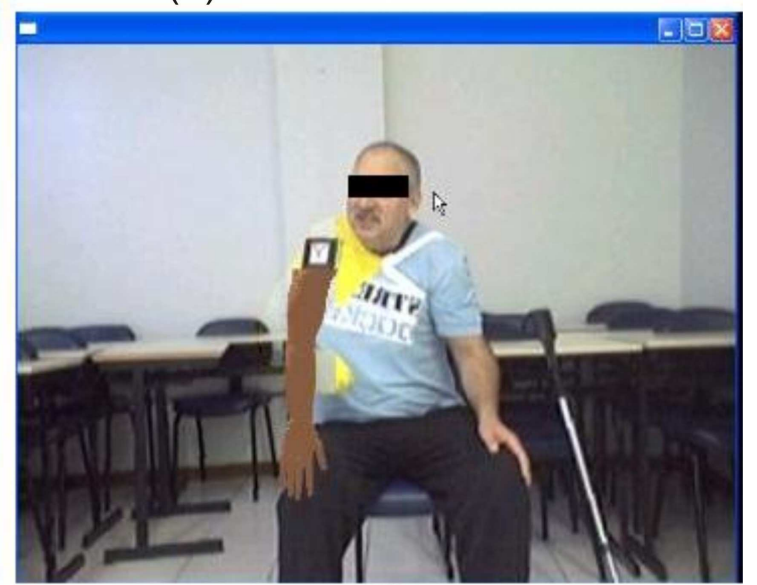

(f) Final do movimento

Figura 5.26 - Paciente CA utiliza adução no NeuroR

$\mathrm{Na}$ segunda sessão com o paciente JO, ele fixou o olhar na tela durante a simulação, diferente da primeira sessão. Ele executou fisicamente todos os exercícios durante a prática mental com o NeuroR. No exercício de adução houve falha de sincronismo, pois o paciente finalizou o movimento antes do braço virtual.

Na segunda sessão com a paciente MA, a Fisioterapeuta 1 orientou a paciente a olhar para o seu próprio braço durante a simulação, o que ocasionou muitos 
problemas de registro e de falta de sincronismo entre o movimento real e o movimento do braço 3D, como mostra a Figura 5.27.
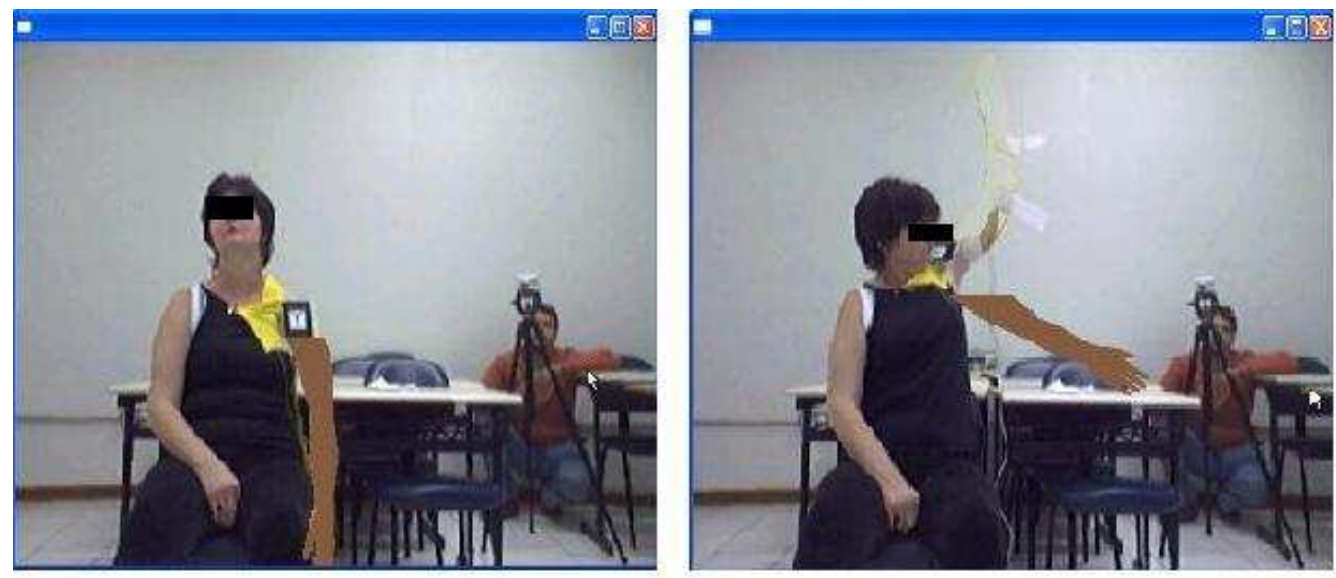

Figura 5.27 - Falha de sincronismo na abdução com o NeuroR

\section{Terceira e Quarta Sessões}

Nas terceira e quarta sessões, evidenciaram-se os problemas ocasionados pela necessidade de, a cada nova execução do programa, capturar novamente a imagem de fundo sem o paciente. Os pacientes CA e JO que têm dificuldades de locomoção e utilizam bengala de apoio, precisavam de apoio para levantar da cadeira e sair da frente da câmera para permitir a obtenção da imagem de fundo. Uma mudança na captura e armazenamento da imagem de fundo foi desencadeada a partir desta constatação.

Foram aplicadas quatro sessões com cada um dos quatro pacientes do GE. Ao final da última sessão, a paciente MA relatou de forma espontânea que havia conseguido erguer o braço o suficiente para estender roupa no varal e que a imagem do braço virtual não saia da cabeça dela.

\subsubsection{Teste com pacientes fora dos Grupos Experimental}

Foi realizando um teste utilizando o sistema NeuroR com a paciente FA que não satisfaz os critérios de inclusão no GE, pois ela já recuperou parte considerável dos movimentos no membro afetado com a fisioterapia convencional. Entretanto, ela manifestou interesse em participar dos testes. A paciente FA sofreu um AVE há 42 
meses, que afetou o lado esquerdo do seu corpo. Ela apresenta ADM satisfatória no braço comprometido e obteve 52 pontos na escala Fugl-Meyer para membro superior, sendo que a única nota zero foi na tarefa de preensão em pinça (segurar uma caneta). Na avaliação do tônus muscular com a escala de Ashworth, FA foi considerada como grau 1, isto é, leve aumento. Ainda que a paciente não faça parte da amostra, este teste foi útil para avaliar a usabilidade do NeuroR com pacientes que sofreram AVE e que já recuperam parte das funções motoras.

Primeiramente foi feito um monitoramento do sinal EMG no músculo deltóide médio da paciente FA durante a execução dos três movimentos que são utilizados no sistema NeuroR: abdução de ombro 0 a 180 graus, flexão de ombro de 0 a 180 graus e flexão de ombro de 0 a 90 graus seguida de rotação/flexão horizontal de 0 a 40 graus (Figura 5.28).

Após a aquisição do sinal EMG, a paciente FA executou os exercícios de abdução, flexão e adução utilizando o NeuroR. 


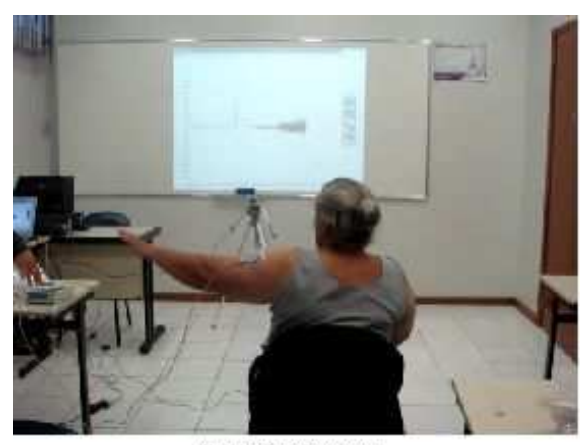

Abdução 90 graus

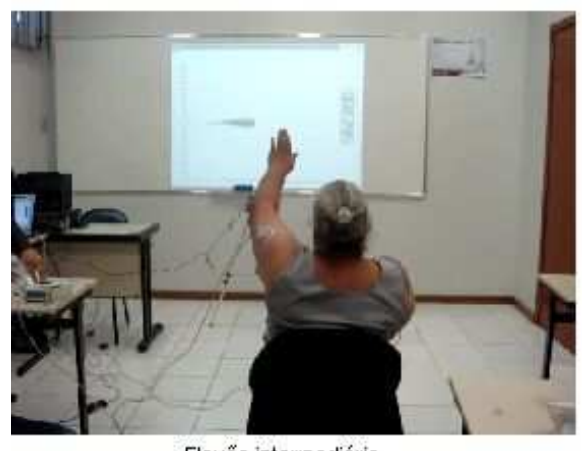

Flexẫo intermediária

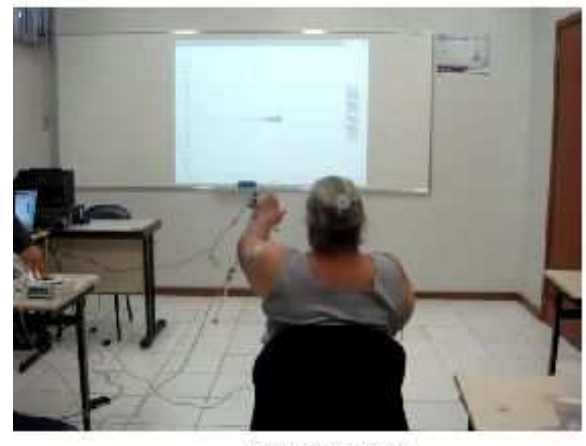

Flexão 90 graus

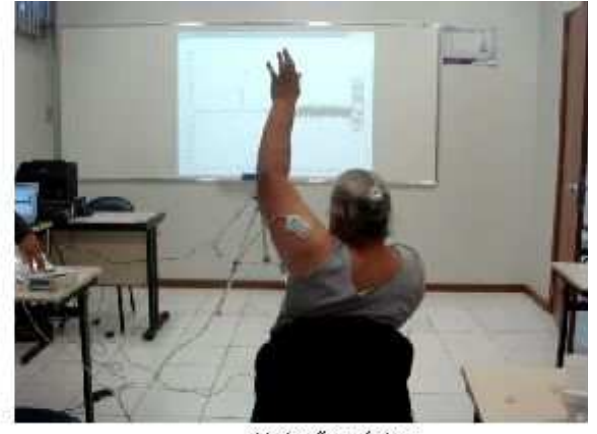

A.bduçã̃o máxima

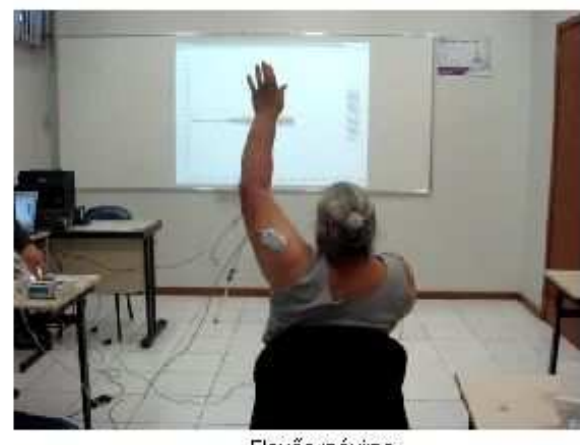

Flexấo máxima

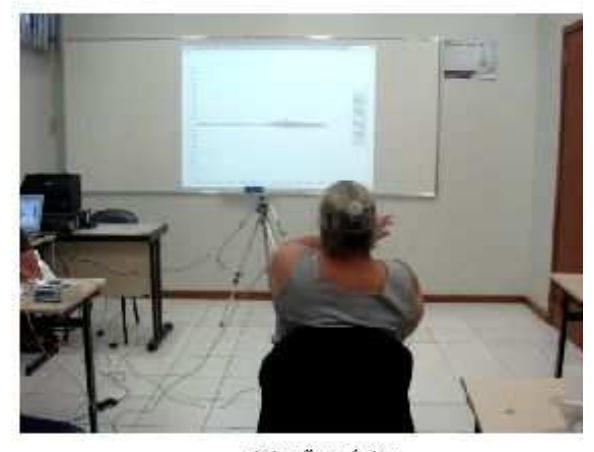

Aduçẫo máxima

Figura 5.28 - EMG do deltóide no membro esquerdo comprometido

Observou-se que a paciente não conseguiu realizar a rotação horizontal de 0 a 40 graus com o cotovelo a zero graus, como solicitado. Ela flexionou o cotovelo durante a rotação horizontal em todas as execuções.

Também evidenciou-se uma diferença na velocidade do movimento físico realizado por FA e o movimento do braço virtual, que estava "mais lento" que o braço real. As amplitudes dos movimentos real e virtual, por sua vez, foram similares.

O paciente CA falou sobre a experiência com o braço virtual para outro paciente da clínica, AL. O paciente AL tem 34 anos e sofreu traumatismo crânio encefálico após um acidente de trânsito há 36 meses. Ele apresenta padrão hemiparético à direita. $O$ paciente $A L$ compareceu à sessão e pediu para participar dos testes com o sistema NeuroR. Ainda que AL não satisfaça o critério de inclusão da doença neurológica, 
permitiu-se que ele utilizasse o sistema como uma forma de análise da viabilidade da aplicação do sistema NeuroR a outras patologias neurológicas, não apenas a AVE. A Figura 5.29 mostra o paciente AL executando a abdução de ombro.

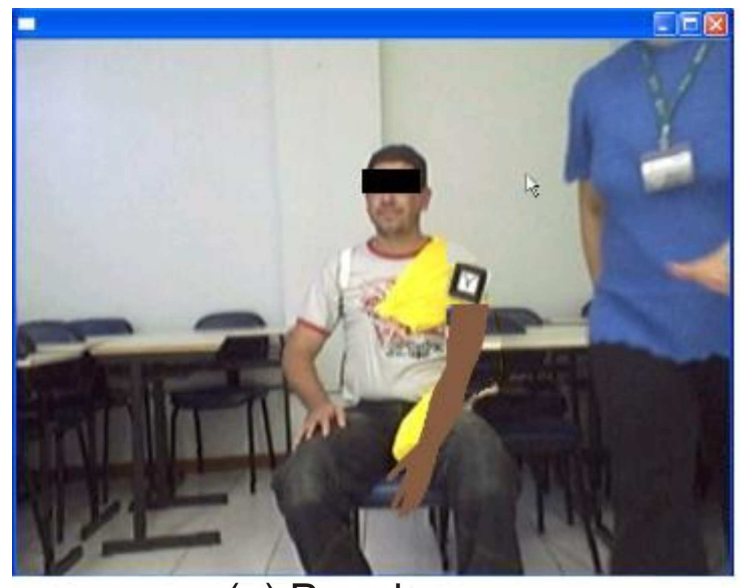

(a) Parado

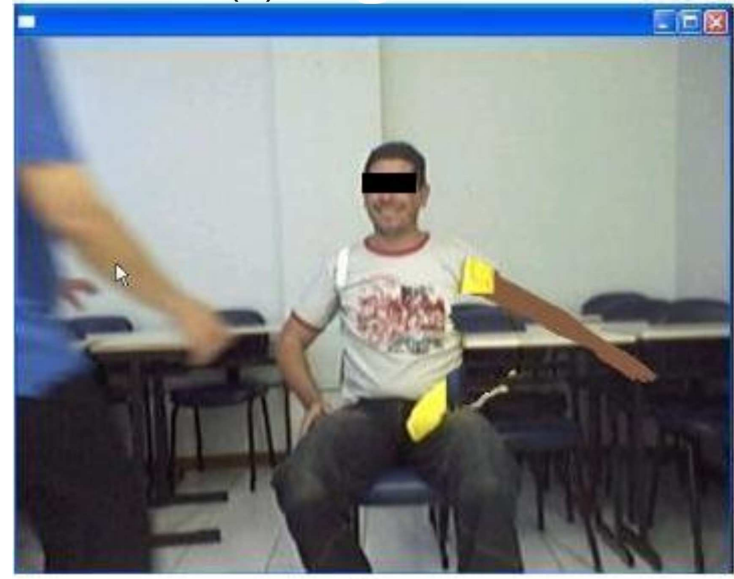

(c ) Abdução na subida

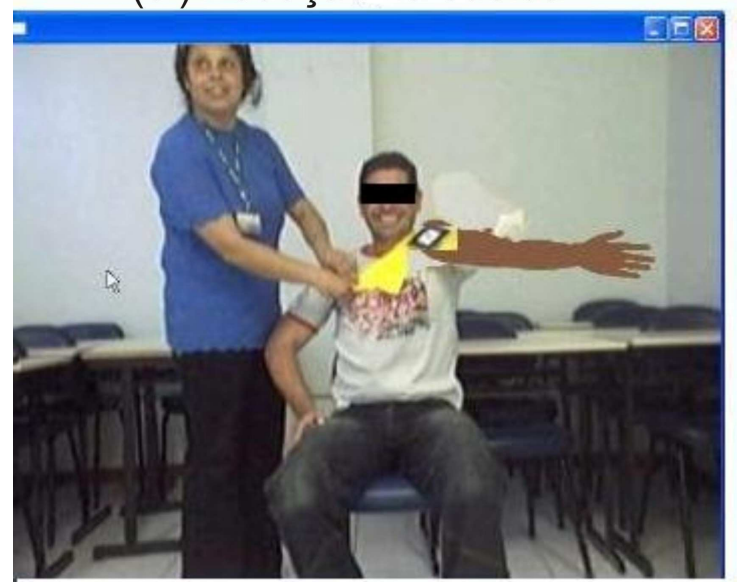

(e) Abdução na descida

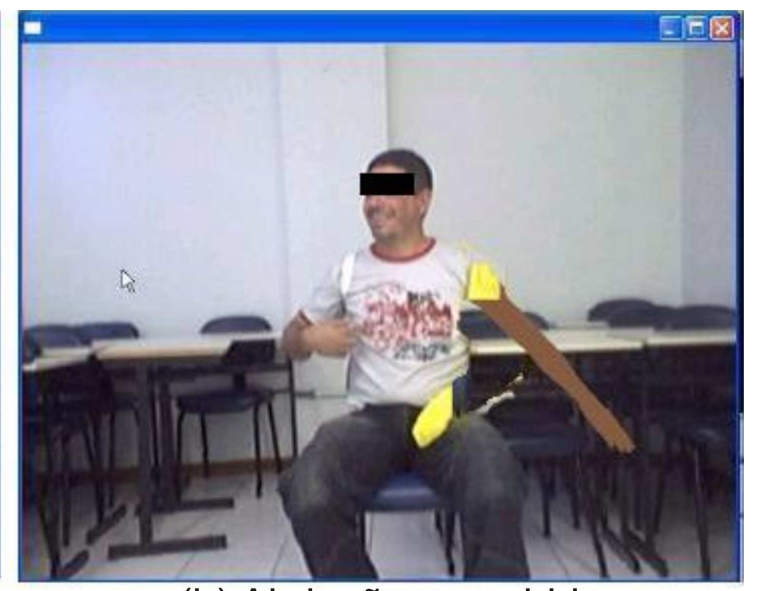

(b) Abdução na subida

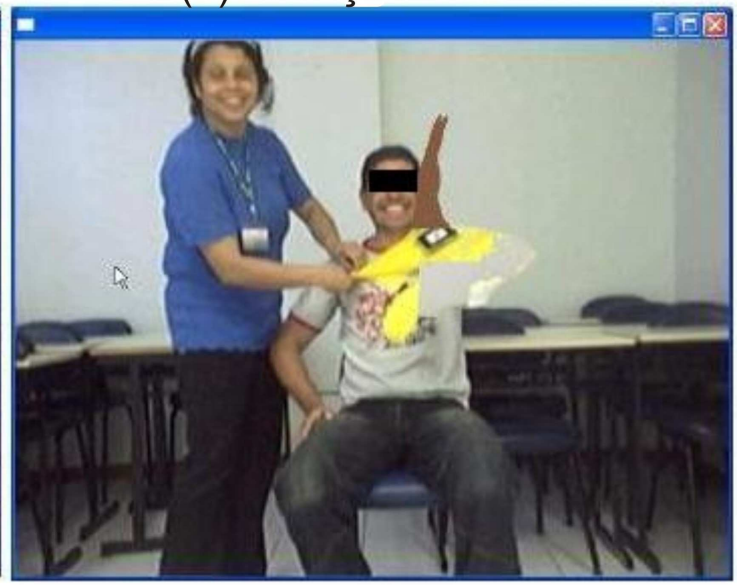

(d) Abdução máxima

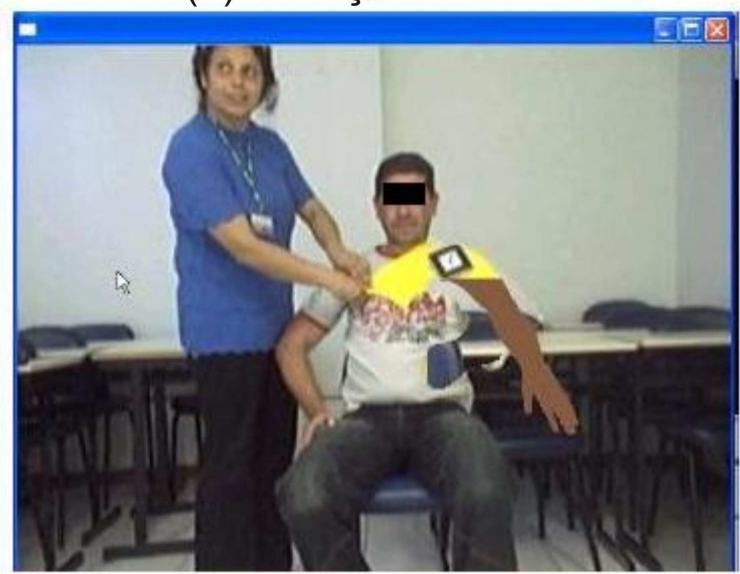

(f) Abdução na descida

Figura 5.29 - Paciente utiliza o NeuroR 


\subsubsection{Avaliação Pós-teste}

Após as quatro sessões semanais, foi realizado o pós-teste (Tabela 5.7).

Tabela 5.7 - Testes de desempenho motor do GE depois do uso do NeuroR

\begin{tabular}{|c|c|c|c|c|}
\hline \multicolumn{4}{|l|}{ Itens Motores da Escala Fugl-Meyer para Membro Superior } & $\mathrm{CA}$ \\
\hline \multicolumn{5}{|l|}{ I. Atividade Reflexa: } \\
\hline 1. Bíceps & 2 & 1 & 1 & 1 \\
\hline 2. Tríceps & 2 & 1 & 1 & 1 \\
\hline \multicolumn{5}{|l|}{ II. Sinergia Flexora: } \\
\hline 3. Retração do Ombro & 1 & 1 & 2 & 1 \\
\hline 4. Elevação do Ombro & 1 & 1 & 1 & 0 \\
\hline 5. Abdução do Ombro & 1 & 1 & 2 & 1 \\
\hline 6. Rotação Externa de Ombro & 1 & 0 & 2 & 0 \\
\hline 7. Flexão de Cotovelo & 1 & 2 & 2 & 0 \\
\hline 8. Supinação de Antebraço & 1 & 0 & 2 & 0 \\
\hline \multicolumn{5}{|l|}{ III.Sinergia Extensora: } \\
\hline 9. Abdução de Ombro com Rotação Interna & 1 & 0 & 1 & 0 \\
\hline 10. Extensão de Cotovelo & 1 & 2 & 2 & 0 \\
\hline 11. Pronação de Antebraço & 1 & 1 & 1 & 0 \\
\hline \multicolumn{5}{|l|}{ IV. Movimentos Combinando Sinergias: } \\
\hline 12. Mão na Coluna Lombar & 1 & 0 & 0 & 0 \\
\hline 13. Flexão de Ombro de 0 ํ a $90^{\circ}$ & 1 & 1 & 2 & 1 \\
\hline 14. Cotovelo a $90^{\circ}$. Realizar Pronação-Supinação & 1 & 0 & 2 & 0 \\
\hline \multicolumn{5}{|l|}{ V. Movimentos Não-Sinérgicos: } \\
\hline 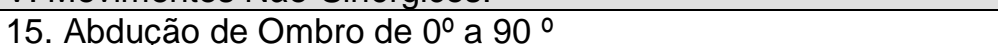 & 1 & 1 & 2 & 1 \\
\hline 16. Flexão de Ombro de $90^{\circ}$ a $180^{\circ}$ & 0 & 0 & 2 & 0 \\
\hline 17. Cotovelo a $0^{\circ}$, Realizar Pronação-Supinação & 1 & 0 & 2 & 0 \\
\hline VI. Atividade Reflexa: & & & 0 & \\
\hline 18. Atividade Reflexa Normal de Bíceps e Tríceps & 2 & 1 & 1 & 1 \\
\hline \multicolumn{5}{|l|}{ VII. Punho: } \\
\hline 19. Cotovelo a $90^{\circ}$, Estabilização de Punho & 1 & 1 & 1 & 1 \\
\hline 20. Cotovelo a $90^{\circ}$, Completa extensão-Flexão de Punho & 1 & 0 & 0 & 0 \\
\hline 21. Cotovelo a $0^{\circ}$, Estabilização de Punho & 2 & 2 & 2 & 2 \\
\hline 22. Cotovelo a 0으, Completa extensão-Flexão de Punho & 1 & 0 & 1 & 0 \\
\hline 23. Circunducão & 0 & 0 & 0 & 0 \\
\hline \multicolumn{5}{|l|}{ VIII.Mão: } \\
\hline 24. Flexão em Massa dos Dedos & 2 & 2 & 2 & 1 \\
\hline 25. Extensão em Massa & 2 & 0 & 0 & 0 \\
\hline $\begin{array}{l}\text { 26. Preensão a: Segurar folha de papel com primeiro e segundo } \\
\text { (superfície radial) dedos, contra um puxão }\end{array}$ & 2 & 1 & 2 & 1 \\
\hline $\begin{array}{l}\text { 27. Preensão b: Preensão com flexão de interfalangiana com } \\
\text { metacarpofalangiana em posição neutra, contra leve puxão }\end{array}$ & 1 & 0 & 1 & 0 \\
\hline 28. Preensão c: Segurar uma caneta (preensão em pinça) & 1 & 1 & 1 & 0 \\
\hline 29. Preensão d: Segurar um cilindro (preensão cilíndrica) & 2 & 0 & 1 & 0 \\
\hline 30. Preensão e: Segurar uma bola contra um leve puxão & 1 & 0 & 1 & 0 \\
\hline \multicolumn{5}{|l|}{ XI. Coordenação/Velocidade: } \\
\hline 31. Tremor & 1 & 2 & 1 & 0 \\
\hline 32. Dismetria & 2 & 2 & 1 & 1 \\
\hline 33. Velocidade & 2 & 2 & 2 & 1 \\
\hline Total & 41 & 26 & 44 & 14 \\
\hline
\end{tabular}


Como não foi possível que o mesmo fisioterapeuta aplicasse o instrumento no préteste e no pós-teste, foi necessário fazer uma análise dos vídeos para confrontar as avaliações dos fisioterapeutas, como forma de garantir que os critérios de decisão foram os mesmos no pré e pós-teste. Esta análise foi feita pelo Fisioterapeuta 1.

\subsection{DISCUSSÃO DOS RESULTADOS}

\subsubsection{Testes com Pacientes}

O projeto piloto apresentou resultados interessantes quanto ao comportamento do paciente durante a prática mental. Ao ser solicitado a imaginar o movimento visualizando o braço 3D na tela, o paciente se esforçou para executar o movimento fisicamente, o que sugere que ele associou o braço virtual com o seu próprio braço.

No estudo principal, os pacientes CA e AN também apresentaram o mesmo comportamento que o paciente $\mathrm{SH}$ no estudo piloto. Os pacientes CA e AN que sofreram o AVE há algum tempo, cerca de 4 e 6 anos, respectivamente. Como foi dito, um dos pacientes comentou surpreso que havia muito tempo que seu braço não subia assim. Também convém ressaltar que não havia vínculo anterior entre os fisioterapeutas e os pacientes, ou seja, eles não atenderam os pacientes anteriormente na fisioterapia convencional, e, portanto a confiança anterior dos pacientes no profissional não influenciou nos resultados motivacionais de uso do sistema. A motivação do paciente CA foi visível inclusive pelos comentários que fez com o paciente $\mathrm{AL}$, incentivando-o a participar dos testes voluntariamente.

Na comparação entre os resultados totais do instrumento UE-FMA aplicado no préteste e pós-teste, tabelas 5.5 e 5.7, verificou-se um aumento da pontuação total para todos os quatro pacientes do GE. O paciente AN passou de 16 para 26 pontos, um aumento relativo de $62.50 \%$; CA de 9 pontos para 14 pontos, aumento relativo de 
55.55\%; MA de 31 para 44 pontos, um aumento em relação ao original de $41.93 \%$ e JO de 35 para 41 pontos, um aumento relativo de $17.14 \%$. Os gráficos da Figura 5.30 sumarizam os resultados do pré e pós-teste para as 33 tarefas.
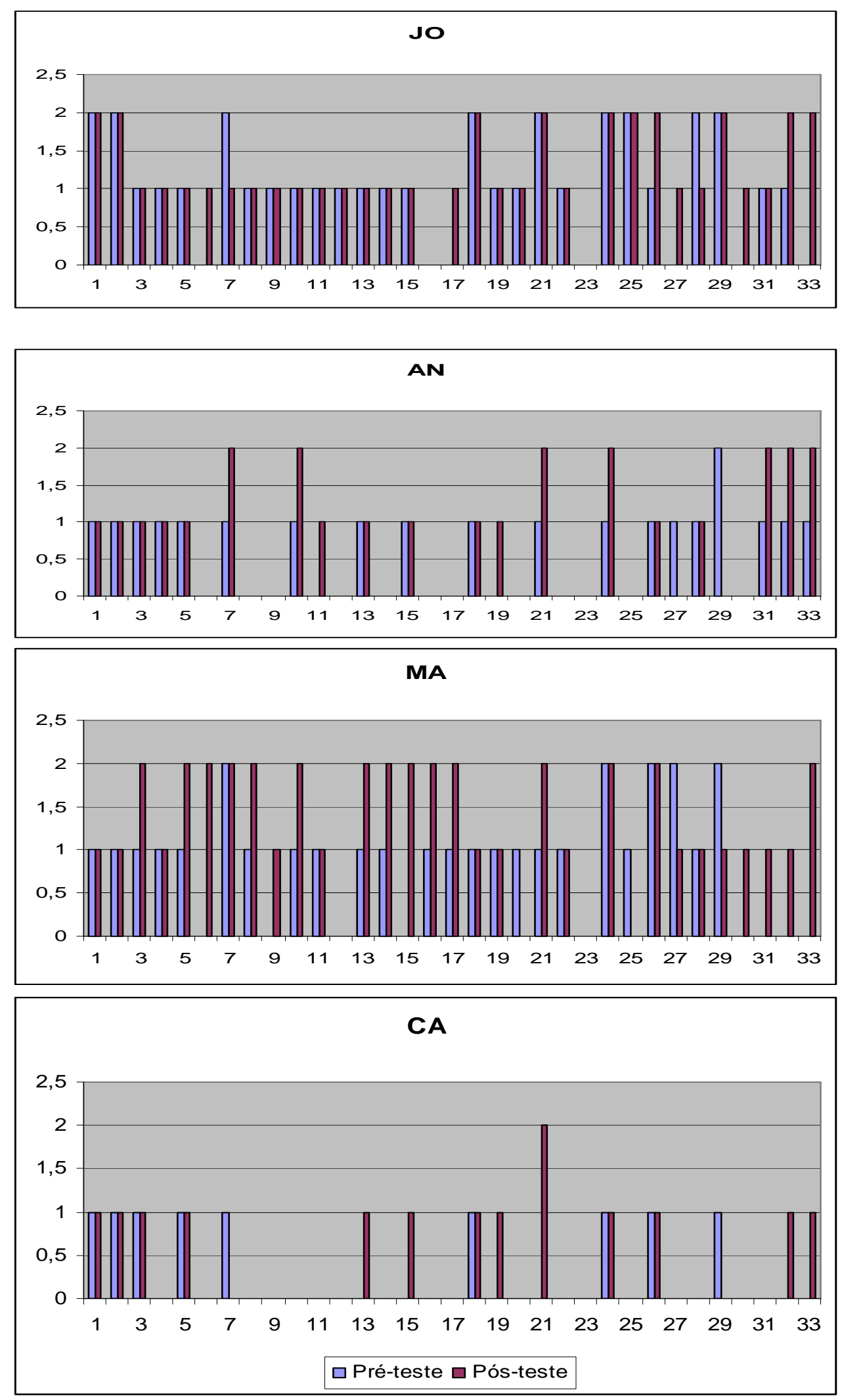

Figura 5.30 - Gráficos pré e pós-teste 
A aplicação do teste $t$ de Student para dados pareados nos pacientes do GE (antes e depois) resultou em um valor $p=0,01933$. Considerando um nível de significância de $\alpha=0.01$, tem-se que $p>\alpha$ e com isso se aceita a hipótese de que os dados não diferem significativamente. Entretanto, se o nível de significância for $\alpha=0.05$, a hipótese e rejeitada e considera-se que os dados diferem significativamente.

O paciente CA teve aumento nas seguintes tarefas executadas: flexão de ombro de 0 a 90 graus; abdução de ombro de 0 a 90 graus e estabilização de punho com cotovelo a 90 graus. Na tarefa de preensão cilíndrica, por outro lado, houve uma diminuição de 1 para 0 . Entretanto, ao analisar os vídeos, observou-se que os cilindros utilizados no pré e pós-teste tinham diâmetros diferentes. Essa diferença na tarefa evidenciou uma falha metodológica no processo, uma vez que os materiais deveriam ser os mesmos.

As Figuras 5.31, 5.32 e 5.33 são meramente ilustrativas. Elas mostram algumas tarefas realizadas pelos pacientes com o membro não comprometido e com o membro afetado antes e depois do período de testes.

A Figura 5.31 mostra a execução da tarefa abdução de ombro de 0 a 90 graus para o paciente CA no pré-teste e no pós-teste. 


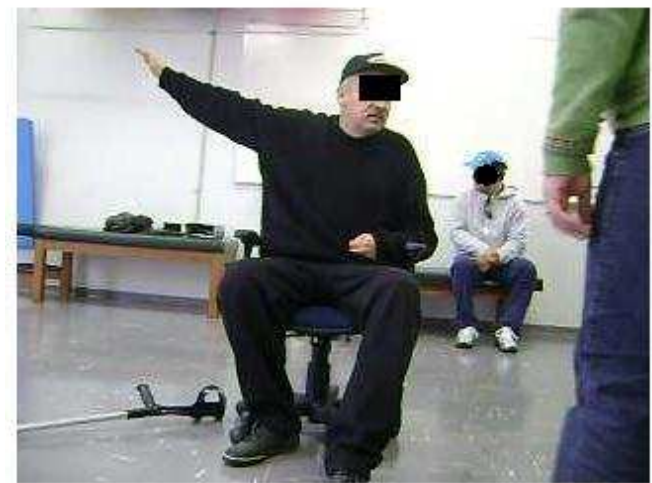

Pré-teste: abdução 0-90 braço bom

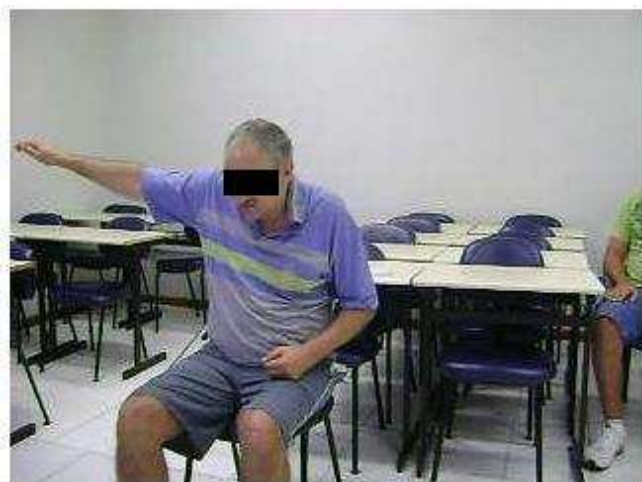

Pós-teste: abduçấo 0-90 braço bom

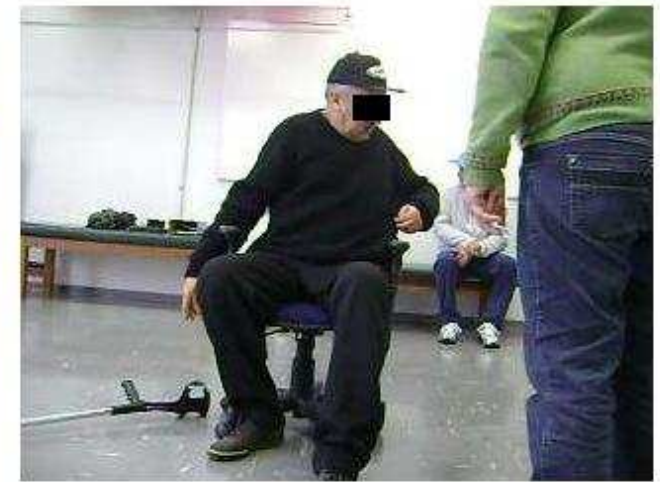

Pré-teste: abdução 0-90 braço lesado

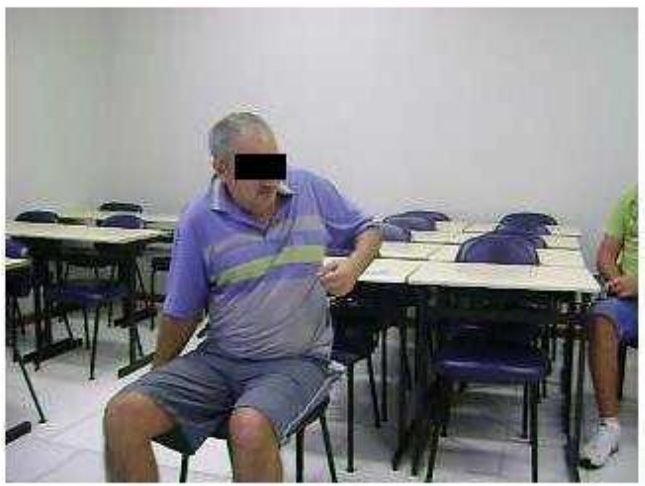

Pós-teste: abdução 0-90 braço lesado

Figura 5.31 - Paciente CA faz abdução de ombro de 0 a 90 graus

Outro aspecto a destacar é a mudança de atitude do paciente $C A$, que no pré-teste nem sequer tentava executar algumas das tarefas solicitadas, afirmando de antemão que não era capaz. No pós-teste, entretanto, ele tentou executar todos os movimentos prontamente e não disse que era incapaz de realizar a tarefa.

O paciente AN teve um aumento nas seguintes tarefas: flexão de cotovelo; extensão de cotovelo; pronação de antebraço; estabilização de punho com o cotovelo a 90 graus; estabilização de punho com o cotovelo a 0 graus; flexão em massa dos dedos; tremor; dismetria e velocidade. Entretanto, ele teve uma redução na tarefa preensão cilindrica. Novamente, houve diminuição na tarefa de preensão cilíndrica com os cilindros utilizados de diâmetros diferentes. A Figura 5.32 mostra o paciente AN executando a tarefa de abdução de ombro de 0 a 90 graus. 


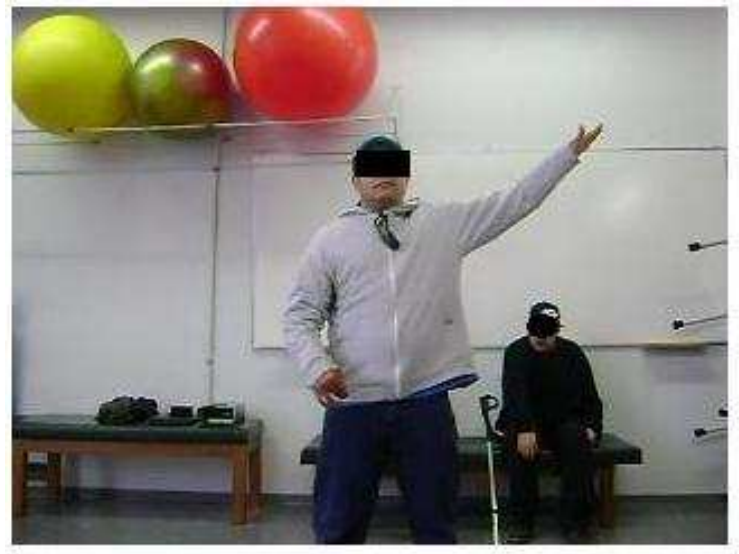

Pré-teste: abduçẫo 0-90 braço bom

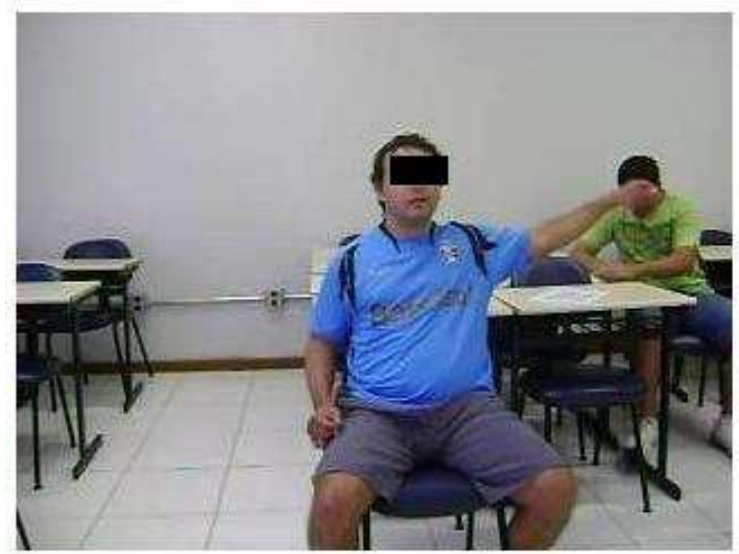

Pós-teste: abduçẫo $0-90$ braço bom

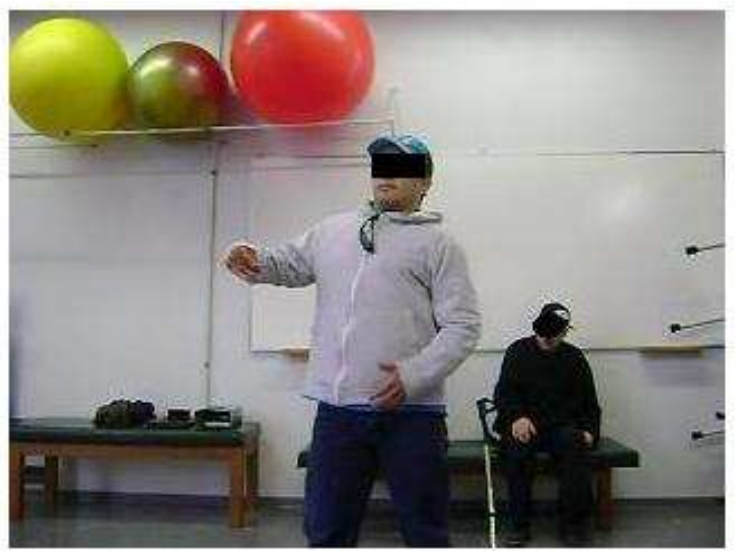

Pré-teste: abdução 0-90 braço lesado

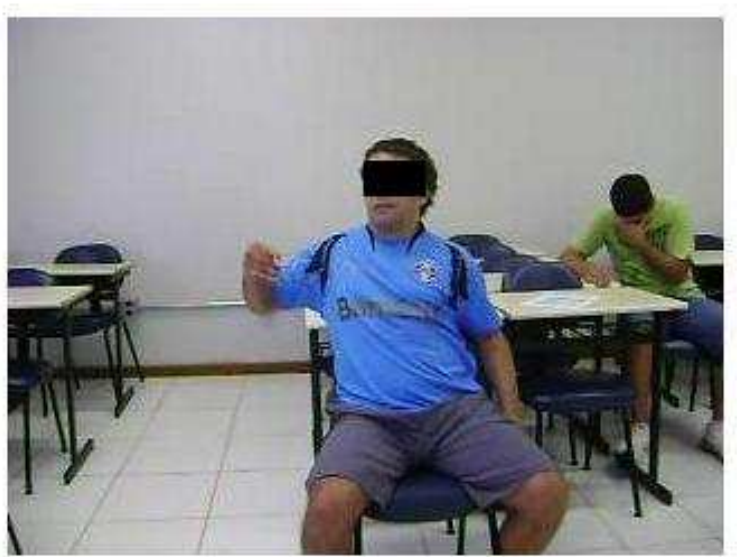

Pós-teste: abdução $0-90$ braço lesado

Figura 5.32 - Paciente AN faz abdução de ombro de 0 a 90 graus

O paciente $\mathrm{JO}$ teve um aumento nas seguintes tarefas: rotação externa de ombro; pronação-supinação com cotovelo a 0 graus; preensão com primeiro e segundo dedos; preensão com flexão de interfalangiana com metacarpofalangiana em posição neutra; preensão de bola; dismetria e velocidade. Por outro lado, houve redução na flexão de cotovelo e preensão em pinça.

A paciente MA teve aumento nas tarefas de: retração do Ombro; abdução do ombro; rotação externa de ombro; abdução de ombro com rotação interna; extensão de cotovelo; flexão de ombro de 0 a 90 graus; pronação-supinação com cotovelo a 90 graus; abdução de ombro de 0 a 90 graus; flexão de ombro de 90 a 180 graus; pronação-supinação com cotovelo a 0 graus; estabilização de punho com cotovelo a 0 graus; preensão com flexão de interfalangiana e metacarpofalangiana; segurar uma bola; tremor, dismetria e velocidade. Houve redução nas tarefas de preensão cilíndrica; extensão em massa dos dedos; completa extensão-flexão de punho com o 
cotovelo a 90 graus. A Figura 5.33 mostra a execução da tarefa de abdução pela paciente MA. Na Figura 5.37 tem-se a tarefa de flexão de ombro de 90 a 180 graus.

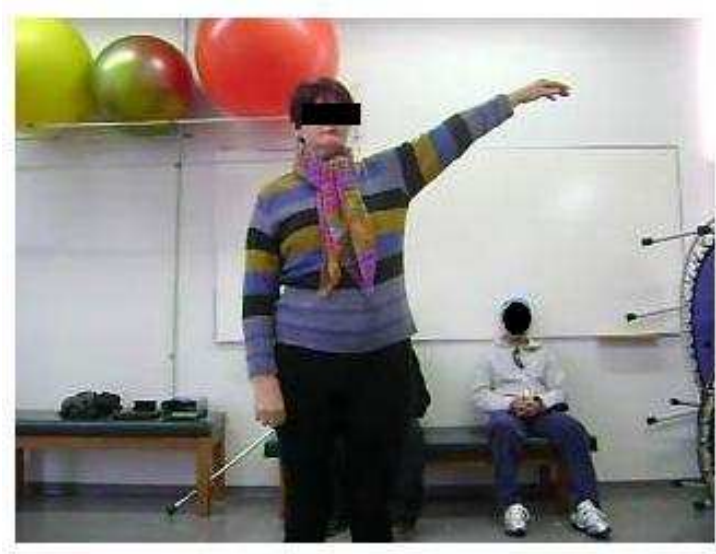

Pré-teste: abduçâo 0-90 braço bom

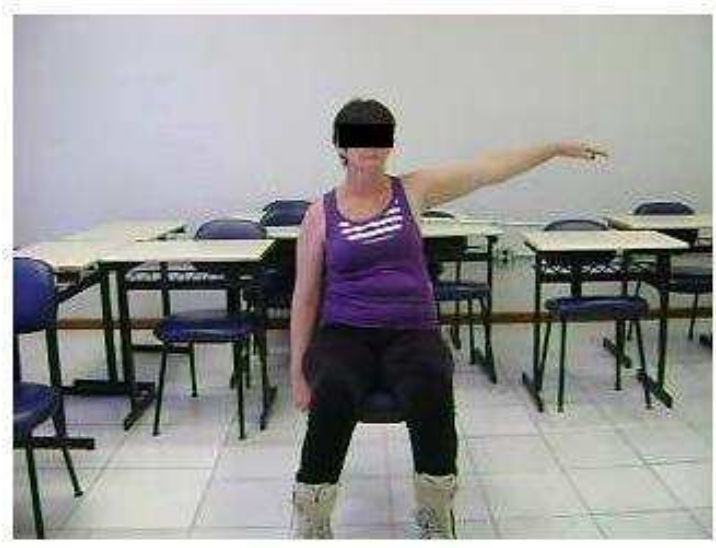

Pós-teste: abdução 0-90 braço bom

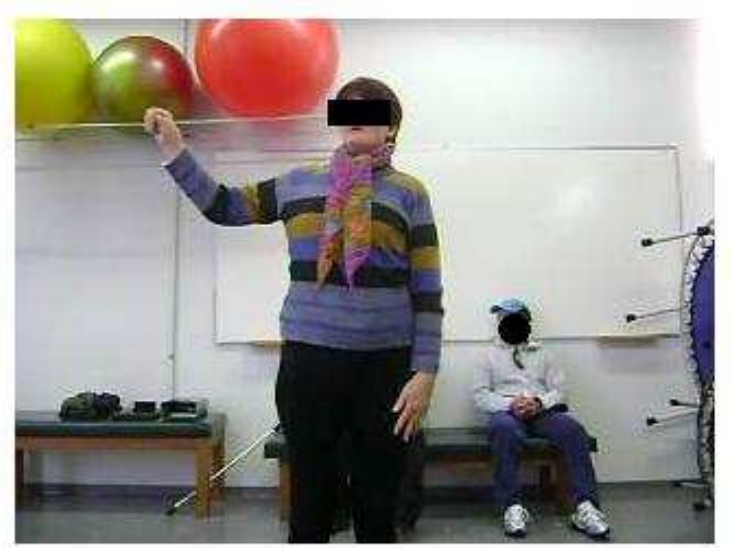

Pré-teste: abdução 0-90 braço lesado

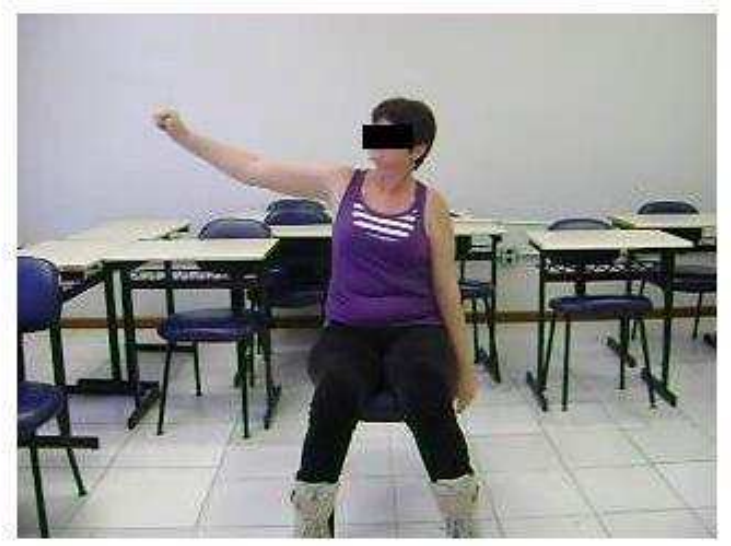

Pós-teste: abdução 0-90 braço ruim

Figura 5.33 - Paciente MA faz abdução de 0 a 90 graus 


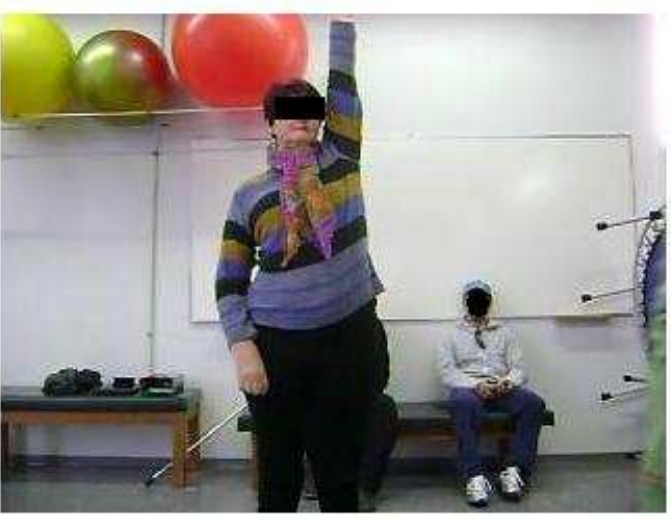

Pré-teste: flexăo $90-180$ braço bom

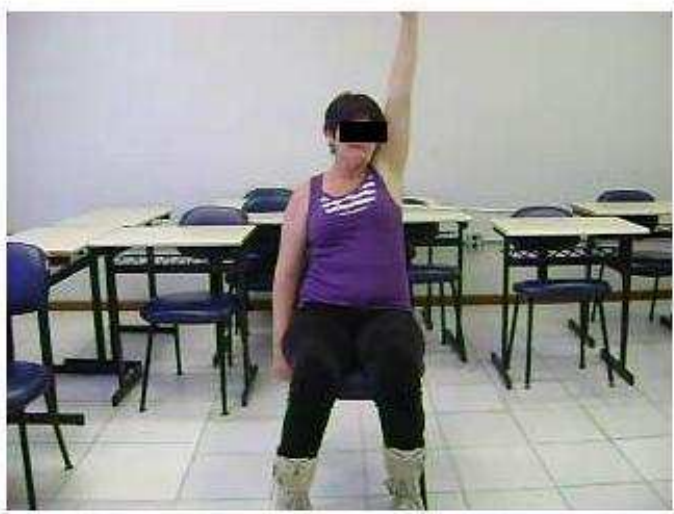

Pós-teste: flexão $90-180$ braço bom

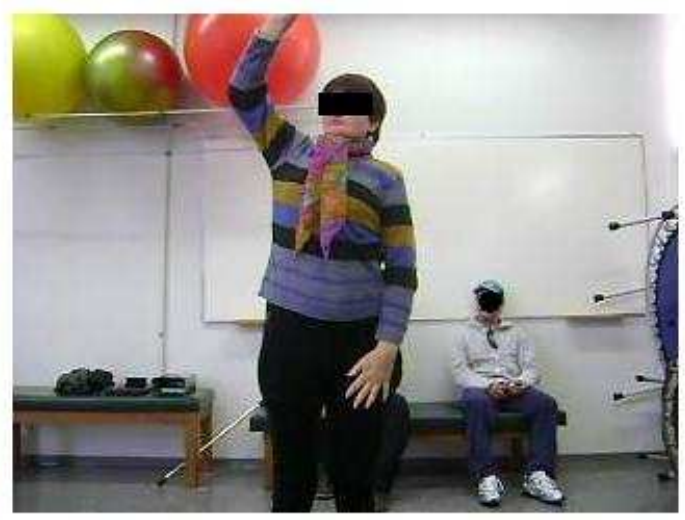

Pré-teste: flexăo $90-180$ braço lesado

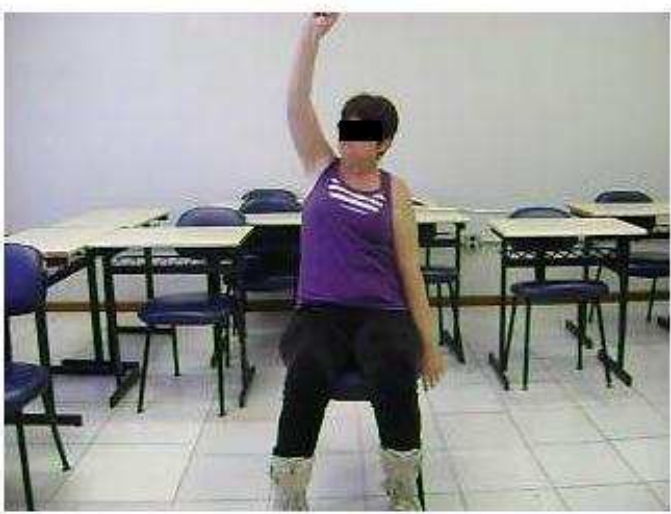

Pós-teste:flexăo 90-180 braço lesado

Figura 5.34 - Paciente MA faz flexão de ombro de 90 a 180 graus

A tabela 5.8, sintetiza as principais observações feitas nos pacientes a partir do instrumento UE-FMA, da análise dos vídeos pelo Fisioterapeuta 1.

Tabela 5.8 - Resultados no GE

\begin{tabular}{|l|l|}
\hline Paciente & Principais observações \\
\hline JO & Aumento na velocidade dos movimentos. \\
\hline AN & $\begin{array}{l}\text { Diminuição do esforço necessário para realizar os movimentos. Aumento } \\
\text { na amplitude dos movimentos de ombro. }\end{array}$ \\
\hline MA & $\begin{array}{l}\text { Aumento na amplitude dos movimentos de abdução e flexão de ombro. } \\
\text { Redução do padrão flexor no cotovelo. Diminuição do esforço necessário } \\
\text { para realizar os movimentos. }\end{array}$ \\
\hline CA & Redução do padrão flexor no cotovelo. \\
\hline
\end{tabular}


Segundo o Fisioterapeuta 1, houve importante melhora da atividade motora no GE, pois o padrão de disfunção motora de pacientes com AVE é ombro elevado, aduzido, flexão de cotovelo, punho e dedos.

\subsubsection{Análise do módulo de Feedback Visual}

Foram definidos anteriormente, na seção 3.16, os critérios de aceitação para o módulo de Feedback Visual. São eles:

a. O braço 3D não pode desaparecer durante a simulação, mesmo que o marcador não seja mais detectado. Este critério foi satisfeito através do armazenamento das últimas coordenadas do marcador detectado anteriormente. Caso o marcador não tenha sido detectado no quadro atual, o sistema utiliza essas coordenadas para exibir o braço 3D.

b. O marcador deve ser detectado a uma distância suficiente para capturar todo o braço do paciente. Este critério foi satisfeito e o marcador foi detectado a uma distância de até $130 \mathrm{~cm}$ da câmera. Para isso foi utilizado um marcador de 10 centímetros quadrados de área

c. A imagem deve ser coerente com uma imagem espelho. Este critério foi satisfeito no sistema através de uma inversão na horizontal dos pixels do quadro capturado em tempo real.

d. O braço virtual deve realizar os movimentos com a mesma amplitude e velocidade que o braço não comprometido. Este critério foi atendido em relação à amplitude do movimento com a captura dos ângulos no braço não comprometido por fotogrametria. Entretanto, o critério da velocidade não foi satisfeito, sendo utilizada uma velocidade constante para todos os pacientes.

e. A coerência temporal e visual nos movimentos do braço virtual foi satisfeita pelo sistema através do uso de incrementos de no máximo 10 graus nos ângulos da animação e também definição de pontos de parada para o braço virtual com número fixo de quadros, durante a animação. Estes pontos de 
parada foram definidos de acordo com o estudo da fisiologia articular do ombro.

f. A coerência do braço virtual com o braço comprometido também foi satisfeita. No início da execução, o usuário informa o lado da hemiplegia para o sistema (direito ou esquerdo) e a remoção do braço real da imagem e as animações são realizadas de acordo com o lado informado.

Foram identificados muitos problemas de registro do braço 3D por causa da grande movimentação do paciente durante os testes.

\subsubsection{Análise do módulo de Aquisição e Armazenamento dos Sinais Cerebrais}

Nos estudos sobre prática mental, identificou-se que esta técnica só tem efeito na reabilitação quando acompanhada de prática física. Para que o braço 3D realize o movimento solicitado durante a prática física, ou seja, quando o paciente já visualizou o movimento do braço 3D e é solicitado a repetir o movimento visto na tela, é necessário que ocorra alguma realimentação do paciente, como garantia de que ele realmente imaginou o movimento solicitado. Esta realimentação poderia ser feita por eletromiografia no ombro ou pelo próprio fisioterapeuta, apalpando o grupo muscular. Como são pacientes graves, que têm pouca ou nenhuma amplitude de movimento no braço comprometido, elaborou-se uma hipótese inicial de que a saída não seria suficiente para ser perceptível por eletromiografia nos músculos do ombro lesado.

Para averiguar isso, foram feitos vários testes com os eletrodos em diferentes posições. Uma das alternativas testadas foi o monitoramento da atividade elétrica da coluna cervical $\mathrm{C} 4$, correspondente aos feixes de motoneurônios que vão para o braço. Entretanto, os testes mostraram que os sinais bioelétricos no C4 eram muito intensos mesmo com o paciente em repouso. Outra alterrnativa testada foi o monitoramento do músculo deltóide no braço comprometido tanto durante o repouso quanto durante a execução do movimento solicitado. Observou-se que o paciente mesmo em repouso apresentava sinal bioelétrico no membro comprometido. 
Também foi possível identificar o período de ativação do músculo a partir do sinal EMG nesta coleta de dados. Portanto, o músculo deltóide foi escolhido para monitoramento de forma a identificar o ponto de ativação do músculo.

Também foram feitos testes com eletrodos em dois canais, no músculo agonista deltóide e no músculo antagonista do movimento, e identificou-se uma atividade bioelétrica em ambos os músculos no braço comprometido, o que explica a pouca amplitude do movimento no braço plégico, pois enquanto o agonista "puxa" o braço a favor do movimento, o antagonista "puxa" o braço no sentido contrário ao movimento.

\subsubsection{Análise da Simulação}

As unidades de movimento do braço 3D consideravam inicialmente um tempo de manutenção de 10 quadros em cada ponto de parada do movimento. Entretanto, a paciente sentia muita dificuldade para manter o braço parado na posição durante o tempo programado após realizar a abdução ou flexão. Isso prejudicou o sincronismo entre o movimento do braço 3D e o movimento que a paciente estava executando.

Um problema com o tempo de parada medido em quadros é que ele depende da taxa de quadros por segundo que varia durante a execução. Assim, uma melhora no sistema é controlar os tempos do do braço na posição em unidades de tempo, de forma também a facilitar para o fisioterapeuta efetuar a contagem para o paciente.

\subsubsection{Procedimento e Instrumentos de Coleta e Análise dos Dados}

O Fisioterapeuta 1 que participou da avaliação com pacientes considerou que o instrumento escala Fugl-Meyer para membro superior tem alguns itens que representam movimentos a favor do padrão patogênico, como flexão em massa dos dedos e preensão. Ela sugere que sejam feitas modificações no instrumento para 
não considerar movimentos a favor do padrão patogênico, pois a reabilitação busca inibir o padrão patogênico do AVE.

De acordo com (Trias, 2009), uma ressalva em relação aos marcadores fiduciais é que a grande maioria das pessoas não é familiarizada com este tipo de recurso e é fácil que incorram em erros simples como não conservar uma borda ao redor do desenho ou sobrepor outros elementos aos marcadores. Portanto, é necessário instruir os fisioterapeutas quanto ao marcador, como e onde colocá-lo no braço do paciente.

De forma geral, os pacientes se moviam muito e com isso o marcador muitas vezes se soltava e caia no chão, ocasionando perda de concentração e também dificuldades no registro. A solução adotada que utiliza as coordenadas do último marcador detectado se mostrou adequada nesta situação, uma vez que mesmo que o marcador não estivesse mais fixado na luva, ainda assim o braço virtual continuava sendo exibido na tela. Entretanto, observou-se a necessidade de um marcador móvel, que não fosse fixo na luva, de forma a ser ajustado ao ombro de cada paciente e que ficasse fixo na posição. Assim, confeccionou-se um marcador que era colocado na luva com o auxílio de um alfinete, de forma a evitar quedas.

Outra questão a considerar é que normalmente os fisioterapeutas orientam o paciente a olhar para o membro afetado durante a execução do movimento como forma de promover a sua consciência corporal. Isso ocorreu na segunda sessão com a paciente MA. Entretanto, com o NeuroR, a orientação deve ser olhar para a tela, valorizando mais o estímulo visual do que a propriocepção.

Como os pacientes apresentavam muita espasticidade na mão, optou-se por utilizar uma luva sem dedos, mais simples e fácil de vestir, de forma que mesmo um familiar possa auxiliar o paciente a vestir a luva, sem a necessidade de um profissional.

\subsubsection{Análise comparativa}

A tabela 5.9 apresenta uma comparação entre o NeuroR e os trabalhos correlatos descritos no capítulo 2. 
O NeuroR foi projetado para ser utilizado em intervenções terapêuticas com a técnica de prática mental. Para avaliar a eficácia do método utilizou-se testes de desempenho motor com o grupo experimental antes e depois de um período de intervenções com o sistema.

Uma diferença de funcionamento entre o sistema do braço robótico MIT-Manus e o NeuroR é que, no segundo, o movimento do braço virtual é determinado pela tarefa a ser realizada no ambiente de RA, enquanto que o braço mecânico é orientado pela tarefa e pelos sinais de força emitidos pelo paciente. Além disso, na terapia robótica havia o estímulo da propriocepção enquanto no NeuroR não estão previstos estímulos para a propriocepção do paciente inicialmente, tendo sido projetado desta forma para que possa ser medido o impacto isolado do estímulo visual na reabilitação.

No sistema de RA de Northwestern é necessário que o usuário já realize algum movimento com o membro lesado. Entretanto, no NeuroR esta condição não é necessária, pois a simulação é disparada pelo teclado, ainda que não se tenha a percepção, por meio dos eletrodos, de qualquer movimento do membro lesado. Outra diferença é que este sistema foi projetado para uso com a participação do terapeuta, enquanto o NeuroR pode ser utilizado em intervenções com ou sem a participação do terapeuta, uma vez que as instruções da terapia de prática mental podem ser fornecidas pelo módulo Prática Mental.

Os resultados positivos do sistema de Rutgers para reabilitação das mãos com RV, onde exercícios de RV são aplicados à reabilitação de pacientes com disfunção da mão causada por danos neurológicos, motivaram a proposta futura de incluir exercícios distais no NeuroR para recuperação das habilidades manuais como garra. A principal diferença entre o sistema proposto e o VR-Mirror é que, no primeiro, pretende-se proporcionar a visualização de uma imagem espelho de todo o paciente e não apenas de seu braço, enquanto que no VR-Mirror é utilizada uma imagem espelhada apenas do braço saudável, sem a sensação de conectividade com o corpo do paciente. 
Tabela 5.9 - Comparação dos Trabalhos Correlatos e NeuroR

\begin{tabular}{|c|c|c|c|c|c|}
\hline Característica & VR-Mirror & MIT-Manus & Sistema de RA & $\begin{array}{l}\text { Sistema de } \\
\text { RV para } \\
\text { mão }\end{array}$ & NeuroR \\
\hline Tecnologia & $\begin{array}{l}\text { Realidade } \\
\text { virtual }\end{array}$ & Robótica & $\begin{array}{l}\text { Realidade } \\
\text { aumentada }\end{array}$ & $\begin{array}{l}\text { Realidade } \\
\text { virtual }\end{array}$ & $\begin{array}{l}\text { Realidade } \\
\text { aumentada }\end{array}$ \\
\hline $\begin{array}{l}\text { Terapias de } \\
\text { reabilitação }\end{array}$ & $\begin{array}{l}\text { Prática mental } \\
\text { e física }\end{array}$ & $\begin{array}{l}\text { Prática } \\
\text { robótica e } \\
\text { física }\end{array}$ & Prática física & Prática física & $\begin{array}{l}\text { Prática } \\
\text { mental e } \\
\text { física }\end{array}$ \\
\hline Hardware & $\begin{array}{l}\text { LCD + } 2 \\
\text { receptores + } 1 \\
\text { transmissor } \\
\text { (rastreamento) + } \\
\text { mesa }\end{array}$ & $\begin{array}{l}\text { Braço robótico } \\
\text { + sensores de } \\
\text { posição, } \\
\text { velocidade e } \\
\text { torque }\end{array}$ & $\begin{array}{l}\mathrm{HMD}+ \\
\text { dataglove } \\
\text { penumática + } \\
\text { joystick }\end{array}$ & $\begin{array}{l}\text { Dataglove } \\
\text { com retorno } \\
\text { de força }\end{array}$ & $\begin{array}{l}\text { Webcam + } \\
\text { marcadores } \\
\text { impressos } \\
\text { em papel+ } \\
\text { luva tecido }\end{array}$ \\
\hline Local & Clínica & Clínica & Clínica & $\begin{array}{l}\text { Clínica e } \\
\text { residência }\end{array}$ & $\begin{array}{l}\text { Clínica e } \\
\text { residência }\end{array}$ \\
\hline $\begin{array}{l}\text { Melhoria } \\
\text { motora }\end{array}$ & $\begin{array}{l}66 \% \text { dos } \\
\text { pacientes } \\
\text { mostraram uma } \\
\text { pequena } \\
\text { redução nas } \\
\text { suas } \\
\text { deficiências } \\
\text { motoras } \\
\text { medidas pela } \\
\text { escala Fugl- } \\
\text { Meyer. }\end{array}$ & $\begin{array}{l}\text { Grupo treinado } \\
\text { com o robô } \\
\text { melhorou suas } \\
\text { funções } \\
\text { motoras duas } \\
\text { vezes mais } \\
\text { que o grupo } \\
\text { controle. }\end{array}$ & $\begin{array}{l}\text { Pacientes } \\
\text { melhoraram } \\
\text { estatisticamente } \\
\text { nas habilidades } \\
\text { de } \\
\text { fracionamento, } \\
\text { faixa e } \\
\text { velocidade de } \\
\text { movimento das } \\
\text { mãos, medidos } \\
\text { pelo teste } \\
\text { Jebsen de } \\
\text { função da mão. }\end{array}$ & $\begin{array}{l}\text { Dados } \\
\text { indisponíveis } \\
\text { na literatura } \\
\text { consultada } \\
\text { até o } \\
\text { momento. }\end{array}$ & $\begin{array}{l}80 \% \text { tiveram } \\
\text { melhorias no } \\
\text { desempenho } \\
\text { motor pela } \\
\text { escala Fugl- } \\
\text { Meyer. }\end{array}$ \\
\hline
\end{tabular}

\subsection{CONCLUSÕES}

Este capítulo apresentou os principais ensaios realizados em laboratório durante a concepção e desenvolvimento do sistema proposto e os resultados dos testes do sistema com um grupo denominado grupo experimental, composto por cinco pacientes voluntários, que utilizaram o sistema uma vez por semana, durante quatro semanas, em sessões que variavam de 20 a 45 minutos. As sessões de utilização do sistema foram registradas em vídeo digital com o auxílio de um software gratuito para captura de tela e em alguns casos, através da própria câmara digital. Alguns 
ajustes foram necessários durante os testes, como troca da luva de dedos por uma luva sem dedos, ajustes no código-fonte relacionados à velocidade do movimento do braço virtual e também no algoritmo de substituição do braço real da imagem pelo virtual. A pesquisadora responsável desempenhou o papel de observadora nas sessões e foi mantido um diário de campo não-estruturado para cada paciente, com as observações e comentários feitos pelos fisioterapeutas e pelos pacientes durante as intervenções. Os resultados obtidos apontam para um potencial promissor de aplicabilidade do sistema na reabilitação motora dos membros superiores de pacientes que sofreram um AVE há mais de um ano, e que apresentam hemiplegia, quer seja no lado direito ou esquerdo. 


\section{CONCLUSÕES E TRABALHOS FUTUROS}

\subsection{CONCLUSÕES}

Os testes realizados mostraram que existe aplicabilidade do sistema proposto na área de reabilitação motora de membros superiores de pacientes que sofreram um AVE. Entretanto, a amostra utilizada não é fidedigna nem significativa para uma conclusão quanto à diminuição do comprometimento motor destes pacientes.

O objetivo desta pesquisa de proporcionar um aparato tecnológico para a realimentação visual com conectividade na reabilitação motora dos membros superiores de pacientes pós-AVE foi atingido com o desenvolvimento do sistema NeuroR. Há indícios de que este sistema possa ser utilizado para promover a reabilitação física como um tratamento adicional para a reabilitação do paciente.

Este trabalho proporcionou uma nova abordagem para 0 treinamento dos movimentos no processo de reabilitação motora, desde que mesmo pacientes sem qualquer saída motora no braço plégico possam treinar os movimentos, uma vez que o braço virtual, que é representado conectado ao corpo do paciente expande as habilidades do braço real do paciente.

Além disso, este sistema pode ser utilizado tanto no centro de reabilitação quanto em outros locais. A simulação dos exercícios pelo braço virtual pode ajudar os pacientes e seus cuidadores a executar os exercícios de reabilitação motora em diferentes cenários de reabilitação.

Da mesma forma, o sistema NeuroR pode proporcionar aos estudantes de fisioterapia um mecanismo para aprendizagem sobre como realizar os principais exercícios de reabilitação motora de membros superiores.

De acordo com um especialista em biofeedback, o NeuroR pode auxiliar no desmame de muitos pacientes neurológicos quando utilizam o biofeedback. Quando eles deixam de visualizar o gráfico do sinal bioelétrico ou sua representação visual ou sonora, que pode ser, por exemplo, uma barra que aparece na tela do 
computador e que aumenta ou diminui como um indicativo do movimento realizado, eles não conseguem mais realizar o movimento sem o estímulo do biofeedback.

A proposta NeuroR contempla exercícios funcionais, importantes para as atividades da vida diária, como o movimento de preensão para a mão plégica do paciente, e também exercícios largamente utilizados nas terapias convencionais.

Dos quatro pacientes que participaram do grupo de teste, três mostraram uma identificação do braço 3D com o seu braço físico. Entretanto, um dos pacientes não teve a mesma reação, negligenciando a associação entre seu braço físico e o braço 3D. Este paciente sofreu uma lesão no tálamo e nos núcleos de base, que em conjunto com a formação reticular, compõem o tronco encefálico. No estudo da viabilidade neurológica do sistema foi comprovado, com base na literatura, que os estímulos visuais podem excitar a formação reticular e esta, por sua vez, excitam os gama-motoneurônios, que são motoneurônios inferiores. Com base nos testes realizados, houve evidências que não só pacientes com lesão na formação reticular como também em outras partes do tronco encefálico, podem apresentar dificuldades em produzir estímulos para os motoneurônios a partir dos visuais.

Todos os pacientes que participaram das quatro sessões com o NeuroR apresentaram melhorias no desempenho motor, medidos através do instrumento Fugl-Meyer. Um aumento relativo de no mínimo $17.14 \%$ e no máximo $62.50 \%$, o que foi considerado pelo fisioterapeuta como importante melhora da atividade motora.

Duas condições de contorno estabelecidas no início do projeto e que nortearam o desenvolvimento do sistema não foram verificadas e precisaram ser revistas para a continuidade do projeto. A primeira é que o braço inicia na posição supinado, ou seja, ao longo do corpo, do lado do tronco. Esta restrição permitiu que fosse feita uma otimização para remover o braço real da cena, onde a classificação dos pixels era feita somente na região delimitada pelo marcador. Entretanto, muitos pacientes sentiam dores ao deixar o braço pender ao longo do corpo. A segunda condição estabelecida foi de que os pacientes iriam apenas visualizar o braço virtual se mover durante a prática mental sem tentar mover o próprio braço. Entretanto, dos cinco pacientes que participaram do piloto e do grupo experimental, quatro tentaram executar o movimento durante a prática mental. 


\subsection{CONTRIBUIÇÕES CIENTÍFICAS E TECNOLÓGICAS}

A principal contribuição tecnológica é o protótipo atual do sistema NeuroR, que possibilitará a continuidade dos testes com um número maior de pacientes e/ou com outros protocolos de reabilitação e também a exploração, com alguns ajustes no sistema, de outras áreas de aplicação, como amputados e indivíduos com agnosia, que ignoram seu lado sem função motora e com isso têm alterações importantes de imagem, esquema corporal, dificultando suas reações de retificações, de equilíbrio e marcha .

A principal contribuição científica deste trabalho são os resultados dos testes realizados com o sistema, que indicam um potencial promissor de aplicabilidade da proposta para reabilitação motora dos membros superiores de pacientes que sofreram alguma lesão neurológica.

Neste período do doutorado a candidata submeteu e obteve aprovação dos seguintes artigos relacionados ao trabalho:

Assis, Gilda Aparecida de, Correa, Ana Grasielle Dionísio, Vaz, Cícero José Nunes, Lopes, Roseli de Deus. An Augmented Reality System For Post-Stroke Rehabilitation Using Mental Practice. In: IADIS International Conference on Computer Graphics and Visualization 2008, Amsterdam, 24-26 July 2008.

Assis, Gilda Aparecida de, Lopes, Roseli de Deus. NeuroR - Realidade Aumentada Aplicada à Reabilitação dos Membros Superiores de Pacientes Vítimas de Acidentes Vasculares Encefálicos. In: SVR 2008 - WTD, 2008, João Pessoa, PB. X Symposium on Virtual and Augmented Reality, 2008.

\subsection{TRABALHOS FUTUROS}

Como proposta de continuidade deste trabalho tem-se: 
- Desenvolver e analisar soluções para os problemas técnicos enfrentados durante os testes de utilização do sistema, como detecção de marcadores asimétricos na imagem espelho, falhas de sincronismo e registro.

- Implementar, testar e avaliar uma versão do sistema em primeira pessoa, com a utilização de um HMD.

- Comparar a versão atual do NeuroR que utiliza a metáfora do espelho com a nova versão com HMD.

- Reformular o planejamento das intervenções de forma a reduzir o número de diferentes fatores que influenciam o processo de reabilitação. Uma possível alteração é proporcionar apenas o estímulo do movimento do braço virtual e a prática física com EMG, sem a inclusão de artefatos como o padrão FNP, que pode ser uma variável no processo. Outro ajuste é a inclusão de uma orientação para que as intervenções sejam conduzidas pelo mesmo profissional, sem vínculo anterior com o paciente. Também devem ser revistos os critérios de inclusão na amostra de forma a considerar a cognição preservada dos pacientes no processo seletivo, que é fundamental para a realização da prática mental.

- Realizar testes de utilização do sistema NeuroR com um grupo de pessoas voluntárias sem danos neurológicos ou motores prévios e que tenham as mesmas características que o grupo de pacientes que participou desta pesquisa. Estes testes tem como objetivo identificar as diferenças e similaridades de comportamento durante a utilização do NeuroR bem como analisar a usabilidade do sistema.

- Definir os instrumentos e critérios a serem adotados na avaliação do sistema NeuroR aplicado à reabilitação motora como, por exemplo, amplitude do movimento obtida por fotogrametria ou ainda intensidade do EMG durante a contração muscular. Também é necessário determinar os momentos de aplicação das avaliações dentro do processo.

- Realizar intervenções utilizando o NeuroR com um grupo experimental que represente uma amostra fidedigna e significativa. Após o período de utilização do sistema, será necessário acompanhar os pacientes para verificar se 
possíveis ganhos motores tem efeito temporário ou permanente, após a interrupção das intervenções.

- Realizar intervenções com um grupo controle de pacientes pós-AVE, utilizando os mesmos procedimentos adotados com o grupo experimental, com exceção do estímulo do braço virtual. Também deve-se colocar a luva e o marcador no membro comprometido e proporcionar a visualização da própria imagem espelho dos pacientes (placebo).

- Comparar os resultados obtidos com o tratamento utilizando o NeuroR e outros protocolos de tratamento relacionados, como a terapia robótica e VRMirror.

- Monitorar ou acompanhar EMG para avaliar a qualidade da ativação muscular por EMG.

- Desenvolver uma versão do sistema NeuroR sem marcadores. Do ponto de vista da ergonomia do sistema, é desejável que a interação com o usuário se dê da forma mais natural possível tanto no momento em que este recebe estímulos quanto quando os envia. Assim o rastreamento do braço do paciente, e não de elementos fixados a ele, ou seja, sem marcadores, se revela uma solução ideal para obter interação natural. Para incorporar esta melhoria ao sistema pode-se usar uma técnica de classificadores em cascata de características Haar-like. Características Haar-like são aquelas determinadas por contrastes na imagem. Elas são mais robustas que a análise pixel a pixel pois carregam informação da relação entre as regiões da imagem, e não apenas comparam valores pontuais. Quando conjuntos deste tipo são empregados em cascata consegue-se identificar elementos mais complexos como, por exemplo, a face de um indivíduo (Trial, 2009).. 


\section{REFERÊNCIAS BIBLIOGRÁFICAS}

ADAMOVICH, S. V. et al. A Virtual Reality Based Exercise System for Hand Rehabilitation Post-Stroke: Transfer to Function. In: Proceedings of the 26th Annual International Conference of the IEEE EMBS. San Francisco, USA. September 1-5, 2004.

AMERICAN HEART ASSOCIATION. Heart Disease and Stroke Statistics 2009 Update: A Report From the American Heart Association Statistics Committee and Stroke Statistics Subcommittee, p. e22-e22, 2009. Disponível em: <http://circ.ahajournals.org/cgi/reprint/CIRCULATIONAHA.108.191261>. Acesso em: 01 de fevereiro de 2009.

AMERICAN HEART ASSOCIATION. Heart Disease and Stroke Statistics 2009 Update At a Glance, 2009. Disponível em: <http://www.americanheart.org/downloadable/heart/123783441267009Heart\%2 0and\%20Stroke\%20Update.pdf>. Acesso em: 01 de novembro de 2009

AZUMA, R. A Survey of Augmented Reality. Presence: Teleoperators and Virtual Environments, v .6, n.4, p. 355-385, 1997.

AZUMA, R. Overview of Augmented Reality. 2004, In: ACM SIGGRAPH 2004 Course Notes, 2004.

BIMBER, O.; RASKAR, R. Modern Approaches to Augmented Reality. Course in Siggraph 2005, 2005.

BREITLING, D.; GUENTHER, W.; RONDOT, P. Motor responses measured by electrical activity mapping. In: Behaviour Neuroscience, 1986, volume 100, 104-116.

BUCHMANN, V. et al. FingARtips-Gesture Based Direct Manipulation in Augmented Reality, ACM 2004.

BURDEA, G.; COIFFET, P. Virtual Reality Technology. New York: Wiley, 1994.

$\mathrm{CHAN}$, L. et al. Disability and health care costs in the Medicare population. Archives of Physical Medicine and Rehabilitation, 83, 1196- 1201, 2002.

CONFORTO, A. B.; FERREIRA, J. R.. Neuroestimulação e reabilitação motora no acidente vascular cerebral. In: ComCiência, v. 109, p. 20, 2009.

CORREA, A. G. D. et al. GenVirtual: An Augmented Reality Musical Game for Cognitive and Motor Rehabilitation. In: 6th International Workshop on Virtual Rehabilitation, 2007, Veneza. In Proceedings of the IWVR 2007. Veneza : Aristea, 2007, p.1-6.

CORREIA, P. P.; MIL-HOMENS, P. A Electromiografia no estudo do movimento humano. Lisboa: MH Edições, 2004.

DECETY, J. The neurophysiological basis of motor imagery. In: Behavioural Brain Research, 77, 1996, pgs. 45-52.

DESMECHT, L.; DACHARY, L.; HEIDELBERGER, B. The Cal3D User's Guide, 2006. Disponível em: <http://download.gna.org/cal3d/documentation/guide/>. Acesso: fevereiro de 2009. 
DIAS, L. Constituição do Sistema Nervoso. Disponível em <http://ciencianatural.blogs.sapo.pt/19124.html>. Acesso: novembro de 2009.

DOUGLAS, C. R. Tratado de Fisiologia Aplicada às Ciências Médicas, 6a edição. Rio de Janeiro: Guanabara Koogan, 2006, 1488p.

FANSLER, C. L.; POFF, C. L.; SHEPHARD, K. F. Effects of mental practice on balance in elderly women.. In: Physical Therapy, 1985, volume 65, 1332-1337.

FILHO, M. T. F. Aplicação de Transformadas Tempo-Freqüência e de Redes Neurais Artificiais no Processamento de Sinais Cerebrais. 2001. 121p. Dissertação (Mestrado) - Escola Politécnica, Universidade de São Paulo, São Paulo, 2001.

FISCHER, J.; BARTZ, D.; STRABER; W. Artistic Reality: Fast Brush Stroke Stylization for Augmented Reality. In: VRST'05, November 7-9, 2005, Monterey, California, USA, p. 155-158.

FUGL-MEYER, A. R. et al. The post-stroke hemiplegic patient: A method for evaluation of physical performance. In: Scand J Rehab Med, 7, pp. 13-31, 1975.

GAGGIOLI, A. et al. A Strategy for Computer-Assisted Mental Practice in Stroke Rehabilitation. In: Neurorehabilitation and Neural Repair, 20(4), 2006.

GAGGIOLI, A. et al. Training with Computer-Supported Motor Imagery in Post-Stroke Rehabilitation. In: CyberPsychology \& Behavior, Vol. 7, No. 3, pp. 327-332, 2004.

GAGGIOLI, A et al. Computer-enhanced mental practice in upper-limb rehabilitation after cerebrovascular accident: a case series study. In: Virtual Rehabilitation, 2007 , vol., no., pp.151-154, 27-29 Sept. 2007.

GEIGER, C.; SCHMIDT, T.; STOCKLEIN, J. Rapid Development of Expressive AR Applications. In: International Symposium on Mixed and Augmented Reality (ISMAR). USA, 2004.

GONZALEZ, R. C.; WOODS, R. E. Processamento de Imagens Digitais. São Paulo: Edgard Blucher, 2000, 509 p.

GUIMARÂES, C. Neuroplasticidade e reabilitação, Disponível em $<\mathrm{http}: / / w w w . d r a u z i o v a r e l l a . c o m . b r / e n t r e v i s t a s / p l a s t i c i d a d e \_n e u r o n a l 6 . a s p>$. Acesso em novembro de2009.

HARDY, E.; BENTO, S. F.; OSIS, M. J. Consentimento Informado Normatizado pela Resolução 196/96: Conhecimento e Opinião de Pesquisadores Brasileiros. RBGO - v. 24, nำ 1, 2002.

HUA, $H$. et al. Using a head-mounted projective display in interactive augmented environments. In Proceedings of IEEE and ACM International Symposium on Augmented Reality 2001, pp. 217-223, 2001.

JORGENSEN, H., et al., Outcome and Time Course of Recovery in Stroke, Parts I and II. The Copenhagen Stroke Study. Arch Phys Med Rehab. 76: p. 399-412, 1995.

KAPANDJI, A. I. Fisiologia Articular 1: membro superior. São Paulo:Panamericana, 5a edição, 2000, 298 p. 
KIYOKAWA, K.; KURATA, Y.; OHNO, H. An Optical See-through Display for Mutual Occlusion of Real and Virtual Environments. In proceedings of IEEE \& ACM ISAR 2000, pp. 60-67, 2000.

KREBS. H. I. et al. Robot-Aided Neurorehabilitation. In: IEEE transactions on rehabilitation engineering, vol. 6, no. 1, march 1998.

LEVINE, S. P. et al. A Direct Brain Interface Based on Event-Related Potentials. In: IEEE Transations on Rehabilitation Engineering, vol. 8, no. 2, June 2000, pgs. 180-185.

LOW, K. et al. Life-Sized Projector-Based Dioramas. In: Symposium on Virtual Reality Software and Technology, 2001.

LOZANO, J. A. et al. VR-Mirror: A Virtual Reality System for Mental Practice in PostStroke Rehabilitation. In: SG 2005, LNCS 3638, pp. 241-251, 2005.

LUNDY-EKMAN, L. Neurociência: Fundamentos para a Reabilitação, Rio de Janeiro: Guanabara Koogan, 2000, 347p.

LUO, X. et al. An Augmented Reality Training Environment for Post-Stroke Finger Extension Rehabilitation. In: IEEE 9th International Conference on Rehabilitation Robotics, Chicago, IL, 2005.

MACHADO, L. S.; CARDOSO, A. Dispositivos de Entrada e Saída para Sistemas de Realidade Virtual. In: TORI, R.; KIRNER, C.; SISCOUTO, R. Fundamentos e Tecnologia de Realidade Virtual e Aumentada. Livro do Pré-Simpósio VIII Symposium Virtual Reality, Belém-PA, 2006. p. 22-38.

MARQUES, A. P. Manual de Goniometria. São Paulo: Manole Editora, 1a edição, 1997.

MASSACHUSETTS INSTITUTE OF TECHNOLOGY. MIT develops Anklebot for stroke patients, 2005. Disponível em $<$ http://web.mit.edu/newsoffice/2005/stroke-robot.html>. Acesso em janeiro de 2009.

MATUSIK, W. et al. Image-based Visual Hulls. International Conference on Computer Graphics and Interactive Techniques, 27. Anais. New York: ACM Press, 2000. p.369-374.

MCGUIRE, M. et al. Defocus Video Matting. Siggraph 2005, 2005.

MENEZES, P. B. Linguagens Formais e Autômatos. Porto Alegre: Instituto de Informática da UFRGS: Editora Sagra Luzzatto, 4a edição, 2002.

MILGRAM, P.; KISHINO, F. 1994. Augmented Reality: A Class of Displays on the Reality-virtuality Continuum. SPIE, Telemanipulator and Telepresence Technologies, 2351 (34). 42-48.

MINISTÉRIO DA SAÚDE, 2006.2 Disponível em: <http://tabnet.datasus.gov.br/tabdata/pacto2006/cadernosmap.htm>. Acesso: 01 de fevereiro de 2009.

MINUTOLI, V. P et al. Efeito do Movimento Passivo Contínuo Isocinético na Hemiplegia Espástica. Acta Fisiátrica, v. 14, p. 142-148, 2007.

MOEHRING, M.; LESSIG, C.; BIMBER, O. Video see-through AR on consumer cellphones. In IEEE/ACM ISMAR'04, 2004. 
MURPHY, G. F.; HANKEN, M. A.; WATERS, K.A. Electronic Health Records: Changing the Vision. Philadelphia: W.B. Saunders Company, 1999.

NUDO, R. J. et al. Neural Substrates for the Effects of rehabilitative training on motor recovery after ischemic infarct, Science, 1996.

NUDO, R. J; PLAUTZ, E. J.; FROST, S. B. Role of adaptive plasticity in recovery of function after damage to motor cortex. Muscle Nerve, vol. 24, pp. 1000-1019, 2001.

OGI, T. et al. Invisible Interface for Immersive Virtual World. In proceedings of the Immersive Projection Technology Workshop (IPT'01), pp. 237-246, Stuttgart, Germany, 2001.

OVANDO, A. C. Acidente Vascular Encefálico: Comprometimento Motor dos Membros inferiores e alteração da marcha. In: Revista Digital, Buenos Aires Ano 14, № 132, Maio de 2009, Disponível em $<$ http://www.efdeportes.com/efd132/acidente-vascular-encefalico-na-alteracoes -na-marcha.htm>, 2009.

PAGE, S. J.; LEVINE, P.; LEONARD, A. C. Effects of Mental Practice on Affected Limb Use and Function in Chronic Stroke. In: American Congress of Rehabilitation Medicine and the American Academy of Physical Medicine and Rehabilitation, vol 86, March 2005, 399-402.

PAGE, S. J. et al. Mental Practice Combined With Physical Practice for Upper-Limb Motor Deficit in Subacute Stroke. In: Physical Therapy, Volume 81, Number 8, August 2001, 1455-1462.

PLATZ, T. et al. Arm Rehabilitation Measurement: Manual for performance and scoring of the Fugl-Meyer test (arm section), Action Research Arm Test, and the Box and Block test. Deutscher Wissenschafts- Verlag, 6-105, 2005.

POPESCU, V. G. et al. A Virtual Reality-based Telerehabilitation System with Force Feedback. IEEE Transactions on Information Technology in Biomedicine, 4(1): p. $45-51,2000$.

PUHL, M. T.. Programa cinesioterapêutico para o ombro doloroso de pacientes hemiplégicos ou hemiparéticos devido ao acidente vascular cerebral. Novo Hamburgo, RS, 2004. 92p, Monografia (Conclusão do Curso de Fisioterapia) - Centro Universitário Feevale, 2004

RIVA, G.; MANTOVANI, F.; GAGGIOLI, A. Presence and rehabilitation: toward second-generation virtual reality applications in neuropsychology. In: Journal of NeuroEngineering and Rehabilitation, 2004.

RIZZO, A. A. et al. Design and Development of Virtual Reality Based PerceptualMotor Rehabilitation Scenarios. In: Proceedings of the 26th Annual International Conference of the IEEE EMBS. San Francisco, CA, USA • September 1-5, 2004.

SANCHES, S. R. R. A Utilização da Técnica de Chromakey para Composição de Cenas em Ambientes de Realidade Misturada. Dissertação (Mestrado) Ciência da Computação. Marília. São Paulo. 2007.

SCHALK, G. et al. "BCl2000: A General-Purpose Brain-Computer Interface (BCl) System", In: IEEE Transations on Biomedical Engineering, vol. 51, no. 6, June 2004, pgs. 1034-1043. 
SHU, J.S.P One-Pixel-Wide Edge Detection, Pattern Recognition, 22(6), 665-673, 1989.

STANSFIELD, S. et al. Interactive Virtual Client for Teaching Occupational Therapy Evaluative Processes. In: ASSETS'05, October 9-12, Baltimore, Maryland, USA, 2005.

STARKEY, C.; RYAN, J. L. Avaliação de lesões ortopédicas e esportivas. 2001.

STECKLOW, M. V.. Imagética Motora Em Tarefa Complexa: Análise Na Banda Alfa Do Eletroencefalograma. Dissertação de Mestrado, COPPE/UFRJ, Rio de Janeiro, junho, 2006.

SULZBACHER, M. E. A avaliação do tape na marcha de pacientes com doença vascular encefálica. 2005. 116 f. Monografia (Conclusão do Curso de Fisioterapia) - Feevale, Novo Hamburgo-RS, 2005.

TAUB, E.; USWATTE, G.; MORRIS, D. M. Improved motor recovery after stroke and massive cortical reorganization following Constraint-Induced Movement therapy. Physical Medicine and Rehabilitation Clinics of North America, 77-91, 2003.

TONIETTO, L. Análise de Algoritmos para Chroma-Key. 2000, 75 p. Trabalho de Curso (Bacharel em Informática - Habilitação em Software Básico) - Unisinos, São Leopoldo, 2000.

TORI, R.; KIRNER, C. Fundamentos de Realidade Aumentada. In: TORI, R.; KIRNER, C.; SISCOUTO, R. Fundamentos e Tecnologia de Realidade Virtual e Aumentada. Livro do Pré-Simpósio VIII Symposium Virtual Reality, Belém-PA, 2006. p. 22-38.

TRIAS, L. P. Janela 3D: uma Ferramenta de Tele-comunicação Visual Sensível ao Ponto de Vista do Usuário. Dissertação (mestrado) - Engenharia. EPUSP. São Paulo. 2009.

WERNER, R. A.; KESSLER, S. Effectiveness of an Intensive Outpatient Rehabilitation Program for Postacute Stroke Patients. American Journal of Physical Medicine Rehabilitation. 75: p. 114-120, 1996. 


\section{GLOSSÁRIO}

Afasia

Agnosia

Deambula

Desmame

Espasticidade

Facilitação neuromuscular Técnica de tratamento fisioterapêutico que utiliza proprioceptiva

Hemiparesia

Hemiplegia

Hipertonia

Hipotonia

Marcha ceifante

Propriocepção
Deterioração da função da linguagem

Perda da capacidade de reconhecer objetos, pessoas, sons, formas

Caminha

Técnica de retirada gradual e progressiva

Rigidez muscular exercício passivo

Perda parcial de movimentos de um hemicorpo (metade do corpo)

Perda total de movimentos de um hemicorpo

Aumento do tônus muscular

Diminuição do tônus muscular

Classificação de tipo de marcha, onde o paciente arrasta o membro inferior

Capacidade em reconhecer a localização espacial do corpo, sua posição e orientação, a força exercida pelos músculos e a posição de cada parte do corpo em relação às demais, sem utilizar a visão. 


\section{APÊNDICE A}

\section{TERMO DE CONSENTIMENTO LIVRE E ESCLARECIDO}

\section{NeuroR- Sistema Computacional de Apoio À Reabilitação Dos Membros Superiores De Pacientes Vítimas De Acidentes Vasculares Encefálicos}

Ao assinar este termo, eu, colaborador ou seu responsável, , estou consentindo a

minha participação no trabalho de doutorado de Gilda Aparecida de Assis, aluna do Programa de Pós-Graduação em Engenharia Elétrica, Universidade de São Paulo, localizado em São Paulo, SP, orientada pela Dra. Roseli de Deus Lopes. A pesquisadora prestou esclarecimentos quanto aos objetivos da pesquisa e sobre os métodos de avaliação que serão utilizados.

Recebi da pesquisadora os seguintes esclarecimentos:

1. O trabalho tem como objetivo avaliar a funcionalidade de um protocolo de tratamento na reabilitação motora do membro superior de pacientes que sofreram um acidente vascular encefálico há mais de um ano. Este protocolo utiliza prática mental combinada com um estímulo visual na tela do computador.

2. Serão avaliados funcionalmente os colaboradores através de um questionário e testes de desempenho motor. A duração dos testes é de 45 a 60 minutos, 2 vezes por semana, durante 4 semanas.

3. Esta pesquisa se justifica pela necessidade de corrigir ou diminuir as deficiências motoras do membro superior de pacientes com diagnóstico clínico de acidente vascular encefálico. A prática mental consiste na simulação mental de repetidos movimentos, com a intenção de promover aprendizagem ou aperfeiçoamento de uma habilidade motora.

4. Todo o trabalho será feito pela pesquisadora Gilda com o acompanhamento de uma fisioterapeuta do projeto Atenção Integrada à Saúde da Comunidade da Feevale através da visita do colaborador à clínica.

5. A participação do colaborador na pesquisa iniciará após eu, o próprio ou seu responsável, ler e assinar em duas vias o presente Termo de Consentimento, ficando uma via comigo e outra com a pesquisadora. 
6. As informações para a realização do presente estudo serão coletadas através de exercícios de avaliação motora e entrevista semi-estruturada elaborada pela aluna. Os exercícios serão gravados em vídeo para posterior análise. Depois de utilizados os dados para os fins propostos os vídeos serão guardados em um arquivo de acesso restrito aos pesquisadores por cinco anos e depois descartados. Sendo este recurso apenas utilizado para o projeto e mantendo em sigilo e anonimato minha identidade.

7. Tenho garantido o direito de resposta a qualquer dúvida que possa surgir, em qualquer momento da pesquisa.

8. É garantido o anonimato dos colaboradores que participarem da pesquisa. Seus nomes não serão mencionados em nenhum momento na pesquisa.

9. Poderá haver a realização de fotos e/ou filmagens do colaborador. Provavelmente as imagens aparecerão na apresentação dos resultados finais deste trabalho, mas em nenhum momento será divulgada sua identidade, preservando seu anonimato, sendo essas imagens usadas somente para fins científicos.

10. Fica garantido que os procedimentos realizados com o colaborador, durante a pesquisa, não acarretarão risco à sua saúde.

11. Serei informado sobre os procedimentos e resultados da minha participação na pesquisa.

12. A autorização para minha participação ou do colaborador de quem sou responsável, é voluntária, e tenho a liberdade de retirar meu consentimento a qualquer momento, sem que isso traga prejuízo à sua saúde ou bem estar físico.

13. A participação do indivíduo é isenta de despesas e não receberá ressarcimento de despesas com alimentação. O colaborador receberá uma ajuda de custo para as despesas com deslocamento, na forma de vale-transporte.

14. Este termo de consentimento livre e estabelecido foi aprovado pelo Comitê de Ética em Pesquisa do Centro Universitário Feevale.

Nome do colaborador ou responsável:

Assinatura do colaborador ou responsável:

Nome da pesquisadora Gilda Aparecida de Assis telefone de contato (51) 93779315 Assinatura da Pesquisadora:

Novo Hamburgo, de de 2009. 


\section{APÊNDICE B}

\section{Feevale}

TERMO DE COMPROMISSO PARA UTILIZAÇÃO DE DADOS

Título do Projeto

Cadastro no CEP

NeuroR- Sistema Computacional de Apoio À Reabilitação Dos Membros

Superiores De Pacientes Vítimas De Acidentes Vasculares Encefálicos

0 pesquisador do presente projeto se compromete a preservar a privacidade dos sujeitos da pesquisa, cujos dados serão dentro do projeto de extensão Atenção Integrada à Saúde da Comunidade do Centro Universitário Feevale. Concorda, igualmente, que essas informações serão utilizadas única e exclusivamente para execução do presente projeto. Compromete-se, igualmente, a fazer divulgação dessas informações coletadas somente de forma anônima.

Novo Hamburgo, de de 200

\begin{tabular}{|l|l|}
\hline Nome do Pesquisador & Assinatura \\
\hline Gilda Aparecida de Assis & \\
\hline & \\
\hline & \\
\hline & \\
\hline & \\
\hline & \\
\hline & \\
\hline
\end{tabular}




\section{ANEXO A}

\section{MIQ-R (Revised Movement Imagery Questionnaire) em Português}

Cada um dos seguintes enunciados descreve uma ação ou movimento particular. Ouça cada enunciado cuidadosamente e então execute o movimento como descrito. Somente execute o movimento uma única vez após o comando "execute o movimento agora". Após executar o movimento retorne à posição de partida anterior à execução, exatamente como se esperasse para executar o movimento uma segunda vez. Então, dependendo das questões que serão solicitadas para a sua execução: Forme uma imagem a mais clara e nítida possível do movimento executado Preste atenção para sentir-se realizando o movimento sem executá-lo efetivamente. Somente inicie as tarefas mentais solicitadas após os comandos "feche os olhos e se veja AGORA" ou "Feche os olhos e sinta-se AGORA". Após ter completado o teste mental proposto classifique em fácil/difícil com relação a sua habilidade na execução de acordo com as escalas abaixo.

Escala de Imagética Visual

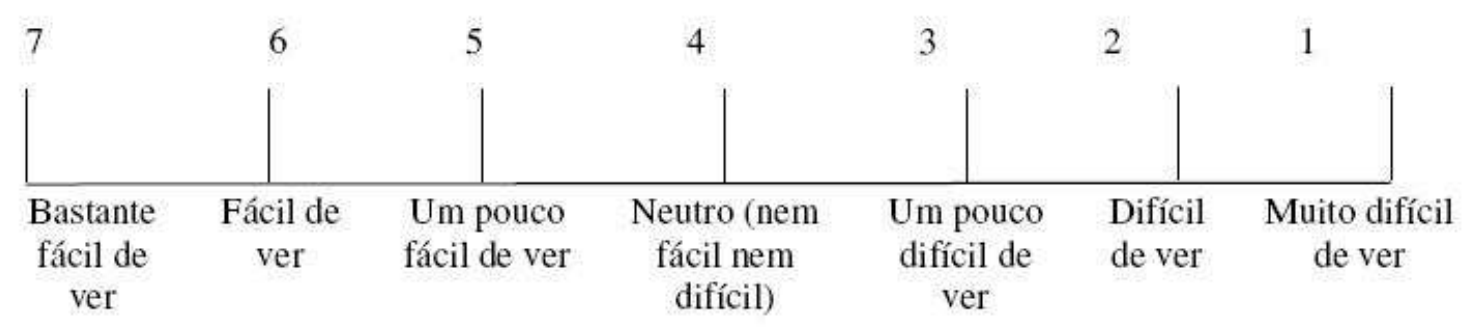

Escala de Imagética Cinestésica

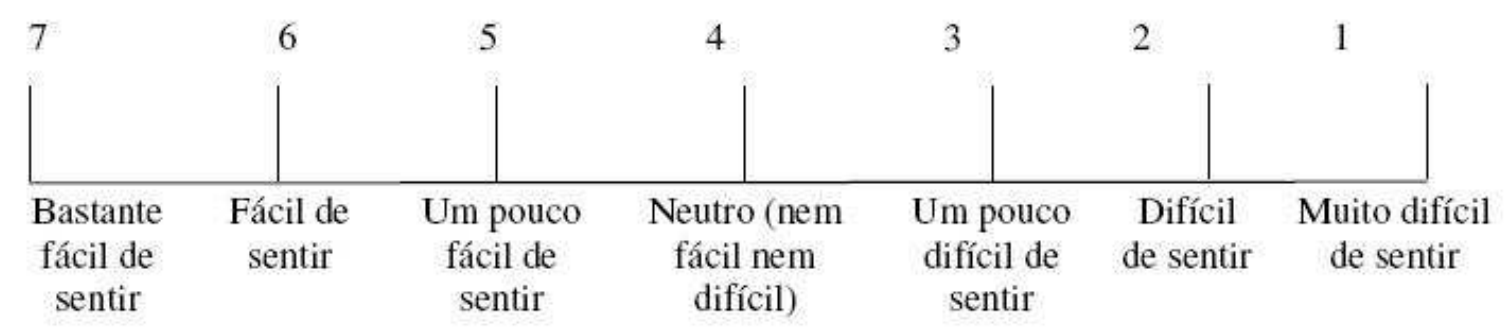




\section{Procedimento do MIQ-R}

\begin{tabular}{|c|c|c|}
\hline \multicolumn{3}{|c|}{ NoME DO PACIENTE: } \\
\hline 1 & $\begin{array}{l}\text { Posição } \\
\text { Inicial }\end{array}$ & Permaneça de pé com os pés juntos e os braços ao longo do corpo \\
\hline & Ação & $\begin{array}{l}\text { Em } 1 \text { segundo será solicitada a execução do seguinte movimento. } \\
\text { Flexione seu joelho direito o máximo possível de maneira que você } \\
\text { permaneça de pé apoiado na perna esquerda com a perna direita totalmente } \\
\text { flexionada. Finalmente abaixe sua perna direita até retornar a posição inicial } \\
\text { de apoio com ambos os pés no solo. } \\
\text { Execute o movimento AGORA. } 10 \text { segundos }\end{array}$ \\
\hline & $\begin{array}{l}\text { Tarefa } \\
\text { Mental }\end{array}$ & $\begin{array}{l}\text { Assuma a posição inicial } \\
\text { Em } 1 \text { segundo você será instruído a sentir-se executando o movimento } \\
\text { anterior sem realizá-lo de fato, da maneira mais clara e nítida possível. } \\
\text { Feche seus olhos e sinta-se executando AGORA. } 10 \text { segundos } \\
\text { Agora, classifique a facilidade/dificuldade encontrada na realização desta } \\
\text { tarefa mental. } 10 \text { segundos }\end{array}$ \\
\hline 2 & $\begin{array}{l}\text { Posição } \\
\text { Inicial }\end{array}$ & Permaneça de pé com suas mãos ao longo do corpo \\
\hline & Ação & $\begin{array}{l}\text { Em } 1 \text { segundo você será instruído a realizar o seguinte movimento. } \\
\text { Curve-se para baixo e então salte em linha reta para cima o mais alto } \\
\text { possível com ambos os braços estendidos acima da cabeça. } \\
\text { Aterrisse com os pés afastados e abaixe os braços até que retornem a } \\
\text { posição ao longo do corpo } \\
\text { Execute o movimento AGORA. } 10 \text { segundos }\end{array}$ \\
\hline & $\begin{array}{l}\text { Tarefa } \\
\text { Mental }\end{array}$ & $\begin{array}{l}\text { Assuma a posição inicial. } \\
\text { Em } 1 \text { segundo você será instruído a visualizar-se realizando a tarefa anterior } \\
\text { sem realizá-lo de fato, da maneira mais clara e nítida possível. } \\
\text { Feche seus olhos e visualize-se executando AGORA. } 10 \text { segundos } \\
\text { Agora, classifique a facilidade/dificuldade encontrada na realização desta } \\
\text { tarefa mental. } 10 \text { segundos }\end{array}$ \\
\hline 3 & $\begin{array}{l}\text { Posição } \\
\text { Inicial }\end{array}$ & $\begin{array}{l}\text { Estenda o braço de sua mão não-dominante para o lado do corpo de } \\
\text { maneira que ele fique paralelo ao solo com a palma da mão para baixo }\end{array}$ \\
\hline & Ação & $\begin{array}{l}\text { Em } 1 \text { segundo você será instruído a realizar o seguinte movimento. } \\
\text { Mova seu braço para frente do corpo permanecendo paralelo ao solo. } \\
\text { Mantenha seu braço estendido durante o movimento executando } \\
\text { vagarosamente. } \\
\text { Execute o movimento AGORA. } 10 \text { segundos }\end{array}$ \\
\hline & $\begin{array}{l}\text { Tarefa } \\
\text { Mental }\end{array}$ & $\begin{array}{l}\text { Assuma a posição inicial } \\
\text { Em } 1 \text { segundo você será instruído a sentir-se executando o movimento } \\
\text { anterior sem realizá-lo de fato. } \\
\text { Feche seus olhos e sinta-se executando AGORA. } 10 \text { segundos } \\
\text { Agora, classifique a facilidade/dificuldade encontrada na realização desta } \\
\text { tarefa mental. } 10 \text { segundos }\end{array}$ \\
\hline 4 & $\begin{array}{l}\text { Posição } \\
\text { Inicial }\end{array}$ & $\begin{array}{l}\text { Permaneça com seus pés afastados e seus braços completamente } \\
\text { estendidos acima da cabeça }\end{array}$ \\
\hline & Ação & $\begin{array}{l}\text { Em } 1 \text { segundo você será instruído a realizar o seguinte movimento. } \\
\text { Lentamente curve seu corpo para frente pela cintura tentando alcançar o } \\
\text { dedão do pé ou o solo com a ponta dos dedos das mãos e então retorne a } \\
\text { posição inicial permanecendo ereto com seus braços estendidos sobre a } \\
\text { cabeça. } \\
\text { Execute o movimento AGORA. } 10 \text { segundos }\end{array}$ \\
\hline & $\begin{array}{l}\text { Tarefa } \\
\text { Mental }\end{array}$ & $\begin{array}{l}\text { Assuma a posição inicial. } \\
\text { Em } 1 \text { segundo você será instruído a visualizar-se realizando a tarefa anterior } \\
\text { da maneira mais clara e nítida possível. } \\
\text { Feche seus olhos e visualize-se AGORA. } 10 \text { segundos } \\
\text { Agora, classifique a facilidade/dificuldade encontrada na realização desta } \\
\text { tarefa mental. } 10 \text { segundos }\end{array}$ \\
\hline
\end{tabular}




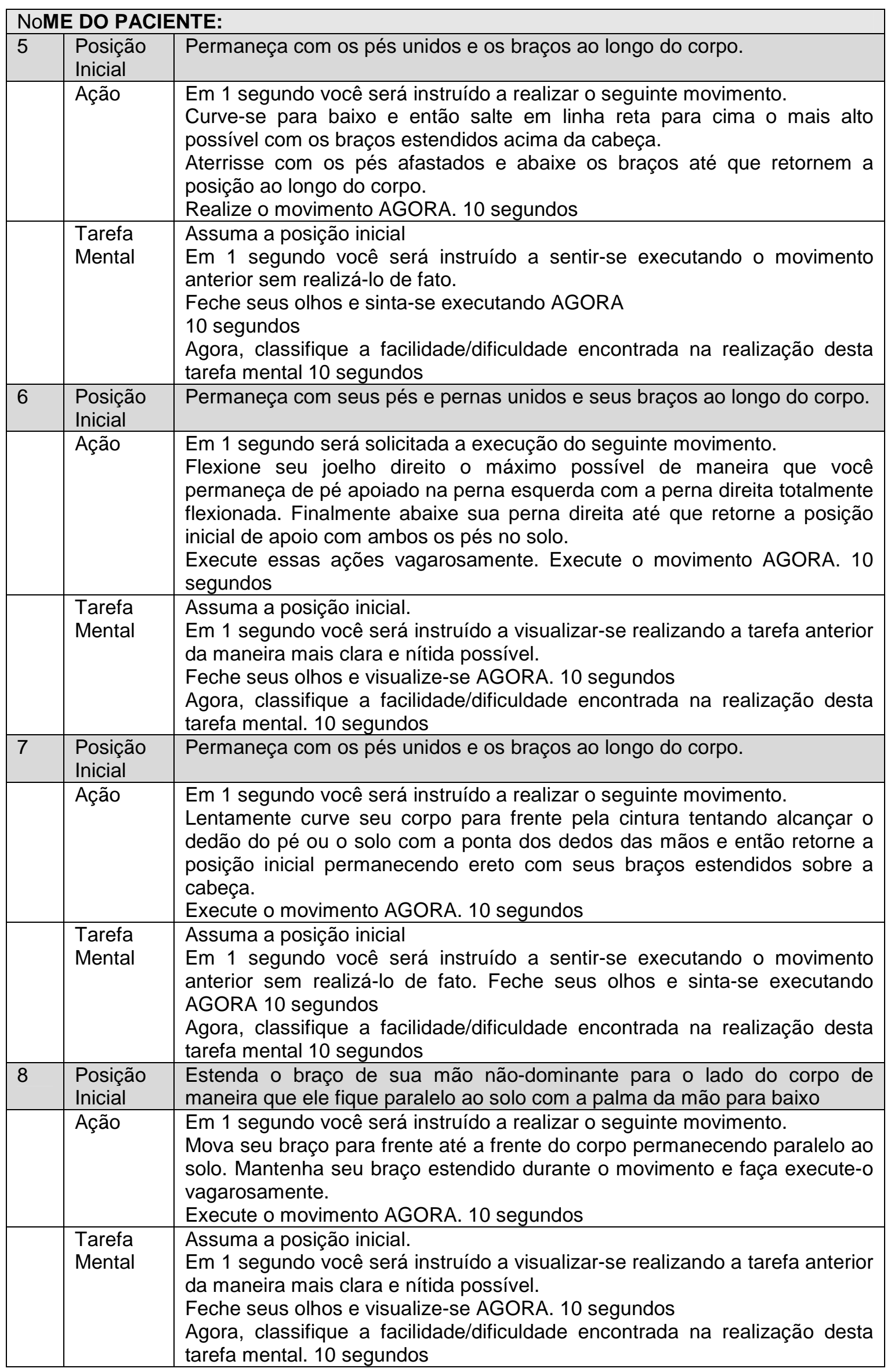

